DANIELLE MATSUMOTO

ESTUDO DE REATOR FOTOCATALÍTICO PARA TRATAMENTO DE GASES CONTAMINADOS COM COMPOSTOS ORGÂNICOS

VOLÁTEIS

São Paulo

2019 


\section{ESTUDO DE REATOR FOTOCATALÍTICO PARA TRATAMENTO DE GASES CONTAMINADOS COM COMPOSTOS ORGÂNICOS VOLÁTEIS}

Tese apresentada a Escola Politécnica da Universidade de São Paulo para obtenção do Título de Doutora em Ciências 


\title{
ESTUDO DE REATOR FOTOCATALÍTICO PARA TRATAMENTO DE GASES CONTAMINADOS COM COMPOSTOS ORGÂNICOS VOLÁTEIS
}

\author{
Tese apresentada a Escola Politécnica da \\ Universidade de São Paulo para obtenção do \\ Título de Doutora em Ciências
}

Área de concentração:

Engenharia Química

Orientador:

Prof. Doutor José Luis de Paiva

São Paulo

Outubro de 2019 
Autorizo a reprodução e divulgação total ou parcial deste trabalho, por qualquer meio convencional ou eletrônico, para fins de estudo e pesquisa, desde que citada a fonte.

Este exemplar foi revisado e corrigido em relação à versão original, sob responsabilidade única do autor e com a anuência de seu orientador.

São Paulo, de de

Assinatura do autor

Assinatura do orientador:

Catalogação-na-publicação

Matsumoto, Danielle

ESTUDO DE REATOR FOTOCATALÍTICO PARA TRATAMENTO DE

GASES CONTAMINADOS COM COMPOSTOS ORGÂNICOS VOLÁTEIS / D.

Matsumoto -- versão corr. -- São Paulo, 2019.

$147 \mathrm{p}$.

Tese (Doutorado) - Escola Politécnica da Universidade de São Paulo. Departamento de Engenharia Química.

1.Fotoquímica 2.CFD 3.COV 4.Reator Fotoquímico 5.Modelagem I.Universidade de São Paulo. Escola Politécnica. Departamento de Engenharia Química II.t. 
"Determinação (s.f.)

É acordar cinco e meia da manhã, cinco vezes por semana. É fazer o que for preciso. É seguir em frente, enquanto em frente for a direção que você quiser seguir. É quando você levanta de uma queda. É ignorar o tempo e focar no motivo. É ensaiar sem voz. É estudar sem livros. É a irmã da persistência.

É ir contra o mundo inteiro se for preciso para realizar um sonho!"

(João Doederlein) 


\section{AGRADECIMENTOS}

Ao meu orientador, Prof. Dr. José Luís de Paiva, pela infinita dedicação, comprometimento, motivação nos momentos difíceis, conselhos, horas de conversas, amizade e, principalmente, por acreditar e confiar no meu trabalho. Enfim, sem a sua ajuda e orientação, finalizar esse doutorado não teria sido possível;

Ao Prof. Dr. Antonio Carlos Silva Costa Teixeira, pelas valiosas conversas e esclarecimentos de dúvidas sobre fotoquímica e pela co-orientação durante todo o doutorado;

Ao Prof. Dr. Roberto Guardani, pelo incentivo, conselhos e pelas excelentes ideias durante a execução de todo projeto;

Ao Leonardo Almeida Diniz, por todas horas gastas montando o reator, todos experimentos, todas conversas, ajuda inestimável e incansável, e todas dificuldades superadas;

Ao Dr. Adriano Ferreira de Mattos Silvares, pela inestimável ajuda com a modelagem fluidodinâmica e pelas valiosas sugestões;

A Dra. Raquel Chacon Ruiz Martinez, por todo apoio e suporte técnico durante a execução do projeto FAPESP e por toda motivação pessoal durante a vida;

Aos meus pais, Newton e Márcia, por me motivarem a sempre buscar o meu melhor, apoiarem todas as minhas decisões e, com muito amor, me ajudarem a concretizar os meus sonhos;

Ao meu irmão Luis Gustavo, pelo apoio, carinho e motivação;

Aos sócios Bia Bonfleuher e Miguel Bonfleuher, todo apoio, motivação e suporte fornecido pela Ecoplas neste período;

A Profa. Dra. Liria Matsumoto Sato, pelo incentivo, ajuda e, principalmente, pelo exemplo de como ser uma engenheira, pesquisadora e mãe;

Aos meus afilhados, Beatriz, Bruna e Pedro, por chegarem nesse período do doutorado para me dar mais motivação para me tornar uma pessoa melhor;

Aos alunos de iniciação científica, Gabriel, Thomas, Letícia e Cesare, por toda contribuição para o desenvolvimento deste trabalho;

Ao Alexander Zerwas, pela ajuda na aprendizagem do Fluent;

Ao Valter, Alexandre Oliveira e a Maria do Carmo Neves, pela ajuda prestada com assuntos de TI e administrativos.

A todos amigos e familiares, que de alguma forma me incentivaram e me deram força para continuar em frente sempre. 


\section{RESUMO}

Este estudo apresenta o desenvolvimento de um reator de leito fluidizado em escala laboratorial para a degradação fotoquímica de compostos orgânicos voláteis, desde seu projeto até a construção de um modelo fluidodinâmico para posterior estudo de scale-up e otimização. $\mathrm{O}$ processo de tratamento baseia-se na foto-oxidação catalítica dos contaminantes em contato com dióxido de titânio $\left(\mathrm{TiO}_{2}\right)$ e radiação ultravioleta. Para a construção da unidade laboratorial, o projeto contou com o financiamento do projeto PIPE - Fase 1 financiado pela FAPESP (No. 00953/2016). Um dos resultados deste projeto foi uma pesquisa de mercado com diversos clientes que mostrou a necessidade de desenvolvimento de novas tecnologias para tratamento de gases contaminados com compostos orgânicos voláteis (COV). A unidade laboratorial foi montada e instalada, sendo realizados dois tipos de experimentos no reator fotocatalítico. $\mathrm{O}$ primeiro foi para tratamento de aromáticos (BTX) utilizando-se como catalisador $\mathrm{TiO}_{2}$, impregnado em sílica, sintetizado em laboratório. Como resultado desta etapa, observou-se que reator foi capaz de remover os contaminantes estudados. No entanto, nas condições investigadas, o processo não foi capaz de reduzir significativamente as concentrações de contaminante no ar tratado e o catalisador foi desativado pelos poluentes, requerendo um processo de regeneração. Para uma melhor avaliação do reator e a sua modelagem, optou-se por utilizar um poluente modelo, n-hexano, de forma a não degradar o catalisador. Para estes experimentos, o catalisador utilizado também foi trocado para $\mathrm{TiO}_{2}$ comercial tipo anatase. Resultados quantitativos relacionaram o aumento da conversão no reator com o aumento de massa de catalisador e diminuição com um aumento na vazão volumétrica. A partir destes experimentos, pode-se obter um modelo cinético baseado na determinação dos parâmetros cinéticos em um reator fotocatalítico usando a abordagem Langmuir-Hinshelwood para a degradação do n-hexano com sucesso. Por fim, a modelagem fluidodinâmica deste reator foi realizada utilizando-se o software comercial Fluent. Desenvolveu-se um modelo que considera a fluidodinâmica e cinética da reação obtida experimentalmente. Algumas simplificações foram feitas para otimizar os tempos de simulação e os principais resultados do CFD foram os campos de pressão, velocidade, fração volumétrica de sólidos e velocidade da reação de decomposição do n-hexano.

Palavras-chave: CFD, Reator Fotoquímico, Simulação, Modelagem, Fotoquímica, Radiação, COV. 


\begin{abstract}
This study presents the development of a fluidized bed photoreactor in laboratorial scale for volatile organic compounds (VOC) photochemical degradation, since the reactor project until a fluid dynamics model construction for future scale-up study and optimization. The treatment process is based on contaminants catalytic photo-oxidation in contact with titanium dioxide $\left(\mathrm{TiO}_{2}\right)$ and ultraviolet radiation. For laboratorial unit construction, this project was beneficed by PIPE project - Phase 1 of the project financed by FAPESP (No. 00953/2016). One of the results of this project was a market research with several clients. It showed a development need of new technologies for contaminated gas treatment with VOC. The laboratorial unit was installed and two experiments types were carried out in the photoreactor. The first type was to aromatic (BTX) treatment using as catalyst $\mathrm{TiO}_{2}$, impregnated in silica and synthesized in laboratory. As result of this phase, the photoreactor was able to remove the contaminants. However, in investigated conditions, the process was not able to eliminate completely the contaminants and the catalyst was inactivated by intermediate products, requiring a regeneration process. To get a better reactor evaluation and modeling, a model pollutant, nhexane, was chosen in order not to degrading the catalyst. For these experiments, the chosen catalyst was commercial $\mathrm{TiO}_{2}$ in anatase type. The results showed that reactor conversion rises with higher catalyst loads and decreases with higher volumetric flow rate. Therefore, a kinetic model was successfully obtained, based on kinetic parameters determination in a photoreactor using Langmuir-Hinshelwood approach to n-hexane degradation. Lastly, a fluid dynamics (CFD) photoreactor modeling was developed using the commercial software Fluent. A model was built considering fluid dynamics and reaction kinetic obtained experimentally. Some model simplifications were done in order to optimize the simulation time and the main CFD results were pressure, velocity, solid volumetric fraction fields and n-hexane decomposition reaction velocity.
\end{abstract}

Keywords: CFD, Photochemical reactor, Simulation, Modeling, Radiation, VOC. 


\section{LISTA DE FIGURAS}

Figura 1.1 - Pesquisa interdisciplinar e áreas de desenvolvimento. 27

Figura 2.1 - Principais Tecnologias por tratamento UV. Fonte: (OPPENLÄNDER, 2003) ... 31

Figura 2.2- Algumas características do radical hidroxila. Fonte: (OPPENLÄNDER, 2003).. 32 Figura 2.3 - Esquema simplificado das reações atmosféricas. (Fonte: OPPENLÄNDER, 2003)

Figura 2.4 - Principais tecnologias para tratamento de correntes gasosas com VOC, gases e particulados. (Fonte: OPPENLÄNDER, 2003).

Figura 2.5 - Representação esquemática da primeira aplicação industrial de um POA em fase gasosa. (Fonte: OPPENLÄNDER, 2003).

Figura 2.6 - Reator fotocatalítico para tratamento de correntes de ar de lixo com odor contendo 24 lâmpadas LP-Hg (Heraeus NNI 120/84, $\mathrm{P}_{\mathrm{el}}=120 \mathrm{~W}$ cada, máxima vazão volumétrica de $20.000 \mathrm{~m}^{3} / \mathrm{h}$ ). (Fonte: OPPENLÄNDER, 2003)

Figura 2.7 - Abordagem teórica para a modelagem do LVREA. (Fonte: (ALFANO; CASSANO, 1986))

Figura 2.8 - Características de modelos bidimensionais de incidência de radiação: (a) Radial, (b) Parcialmente difusa e (c) Difusa. (Fonte: (ALFANO; CASSANO, 1986)) .......................54

Figura 3.1 - Plano de Trabalho. (Fonte: O autor, 2017) ...................................................56

Figura 4.1 - Reatores fotocatalíticos: (a) imobilizado na parede, (b) em leito fluidizado, (c) em

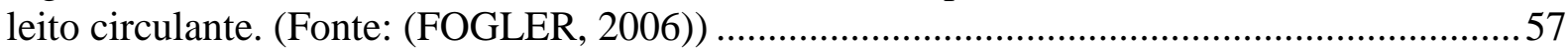

Figura 4.2 - Fluxograma simplificado do processo. …....................................................... 60

Figura 4.3 - Fluxograma do Processo. (1) Reator fotocatalítico com lâmpada anular (2) Ciclone

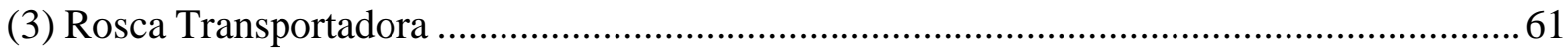

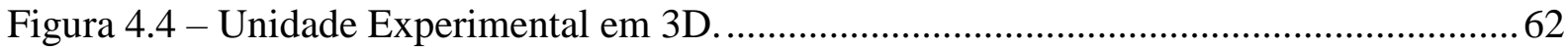

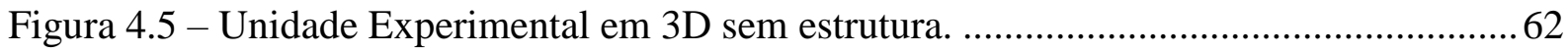

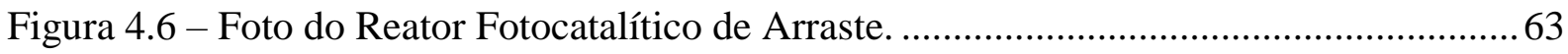

Figura 4.7 - Unidade laboratorial construída. (A) compressor para alimentação de ar; (B) coluna de secagem e medidores de vazão; (C) reservatório de poluente (contaminação do ar limpo por

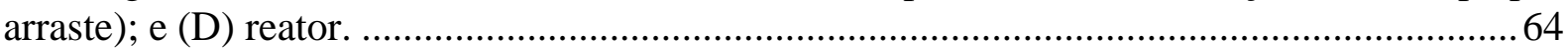

Figura 4.8 - Detalhe do Reator Fotocatalítico de Arraste modelado em 3D...........................65

Figura 4.9 - (a) Distribuição da parcela percentual de produção de solventes orgânicos no Brasil. (b) Relação de áreas contaminadas do estado de São Paulo. (Fonte: $6^{\circ}$ EBDQUIM da

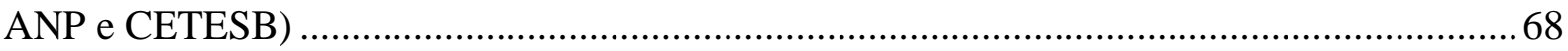

Figura 4.10 - Fluxograma simplificado do procedimento de preparo do catalisador. (Fonte:

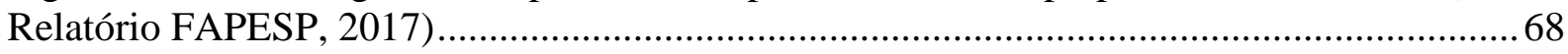

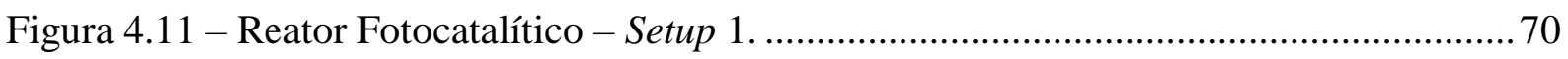

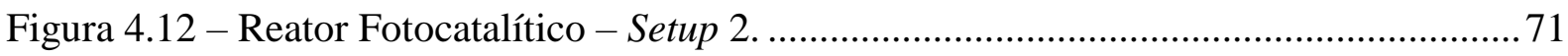


Figura 4.13 - Geometria 3D do reator modelado no Ansys.

Figura 4.14 - Cortes no plano YZ e no plano XZ reator modelado no Ansys. ........................ 73

Figura 4.15 - Geometria 2D do reator modelado no Ansys - Saída Lateral........................... 73

Figura 4.16 - Geometria 2D do reator modelado no Ansys - Saída Lateral em verde............74

Figura 4.17 - Geometria 2D do reator modelado no Ansys - Saída Superior em verde. ........ 74

Figura 4.18 - Malha 1, com 334712 elementos, selecionada para simulações tridimensionais.

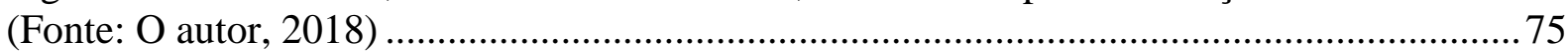

Figura 4.19 - Detalhes da Malha 1 na entrada e saída de gases, respectivamente.................. 75

Figura 4.20 - Malha 2, com 17.500 elementos, selecionada para simulações bidimensionais. (Fonte: $\mathrm{O}$ autor, 2018)

Figura 4.21 - Campo de pressão para Malha 1, Malha 2 e Malha 3 em t $=10$ s. Condições simuladas: $\mathrm{Q}=10 \mathrm{~L} \cdot \mathrm{min}^{-1} \mathrm{e} \mathrm{m}=0,1 \mathrm{~kg}$. (Fonte: $\mathrm{O}$ autor, 2018).....

Figura 4.22 - Campo de velocidade para Malha 1, Malha 2 e Malha 3, em $\mathrm{t}=10 \mathrm{~s}$. Condições simuladas: $\mathrm{Q}=10 \mathrm{~L} \cdot \mathrm{min}^{-1} \mathrm{e} \mathrm{m}=0,1 \mathrm{~kg}$. (Fonte: $\mathrm{O}$ autor, 2018).

Figura 4.23 - Perfil de pressão em função de x para cada malha em $\mathrm{t}=10 \mathrm{~s}$. Condições simuladas: $\mathrm{Q}=10 \mathrm{~L} \cdot \mathrm{min}^{-1} \mathrm{e} \mathrm{m}=0,1 \mathrm{~kg}$. (Fonte: $\mathrm{O}$ autor, 2018).

Figura 4.24 - Perfil de velocidade por y para cada malha analisada em $t=10$ s. Condições simuladas: $\mathrm{Q}=10 \mathrm{~L} \cdot \mathrm{min}^{-1} \mathrm{e} \mathrm{m}=0,1 \mathrm{~kg}$.

Figura 4.25 - Fração volumétrica de sólidos para $\mathrm{t}=7 \mathrm{~s}$ a $10 \mathrm{~s}$, Malha 2 e na condição de regime permanente $\left(\mathrm{Q}=10 \mathrm{~L} \cdot \mathrm{min}^{-1} \mathrm{e} \mathrm{m}=0,1 \mathrm{~kg}\right)$. (Fonte: $\mathrm{O}$ autor, 2018)

Figura 4.26 - Fração volumétrica de sólido, média na secção, em função da altura do leito (x) do reator para 13 instantes de tempo: malhas 1,2 e 3 .

Figura 4.27 - Campo de pressão e velocidade para $\Delta t=0,01 \mathrm{~s}, \Delta t=0,005 \mathrm{~s}$ e $\Delta t=0,001 \mathrm{~s}$ em $\mathrm{t}=10 \mathrm{~s}$. Condições simuladas: $\mathrm{Q}=10 \mathrm{~L} \cdot \mathrm{min}^{-1} \mathrm{e} \mathrm{m}=0,1 \mathrm{~kg}$. (Fonte: $\mathrm{O}$ autor, 2018).... 80

Figura 4.28 - Perfil de pressão em função de $\mathrm{x}$, para $\Delta t=0,01 \mathrm{~s}, \Delta t=0,005 \mathrm{~s}$ e $\Delta t=0,001 \mathrm{~s}$ em $\mathrm{t}=10 \mathrm{~s}$. Condições simuladas: $\mathrm{Q}=10 \mathrm{~L} \cdot \mathrm{min}^{-1} \mathrm{e} \mathrm{m}=0,1 \mathrm{~kg}$. (Fonte: $\mathrm{O}$ autor, 2018)

Figura 4.29 - Perfil de velocidade em função da posição radial (y), para $\Delta t=0,01 \mathrm{~s}, \Delta t=$ $0,005 \mathrm{~s}$ e $\Delta t=0,001 \mathrm{~s}$ em $\mathrm{t}=10 \mathrm{~s}$ na altura $\mathrm{h}=500 \mathrm{~mm}$. Condições simuladas: $\mathrm{Q}=10 \mathrm{~L} \cdot \mathrm{min}^{-1}$ e $\mathrm{m}=0,1 \mathrm{~kg}$. (Fonte: $\mathrm{O}$ autor, 2018)

Figura 4.30 - Fração volumétrica de sólidos para $\mathrm{t}=7 \mathrm{~s} 10 \mathrm{~s}$ para $\Delta t=0,001 \mathrm{~s}$, na condição de regime permanente: $\mathrm{Q}=10 \mathrm{~L} \cdot \mathrm{min}^{-1}$ e $\mathrm{m}=0,1 \mathrm{~kg}$.. (Fonte: $\mathrm{O}$ autor, 2018)

Figura 4.31 - Fração volumétrica de sólido, média na secção, em função da altura do leito (x) do reator para 10 instantes de tempo e para cada passo de tempo analisado. 83

Figura 5.1 - Multas e advertências aplicadas pela CETESB em 2015, referentes à poluição atmosférica. (Fonte: CETESB).

Figura 5.2 - Classificação das multas advertências aplicadas pela CETESB em 2015, referentes à poluição atmosférica. ${ }^{3}$ (Fonte: CETESB)

Figura 5.3 - Setor de tintas no Brasil no ano de 2014. (Fonte: ABRAFATI) ......................... 88

Figura 5.4 - Mercado Brasileiro de Solventes (Fonte: ABRAFATI) …................................ 89

Figura 5.5 - Principais Solventes Hidrocarbônicos por aplicação. ${ }^{5}$ (Fonte: ABRAFATI) ....... 89 
Figura 5.6 - Difração de Raios-X da sílica-gel comercial (azul), cristal $\mathrm{TiO}_{2}$ anatase (laranja) e dos compósitos $\mathrm{TiO}_{2} / \mathrm{SiO}_{2}$ (preta). Os picos indicam a formação da fase anatase no $\mathrm{TiO}_{2} / \mathrm{SiO}_{2}$. (Fonte: Central Analítica IQ-USP)

Figura 5.7 - (A) Partículas de sílica-gel $\left(\mathrm{SiO}_{2}\right)$ pura; (B) Compósitos $\mathrm{TiO}_{2} / \mathrm{SiO}_{2}$ com $20 \%$ de $\mathrm{TiO}_{2}$. Nota-se a geração de partículas menores; (C) Compósitos $\mathrm{TiO}_{2} / \mathrm{SiO}_{2}$ com $20 \%$ de $\mathrm{TiO}_{2}$. Nota-se a não homogeneidade do recobrimento. (Fonte: Central Analítica IQ-USP)

Figura 5.8 - Distribuição de tamanho de partículas para (A) Partículas de sílica-gel comerciais $\left(\mathrm{SiO}_{2} 63-200 \mu \mathrm{m}\right)$ pura; (B) Compósitos $\mathrm{TiO}_{2} / \mathrm{SiO}_{2}$ com $20 \%$ de $\mathrm{TiO}_{2}$. (Fonte: LCT) ........91

Figura 5.9 - Análise DLS do $\mathrm{TiO}_{2}$ Anatase . (Fonte: LCT) .................................................. 92

Figura 5.10 - Fotografias de partículas de $\mathrm{TiO}_{2}$, (A) antes da fluidização; (B) após a fluidização . (Fonte: DEQ-Poli USP)....

Figura 5.11 - Fotografias de partículas de $\mathrm{TiO}_{2}$ após a fluidização. (Fonte: DEQ-Poli USP).93

Figura 5.12 - Queda de pressão no leito em função da vazão volumétrica de gás. 96

Figura 5.13 - Degradação no reator devido à fotólise por radiação luminosa $(\lambda=254 \mathrm{~nm})$ para benzeno $\left(\mathrm{C}_{0}=100 \pm 0,7 \mathrm{ppmv}\right)$, tolueno $\left(\mathrm{C}_{0}=100 \pm 1,1 \mathrm{ppmv}\right)$ e xilenos $\left(\mathrm{C}_{0}=100 \pm 2,0 \mathrm{ppmv}\right)$. (Fonte: Relatório Fapesp, 2017).

Figura 5.14 - Degradação fotocatalítica do benzeno: avaliação de diferentes vazões com $100 \mathrm{~g}$ $\left(20 \% \mathrm{TiO}_{2} / 80 \% \mathrm{SiO}_{2}\right)$ e UR $=50 \%$. (Fonte: Relatório Fapesp, 2017) 97

Figura 5.15 - Degradação fotocatalítica do benzeno: avaliação de diferentes vazões com $200 \mathrm{~g}$ $\left(20 \% \mathrm{TiO}_{2} / 80 \% \mathrm{SiO}_{2}\right)$ e UR=50\%. (Fonte: Relatório Fapesp, 2017) 98

Figura 5.16 - Degradação fotocatalítica do benzeno: avaliação de diferentes concentrações de entrada. Condições de ensaio: $\mathrm{m}=200 \mathrm{~g}, \mathrm{Q}=15 \mathrm{~L} \mathrm{~min}^{-1}$, UR $=50 \%$.

Figura 5.17 - Degradação fotocatalítica do tolueno: avaliação de diferentes concentrações de entrada. Condições de ensaio: $\mathrm{m}=100 \mathrm{~g}, \mathrm{Q}=15 \mathrm{~L} \mathrm{~min}^{-1}$, UR $=50 \%$. 100

Figura 5.18 - Degradação fotocatalítica dos xilenos: avaliação de diferentes concentrações de entrada. Condições de ensaio: $\mathrm{m}=100 \mathrm{~g}, \mathrm{Q}=15 \mathrm{~L} \mathrm{~min}^{-1}$, UR $=50 \%$. 101

Figura 5.19 - Degradação fotocatalítica de uma mistura BTX: avaliação do tempo de operação antes da ocorrência de desativação do fotocatalisador pela deposição de espécies intermediárias. Teste realizado com $\mathrm{m}=100 \mathrm{~g}, \mathrm{Q}=15 \mathrm{~L} \mathrm{~min}^{-1}, \mathrm{C}_{0}=50 \mathrm{ppmv}$ de benzeno, $25 \mathrm{ppmv}$ de tolueno e 20 ppmv de xilenos, UR $=50 \%$. 102

Figura 5.20 - Reator para os experimentos do poluente modelo n-hexano - Setup 1. 104

Figura 5.21 - Queda de pressão no leito em função da vazão volumétrica de gás para o catalisador $\mathrm{TiO}_{2}$ comercial. 105

Figura 5.22 - Degradação do n-hexano no reator devido à fotólise por radiação luminosa $(\lambda=$ $254 \mathrm{~nm}$ e $\left.[\mathrm{C}]_{0}=171 \pm 14 \mathrm{ppmv}\right)$.. 106

Figura 5.23 - Degradação fotocatalítica do n-hexano em função da concentração de entrada nas seguintes condições: lâmpada parcialmente coberta, $100 \mathrm{~g}\left(\mathrm{TiO}_{2}\right.$ comercial) e UR $=50 \% .107$

Figura 5.24 - Degradação fotocatalítica do n-hexano em função da concentração de entrada na região diluída, nas seguintes condições: lâmpada descoberta, $100 \mathrm{~g}\left(\mathrm{TiO}_{2}\right.$ comercial) e UR = $50 \%$.

Figura 5.25 - Degradação fotocatalítica do n-hexano: Efeito da cobertura da lâmpada com 100

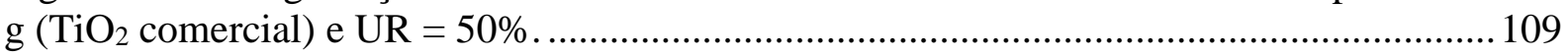


Figura 5.26 - Quantidade de partículas de TiO2 na região diluída do reator.

Figura 6.1 - Esquema da Modelagem Cinética - Setup 1

Figura 6.2 - Esquema da Modelagem Cinética - Setup 2.

Figura 6.3 - Linearização da velocidade de reação para a região densa do reator. (Fonte: $\mathrm{O}$ autor, 2018).

Figura 6.4 - Linearização da velocidade de reação para a região diluída do reator.

Figura 6.5 - Validação do modelo cinético do reator fotocatalítico (Região densa $=$ CSTR, Região diluída = PFR). $Q=10$ L. $\mathrm{min}^{-1}, m=0,1 \mathrm{~kg}$ (Fonte: $\mathrm{O}$ autor, 2018).....

Figura 6.6 - Validação do modelo cinético do reator fotocatalítico (Região densa = CSTR, Região diluída = PFR). $Q=5,7,5,10,15 \mathrm{~L} \cdot \mathrm{min}^{-1}, m=0,1 \mathrm{~kg}$.

Figura 6.7 - Conversões experimentais e predições do modelo para $Q=10 \mathrm{~L} \cdot \mathrm{min}^{-1}, m=0,1 \mathrm{~kg}$ e $m=0,2 \mathrm{~kg}$. (Fonte: $\mathrm{O}$ autor, 2018)

Figura 6.8 - Validação do modelo cinético do reator fotocatalítico (região densa $=$ CSTR, região diluída $=$ PFR $) \cdot Q=10 \mathrm{~L} \cdot \mathrm{min}^{-1}, m=0,2 \mathrm{~kg}$.

Figura 6.9 - Campos de Pressão e de Velocidade do Gás. Condições simuladas: Q = 10 L.min ${ }^{-}$ ${ }^{1} \mathrm{e} \mathrm{m}=0,17 \mathrm{~kg}$. (Fonte: O autor, 2018). 118

Figura 6.10 - Isossuperfície de fração volumétrica de sólido de 0,1 obtida por simulação e fotos do leito durante o experimento. (Fonte: $\mathrm{O}$ autor, 2018)

Figura 6.11 - Fração volumétrica de sólidos para $t=5 \mathrm{~s}$ a $7 \mathrm{~s}$, após o regime permanente ser atingido: $\mathrm{Q}=10 \mathrm{~L} \cdot \mathrm{min}^{-1} \mathrm{e} \mathrm{m}=0,1 \mathrm{~kg}$. (Fonte: $\mathrm{O}$ autor, 2018).

Figura 6.12 - Fração volumétrica média na secção em função da altura do reator, para diferentes instantes de tempo. Condições simuladas: $\mathrm{Q}=10 \mathrm{~L} \cdot \mathrm{min}^{-1} \mathrm{e} \mathrm{m}=0,1 \mathrm{~kg}$.

Figura 6.13 - Perfis de Pressão Tridimensional e Bidimensional. Condições simuladas: $Q=10$ L. $\min ^{-1}$ e $\mathrm{m}=0,1 \mathrm{~kg}$.

Figura 6.14 - Campos de Velocidade do Gás para geometrias: tridimensional e bidimensional.

Figura 6.15 - Fração volumétrica média na secção em função da altura do reator, para diferentes instantes de tempo : tridimensional e bidimensional. Condições simuladas: $\mathrm{Q}=10 \mathrm{~L} \cdot \mathrm{min}^{-1} \mathrm{e} \mathrm{m}$ $=0,1 \mathrm{~kg}$ (Fonte: $\mathrm{O}$ autor, 2018).....

Figura 6.16 - Perfis de Pressão - Saída Lateral e Saída Superior.

Figura 6.17 - Perfis de Velocidade - Saída Lateral e Saída Superior. Condições simuladas: Q = 10 L.min ${ }^{-1}$ e $\mathrm{m}=0,1 \mathrm{~kg}$

Figura 6.18 - Fração volumétrica média na secção em função da altura do reator para diferentes instantes de tempo e para as duas geometrias bidimensionais. Condições simuladas: $Q=10$ L. $\mathrm{min}^{-1}$ e $\mathrm{m}=0,1 \mathrm{~kg}$ (Fonte: $\mathrm{O}$ autor, 2018) 125

Figura 6.19 - Perfis de Pressão e Velocidade do Gás. Condições simuladas: Q = 10 L.min ${ }^{-1}$ e $\mathrm{m}=0,1 \mathrm{~kg}$ (Fonte: $\mathrm{O}$ autor, 2018).

Figura 6.20 - Fração volumétrica de sólidos para $\mathrm{t}=7 \mathrm{~s}$ a $10 \mathrm{~s}$, após o regime permanente ser atingido. Condições simuladas: $\mathrm{Q}=10 \mathrm{~L} \cdot \mathrm{min}^{-1} \mathrm{e} \mathrm{m}=0,1 \mathrm{~kg}$ (Fonte: $\mathrm{O}$ autor, 2018).... 127 
Figura 6.21 - Fração volumétrica média na secção em função da altura do reator para 13 instantes de tempo após o regime permanente ser atingido. Condições simuladas: $\mathrm{Q}=10 \mathrm{~L} \cdot \mathrm{min}^{-}$

${ }^{1}$ e $\mathrm{m}=0,1 \mathrm{~kg}$ (Fonte: $\mathrm{O}$ autor, 2018)

Figura 6.22 - Fotos do experimento mostrando as oscilações na altura do leito. (Fonte: $\mathrm{O}$ autor, 2018)

Figura 6.23 - Campos de Pressão e Velocidade do Gás. Condições simuladas: Q = 5, 7,5, 10 e 15 L. $\min ^{-1}$ e $\mathrm{m}=0,1 \mathrm{~kg}$ (Fonte: $\mathrm{O}$ autor, 2018)

Figura 6.24 - Campos de Pressão e Velocidade do Gás com zoom na parte inferior do reator. Condições simuladas: $\mathrm{Q}=5,7,5,10$ e $15 \mathrm{~L} \cdot \mathrm{min}^{-1}$ e $\mathrm{m}=0,1 \mathrm{~kg}$ (Fonte: $\mathrm{O}$ autor, 2018) 130

Figura 6.25 - Fração volumétrica de sólidos para $\mathrm{t}=7 \mathrm{~s}$ a $10 \mathrm{~s}$, após o regime permanente ser atingido. Condições simuladas: : $\mathrm{Q}=5,7,5,10$ e $15 \mathrm{~L} \cdot \mathrm{min}^{-1}$ e $\mathrm{m}=0,1 \mathrm{~kg}$ (Fonte: $\mathrm{O}$ autor, 2018)

Figura 6.26 - Fração volumétrica média na secção em função da altura do reator para vários instantes de tempo após o regime permanente ser atingido. Condições simuladas: : $Q=5,7,5$, 10 e 15 L.min ${ }^{-1}$ e $\mathrm{m}=0,1 \mathrm{~kg}$ (Fonte: $\mathrm{O}$ autor, 2018) 132

Figura 6.27 - Porcentagem de conversão de n-hexano em função do tempo de simulação na região densa. Condições simuladas: $Q=10 \mathrm{~L} \mathrm{~min}^{-1} \mathrm{e} \mathrm{m}=0,1 \mathrm{~kg}$ para $\mathrm{C}=250$ a $3000 \mu \mathrm{mol} \mathrm{m}$ ${ }^{3}$ (Fonte: O autor, 2018). 133

Figura 6.28 - Porcentagem de conversão de n-hexano em função do tempo de simulação em todo reator. Condições simuladas: $\mathrm{Q}=10 \mathrm{~L} \cdot \mathrm{min}^{-1} \mathrm{e} \mathrm{m}=0,1 \mathrm{~kg}$ para $\mathrm{C}=250$ a $3000 \mu \mathrm{mol} \mathrm{m}$

Figura 6.29 - Concentração de n-hexano ao longo do comprimento do reator. Condições simuladas: $\mathrm{Q}=10 \mathrm{~L}_{\mathrm{min}} \mathrm{mi}^{-1} \mathrm{e} \mathrm{m}=0,1 \mathrm{~kg}$ para $\mathrm{C}=250$ a $3000 \mu \mathrm{mol} \mathrm{m} \mathrm{m}^{-3}$ (Fonte: $\mathrm{O}$ autor, 2018).

Figura 6.30 - Campos de Concentração de n-Hexano. Condições simuladas: $\mathrm{Q}=10$ L.min ${ }^{-1} \mathrm{e}$ $\mathrm{m}=0,1 \mathrm{~kg}$ para $\mathrm{C}=250$ a $3000 \mu \mathrm{mol} \mathrm{m}{ }^{-3}$ (Fonte: $\mathrm{O}$ autor, 2018). 136

Figura 6.31 - Comparativo dos resultados de simulação com resultados experimentais - Região Densa - Conversão em função da concentração de entrada de poluente. 137

Figura 6.32 - Comparativo dos resultados de simulação com resultados experimentais - Reator Completo - Conversão em função da concentração de entrada de poluente - Condições simuladas: $\mathrm{Q}=10 \mathrm{~L} \cdot \mathrm{min}^{-1}$ e $\mathrm{m}=0,1 \mathrm{~kg}$ para $\mathrm{C}=250$ a $3000 \mu \mathrm{mol} \mathrm{m}{ }^{-3}$ (Fonte: $\mathrm{O}$ autor, 2018) 


\section{LISTA DE TABELAS}

Tabela 2.1 - Principais tecnologias atualmente utilizadas para tratamento de COVs. (Fonte: SANCHES, 2009, p. 33)....

Tabela 2.2 - Compostos tratados por fotocatálise na fase gasosa (Fonte: CARP; HUISMAN; RELLER, 2004; ZHANG, 2013)

Tabela 2.3 - Unidades de abatimento de odor por oxidação foto-iniciada das correntes gasosas de entrada. (Fonte: OPPENLÄNDER, 2003).

Tabela 2.4 - Trabalhos de fotocatálise em reatores de leito fluidizado e em leito circulante (Fonte: $\mathrm{O}$ autor, 2017)

Tabela 2.5 - Principais modelos desenvolvidos para reatores fotoquímicos, grupos de pesquisa e período de publicação. (Fonte: (ALFANO; CASSANO, 1986)).....

Tabela 2.6 - Definições das principais propriedades utilizadas nos estudos de radiação. (Fonte: (CASSANO et al., 1995))....

Tabela 2.7 - Classificação utilizada para os principais modelos de radiação. (Fonte: (ALFANO; CASSANO, 1986)) 54

Tabela 4.1 - Resumo das metodologias de análise. 58

Tabela 4.2 - Coeficiente de ajuste linear e limites de detecção e quantificação por CG.........59

Tabela 4.3 - Equipamentos adquiridos na construção unidade experimental. .........................60

Tabela 4.4 - Medidas necessárias na unidade em escala laboratorial. .....................................66

Tabela 4.5 - Computadores utilizados nas simulações.

Tabela 4.6 - Malhas testadas no software ANSYS para seleção de malha para geometria tridimensional. 75

Tabela 4.7 - Malhas testadas no software ANSYS para seleção de malha da geometria

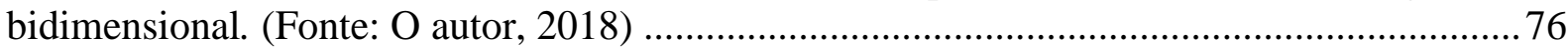

Tabela 4.8 - Alturas médias e perda de carga para cada malha estudada. ............................. 77

Tabela 4.9 - Alturas médias e perda de carga para cada passo de tempo estudado. .81

Tabela 4.10 - Parâmetros e propriedades para o modelo multifásico. (Fonte: O autor, 2018) 84

Tabela 4.11 - Condições iniciais e de contorno - Tridimensional x Bidimensional. .84

Tabela 4.12 - Condições de contorno - Saídas Lateral e Superior. 84

Tabela 4.13 - Condições de contorno - Seleção de malhas e passo de tempo . .85

Tabela 4.14 - Condições iniciais e de contorno - Analise da Hidrodinâmica . .85

Tabela 4.15 - Condições de contorno e iniciais - Modelagem Cinética .... 86

Tabela 5.1 - Resultado da análise quantitativa de elementos da fração de sólidos aproveitável $\left(\mathrm{d}_{\mathrm{p}}>38 \mu \mathrm{m}\right)$ e não aproveitável $\left(\mathrm{d}_{\mathrm{p}}<38 \mu \mathrm{m}\right)$. (Fonte: Relatório FAPESP, 2017)....

Tabela 5.2 - Planejamento dos ensaios de degradação fotocatalítica de benzeno, tolueno e xilenos. (Fonte: Relatório FAPESP, 2017). 
Tabela 5.3 - Análise TGA do fotocatalisador novo, degradado e após do processo de

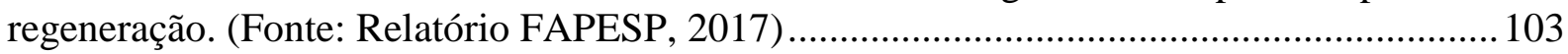

Tabela 6.1 - Condições experimentais. (Fonte: O autor, 2018) ............................................ 112

Tabela 6.2 - Parâmetros cinéticos obtidos pela linearização de dados experimentais do Setup 1 (região densa) e do Setup 2 (região diluída) (Fonte: O autor, 2018) .....................................113

Tabela 6.3 - Resultados de queda de pressão no leito e altura do leito.................................. 115

Tabela 6.4 - Condições experimentais para a predição do modelo com carga maior de

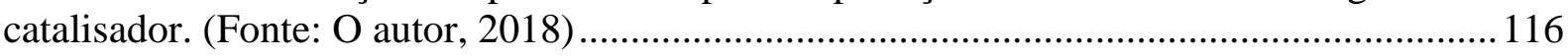

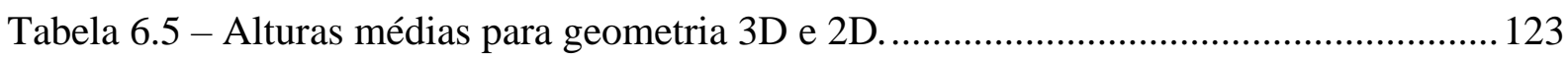

Tabela 6.6 - Alturas médias para geometria com saída lateral e com saída superior. (Fonte: O

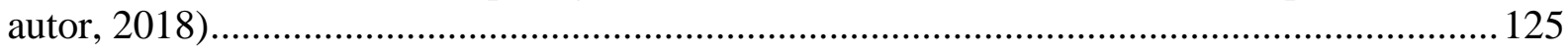

Tabela 6.7 - Alturas médias para diferentes vazões testadas e simuladas. ........................... 132

Tabela 7.1 - Sumário de resultados da degradação de BTX no reator de leito fluidizado circulante. Condições do experimento: $\mathrm{m}=100 \mathrm{~g}, \mathrm{Q}=15 \mathrm{~L} \mathrm{~min}^{-1}$ e UR $=50 \%$. 


\section{LISTA DE SÍMBOLOS}

\begin{tabular}{|c|c|c|}
\hline Símbolo & Descrição & Unidade \\
\hline$A$ & Área & $\mathrm{m}^{2}$ \\
\hline$[C]$ & Concentração molar de um Componente C & $\mathrm{kmol} \cdot \mathrm{m}^{-3}$ \\
\hline$\alpha$ & Coeficiente Neperiano de Absorção & $\mathrm{m}^{2} \cdot \mathrm{kmol}^{-1}$ \\
\hline$\beta$ & Coeficiente de Extinção Volumétrico & $\mathrm{m}^{-1}$ \\
\hline$c$ & Velocidade da Luz & $\mathrm{m} \cdot \mathrm{s}^{-1}$ \\
\hline $\mathrm{C}_{\mathrm{A}}$ & Concentração volumétrica de um Componente A & ppm \\
\hline$\Delta P$ & Perda de carga & $\mathrm{Pa}$ \\
\hline$d$ & Diâmetro & $\mathrm{m}$ \\
\hline$D_{i}$ & Difusividade do Componente i & $\mathrm{m}^{2} \cdot \mathrm{s}^{-1}$ \\
\hline$\varepsilon$ & Desvio médio & - \\
\hline $\mathrm{e}_{v}^{\mathrm{a}}$ & Energia Local Absorvida Volumétrica & einstein. $\mathrm{m}^{-3} \cdot \mathrm{s}^{-1}$ \\
\hline$E_{v}$ & Energia Radiante & $\mathrm{J}$ \\
\hline $\mathrm{E}$ & Taxa de Dissipação de Energia Cinética de Turbulência & $\mathrm{J} . \mathrm{kg}^{-1} \cdot \mathrm{s}^{-1}$ \\
\hline$G_{v}$ & Radiação Incidente & einstein. $m^{2}$ \\
\hline $\mathrm{h}$ & Altura & $\mathrm{m}$ \\
\hline$h$ & Constante de Planck & J.s \\
\hline$I_{v}$ & Intensidade Específica & $\mathrm{W} \cdot \mathrm{m}^{-2} \cdot \mathrm{sr}^{-1}$ \\
\hline $\mathrm{k}$ & Coeficientes da Equação de Langmuir-Hinshelwood & $\mathrm{s}^{-1} / \mathrm{m}^{3} \cdot \mathrm{kmol}^{-1}$ \\
\hline $\boldsymbol{k}$ & Coeficiente de Transferência de Energia & $\mathrm{W} \cdot \mathrm{m}^{-2} \cdot \mathrm{K}^{-1}$ \\
\hline$k$ & Energia Cinética de Turbulência & $\mathrm{J}^{\mathrm{kg}} \mathrm{kg}^{-1}$ \\
\hline$k_{v}$ & Coeficiente de Absorção Volumétrico & $\mathrm{m}^{-1}$ \\
\hline$\lambda$ & Comprimento de Onda & $\mathrm{nm}$ \\
\hline$L$ & Comprimento do reator & $\mathrm{m}$ \\
\hline$l$ & Caminho Ótico Percorrido & $\mathrm{m}$ \\
\hline M & Massa de Catalisador & $\mathrm{kg}$ \\
\hline$M M_{A}$ & Massa Molar de um Componente A & $\mathrm{kg} \cdot \mathrm{kmol}^{-1}$ \\
\hline$n_{\Omega, v}$ & $\begin{array}{l}\text { Número de Fótons por Ângulo Sólido e por Unidade } \\
\text { de Intervalo de Frequência }\end{array}$ & fótons. $\mathrm{m}^{-3} \cdot \mathrm{s}^{-1}$ \\
\hline $\boldsymbol{n}$ & Versor Normal a Área & - \\
\hline$n_{\Omega, v}^{a}$ & Taxa de Absorção de Fótons & fótons.s ${ }^{-1}$ \\
\hline
\end{tabular}




\begin{tabular}{|c|c|c|}
\hline$n_{\Omega, v}^{e}$ & Taxa de Emissão de Fótons & fótons. $\mathrm{s}^{-1}$ \\
\hline$n^{s-i n} \Omega, v$ & $\begin{array}{l}\text { Taxa de Ganho de Fótons devido à Entrada por } \\
\text { Espalhamento }\end{array}$ & fótons. $\mathrm{s}^{-1}$ \\
\hline$n^{s-o u t} \Omega, v$ & $\begin{array}{l}\text { Taxa de Perda de Fótons devido à Saída por } \\
\text { Espalhamento }\end{array}$ & fótons. $\mathrm{s}^{-1}$ \\
\hline$\Omega$ & Ângulo Sólido & $\mathrm{sr}$ \\
\hline $\mathbf{\Omega}$ & Versor de Direção de Propagação da Radiação & - \\
\hline$\varnothing$ & Variável Genérica & - \\
\hline$\phi$ & Ângulo & o \\
\hline$\phi$ & Diâmetro & $\mathrm{m}$ \\
\hline$\Phi$ & Rendimento Quântico & kmol.einstein ${ }^{-1}$ \\
\hline$P$ & Taxa de Fótons & Fótons \\
\hline$\rho$ & Densidade & $\mathrm{kg} \cdot \mathrm{m}^{-3}$ \\
\hline $\mathrm{P}$ & Pressão & $\mathrm{Pa}$ \\
\hline$P_{e l}$ & Potência de Radiação & $\mathrm{W}$ \\
\hline$Q$ & Vazão Volumétrica & L. $\min ^{-1}$ \\
\hline $\boldsymbol{q}_{v}^{R}$ & Vetor de Fluxo Radiante & $\mathrm{W} \cdot \mathrm{m}^{-2}$ \\
\hline$R$ & Taxa de Reação & $\begin{array}{l}\mathrm{kmol} \cdot \mathrm{m}^{-3} \cdot \mathrm{s}^{-1} / \\
\operatorname{ppmv} \mathrm{g}^{-1} \mathrm{~s}^{-1}\end{array}$ \\
\hline$R e$ & Número de Reynolds & - \\
\hline$\sigma$ & Coeficiente de Espalhamento Volumétrico & $\mathrm{m}^{-1}$ \\
\hline$S^{\varnothing}$ & Termo Fonte & - \\
\hline $\mathrm{U}_{\mathrm{g}}$ & Velocidade Superficial do Gás & $\mathrm{m} \cdot \mathrm{s}^{-1}$ \\
\hline$U_{m f}$ & Velocidade mínima de fluidização & $\mathrm{m} \cdot \mathrm{s}^{-1}$ \\
\hline UR & Umidade do ar & $\%$ \\
\hline$\Theta$ & Ângulo & o \\
\hline $\mathrm{T}$ & Temperatura & ${ }^{\circ} \mathrm{C}$ \\
\hline$t$ & Tempo & $\mathrm{s}$ \\
\hline$\tau$ & Tempo de residência & $\mathrm{s}$ \\
\hline$T_{\lambda}$ & Transmitância da Parede de Vidro & - \\
\hline$T$ & Fração de Energia Transmitida & - \\
\hline $\mathrm{V}$ & Volume & $\mathrm{m}^{3}$ \\
\hline$v$ & Velocidade & $\mathrm{m} \cdot \mathrm{s}^{-1}$ \\
\hline
\end{tabular}




$\begin{array}{cll}\mu & \text { Viscosidade } & \text { Pa.s } \\ u_{v}^{R} & \text { Densidade de Energia Radiante } & \mathrm{J}^{-3} \mathrm{~m}^{-3} \\ y & \text { Coordenada em y } & \mathrm{m} \\ x & \text { Coordenada em x } & \mathrm{m} \\ \mathrm{X} & \text { Conversão de poluente } & \% \\ \boldsymbol{x}_{A} & \text { Fração Mássica de um Componente A } & - \\ z & \text { Coordenada em z } & \mathrm{m}\end{array}$




\section{LISTA DE ÍNDICES}

$\begin{array}{cl}0 & \text { Inicial } \\ \text { Abs } & \text { Absorvidos } \\ \text { densa } & \text { Fase densa do reator } \\ \text { diluída } & \text { Fase diluída do reator } \\ \mathrm{e} & \text { Externo } \\ \text { entrada } & \text { Entrada do reator } \\ g & \text { Gás } \\ \mathrm{i} & \text { Interno } \\ \mathrm{I} & \text { Componente i } \\ \text { limiar } & \text { Limite entre a fase densa e a fase leve } \\ \mathrm{J} & \text { Componente } \mathrm{j} \\ \lambda & \text { Comprimento de Onda } \\ \text { máx } & \text { Valor Máximo } \\ m f & \text { Mínima de Fluidização } \\ p & \text { Pressão Constante } \\ P & \text { Peneira } \\ \text { Previsto } & \text { Dado Previsto pelo modelo } \\ \text { saída } & \text { Saída do reator } \\ T & \text { Transmitida }\end{array}$




\section{LISTA DE ABREVIATURAS}

ABRAFATI Associação Brasileira dos Fabricantes de Tintas

ANP Agência Nacional de Petróleo

APN

Nitratos de Peroxiacetil

BET Brunauer-Emmett-Teller Analysis

BTX Benzento, Tolueno e Xileno

CETESB Companhia de Tecnologia e Saneamento Ambiental

CA Central Analítica

CFB Reator de leito fluidizado circulante

CFD Computational Fluid Dynamics

CG Cromatografia Gasosa

COV Compostos Orgânicos Voláteis

CSTR Reator de Mistura Perfeita

DEQ Departamento de Engenharia Química

DLS Espalhamento de Luz Dinamico

DSD Duales System Deutschland

DMS Dimetil Sulfito

GRG Gradiente Reduzido Generalizada

HDCFB Leito Fluidizado Circulante de Alta Densidade

ICP Inductively Coupled Plasma

IQ-USP Instituto de Química da USP

IUPAC International Union of Pure and Applied Chemistry

LCT Laboratório de Caraterização da Engenharia de Materiais

LED Light-emitting Diode

LH Langmuir-Hinshelwood

LVREA Local Volumetric Rate of Energy Absorption

MEK Metil Etil Cetona

MVF Método de Volumes Finitos

PAH Hidrocarbonetos Policíclicos Aromáticos

PCE Tetra-cloroetileno

PCO Oxidação Fotocatalítica

PFR Reator plug flow 


$\begin{array}{ll}\text { PNQA } & \text { Plano Nacional de Qualidade do Ar } \\ \text { POA } & \text { Processos Oxidativos Avançados } \\ \text { PRONAR } & \text { Programa Nacional de Controle e Polução do Ar } \\ \text { SEM/EDS } & \begin{array}{l}\text { Scanning Electron Microscopy / Energy Dispersive X-Ray } \\ \text { Spectroscopy }\end{array} \\ \text { STTR } & \text { Straight-Throught Transport Reactor } \\ \text { SVE } & \text { Sistema de Extração de Vapores } \\ \text { TCE } & \text { Tri-cloroetileno } \\ \text { TGA } & \text { Thermogravimetric analysis } \\ \text { USEPA } & \text { Agência Reguladora Ambiental dos Estados Unidos } \\ \text { USP } & \text { Universidade de São Paulo } \\ \text { UV } & \text { Radiação Ultravioleta } \\ \text { VUV } & \text { Radiação Visível Ultravioleta } \\ \text { XRD } & \text { Difratometria de Raios-X }\end{array}$




\section{SUMÁRIO}

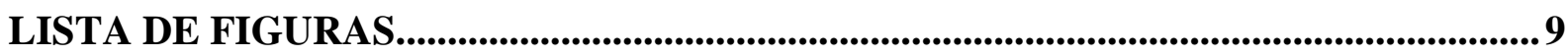

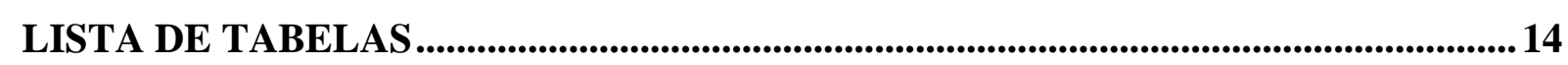

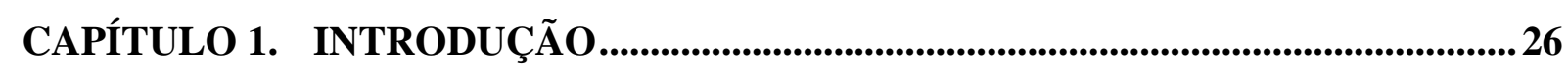

1.1 OBJETIVOS GERAIS E ESPECÍFICOS ................................................................. 28

1.2 ESTRUTURA DO TRABALHO .....................................................................28

CAPÍTULO 2. REVISÃO BIBLIOGRÁFICA ..................................................................... 29

2.1 LEGISLAÇÃO AMBIENTAL E CENÁRIO ATUAL .............................................29

2.2 FONTES DE COMPOSTOS ORGÂNICOS VOLÁTEIS .................................30

2.3 PROCESSOS OXIDATIVOS AVANÇADOS ......................................................31

2.3.1 Foto-oxidação e Foto-mineralização de Matéria Orgânica no Ar ...................... 33

2.4 FOTOCATÁLISE HETEROGÊNEA PARA TRATAMENTO DE EMISSÕES

GASOSAS CONTENDO COV ..................................................................................36

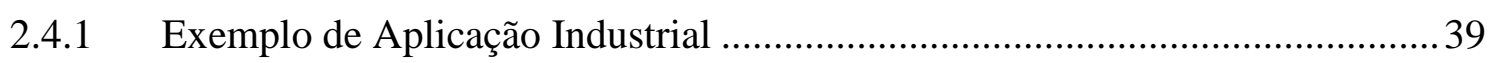

2.5 FOTOCATÁLISE HETEROGÊNEA EM LEITO FLUIDIZADO E

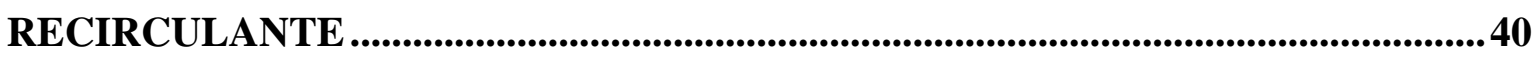

2.6 MODELOS MATEMÁTICOS PARA DESCRIÇÃO DA CINÉTICA DE

REAÇÃO FOTOQUÍMICA …............................................................................................. 45

2.7 FLUIDODINÂMICA COMPUTACIONAL EM PROCESSOS OXIDATIVOS AVANÇADOS. 46

2.8 MODELOS MATEMÁTICOS PARA DESCRIÇÃO DO TRANSPORTE DE

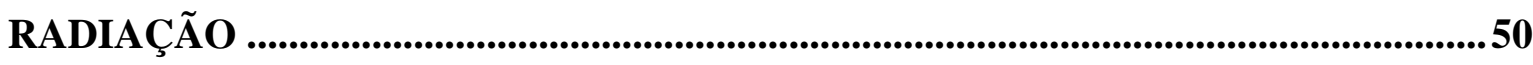

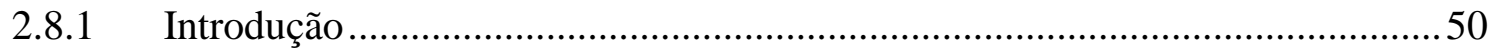

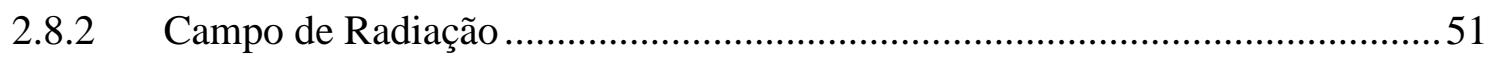

2.8.3 Modelos de Incidência de Radiação ................................................................54

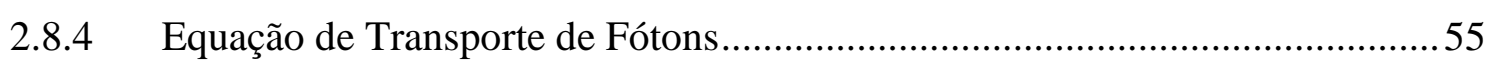

CAPÍTULO 3. PLANO DE TRABALHO .................................................................56

CAPÍTULO 4. METODOLOGIA .........................................................................................5 57

4.1 REATOR EM LEITO CIRCULANTE EXPERIMENTAL ...............................57

4.2 MÉTODOS ANALÍTICOS ........................................................................................5

4.3 EQUIPAMENTOS E FLUXOGRAMA DE PROCESSO .................................59

4.4 O REATOR FOTOCATALÍTICO_............................................................64

4.5 PARÂMETROS E VARIÁVEIS DE PROCESSO ................................................... 65 
4.6 INSTRUMENTAÇÃO .................................................................................66

4.7 COMPOSTO ORGÂNICO VOLÁTIL BTX ........................................................67

4.7.1 Seleção Do Composto Orgânico Volátil ..........................................................67

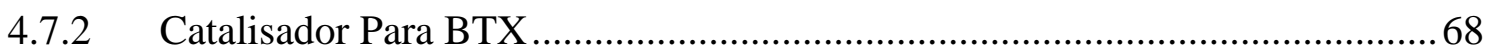

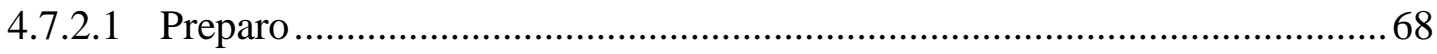

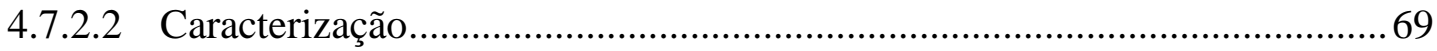

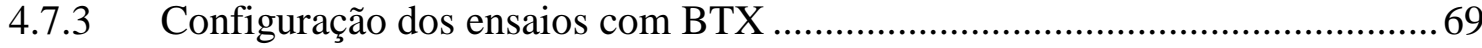

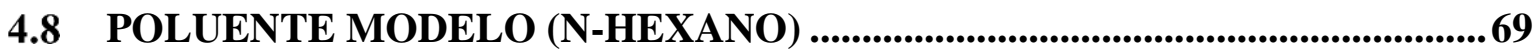

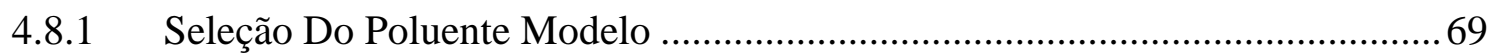

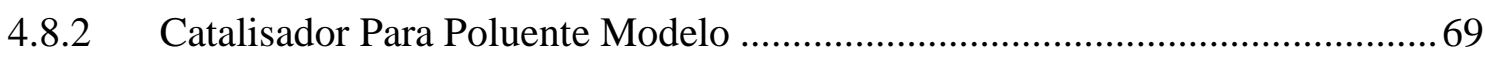

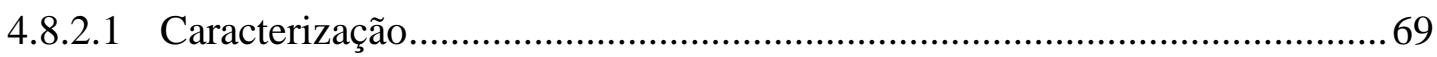

4.8.3 Configuração dos ensaios com Poluente modelo .......................................... 70

4.9 CÓDIGO DE CFD UTILIZADO........................................................................... 71

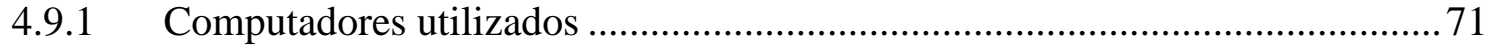

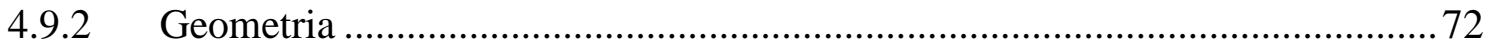

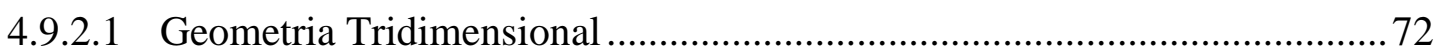

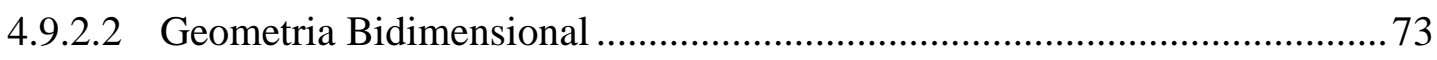

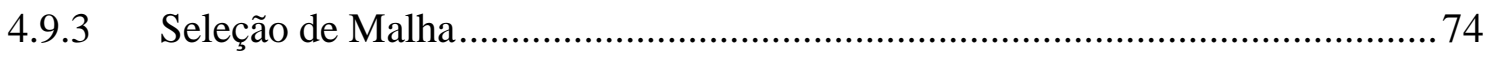

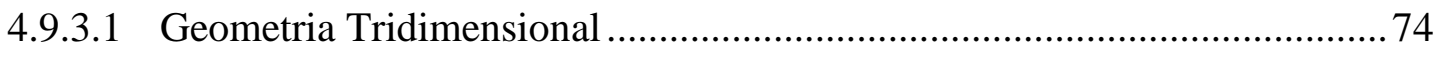

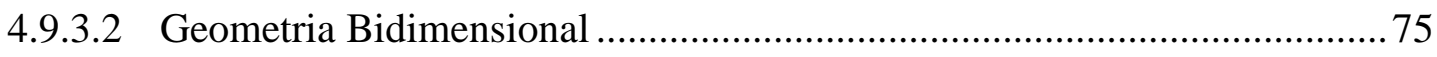

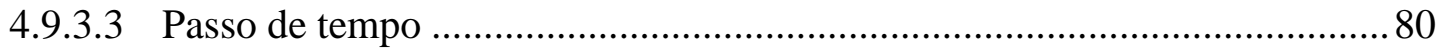

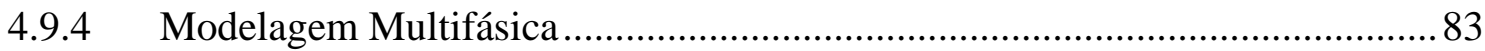

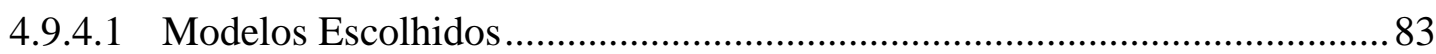

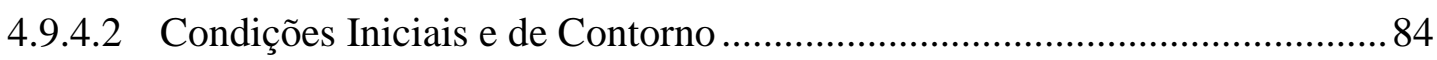

4.9.5 Modelagem da Reação Fotoquímica ........................................................... 85

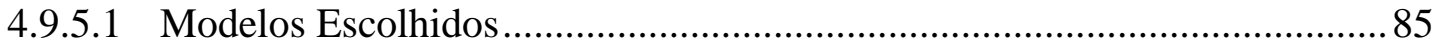

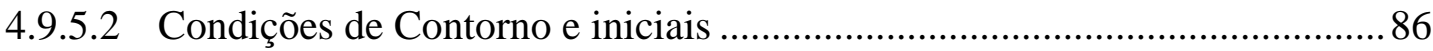

CAPÍTULO 5. RESULTADOS PARA COMPOSTOS ORGÂNICOS VOLÁTEIS ....87

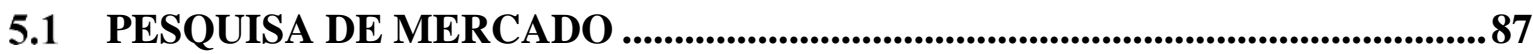

5.2 CARACTERIZAÇÃO DE CATALISADORES ................................................90

5.3 ENSAIOS EXPERIMENTAIS DE DEGRADAÇÃO DE BTX ...........................93

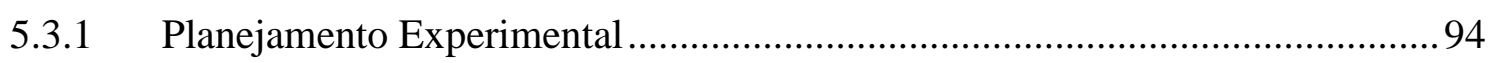

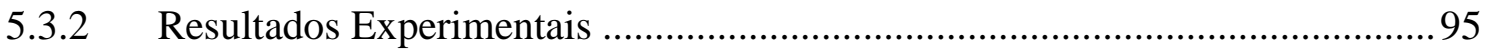


5.3.2.1 Velocidade mínima de fluidização ........................................................... 95

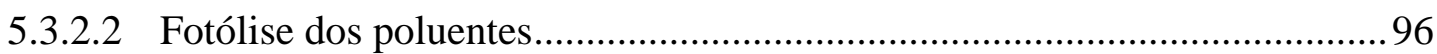

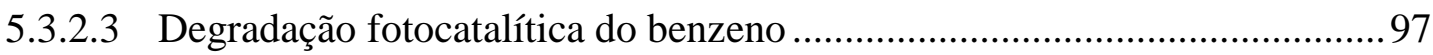

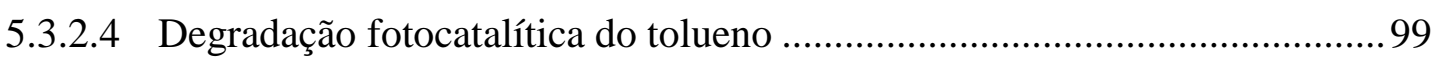

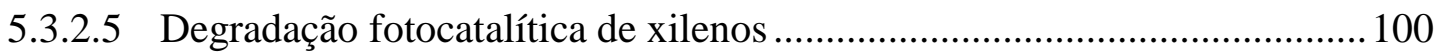

5.3.2.6 Degradação fotocatalítica de uma mistura BTX: teste para avaliação da

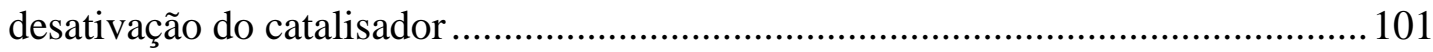

5.4 REGENERAÇÃO DO CATALISADOR.....................................................103

5.5 ASPECTOS OPERACIONAIS DO REATOR..................................................103

5.6 ENSAIOS EXPERIMENTAIS DE DEGRADAÇÃO DE POLUENTE

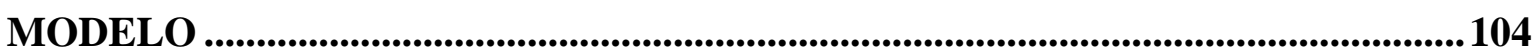

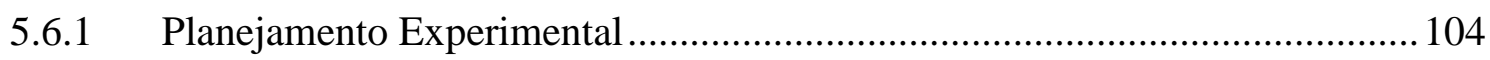

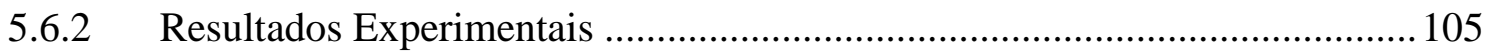

5.6.2.1 Velocidade mínima de fluidização .............................................................. 105

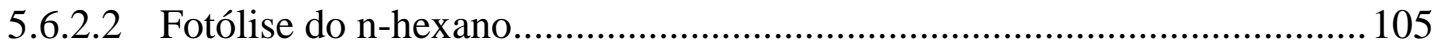

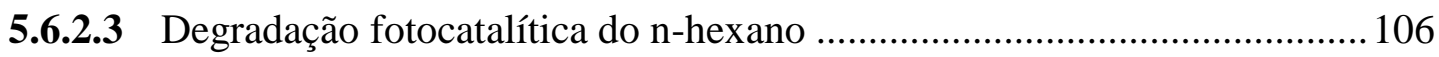

CAPÍTULO 6. RESULTADOS DA MODELAGEM MATEMÁTICA E

SIMULAÇÃO COMPUTACIONAL DO REATOR FOTOQUÍMICO ...........................110

6.1 MODELAGEM DA CINÉTICA DA REAÇÃO DO POLUENTE MODELO ABORDAGEM LANGMUIR-HINSHELWOOD ...................................................110

6.1.1 Determinação dos parâmetros cinéticos .......................................................... 112

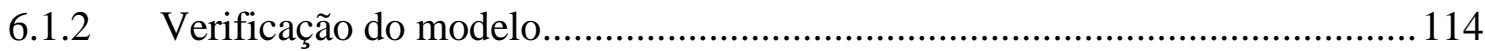

6.2 FLUIDODINAMICA COMPUTACIONAL ......................................................118

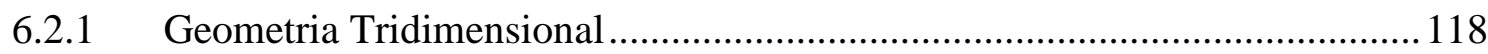

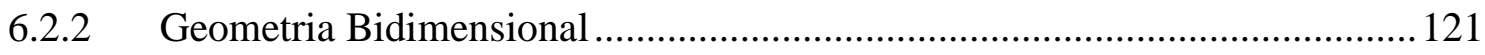

6.2.2.1 Comparação entre as Geometrias Tridimensional e Bidimensional ........... 121

6.2.2.2 Simplificação da Saída de Gases ............................................................ 123

6.2.2.3 Resultados para a malha escolhida ........................................................ 125

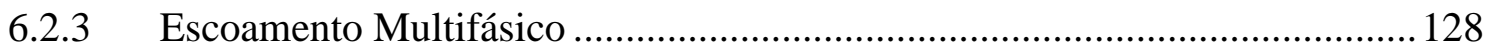

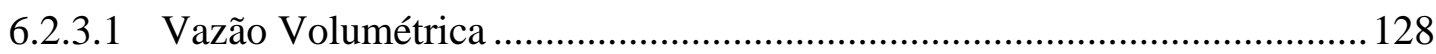

6.2.4 Reator Fotoquímico de Leito Fluidizado...................................................... 133

CAPÍTULO 7. CONCLUSÕES E CONSIDERAÇÕES FINAIS....................................138

7.1 ASPECTOS GERAIS.................................................................................................. 138 


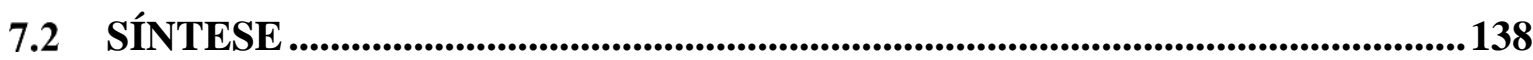

7.3 ASPECTOS OPERACIONAIS DO REATOR.....................................................138

7.4 DEGRADAÇÃO DE BTX ...........................................................................................138

7.5 DEGRADAÇÃO DO POLUENTE MODELO........................................................140

7.6 MODELAGEM CINÉTICA DE REATOR FOTOQUÍMICO .............................140

7.7 MODELAGEM FLUIDODINÂMICA DE REATOR FOTOQUÍMICO...........140

CAPÍTULO 8. CONTINUIDADE DO TRABALHO ...................................................141

REFERÊNCIAS BIBLIOGRÁFICAS .....................................................................142 


\section{CAPÍTULO 1. INTRODUÇÃO}

Para disciplinar as relações entre o homem e o meio ambiente, de forma a proteger o meio ambiente e o próprio homem dos efeitos associados à exploração irracional dos recursos naturais, diversos países criam uma Legislação Ambiental.

Essas legislações criam diversas restrições à indústria química atual, que dificilmente consegue produzir sem gerar resíduos, seja sólido, liquido ou gasoso. Atualmente, há um constante enrijecimento nas legislações relacionadas às emissões atmosféricas tendo em vista seus impactos ambientais e à saúde humana. Neste cenário, compreende-se que a mitigação da emissão de compostos orgânicos voláteis (COV) merece atenção especial. Portanto, é necessário desenvolver processos que possibilitem o tratamento destes poluentes (LI; ARMOR, 1992).

Por outro lado, atualmente, existe um grande interesse no estudo e desenvolvimento de processos fotoquímicos, denominados de Processos Oxidativos Avançados (POA) (RIBEIRO, 2009). Estes processos possuem uma ampla variedade de aplicações industriais, tais como reações de cloração e nitração, síntese de fármacos e eliminação de poluentes.

Nesse sentido, a utilização de POA vem se mostrando uma alternativa muito interessante particularmente para o tratamento de emissões atmosféricas devido a sua capacidade de oxidar e mineralizar muitos contaminantes por processos fotoquímicos. No entanto, o desenvolvimento teórico e a implantação de processos fotoquímicos para tratamento de emissões em escala laboratorial, piloto e industrial são desafios para a engenharia química, pois esses processos são altamente não lineares e os modelos de mecanismos de reações são muito complexos.

Baseando-se nesses pontos apresentados, diversos pesquisadores e especialistas concentram seus esforços no desenvolvimento e pesquisa de estratégias que relacionem os tópicos interdisciplinares:

- Meio ambiente

- Tecnologias de controle de poluição

- Luz e radiação UV.

A intersecção destes três temas, conforme a Figura 1.1, mostra um potencial desenvolvimento para o futuro, sendo o uso de luz e radiação UV para diversas aplicações um dos avanços de tecnologia do século XXI (OPPENLÄNDER, 2003). 


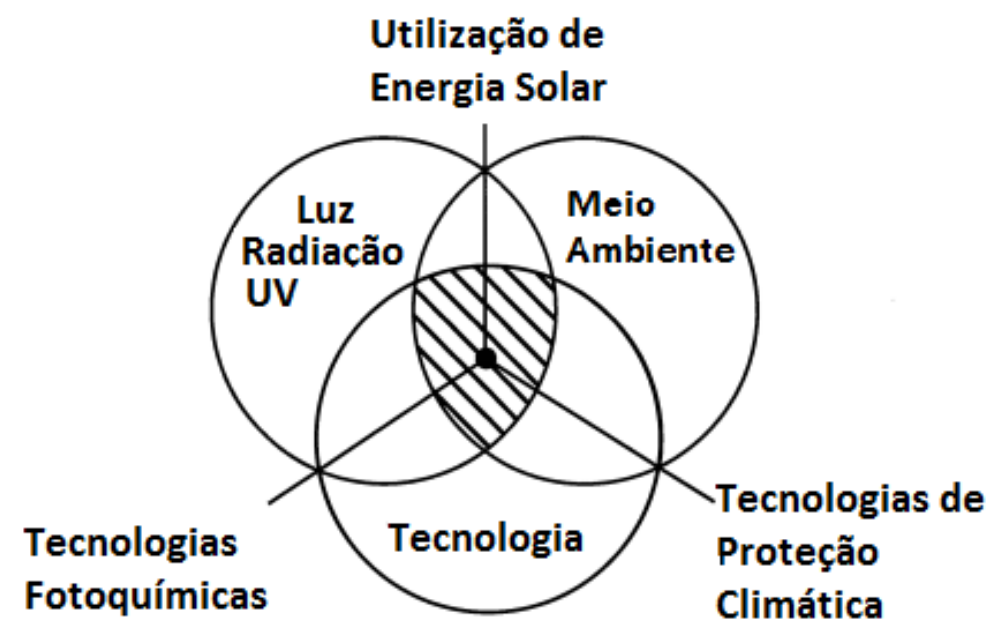

Figura 1.1 - Pesquisa interdisciplinar e áreas de desenvolvimento.

Fonte: (OPPENLÄNDER, 2003)

Os métodos convencionais de análise de um equipamento proporcionam uma visão global, não permitindo análises locais do interior do reator. Para uma visão mais detalhada, a ferramenta Fluidodinâmica Computacional (CFD) pode ser utilizada.

Portanto, visando contribuir para o conhecimento destas técnicas, o presente trabalho propõe um sistema que apresenta inovações para o estudo de abatimento de COV, apropriado em condições nas quais as tecnologias atualmente empregadas mostram deficiências. O processo de tratamento baseia-se na foto-oxidação catalítica dos contaminantes em contato com dióxido de titânio $\left(\mathrm{TiO}_{2}\right)$ e radiação ultravioleta. Com base na compreensão e experiência existente quanto à aplicação desta técnica ao tratamento de emissões gasosas obtida nas últimas duas décadas, este trabalho objetiva estudar um reator de leito fluidizado de catalisador heterogêneo. Estas configurações potencializaram a capacidade de tratamento e facilitaram a operação do processo. $\mathrm{O}$ modelo foi validado com dados experimentais obtidos de uma unidade em escala laboratório através de um projeto PIPE - Fase 1 financiado pela FAPESP (No. 00953/2016), desenvolvido no período de 01 de Setembro de 2016 a 31 de Agosto de 2017.

A aplicação de leito fluidizado em processos oxidativos é uma inovação promissora para tratamento de emissões gasosas e tem sido objeto de estudos recentes, mas ainda não é aplicada industrialmente em ampla escala.

O presente estudo está baseado no desenvolvimento de um reator fotoquímico em escala de laboratório e na modelagem cinética e fluidodinâmica do equipamento. Este procedimento tem potencial para adequar-se às condições operacionais em que as tecnologias vigentes de tratamento dos COV por oxidação térmica e catalítica mostram-se inadequadas, isto é, quando as concentrações de poluentes são baixas (SANCHES, 2009), quando o tratamento por 
combustão completa requer temperaturas extremamente elevadas ou são gerados produtos tóxicos na queima (TANG, 2000).

\subsection{OBJETIVOS GERAIS E ESPECÍFICOS}

O objetivo principal deste estudo é o desenvolvimento de um reator de leito fluidizado em escala laboratório para a degradação fotoquímica de compostos orgânicos voláteis, desde seu projeto até a construção de um modelo fluidodinâmico para posterior estudo de scale-up e otimização.

Os objetivos específicos desta tese são:

- Desenvolver e projetar um reator fotocatalítico de contato gás-catalisador-radiação UV do tipo leito fluidizado e do tipo circulante de arraste em escala de laboratório, investigando os parâmetros de operação do reator e avaliando sua eficiência para degradação de compostos orgânicos no estado gasoso, presentes como contaminantes;

- Desenvolver a modelagem fluidodinâmica para o reator, considerando-se o escoamento reativo e processos fotoquímicos, com o apoio de CFD;

- Validar o modelo fluidodinâmico com dados experimentais.

\subsection{ESTRUTURA DO TRABALHO}

A presente tese está dividida nas seguintes seções:

- Revisão Bibliográfica

- Plano de Trabalho

- Metodologia

- Resultados Experimentais

- Resultados de Modelagem

- Considerações Finais 


\section{CAPÍTULO 2. REVISÃO BIBLIOGRÁFICA}

Este capítulo apresenta a revisão bibliográfica elaborada para este trabalho. O item 2.1 e o item 2.2 mostram a importância do trabalho para adequação à legislação vigente para compostos orgânicos voláteis, as principais fontes destes poluente e como eles são tratados atualmente.

O item 2.3 traz uma apresentação aos processos oxidativos avançados descrevendo a foto-mineralização de poluentes gasosos.

O item 2.4 apresenta um tipo de processo oxidativo para tratamento de ar, a fotocatálise heterogênea aplicada ao tratamento de compostos orgânicos voláteis e, por fim, apresenta uma aplicação industrial do processo.

Por sua vez, o item 2.5 traz um resumo de diversos trabalhos de fotocatálise heterogênea em leitos fluidizados e circulantes para tratamento de emissões gasosas. Esta configuração proporciona maior área de contato por unidade de volume do reator e melhor transferência de massa entre o foto-catalisador e o gás (DIBBLE; RAUPP, 1992).

O item 2.6 traz a abordagem de modelagem cinética para reatores fotocatalíticos para diferentes COV's.

O item 2.7 apresenta alguns trabalhos que utilizaram a ferramenta fluidodinâmica computacional aplicada a processos fotoquímicos. $\mathrm{O}$ item 2.8 apresenta os principais modelos de radiação para reatores fotoquímicos.

\subsection{LEGISLAÇÃO AMBIENTAL E CENÁRIO ATUAL}

Nas últimas décadas, compostos orgânicos voláteis (COV) passaram a receber atenção da comunidade científica internacional. Além de seu potencial mutagênico e cancerígeno, a presença destes compostos na atmosfera está relacionada à formação de ozônio e nitratos de peroxiacetil (APN), prejudiciais à saúde humana (ALBERICI; JARDIM, 1997). As emendas do Clean Air Act (1990), associadas à Agência Reguladora Ambiental dos Estados Unidos (USEPA), aumentaram o número de compostos tóxicos a serem controlados de 7 para 189 (dos quais $50 \%$ são COV), além de incrementarem as penalidades legais aos poluidores (LI; ARMOR, 1992).

O Brasil segue padrões internacionais para emissão de poluentes gasosos desde a disposição do Programa Nacional de Controle e Polução do Ar (PRONAR) em 1989. O Conselho Nacional do Meio Ambiente (CONAMA) definiu compostos orgânicos voláteis pela Resolução n³82/2006 como: “compostos orgânicos que possuem ponto ebulição de até $130{ }^{\circ} \mathrm{C}$ 
na pressão atmosférica e podem contribuir na formação dos oxidantes fotoquímicos”, mas não estipulou limites legais de emissão. Em 2009, o Plano Nacional de Qualidade do Ar (PNQA) trouxe como projeto a quantificação de emissões locais de COV e designação de áreas críticas.

O Decreto $\mathrm{n}^{\mathrm{o}} 8.468$ define as bases de toda a legislação ambiental do estado de São Paulo, além de servir de molde para as legislações dos demais estados. A última versão data de 2004. Esse decreto define importantes conceitos, tais como poluição, poluente e fontes de poluição. Além disso, define quem é responsável pela fiscalização, quais são os padrões de lançamentos e emissões e o que é necessário para o licenciamento de empreendimentos (DECRETO, 2004).

Mais recentemente em 2013, o Decreto $\mathrm{N}^{\circ} 59.113$ da Assembleia Legislativa do Estado de São Paulo permitiu classificar a qualidade do ar de sub-regiões do estado com base em medições que consideram COV exceto metano, visando a minimizar os problemas de saúde pública e de odor (DECRETO, 2013).

\subsection{FONTES DE COMPOSTOS ORGÂNICOS VOLÁTEIS}

Dentre as fontes antrópicas de COV, destaca-se a mineração, distribuição e estocagem de combustíveis fósseis. Outra fonte considerável são as indústrias de produtos químicos e solventes orgânicos (LOPES, 2010). Estas atividades causam contaminação do ar por emissões localizadas e fugitivas e contaminação dos solos por vazamentos subterrâneos. Na Relação de Áreas Contaminadas de 2014 da Companhia de Tecnologia e Saneamento Ambiental (CETESB), há um total de 5.148 relatos de solos contaminados. Na remediação destes solos, a tecnologia mais utilizada é a extração de vapores (SVE), que exige ser combinada com algum tipo de tratamento dos vapores extraídos (SANCHES, 2009, p. 33). Além dos vapores de SVE, incluem-se como correntes gasosas que exigem o mesmo tratamento: ar ventilado em processos, emissões gasosas de tratamentos de efluentes, vapores de processo de extração (esgotamento), entre outros (TABATABAIE-RAISSI et al., 2003). A Tabela 2.1 mostra as principais tecnologias utilizadas para o tratamento de correntes de ar contaminadas por COV. 
Tabela 2.1 - Principais tecnologias atualmente utilizadas para tratamento de COVs. (Fonte:

SANCHES, 2009, p. 33)

\begin{tabular}{|c|c|c|c|c|}
\hline Tecnologia & $\begin{array}{l}\text { Faixa de } \\
\text { Concentração } \\
\text { Aplicável } \\
(\text { ppm) }\end{array}$ & Eficiência & Resíduos & Limitações \\
\hline $\begin{array}{l}\text { Adsorção em } \\
\text { Carvão Ativado }\end{array}$ & $0-5000$ & $90-98 \%$ & $\begin{array}{l}\text { Carvão } \\
\text { utilizado }\end{array}$ & $\begin{array}{l}\text { Umidade abaixo } \\
\text { de } 50 \% \text {, baixas } \\
\text { eficiências de } \\
\text { adsorção de } \\
\text { cetonas e aldeídos }\end{array}$ \\
\hline Oxidação Térmica & $100-4000$ & $95-99 \%$ & $\begin{array}{l}\text { Produtos de } \\
\text { combustão }\end{array}$ & $\begin{array}{l}\text { Produtos tóxicos } \\
\text { de halogenados, } \\
\text { concentração deve } \\
\text { ser superior a } 25 \% \\
\text { do Limite Inferior } \\
\text { de Explosividade }\end{array}$ \\
\hline $\begin{array}{l}\text { Oxidação } \\
\text { Catalítica }\end{array}$ & $100-2000$ & $90-95 \%$ & $\begin{array}{l}\text { Produtos de } \\
\text { combustão }\end{array}$ & $\begin{array}{l}\text { Produtos tóxicos } \\
\text { de halogenados, } \\
\text { concentração deve } \\
\text { ser superior a } 20 \% \\
\text { do Limite Inferior } \\
\text { de Explosividade }\end{array}$ \\
\hline
\end{tabular}

\subsection{PROCESSOS OXIDATIVOS AVANÇADOS}

As tecnologias fotoquímicas utilizam radiação ou luz UV como um reagente seletivo para a quebra de ligações químicas e para destruição de compostos químicos ou microrganismos indesejados. Estes métodos são amplamente utilizados no tratamento de água ou ar, com a presença de auxiliares oxidativos ou foto-catalisadores, apresentando boa eficiência na purificação, desintoxicação ou remediação conforme a Figura 2.1.

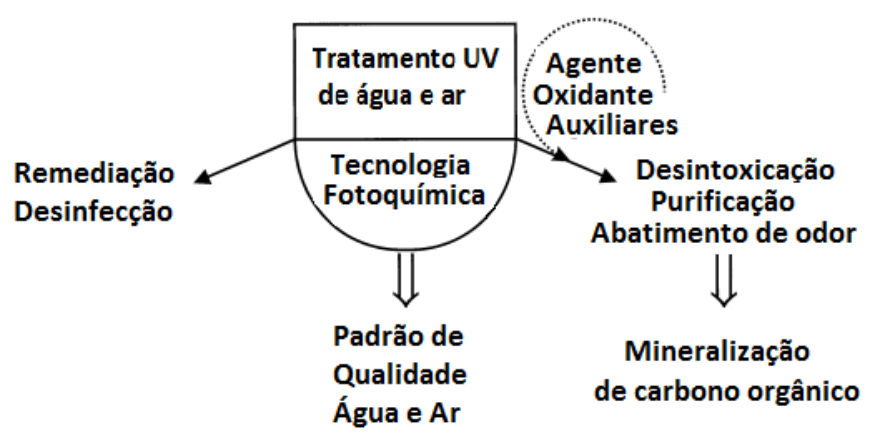

Figura 2.1 - Principais Tecnologias por tratamento UV. Fonte: (OPPENLÄNDER, 2003)

OPPENLÄNDER, 2003, apresenta que o sistema de reação de superfície fotocatalítico é classificado como um Processo Oxidativo Avançado (POA), pois há a produção de radical hidroxila, $\bullet \mathrm{OH}$, espécie altamente oxidante, não seletiva e fácil de produzir. 


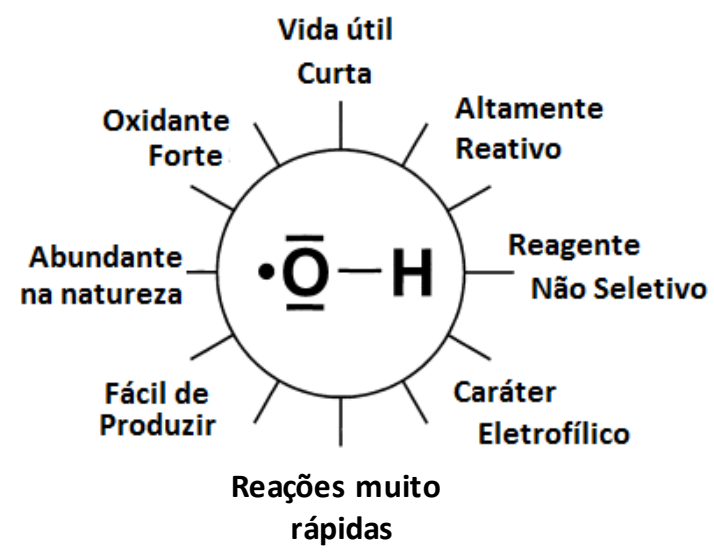

Figura 2.2- Algumas características do radical hidroxila. Fonte: (OPPENLÄNDER, 2003)

Estes processos podem ser homogêneos ou heterogêneos e usarem ou não a radiação eletromagnética. O radical hidroxila possui um alto potencial de oxidação, sendo capaz de oxidar quase todos compostos orgânicos a $\mathrm{CO}_{2}$ e água (RIBEIRO, 2009).

Os radicais $\bullet \mathrm{OH}$ quebram a ligação de um hidrogênio que forma radicais orgânicos que reagem com o oxigênio molecular gerando radicais peroxila. Os radicais peroxila iniciam reações de degradação oxidativas produzindo compostos intermediários e finais, podendo chegar a $\mathrm{CO}_{2}$ e água (RIBEIRO, 2009).

As reações podem ser visualizadas na equação ( Equação 2.1), a seguir:

$$
\begin{aligned}
& \mathrm{HO}^{\bullet}+\mathrm{RH} \rightarrow \mathrm{R}^{\bullet}+\mathrm{H}_{2} \mathrm{O} \\
& \mathrm{R}^{\bullet}+\mathrm{O}_{2} \rightarrow \mathrm{RO}_{2}^{\bullet}+\mathrm{H}_{2} \mathrm{O}
\end{aligned}
$$

( Equação 2.1)

As principais vantagens desta reação são: não há consumo de produtos químicos; não é necessário transformar o oxigênio do ar (como na ozonização); e não existe a necessidade de separar subprodutos ao final da reação (exceto no caso de se utilizar em reatores de lama ou suspensão). Uma desvantagem deste processo é o alto custo.

A transferência do processo natural de fotocatálise para processos tecnológicos requer métodos de produção eficientes dos chamados radicais hidroxilas livres em concentrações suficientes para funcionarem como percursores da reação. Diversas tecnologias inovadoras estão sendo propostas para o tratamento de efluentes líquidos e emissões gasosas (OPPENLÄNDER, 2003):

- Processos Fotoquímicos

- Oxidação Super Crítica da Água 
- Irradiação de Elétrons

- Y-Radiólise

- Irradiação de raios-X

- Sonólise

- Técnicas de Plasma Não Térmicas

- Processos Eletroquímicos

- Processos Catalíticos

- Fotocatálise com processos solares

\subsubsection{Foto-oxidação e Foto-mineralização de Matéria Orgânica no Ar}

Processos oxidativos avançados podem ser utilizados para tratamento de poluentes orgânicos em correntes gasosas através de sistemas homogêneos ou heterogêneos. Essas tecnologias apresentam muitas vantagens em relação a sistemas aquosos e em relação às tecnologias convencionais (RAJESHWAR, 1996), tais como:

- Tecnologia de processo e design do reator são complexas;

- Operação a temperatura e pressão ambientes;

- Sistemas em escala laboratorial e em escala industrial podem ser usados;

- Alta profundidade de penetração da radiação UV, dependendo da pressão de vapor dos substratos de absorção;

- Vazões de gases poluídos maiores que $100.000 \mathrm{~m}^{3} / \mathrm{h}$ podem ser tratadas;

- Concentração dos poluentes na faixa de 0,1 a 1000 ppm garantem um excesso de oxigênio para a reação em qualquer tempo de tratamento;

- Transferência de massa eficiente do substrato em fase gasosa;

- Facilidade de uso de sistemas heterogêneos, com foto catalisador imobilizado.

O princípio fundamental desta tecnologia de processo é baseado nos mecanismos de foto-oxidação de traços de poluentes da atmosfera terrestre, envolvendo ciclos complexos de oxidação radicalar iniciados por $\mathrm{HOx}$. Radicais $\bullet \mathrm{OH}$ podem ser produzidos em fase gasosa pela fotólise do ozônio e reação subsequente de átomos de oxigênio singletes com vapor de água. Existem muitas outras reações de formação como reação de hidroxila com NO ou fotólise de $\mathrm{H}_{2} \mathrm{O}_{2}$.

Para o meio gasoso, os radicais possuem um tempo de vida útil muito maior que em meio aquoso, sendo $1 \mathrm{~s}$ para $\mathrm{o} \bullet \mathrm{OH}$ e 60 s para o $\mathrm{HO}_{2} \bullet$. 
$\mathrm{Na}$ atmosfera terrestre, existe um complexo esquema de reações foto-induzidas e fotoiniciados por radicais em conexão com a fotólise direta de substratos gasosos que é responsável pela degradação oxidativa de composto orgânicos voláteis, conforme a Figura 2.3.

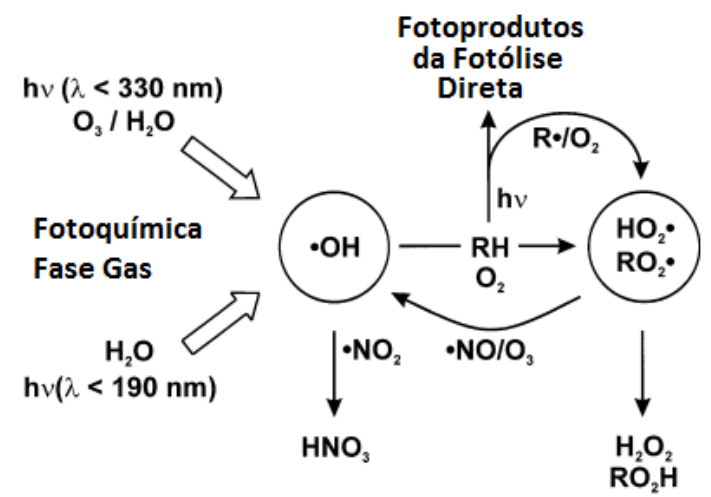

Figura 2.3 - Esquema simplificado das reações atmosféricas. (Fonte: OPPENLÄNDER, 2003)

As principais tecnologias para tratamento de correntes gasosas com VOC, gases e particulados podem ser visualizadas na Figura 2.4 (OPPENLÄNDER, 2003).

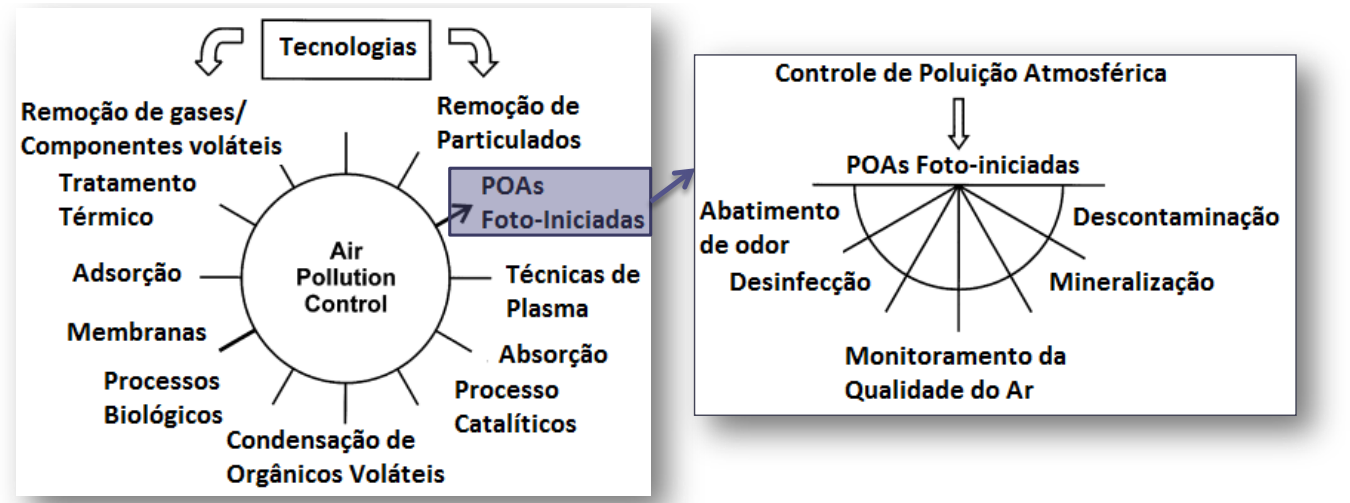

Figura 2.4 - Principais tecnologias para tratamento de correntes gasosas com VOC, gases e particulados. (Fonte: OPPENLÄNDER, 2003)

Essas tecnologias cobrem a remoção de material particulado, gases inorgânicos e compostos orgânicos voláteis. Usualmente o material particulado é removido por processos físicos, como ciclones, filtros e também por precipitadores eletrostáticos ou lavadores de gases. Já a limpeza de gases e compostos orgânicos voláteis pode ser feita por várias técnicas, tais como tratamento térmico, adsorção, absorção com água, membranas, processos biológicos e condensação.

A primeira emulação industrial destes processos atmosféricos foi um processo $\mathrm{O}_{3}-\mathrm{UV}$ que usava a fotólise de ozônio, com lâmpadas LP-Hg, emitindo em $\lambda=184,9 \mathrm{~nm}$ e $\lambda=253,7 \mathrm{~nm}$. No entanto, o ozônio também reage com a água, apresentando uma limitação em relação à comercialização. 
Segundo OPPENLÄNDER, 2003, existe uma promessa inovadora em desenvolvimento para esta aplicação, envolvendo o uso de plasma não-térmico e POA foto-iniciados. Existe um grande potencial de aplicação para controle de odor, desinfecção do ar contaminados com bactérias e mineralização de contaminantes orgânicos.

A primeira aplicação industrial de POA foi para a medição analítica de PAH (hidrocarbonetos policíclicos aromáticos) (Matter, 1994). Essa tecnologia foi desenvolvida pela empresa EcoChem Technologies e consistia em um sensor aerosol foto-elétrico com lâmpadas excímeras de $\mathrm{KrCl}^{*}$, a um $\lambda_{\text {máx }}=222 \mathrm{~nm}$, conforme a Figura 2.5 .

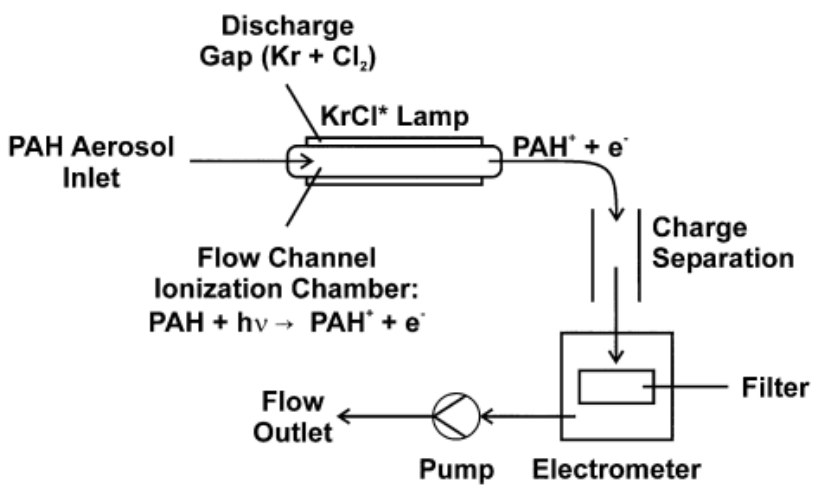

Figura 2.5 - Representação esquemática da primeira aplicação industrial de um POA em fase gasosa. (Fonte: OPPENLÄNDER, 2003)

OPPENLÄNDER, 2003, traz uma coleta dos principais trabalhos de POA foto-iniciados para tratamento de gases, sendo com ou sem fotocatalisadores. Este autor também apresenta as principais conclusões destes últimos trabalhos, como:

- Os principais compostos estudados são os álcoois saturados simples, cetonas e VOC's clorados.

- Segmento principal é da indústria de solventes.

- Sistemas heterogêneos com $\mathrm{TiO}_{2}$ prevalecem em relação a sistemas homogêneos.

- $\quad \mathrm{TiO}_{2}-\mathrm{UV} / \mathrm{Vis} \mathrm{POA}$ é o tratamento de correntes gasosas e tecnologia de purificação mais usado.

- Ao se tratar gases contendo hidrocarbonetos halogenados com POA, é necessário um controle de processo analítico eficiente dos gases de saída devido a possibilidade de formação de intermediários tóxicos.

- Uma possibilidade interessante da fotólise gasosa é a possibilidade de geração de ozônio por irradiação VUV de oxigênio. 


\subsection{FOTOCATÁLISE HETEROGÊENA PARA TRATAMENTO DE EMISSÕES GASOSAS CONTENDO COV}

A foto-oxidação catalítica de COV em superfícies irradiadas é um procedimento estudado desde os anos 90 (HASHIMOTO; IRIE; FUJISHIMA, 2006).

Conforme ZHANG (2013), se uma reação fotoquímica é feita pelo uso de catalisador, o processo é chamado de fotocatálise. A IUPAC define fotocatálise como "Mudança na taxa de reação química ou na iniciação sob ação de radiação ultravioleta, visível ou infravermelha na presença de uma substância - o fotocatalisador - que absorve luz e é envolvido na transformação de compostos em reações". Essa tecnologia se mostra capaz de oxidar completamente baixas concentrações de contaminantes orgânicos, incluindo a oxidação de COVs e microrganismos em produtos não tóxicos.

Para a purificação do ar, a fotocatálise normalmente utiliza fotocalisadores semicondutores, tais como $\mathrm{TiO}_{2}$ e $\mathrm{ZnO}$. A reação global pode ser dada por:

$$
\text { contaminantes orgânicos } \stackrel{\mathrm{TiO}_{2} / h v}{\longrightarrow} \text { intermediários } \stackrel{\text { oxid. }}{\longrightarrow} \mathrm{CO}_{2}+\mathrm{H}_{2} \mathrm{O}
$$

( Equação 2.2)

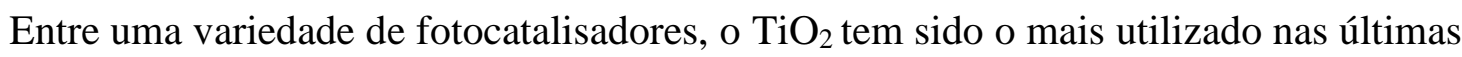
décadas devido ao seu baixo custo, baixa periculosidade, estabilidade química e alta atividade (CARP; HUISMAN; RELLER, 2004; HASHIMOTO; IRIE; FUJISHIMA, 2006; ZHANG, 2013). $\mathrm{O} \mathrm{TiO}_{2}$ possui três principais formas cristalinas: anatase, rutila e brookita. Sendo a anatase e rutila as fases que apresentam atividade fotocatalítica e a anatase com a maior atividade (HASHIMOTO; IRIE; FUJISHIMA, 2006).

O dióxido de titânio comercial mais largamente utilizado em foto-oxidação catalítica é o $\mathrm{TiO}_{2}$ Evonik Degussa P25, por apresentar maior atividade catalítica (ZHANG, 2013 apud MALATO et al., 2009). No entanto, por ser constituído de partículas muito pequenas, esse material apresenta dificuldades para ser fluidizado (é classificado como do grupo Geldart C, o que significa ser inviável como meio fluidizante, conforme PARK et al., 2011). Por este motivo, faz-se necessária a incorporação das partículas de dióxido de titânio em outro meio sólido. Kim e Hong (2002), Park et al. (2011) e Yao e Kuo (2015) fluidizaram partículas de sílica impregnadas com $\mathrm{TiO}_{2}$ com sucesso.

ZHANG (2013) relata que os contaminantes orgânicos primeiramente degradam para seus intermediários e depois mineralizam em $\mathrm{CO}_{2}$ e $\mathrm{H}_{2} \mathrm{O}$. As reações primárias em uma oxidação fotocatalítica por dióxido de titânio são resumidas por:

$$
\mathrm{TiO}_{2}+h v \rightarrow \mathrm{TiO}_{2}\left(e_{C B}^{-}+h_{V B}^{+}\right)
$$




$$
\begin{aligned}
& \mathrm{TiO}_{2}\left(e_{C B}^{-}+h_{V B}^{+}\right) \stackrel{\text { recomb }}{\longrightarrow} \mathrm{TiO}_{2}+\text { calor } \\
& \mathrm{TiO}_{2}\left(h_{V B}^{+}\right)+\mathrm{H}_{2} \mathrm{O} \rightarrow \mathrm{TiO}_{2}+\mathrm{H}^{+}+\mathrm{OH}
\end{aligned}
$$

$$
\mathrm{TiO}_{2}\left(h_{V B}^{+}\right)+\mathrm{OH}^{-} \rightarrow \mathrm{TiO}_{2}+{ }^{\circ} \mathrm{OH}
$$

( Equação 2.6)

$$
\mathrm{TiO}_{2}\left(e_{\mathrm{CB}}^{-}\right)+\mathrm{O}_{2} \rightarrow \mathrm{TiO}_{2}+\mathrm{O}_{2}^{--}
$$

$$
\mathrm{O}_{2}^{--}+\mathrm{H}^{+} \rightarrow \mathrm{HO}_{2}
$$

$$
\begin{gathered}
\mathrm{HO}_{2}^{-}+\mathrm{HO}_{2}^{-} \rightarrow \mathrm{H}_{2} \mathrm{O}_{2}+\mathrm{O}_{2} \\
\mathrm{TiO}_{2}\left(e_{\mathrm{CB}}^{-}\right)+\mathrm{H}_{2} \mathrm{O}_{2} \rightarrow \mathrm{OH}+\mathrm{OH}^{-} \\
\mathrm{H}_{2} \mathrm{O}_{2}+\mathrm{O}_{2}^{--} \rightarrow \mathrm{OH}+\mathrm{OH}^{-}+\mathrm{O}_{2} \\
\mathrm{H}_{2} \mathrm{O}_{2}+\mathrm{hv} \rightarrow 2 \mathrm{OH}^{\circ}
\end{gathered}
$$

( Equação 2.11)

( Equação 2.12)

contaminantes orgânicos $+{ }^{\circ} O H \rightarrow$ Produtos de degradação

( Equação 2.13)

contaminantes orgânicos $+\mathrm{TiO}_{2}\left(h_{V B}^{+}\right) \rightarrow$ Produtos de oxidação

( Equação 2.14)

contaminantes orgânicos $+\mathrm{TiO}_{2}\left(e_{C B}^{-}\right) \rightarrow$ Produtos de redução

( Equação 2.15)

A fotocatálise é um processo de reação em superfície e pode ser dividida em cinco passos independentes:

1. Transferência de massa do contaminante orgânico até a superfície do catalisador.

2. Adsorção do contaminante orgânico na superfície catalítica fotoativa.

3. Reação fotocatalítica.

4. Dessorção dos produtos de degradação da superfície do catalisador.

5. Transferência de massa do produto de degradação da interface para o fluido. 
Uma breve lista de diversos contaminantes gasosos, principalmente orgânicos, que foram tratados por fotocatálise pode ser vista na Tabela 2.2 (CARP; HUISMAN; RELLER, 2004).

Tabela 2.2 - Compostos tratados por fotocatálise na fase gasosa (Fonte: CARP; HUISMAN; RELLER, 2004; ZHANG, 2013)

\begin{tabular}{ll}
\hline Classe & Compostos \\
\hline Hidrocarbonetos & Metano, Etano, Propano, n-Butano, Hexano, Heptano, \\
& Ciclohexano, Etileno, Propeno, Metil-acetileno, Ciclohexano, \\
& Benzeno, Xileno, Tolueno \\
\hline Halogenados & Diclorometano, Triclorometano, Tricloroetileno, PCE, Cloreto de \\
& vinila, 1,3-Diclorobenzeno \\
\hline Compostos Nitrogenados & Dietilamina, Propilamina, Piridina \\
\hline Hidroxilados & Metanol, Etanol, 2-Propanol, Butanol, T-Butil-Alcool \\
\hline Éteres & Di-etil éter, Metil-Butil-Éter \\
\hline Compostos sulfurados & Di-etil sulfeto, 2-Cloroetil etil sulfeto \\
\hline Aldeídos, Cetonas & Formaldeído, Acetaldeído, Acetona, MEK \\
\hline Inorgânico & $\mathrm{NO}_{\mathrm{x}}, \mathrm{O}_{3}$ \\
\hline Orgânico-Inorgânico & $\mathrm{NO}^{\mathrm{B} T E X}, \mathrm{NO}+\mathrm{BTEX}+\mathrm{SO}_{2}$ \\
\hline
\end{tabular}

Alberici e Jardim (1997) realizaram experimentos em escala laboratorial, empregandose reator anular de leito fixo na parede do reator, irradiado por UV-B e UV-C. Obtiveram conversões superiores a $70 \%$ na degradação de 12 COV entre 17 estudados, incluindo aromáticos e organoclorados. Na última década, muitos estudos de aplicação e otimização deste método abordaram a degradação de poluentes gasosos da indústria química, entre eles percloroetileno (IMOBERDORF et al., 2007), tricloroetileno (LIM; KIM, 2004a), benzeno, tolueno, etil-benzeno e xilenos (BTEX) (PARK et al., 2011; PRIETO; FERMOSO; IRUSTA, 2007; YAO; KUO, 2015a; ZHANG, 2013; ZHONG et al., 2007), entre outros.

As principais dificuldades técnicas associadas à aplicação do processo são: baixa eficiência de conversão associada ao contato gás-radiação UV-catalisador, necessidade de mineralização total em regime contínuo e a formação de produtos de reação que causam desativação do catalisador por impregnação, devida à oxidação de aromáticos (ROCHETTO, 2012, p. 59). Em casos reportados de desativação, conseguiu-se regenerar o catalisador pela exposição à radiação UV em combinação com peróxido de hidrogênio $\left(\mathrm{H}_{2} \mathrm{O}_{2}\right)$, ar úmido ou 
tratamento térmico (ALBERICI; JARDIM, 1997; PRIETO; FERMOSO; IRUSTA, 2007). GANDHI, MISHRA e JOSHI, 2012 compararam a eficiência da regeneração de $\mathrm{TiO}_{2}$ utilizado na remoção de ácido ftálico por diferentes métodos e, ao compararem a cinética de degradação utilizando-se os catalisadores regenerados por diferentes métodos, apontaram a necessidade do uso de $\mathrm{H}_{2} \mathrm{O}_{2}$ para reativação completa.

\subsubsection{Exemplo de Aplicação Industrial}

Conforme OPPENLÄNDER, 2003, a maioria das moléculas de odor, compostos provenientes de processos de tratamento de resíduos sólidos, absorve radiação UV em $\lambda<$ $300 \mathrm{~nm}$ e se convertem em substâncias sem cheiro por foto-oxidação. A radiação direta de correntes gasosas com odor por lâmpadas LP $\mathrm{Hg}$ a $\lambda=253,7 \mathrm{~nm}$ leva a uma redução significante do odor emitido pela planta. Dois exemplos de abatimento de odor são mostrados na Tabela 2.3.

Tabela 2.3 - Unidades de abatimento de odor por oxidação foto-iniciada das correntes gasosas de entrada. (Fonte: OPPENLÄNDER, 2003)

\begin{tabular}{ccccc}
\hline \multirow{2}{*}{ Fonte de Odor } & $\begin{array}{c}\text { Vazão Volumétrica } \\
\mathbf{Q}\left(\mathbf{m}^{\mathbf{3}} \mathbf{h}\right)\end{array}$ & \multicolumn{2}{c}{ Medida de Odor } & \% Redução de \\
\cline { 3 - 4 } & $16200^{\mathrm{d})}$ & Antes $^{\text {a) }}$ & Depois $^{\mathbf{b})}$ & Odor \\
\hline $\begin{array}{c}\text { Planta de Reciclagem } \\
\text { de lixo (DSD) }\end{array}$ & & 3620 & $200 \pm 13$ & $94 \%$ \\
\hline $\begin{array}{c}\text { Indústria Alimentícia } \\
\text { e) }\end{array}$ & $2800^{\mathrm{f})}$ & 8540 & 1230 & $86 \%$ \\
\hline
\end{tabular}
a) Gás bruto.
b) Corrente gasosa irradiada por radiação UV a $\lambda=253.7 \mathrm{~nm}$
c) DSD: Duales System Deutschland.
d) A corrente de ar seca foi filtrada antes do tratamento UV. Sua temperatura é de $22,9^{\circ} \mathrm{C}$.
e) Processamento e secagem de cereais (capacidade de produção de $1970 \mathrm{~kg} / \mathrm{h}$ ).
f) A corrente de ar úmido tem uma temperatura de $90^{\circ} \mathrm{C}$. Em adição às lâmpadas LP $\mathrm{Hg}$, o reator fotocatalítico contém $\mathrm{TiO}_{2}$ imobilizada em suporte de titânio.

O processo para o reator fotoquímico é relativamente simples. Inicialmente, a corrente gasosa contaminada é filtrada para remoção de particulados, aerossóis e poeira. Em seguida, a corrente gasosa é irradiada um uma câmara que contém as lâmpadas de LP Hg e camadas de catalisador $\mathrm{TiO}_{2}$ imobilizadas. A vazão tratada pode ser de $100 \frac{\mathrm{m}^{3}}{\mathrm{~h}}$ a $100.000 \frac{\mathrm{m}^{3}}{\mathrm{~h}}$.

Uma instalação correspondente pode ser vista na Figura 2.6. Essa instalação foi feita pela HDN Technik, na Alemanha e possui 72 lâmpadas com uma potência de 5,4kW. 


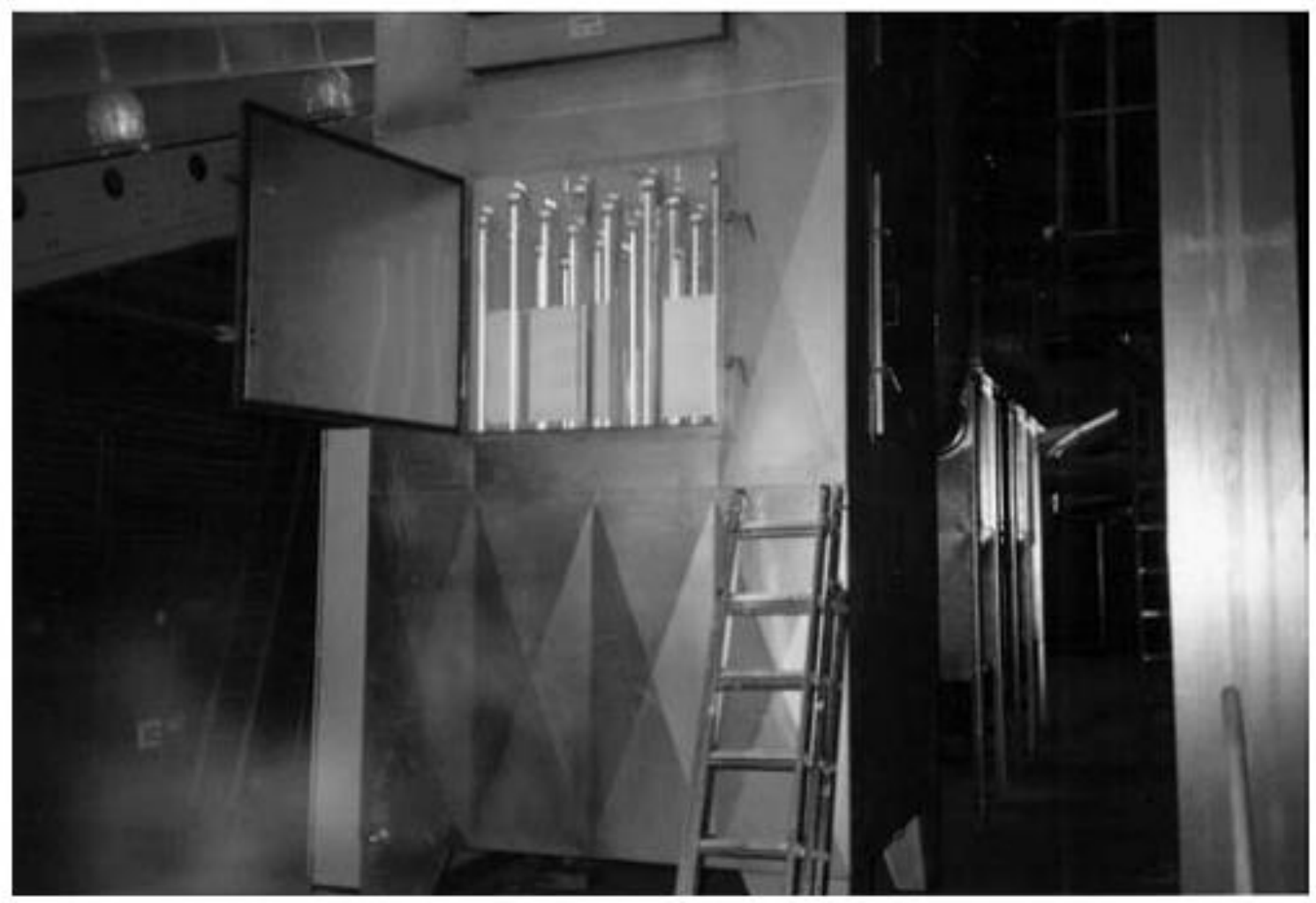

Figura 2.6 - Reator fotocatalítico para tratamento de correntes de ar de lixo com odor contendo 24 lâmpadas LP-Hg (Heraeus NNI 120/84, $\mathrm{P}_{\mathrm{el}}=120 \mathrm{~W}$ cada, máxima vazão volumétrica de $20.000 \mathrm{~m}^{3} / \mathrm{h}$ ). (Fonte: OPPENLÄNDER, 2003)

\subsection{FOTOCATÁLISE HETEROGÊNEA EM LEITO FLUIDIZADO E RECIRCULANTE}

A ideia de usar um leito fluidizado para aumentar a velocidade da síntese fotoinduzida da amônia foi originalmente proposta por YUE; KHAN; RIZZUTI, 1983, pois o contato sólidoradiação é aumentado quando comparado com reatores com superfície imobilizada para fotocatálise.

DIBBLE; RAUPP, 1992, LIM e KIM, 2004, FERMOSO et al., 2007, PARK et al., 2011, DASHLIBORUN et al., 2013, YAO e KUO, 2015, entre outros estudaram a possibilidade da foto-oxidação de COVs em reator de leito fluidizado de partículas impregnadas com $\mathrm{TiO}_{2}$. Quando comparada a reatores de catalisador imobilizado, esta configuração proporciona maior área de contato por unidade de volume do reator e melhor transferência de massa entre o fotocatalisador e o gás, embora a concentração demasiada alta de partículas possa dificultar a penetração da radiação UV. Neste tipo de reator, o caminho óptico, a granulometria das partículas e a fração de vazios no leito influenciam esta penetração e, consequentemente, a eficiência do reator. 
DIBBLE; RAUPP, 1992 utilizaram um reator do tipo flat-plate de leito fluidizado para degradar tricloroetileno em correntes gasosos usando $\mathrm{TiO}_{2} / \mathrm{SiO}_{2}$. Altas taxas de conversão foram obtidas para baixas concentrações iniciais de TCE em correntes úmidas e o catalisador apresentou total atividade por longos períodos de tempo.

LIM; KIM, 2004b apresentam uma comparação entre um reator anular de leito fixo e um reator anular de leito fluidizado, mostrando que a fluidização contribui para um contato mais eficiente entre o catalisador $\mathrm{TiO}_{2} / \mathrm{SiO}_{2}$ e $\mathrm{o}$ gás contendo tricloroetileno. Consequentemente, apresenta um aumento na fotodegradação quando comparado ao reator anular de leito fixo. A taxa de degradação no reator fluidizado apresentou variação com a concentração inicial de poluente e a umidade da corrente de entrada.

FERMOSO et al., 2007 utilizou um reator tubular fluidizado com lâmpada de baixa pressão de mercúrio para estudar a degradação de tolueno com dióxido de titanio suportado em sílica como catalisador. As taxas de conversões obtidas foram de 77 a 100\% para uma concentração máxima de alimentação de 200 ppm. Este estudo apresenta o processo de regeneração do catalisador desativado e identificou como intermediários formados os seguintes compostos: ácido benzóico, benzaldeído e álcool benzílico. KUO; WU; HSU, 2009 também estudaram a degradação de tolueno utilizando como catalisador $\mathrm{TiO}_{2}$ cobrindo partículas de carvão ativado e obtiveram taxas de degradação superiores a 99\%. KUO; WU; HSU, 2011 apresenta a degradação de tolueno em um reator multi-estágios fluidizado catalítico . A utilização de três estagios de reação melhora a eficiencia de remoção em $37 \%$ quando comparado ao sistema de um único estágio.

PARK et al., 2011 demonstraram que, nesta configuração, partículas mais grossas podem melhorar a eficiência do volume reacional, efeito explicado pela melhora na penetração de radiação UV no $\mathrm{TiO}_{2} / \mathrm{SiO}_{2}$. Neste estudo, analisaram a degradação de BTEX em uma concentração inicial de 100 ppm. As taxas de degradação em função da concentração de entrada em um reator anular fluidizado obtidas foram altas em um sistema batelada operado por 10 minutos.

YAO e KUO, 2015 analisaram a degradação de tolueno em um reator anular fluidizado, obtendo uma taxa de degradação de 30-40\%, estado estacionário para uma concentração inicial de 1000 ppm. Para caracterização do catalisador, realizaram SEM/EDS, XRD e BET.

DASHLIBORUN et al., 2013 apresenta uma modelagem de um reator fluidizado fotocatalitico para degradação de MEK. Para o modelo cinético, o model de LangmuirHinshelwood (LH) foi adotado e seus parametros cinéticos foram obtidos experimentalmente. 
Para a modelagem da hidrodinamica do reator, foram testados o modelo de duas fases simples e o modelo de duas fases dinâmico. Estes modelos foram comparados com os dados experimentais e o modelo de duas fases dinamico apresentou validade com os dados experimentais.

O primeiro trabalho reportado de um reator fotocatalítico do tipo leito fluidizado circulante (CFB) foi apresentado por LIM; KIM, 2005 para tratamento de TCE em fase gasosa. Um reator fotocatalítico do tipo CFB é composto por um leito, um riser, um ciclone e um sistema de alimentação de sólidos e apresenta como vantagens principais em reação a leitos fluidizados comuns (CHOI et al., 2001):

- Melhor contato entra a luz UV, o foto-catalisador e o gás a ser tratado.

- Maior produção de radicais.

- Redução das limitações do transporte de massa.

- Menor perda de carga.

LIM; KIM, 2005 mostram que o desempenho do reator fotocatalítico do tipo CFB é governado pela retenção do sólido como uma função da velocidade superficial do gás e da taxa de recirculação de sólidos. A conversão de TCE diminuiu com o aumento do comprimento de onda da luz UV e da umidade da corrente gasosa.

Outra aplicação de reator fotocatalítico do tipo CFB pode ser vista em MATSUDA; HATANO, 2005 para a remoção de $\mathrm{NO}_{\mathrm{x}}$ de correntes gasosas. Neste estudo foi realizado um teste de dureza para avaliar o descolamento do titânio da sílica gel pelo atrito e notou-se que parte das partículas não mensuradas são desprendidas. A eficiência de remoção obtida foi maior que $90 \%$ e varia de acordo com o volume de sólidos e a velocidade superficial do gás. O processo de adsorção se mostrou mais importante como etapa limitante do que a oxidação fotocatalítica.

Um resumo dos principais trabalhos com reatores de leito fluidizado e leito circulantes podem ser visualizados na Tabela 2.4 seguinte. 


\begin{tabular}{|c|c|c|c|c|c|c|c|}
\hline Contaminante & Tipo de Reator & Catalisador & Tipo de Lâmpada & $\begin{array}{c}\text { Vazão } \\
\mathbf{Q} \\
(\mathbf{L} / \mathbf{h})\end{array}$ & $\begin{array}{c}\text { Concentração } \\
\text { C } \\
(\mathbf{p p m})\end{array}$ & $\begin{array}{c}\text { Degradação } \\
\mathbf{X} \\
(\%)\end{array}$ & Referência \\
\hline TCE & $\begin{array}{l}\text { Flat-Plate } \\
\text { Fluidizado }\end{array}$ & $\mathrm{TiO}_{2} / \mathrm{SiO}_{2}$ & $\begin{array}{c}\text { Lâmpada UV de } 4 \mathrm{~W} \\
\lambda=300-500 \mathrm{~nm}\end{array}$ & 21,6 & 6,3 & 99 & $\begin{array}{c}\text { (DIBBLE; RAUPP, } \\
\text { 1992) }\end{array}$ \\
\hline TCE & $\begin{array}{c}\text { Anular } \\
\text { Fluidizado }\end{array}$ & $\mathrm{TiO}_{2} / \mathrm{SiO}_{2}$ & $\begin{array}{l}\text { Lâmpada UV de } 10 \mathrm{~W} \\
\lambda_{\max }=254 \mathrm{~nm}\end{array}$ & 720 & 256 & 88 & (LIM; KIM, 2004c) \\
\hline Tolueno & $\begin{array}{c}\text { Tubular } \\
\text { Fluidizado }\end{array}$ & $\mathrm{TiO}_{2} /$ Amido & $\begin{array}{c}\text { Lâmpada UV de Hg de } 40 \mathrm{~W} \\
\lambda_{\max }=365 \mathrm{~nm}\end{array}$ & 300 & $0-200$ & $77-100$ & $\begin{array}{c}\text { (FERMOSO et al., } \\
\text { 2007) }\end{array}$ \\
\hline Tolueno & $\begin{array}{c}\text { Anular } \\
\text { Fluidizado }\end{array}$ & $\mathrm{TiO}_{2} / \mathrm{AC}$ & $\begin{array}{l}\text { Lâmpada UV } \\
\lambda_{\max }=254 \mathrm{~nm}\end{array}$ & $180-900$ & $200-1000$ & $>99$ & $\begin{array}{c}\text { (KUO; WU; HSU, } \\
\text { 2009) }\end{array}$ \\
\hline $\begin{array}{c}\text { Benzeno, } \\
\text { Tolueno } \\
\text { Etil-benzeno e } \\
\text { Xileno }\end{array}$ & $\begin{array}{l}\text { Anular } \\
\text { Fluidizado }\end{array}$ & $\mathrm{TiO}_{2} / \mathrm{SiO}_{2}$ & $\begin{array}{l}\text { Lâmpada UV de } 2,6 \mathrm{~W} \\
\lambda_{\max }=368 \mathrm{~nm}\end{array}$ & 360 & 100 & $\begin{array}{l}76,3 \\
78,4 \\
99,6 \\
99,8\end{array}$ & (PARK et al., 2011) \\
\hline Tolueno & $\begin{array}{l}\text { Multi-estágio } \\
\text { Anular } \\
\text { Fluidizado }\end{array}$ & $\mathrm{TiO}_{2} / \mathrm{AC}$ & $\begin{array}{c}\text { Lâmpada UV de } 15 \mathrm{~W} \\
\lambda_{\max }=254 \mathrm{~nm}\end{array}$ & $\begin{array}{l}180- \\
1200\end{array}$ & 1000 & $>99$ & $\begin{array}{c}\text { (KUO; WU; HSU, } \\
\text { 2011) }\end{array}$ \\
\hline Tolueno & $\begin{array}{l}\text { Tubular } \\
\text { Fluidizado }\end{array}$ & $\begin{array}{c}\mathrm{TiO}_{2} / \mathrm{Si} \\
\text { mesoporosa }\end{array}$ & $\begin{array}{c}\text { Seis Lâmpadas UVA-Hg } \\
15 \mathrm{~W} \\
\lambda_{\max }=355 \mathrm{~nm}\end{array}$ & 24 & 20 & 93 & $\begin{array}{l}\text { (TASBIHI et al., } \\
\text { 2011) }\end{array}$ \\
\hline Tolueno & $\begin{array}{c}\text { Anular } \\
\text { Fluidizado }\end{array}$ & $\mathrm{TiO}_{2} / \mathrm{SiO}_{2}$ & $\begin{array}{l}\text { Lâmpada UV de } 15 \mathrm{~W} \\
\lambda_{\max }=254 \mathrm{~nm}\end{array}$ & 300 & 1000 & $30-40$ & $\begin{array}{l}\text { (YAO; KUO, } \\
2015 b)\end{array}$ \\
\hline $\begin{array}{c}\text { Metil Etil } \\
\text { Cetona (MEK) }\end{array}$ & $\begin{array}{c}\text { Anular } \\
\text { Fluidizado }\end{array}$ & $\begin{array}{c}\mathrm{TiO}_{2} / \gamma- \\
\mathrm{Al}_{2} \mathrm{O}_{3}\end{array}$ & $\begin{array}{c}\text { Lâmpada UVC de } 15 \mathrm{~W} \\
\text { Anular }\end{array}$ & 60 & 700 & 95 & $\begin{array}{l}\text { (DASHLIBORUN } \\
\text { et al., 2013) }\end{array}$ \\
\hline
\end{tabular}


Tabela 2.4 - Trabalhos de fotocatálise em reatores de leito fluidizado e em leito circulante (Fonte: O autor, 2017)

\begin{tabular}{|c|c|c|c|c|c|c|c|}
\hline Contaminante & Tipo de Reator & Catalisador & Tipo de Lâmpada & $\begin{array}{c}\text { Vazão } \\
\mathbf{Q} \\
(\mathbf{L} / \mathbf{h}) \\
\end{array}$ & $\begin{array}{c}\text { Concentração } \\
\text { C } \\
(\mathbf{p p m}) \\
\end{array}$ & $\begin{array}{c}\text { Degradação } \\
\mathbf{X} \\
(\%) \\
\end{array}$ & Referência \\
\hline & & & $\begin{array}{l}\text { Quatro Lâmpadas UVA de } \\
15 \mathrm{~W} \text { cada Externas }\end{array}$ & & & & \\
\hline TCE & $\begin{array}{l}\text { Tubular } \\
\text { Fluidizado } \\
\text { Circulante }\end{array}$ & $\mathrm{TiO}_{2} / \mathrm{SiO}_{2}$ & $\begin{array}{c}\text { Quinze lâmpadas germicidas } \\
\text { brancas e Quinze lâmpadas } \\
\text { fluorescentes pretas } \\
8 \mathrm{~W} \text { cada }\end{array}$ & $621-716$ & $100-500$ & $60-95$ & (LIM; KIM, 2004c) \\
\hline $\mathrm{NO}_{\mathrm{x}}$ & $\begin{array}{c}\text { Anular } \\
\text { Fluidizado } \\
\text { Circulante }\end{array}$ & $\mathrm{TiO}_{2} / \mathrm{SiO}_{2}$ & Lâmpada UV & $150-186$ & 5 & $<90$ & $\begin{array}{c}\text { (MATSUDA; } \\
\text { HATANO, 2005) }\end{array}$ \\
\hline $\begin{array}{l}\text { Tolueno } \\
\text { Acetona } \\
\text { Heptano }\end{array}$ & $\begin{array}{l}\text { Fotocatalitico } \\
\text { Dinâmico }\end{array}$ & $\begin{array}{c}\mathrm{TiO}_{2} / \text { Fibra } \\
\text { de quartzo }\end{array}$ & $\begin{array}{c}\text { Quatro lâmpadas UV 9W } \\
\begin{array}{c}\lambda_{\max }=365 \mathrm{~nm} \\
\lambda_{\max }=254 \mathrm{~nm}\end{array}\end{array}$ & 150.000 & $5-10$ & 90 & $\begin{array}{c}\text { (MAUDHUIT et al., } \\
\text { 2011) }\end{array}$ \\
\hline
\end{tabular}




\subsection{MODELOS MATEMÁTICOS PARA DESCRIÇÃO DA CINÉTICA DE REAÇÃO FOTOQUÍMICA}

Conforme descrito no item anterior, diversos trabalhos contendo dados experimentais para foto-oxidação de COVs em reatores de leito fluidizado podem ser encontrados na literatura. No entanto, trabalhos sobre desenvolvimento de modelos fenomenológicos para estes sistemas são escassos (DASHLIBORUN et al., 2013). Especificamente, valores experimentais obtidos por (FERMOSO et al., 2007) puderam ser bem representados pelo acoplamento da hidrodinâmica de um modelo de reator de mistura perfeita (CSTR) com um comportamento cinético do tipo Langmuir-Hinshelwood (LH):

$$
R=\frac{k_{1}[C]}{1+k_{2}[C]}
$$

( Equação 2.16)

Onde,

$\mathrm{R}$ : Taxa de reação $\left(\mathrm{kmol} \cdot \mathrm{m}^{-3} \cdot \mathrm{s}^{-1}\right)$

$k_{1}, k_{2}$ : Coeficientes da Equação de Langmuir-Hinshelwood $\left(\mathrm{s}^{-1} / \mathrm{m}^{3} \cdot \mathrm{kmol}^{-1}\right)$

$[C]$ : Concentração molar de um Componente $\mathrm{C}\left(\mathrm{kmol} \cdot \mathrm{m}^{-3}\right)$

Em uma abordagem mais detalhada, DASHLIBORUN et al., 2013 modelou um reator fotocatalítico fluidizado para oxidação de metil-etil-cetona com sucesso. Neste trabalho, os parâmetros cinéticos foram obtidos em um reator diferencial, o comportamento cinético LH também foi adotado e foram testados dois tipos de modelos hidrodinâmicos não ideais.

A degradação de alcanos C5-C7 em fase gasosa é apresentada por BOULAMANTI; PHILIPPOPOULOS, 2009. Foram realizados experimentos com diferentes condições de umidade e concentração de entrada em um reator anular com leito imobilizado com fluxo contínuo. Os resultados da oxidação fotocatalítica mostraram dois regimes cinéticos, característicos de um modelo LH. O modelo mostrou um bom ajuste com os dados experimentais.

A degradação fotocatalítica de n-hexano em fase gasosa foi apresentada por ZHANG; LIU, 2004. O catalisador utilizado foi o $\mathrm{TiO}_{2}$ com e sem adição de ozônio e diversas condições experimentais foram variadas, tais como: vazão volumétrica, concentração de n-hexano, umidade e dosagem de ozônio. A adição de ozônio aumentou razoavelmente a degradação do poluente. A partir dos dados experimentais, um modelo L-H bimolecular foi usado para correlacionar a taxa de reação para diferentes concentrações de n-hexano e de vapor. Um novo 
modelo L-H também foi feito em conjunto com a fotólise pelo ozônio para os dados experimentais obtidos.

Em reator fotocatalitico de loop fechado, MOULIS; KRÝSA, 2013 realizoaram a oxidação de diversos COVs, sendo: N-hexano, h-butyl acetato e tolueno, utilizando um reator com camadas de $\mathrm{TiO}_{2}$. As reações cinéticas consideradas foram a de mineralização completa dos poluentes a $\mathrm{CO}_{2}$ e $\mathrm{H}_{2} \mathrm{O}$. Foram testadas diversas concentrações de entrada e a partir destes dados experimentais, uma cinética L-H pode ser obtida. Como resultado principal, o n-hexano e o n-butil acetato foram degradados com sucesso. No entanto, o tolueno não pode ser degradado e desativou o catalisador em todas condições testadas.

Ressalta-se que quando a fluidização ocorre em velocidades do gás não muito maiores que a velocidade mínima de fluidização, duas regiões diferentes são formadas: uma região densa na parte inferior do reator, caracterizada por intenso borbulhamento e alta concentração de sólidos; e uma região diluída na parte superior do reator, caracterizada por baixa concentração de sólidos e pelo acúmulo de partículas finas de sólido na parede do reator (KUNII, D.; LEVENSPIEL, 1991).

\subsection{FLUIDODINÂMICA COMPUTACIONAL EM PROCESSOS OXIDATIVOS AVANÇADOS}

A modelagem de reatores fotocatalíticos é complexa e inclui a resolução de balanços de quantidade de movimento, massa, energia e radiação. Além disso, diferentes geometrias de reatores podem ser usadas (PASSALÍA; ALFANO; BRANDI, 2011). Os métodos convencionais de análise de um equipamento proporcionam uma visão global, não permitindo análises locais do interior do reator. Para uma visão mais detalhada, a ferramenta Fluidodinâmica Computacional (CFD) pode ser utilizada.

Estudos recentes demonstraram que o CFD é uma ferramenta poderosa para modelar o escoamento, a advecção, difusão molecular e reações químicas em reatores fotocatalíticos, que apresentam uma vantagem em relação aos reatores convencionais: a possibilidade de um design da irradiação - o que pode auxiliar no desenvolvimento de modelos de otimização de campos de radiação (WANG et al., 2012). Os modelos utilizados para reatores fotoquímicos com CFD são necessários e mais sofisticados que os modelos hidrodinâmicos simplificados, tais como plug flow e de mistura perfeita, os quais não mostram o que ocorre no interior do reator (TAGHIPOUR; MOHSENI, 2005).

Em reatores fotocatalíticos com reações volumétricas, a cinética da reação é usualmente uma função da taxa da propagação da radiação e modelos de radiação são requeridos para 
consideração dos efeitos de radiação na performance do reator (TAGHIPOUR; MOHSENI, 2005).

PAREEK., 2003 conduziu a modelagem com CFD de um reator trifásico de bolhas usando uma abordagem Euler-Euler e reportou que o modelo se adequou com os resultados experimentais e com a performance do reator.

Para tratamento de correntes gasosas contendo cloreto de vinila, um reator fotocatalítico anular com $\mathrm{TiO}_{2}$ imobilizado na parede externa em fase gás foi modelado por MOHSENI; TAGHIPOUR, 2004. A cinética de reação foi obtida experimentalmente através de um reator fotoquímico diferencial e foi utilizada para modelar e predizer a performance do reator com modelos em CFD. A cinética diferencial obtida foi uma cinética de primeira ordem para concentrações de entrada maiores que $0,28 \mathrm{~g} \cdot \mathrm{m}^{-3}$. Foi demonstrado que a modelagem em CFD e a abordagem experimental apresentaram tendências similares sobre a remoção do cloreto em função da concentração de entrada.

Um reator fotocatalítico anular com dióxido de titânio impregnado em suas paredes foi modelado por TAGHIPOUR; MOHSENI, 2005 através da fluidodinâmica computacional para tratamento de emissões atmosféricas contendo tricloroetileno (TCE). Foram simuladas diversas concentrações de entrada, vazões e comprimentos do reator e obtidos como respostas os perfis de pressão e concentração de TCE ao longo do reator. Os resultados foram comparados e validados com dados experimentais. Na parte experimental, foi utilizado um reator diferencial para obtenção de dados cinéticos e reator fotocatalítico anular para investigação da remoção do poluente. As predições da modelagem mostraram uma forte concordância com os dados experimentais. Após a validação do modelo, a ferramenta CFD pode ser usado para predizer a performance de diferentes conceitos de design do reator, tais como posição da entrada do fluxo de ar e estudar os impactos na remoção do poluente.

Reatores fotoquímicos em fase líquida também foram investigados e modelados pela ferramenta CFD. DENNY et al., 2009 apresentou a modelagem de um reator fotocatalítico com esferas recobertas com $\mathrm{TiO}_{2}$ para degradação de ácido oxálico em fase líquida. $\mathrm{O}$ reator foi irradiado por dois tipos de fibras óticas. O modelo de radiação foi acoplado com a fluidodinâmica e modelo cinético para estudo da degradação fotocatalítica do ácido. A aplicabilidade do modelo foi confirmada pela comparação dos resultados das simulações como dados experimentais sob diferentes condições de operação.

Um reator fotocatalítico do tipo prato corrugado foi modelado e estudado por PASSALÍA et al., 2011 para abatimento de formaldeído em baixas concentrações, poluente 
presente em poluição de ambientes fechados. O prato corrugado foi recoberto com dióxido de titânio e irradiado por ambos lados com lâmpadas UV. O reator foi modelado completamente utilizando CFD. No entanto, o modelo de radiação foi modelado externamente ao software por fatores de vista. A cinética da reação foi obtida a partir de experimentos prévios e colocada como condição de contorno. As predições do modelo para conversão global do formaldeído mostraram uma boa concordância com os experimentos, com um desvio inferior a $4 \%$.

Para a redução de odor, a técnica de oxidação fotocatalítica por um semicondutor (PCO) é promissora, uma vez que opera a temperaturas ambientes sem adição extra de oxidantes químicos. Ainda assim, uma das barreiras dessa tecnologia é a limitação de ferramentas confiáveis para auxiliar o design, otimização e dimensionamento dos reatores. WANG et al., 2012 utilizou CFD para modelar a cinética dentro de um reator fotocatalítico com radiação UV proveniente de LEDs. Como poluente a ser abatido, escolheu o dimetil sulfito (DMS), representativo de vários decaimentos anaeróbicos. O modelo de CFD pôde prever o perfil de concentração do poluente DMS no estado estacionário por meio do cálculo da advecção, difusão e reação química, que era função da concentração do poluente na superfície e da intensidade da irradiação. O modelo também mostrou que a posição do LED pode afetar substancialmente a performance do reator. Esse estudo apresentou um exemplo para o modelamento de um conjunto de LED baseado em um processo fotocatalítico e trouxe ideias de estratégias de otimização para aplicações do LED em processos fotocatalíticos.

Diversos estudos de leitos fluidizados e leitos circulantes foram realizados nos últimos vinte anos utilizando diferentes modelos de fluidodinâmica computacional. (ALMUTTAHAR; TAGHIPOUR, 2008a, 2008b; ASKARISHAHI et al., 2015; BENYAHIA et al., 2000; CHEN et al., 2016; HARTGE et al., 2009; LI et al., 2014; LI; PANNALA; SHAHNAM, 2014; MAHMOUDI; SEVILLE; BAEYENS, 2010; MATHIESEN; SOLBERG; HJERTAGER, 2000; PETIT; HEMATI; SIMONIN, 2008; SHAH et al., 2015a, 2015b; UPADHYAY; PARK, 2015) . No entanto, estas pesquisas foram desenvolvidas para análises de risers, equipamento utilizados na indústria petroquímica no processo de FCC (craqueamento fluido catalítico).

BENYAHIA et al., 2000 e MATHIESEN; SOLBERG; HJERTAGER, 2000 simularam o comportamento do escoamento gás-sólido na seção do riser, em um leito fluidizado circulante (CFB) usando um código comercial de fluidodinâmica computacional. Os valores obtidos pela simulação estavam em concordância com os dados experimentais.

Um modelo em CFD foi desenvolvido por ALMUTTAHAR; TAGHIPOUR, 2008 para análise de um leito fluidizado circulante sob várias condições de fluidização usando um modelo 
multifásico Euler-Granular. O modelo foi avaliado e validado por comparação com resultados experimentais de um CFB riser operando em diversos fluxos mássicos e diferentes velocidades superficiais. ALMUTTAHAR; TAGHIPOUR, 2008 apresentaram em outro estudo uma análise em CFD para um leito fluidizado circulante de alta densidade (HDCFB) em que parâmetros da modelagem foram testados.

Dois reatores Photo-CREC tiveram sua performance analisada através do uso de CFD por (CASTRILLO, 2007). Ambos reatores foram usados para o tratamento de acetona em ar. O primeiro reator projetado apresentou diversos zonas mortas devido a falta de radiação em diversos pontos. Então, este reator foi projetado novamente de forma a favorecer a propagação da luz. O novo reator simulado apresentou uma distribuição do fluxo de fótons mais homogênea, melhorando a performance do mesmo para abatimento do poluente modelo.

Reatores fotocatalíticos estão sendo constantemente utilizados para tratamento de correntes gasosas indoor na forma de purificadores para eliminação de VOC (QUEFFEULOU; GERON; SCHAER, 2010). Estes autores apresentam a utilização de parâmetros cinéticos determinados experimentalmente em uma simulação destes reatores com o uso de CFD. O CFD foi usado para modelar o fluxo de gases pela sala e calcular a concentração de VOC e sua dispersão ao longo de tempo. Neste caso o poluente utilizado foi o acetaldeído e o catalisador $\mathrm{TiO}_{2}$ impregnado em um filme fino em uma estrutura de metal.

Outro trabalho que apresenta uma comparação entre um modelo teórico analítico e uma simulação em CFD foi apresentado por (VERBRUGGEN; LENAERTS; DENYS, 2015). A degradação fotocatalítica de acetaldeído em ar em um reator com peças de silicone cobertas com uma camada de $\mathrm{TiO}_{2}$ P25 Degussa. O modelo em CFD uma concordância melhor com os dados experimentais do que o modelo analítico. Ambos usaram uma cinética do L-H para modelagem da reação fotocatalítica.

A adsorção e dessorção de um poluente em um fotocatalisador também pode ser modelada por CFD, conforme pode ser visto em (VERBRUGGEN et al., 2016). Neste caso foi simulado um reator fotocatalítico com fibras. A adsorção de acetaldeído no $\mathrm{TiO}_{2}$ foi modelada em estado transiente baseando-se em uma adsorção de Langmuir. O CFD possibilitou a visualização dos efeitos de deslocamento de ar no reator e no seu detector.

Uma modelagem de cinética em um reator fotocatalítico baseado em parâmetros determinados por um reator diferencial foi feita por (CASADO et al., 2017). Os parâmetros cinéticos para o $\mathrm{TiO}_{2}$ foram obtidos a partir de experimentos em um reator diferencial. Então esses parâmetros foram utilizados para a modelagem em CFD de um reator anular com $\mathrm{TiO}_{2}$ 
na parede. A modelagem apresentou bons resultados em relação aos dados experimentais e foi usado para tratamento de metanol.

ROEGIERS; VAN WALSEM; DENYS, 2018 apresenta a modelagem multifásica de um reator do tipo tubular com diversos tubos recobertos com $\mathrm{TiO}_{2}$ para abatimento de acetaldeido como poluente modelo. Um modelo de radiação foi acoplado ao modelo multifásico com sucesso, apresentando boa concordância com os dados experimentais.

\subsection{MODELOS MATEMÁtICOS PARA DESCRIÇÃO DO TRANSPORTE DE RADIAÇ̃OO}

\subsubsection{Introdução}

Para a aplicação dos POA ao tratamento de efluentes, diferentes reatores fotoquímicos foram estudados, analisados e projetados. Diversas modelagens para esses reatores fotoquímicos foram estudadas por muitos grupos de pesquisa. A Tabela 2.5, apresentada por (ALFANO; CASSANO, 1986), apresenta os principais estudos e modelos desenvolvidos.

Tabela 2.5 - Principais modelos desenvolvidos para reatores fotoquímicos, grupos de pesquisa e período de publicação. (Fonte: (ALFANO; CASSANO, 1986))

\begin{tabular}{ccc}
\hline Grupo de Pesquisa & Modelo & Período \\
\hline Faraboschi, Santarelli e & Fonte extensa com emissão superficial & \\
co-autores & Fonte linear com emissão esférica & 1959-1983 \\
Smith e co-autores & Fonte linear com emissão em planos paralelos & \\
& Incidência parcialmente difusa & 1965-1974 \\
\hline Hill e co-autores & Incidência difusa bidimensional & \\
\hline Dranof e co-autores & Fonte linear com emissão esférica radial & $1965-1978$ \\
\hline Sugawara e co-autores & Fonte linear com emissão em planos paralelos & $1965-1978$ \\
& Fonte extensa com emissão superficial difusa & \\
& Fonte linear de emissão & $1969-1981$ \\
& Incidência paralela & $1970-1978$ \\
\hline Williams e co-autores & Incidência difusa tridimensional \\
& Incidência difusa bidimensional & \\
\hline
\end{tabular}




\begin{tabular}{|c|c|c|}
\hline Grupo de Pesquisa & Modelo & Período \\
\hline \multirow{4}{*}{ Akehata e co-autores } & Incidência difusa bidimensional & \multirow{4}{*}{$1971-1973$} \\
\hline & Fonte linear com emissão difusa & \\
\hline & Fonte linear com emissão esférica & \\
\hline & Fonte linear com emissão em planos paralelos & \\
\hline \multirow{2}{*}{ Shirotsuka e co-autores } & Fonte extensa de emissão & \multirow{2}{*}{$1971-1979$} \\
\hline & Incidência radial e paralela & \\
\hline \multirow{3}{*}{ Costa e co-autores } & Fonte extensa com emissão volumétrica & \multirow{3}{*}{$1972-1980$} \\
\hline & Fonte linear de emissão & \\
\hline & Incidência radial e difusa bidimensional & \\
\hline \multirow{4}{*}{ Cassano e co-autores } & Fonte extensa com emissão volumétrica & \multirow{4}{*}{$\begin{array}{l}1972-1978 \\
1982-1984\end{array}$} \\
\hline & Fonte extensa com emissão superficial difusa & \\
\hline & Fonte linear com emissão esférica & \\
\hline & Fonte linear com emissão em planos paralelos & \\
\hline \multirow{2}{*}{ Thiele e co-autores } & Incidência paralela & \multirow{2}{*}{$1975-1980$} \\
\hline & Fonte linear de emissão & \\
\hline \multirow{3}{*}{ Yokota e co-autores } & Fonte extensa com emissão superficial difusa & \multirow{3}{*}{$1976-1983$} \\
\hline & Fonte linear com emissão difusa & \\
\hline & Fonte linear com emissão esférica & \\
\hline Villermaux e co-autores & Incidência difusa & $1979-1983$ \\
\hline \multirow{2}{*}{ Andre e co-autores } & Fonte linear com emissão esférica & \multirow{2}{*}{$1981-1983$} \\
\hline & Fonte linear com emissão em planos paralelos & \\
\hline
\end{tabular}

\subsubsection{Campo de Radiação}

Diversos modelos foram propostos para descrever o campo de radiação, que é empregado na determinação da taxa volumétrica local de energia absorvida (Local volumetric rate of energy absorption - LVREA), a característica fundamental para análise e projeto de um reator fotoquímico (ALFANO; CASSANO, 1986).

Para a modelagem correta do reator, há a necessidade de se considerar a distribuição do campo de radiação, as propriedades físicas e as características geométricas do reator e estabelecer os balanços de massa, quantidade de movimento e energia, conforme esquema da Figura 2.7. 


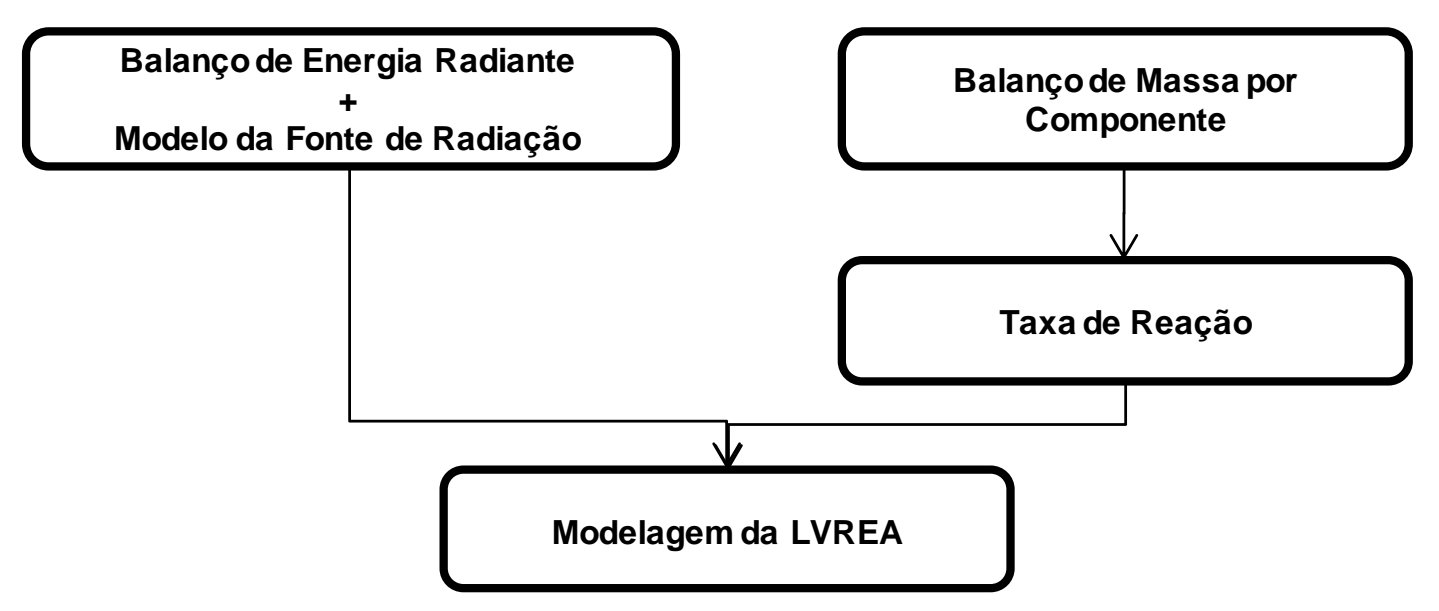

Figura 2.7 - Abordagem teórica para a modelagem do LVREA. (Fonte: (ALFANO;

CASSANO, 1986))

O LVREA $\left(e_{v}^{a}\right)$ representa a quantidade de fótons (em unidades de energia por um intervalo de frequência) que é absorvida por unidade de tempo e unidade de volume de reação. O valor do LVREA é definido para uma radiação monocromática, mas pode ser estendido para campos policromáticos através da integração para os comprimentos de onda de interesse (CASSANO et al., 1995).

A taxa de reação ativada pela radiação é proporcional à taxa de energia absorvida ( $a$ local volumetric rate of energy absorption). A constante de proporcionalidade é chamada de rendimento quântico $\left(\Phi_{\text {TiO2, }} \lambda\right)$ e tem unidade kmol.einstein ${ }^{-1}$ :

$$
R=\Phi_{T i o 2, \lambda} \cdot \mathrm{e}_{v}^{\mathrm{a}}(x, t) .
$$

(Equação 2.17)

Sendo:

$R:$ Taxa de Reação $\left(\mathrm{kmol} \cdot \mathrm{m}^{-3} \cdot \mathrm{s}^{-1}\right)$

$\Phi_{\text {Tio2, } \lambda}$ : Rendimento Quântico (kmol.einstein $\left.{ }^{-1}\right)$

$\mathrm{e}_{v}^{\mathrm{a}}(x, t)$ : Energia Local Absorvida Volumétrica (einstein. $\mathrm{m}^{-3} \cdot \mathrm{s}^{-1}$ )

A transferência de radiação em um meio participante é um tema bem estabelecido nos campos de ciências físicas e engenharias. No entanto, quando o assunto é agregado a um meio reativo, existem diferentes abordagens, cada uma com suas unidades, simbologias e definições. Em (CASSANO et al., 1995), foi utilizada uma abordagem aderida a ideias existentes na engenharia. As principais propriedades podem ser vistas na Tabela 2.6.

Tabela 2.6 - Definições das principais propriedades utilizadas nos estudos de radiação.

(Fonte: (CASSANO et al., 1995)) 


\begin{tabular}{lcccc}
\hline Propriedade & Nome & Definição & Símbolo & Unidade \\
\hline Energia & $\begin{array}{c}\text { Energia } \\
\text { Radiante } \\
\text { Potência de } \\
\text { Radiação }\end{array}$ & $d E_{v} / d t$ & $E_{v}$ & $\mathrm{~J}$ \\
$\begin{array}{l}\text { Energia por tempo } \\
\text { Energia por tempo, } \\
\text { área e ângulo } \\
\text { sólido sobre a } \\
\text { direção de } \\
\text { propagação }\end{array}$ & $\begin{array}{c}\text { Intensidade } \\
\text { Específica }\end{array}$ & $d E_{v} /[(d A \cos \theta) d t d \Omega]$ & $P_{v}$ & $\mathrm{~W}$ \\
$\begin{array}{l}\text { Energia por } \\
\text { volume }\end{array}$ & $\begin{array}{c}\text { Densidade de } \\
\text { Energia }\end{array}$ & $(1 / c) \int_{\Omega} I_{v} d \Omega$ & $\mathrm{W} /\left(\mathrm{m}^{2} \mathrm{sr}\right)$ \\
$\begin{array}{l}\text { Radiante } \\
\text { Energia por tempo } \\
\text { e área }\end{array}$ & $\begin{array}{c}\text { Vetor de Fluxo } \\
\text { Radiante }\end{array}$ & $\int_{\Omega} I_{v} \Omega d \Omega$ & $u_{v}^{R}$ & $\mathrm{~J} / \mathrm{m}^{3}$ \\
$\begin{array}{l}\text { Energia por tempo } \\
\text { e área para todas } \\
\text { as direções }\end{array}$ & $\begin{array}{c}\text { Radiação } \\
\text { Incidente }\end{array}$ & $\int_{\Omega} I_{v} d \Omega$ & $\boldsymbol{q}_{v}^{R}$ & $\mathrm{~W} / \mathrm{m}^{2}$ \\
\hline
\end{tabular}

Para complementar a Tabela 2.6, tem-se que:

- $\quad c$ : velocidade da luz $\left(\mathrm{m} . \mathrm{s}^{-1}\right)$;

- $\Omega$ : ângulo sólido (sr);

- $\boldsymbol{\Omega}$ : versor de direção de propagação da radiação (Adimensional)

Para radiações policromáticas, uma integração sobre todo o intervalo de frequência de interesse deve ser realizada, obtendo-se a (Equação 2.18) (CASSANO et al., 1995).

$$
G=\int_{v_{1}}^{v_{2}} \int_{\theta_{1}}^{\theta_{2}} \int_{\phi_{1}}^{\phi_{2}} I_{\nu} \sin \theta d \phi d \theta d \nu
$$

(Equação 2.18)

Em um volume elementar onde acontece a absorção da radiação, se um único fóton é absorvido, a energia absorvida segue a (Equação 2.19).

$$
\mathrm{e}_{v}^{\mathrm{a}}(x, t)=k_{v}(x, t) \cdot G_{v}(x, t)
$$

(Equação 2.19)

Sendo:

$G_{v}:$ Radiação Incidente (einstein. $\mathrm{m}^{2}$ );

$\mathrm{e}_{v}^{\mathrm{a}}(x, t)$ : LVREA espectral (einstein. $\mathrm{m}^{-3} \cdot \mathrm{s}^{-1}$ );

$k_{v}(x, t)$ : Coeficiente molar de absorção $\left(\mathrm{m}^{3} \cdot \mathrm{mol}^{-1} \cdot \mathrm{cm}^{-1}\right)$ (SILVARES, 2006). 
Portanto, para obter o LVREA, a intensidade espectral específica deve ser conhecida em cada ponto do reator. Esse valor pode ser obtido através da equação de transporte de fótons.

\subsubsection{Modelos de Incidência de Radiação}

Os principais modelos de reatores fotoquímicos podem ser classificados em modelos de incidência e de emissão, conforme a Tabela 2.7.

Tabela 2.7 - Classificação utilizada para os principais modelos de radiação. (Fonte:

(ALFANO; CASSANO, 1986))

\begin{tabular}{lcc}
\hline Tipo & Característica & Nome \\
\hline \multirow{2}{*}{$\begin{array}{l}\text { Modelos de } \\
\text { Incidência }\end{array}$} & Bidimensional & Radial \\
& & Parcialmente Difusa \\
\cline { 2 - 3 } & Tridimensional & Difusa \\
& & Difusa \\
\hline \multirow{2}{*}{ Fodelos de Emissão } & Emissão em Planos Paralelos \\
\cline { 2 - 3 } & & Emissão Esférica \\
& Fonte Extensa & Emissão Difusa \\
\hline & & Emissão Superficial Esférica \\
& & Emissão Superficial Difusa \\
\hline
\end{tabular}

Nesta seção, serão apresentados apenas os modelos de incidência utilizados neste trabalho: bidimensional radial e bidimensional difusa. A Figura 2.8 mostra o diagrama de cada modelo de incidência bidimensional.

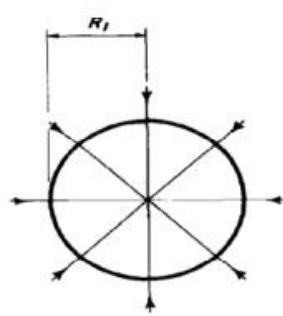

(a)

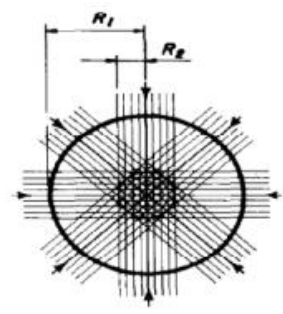

(b)

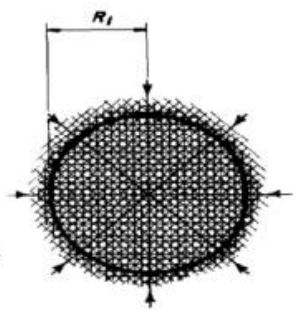

(c)

Figura 2.8 - Características de modelos bidimensionais de incidência de radiação: (a) Radial,

(b) Parcialmente difusa e (c) Difusa. (Fonte: (ALFANO; CASSANO, 1986))

Os raios incidentes estão em um plano normal ao eixo do reator e a circunferência representa a parede do reator para cada caso. O modelo parcialmente difuso assume que um feixe de raios paralelos, de largura $2 \mathrm{R}_{2}$, incide em qualquer direção no reator com a mesma probabilidade. Assumindo que $\mathrm{R}_{2}$ tenda a zero, obtêm-se o modelo de incidência radial. Ao considerar que a largura do feixe é próxima do valor do diâmetro do reator, obtêm-se o modelo difuso (ALFANO; CASSANO, 1986). 
O modelo de incidência radial não apresenta dependência radial ou axial em sua formulação e prevê uma densidade de fluxo de energia infinita na linha de centro do reator. Já para o modelo de incidência difusa, é observado, para meios com baixa absortividade, que existirá uma densidade de fluxo constante ao longo da coordenada radial (ALFANO; CASSANO, 1986).

\subsubsection{Equação de Transporte de Fótons}

A transferência de radiação em um meio reativo participante é resultado da interação do material multicomponente contínuo com uma fase de fótons imaterial. Ambas as fases coexistem em uma dada região e interagem entre elas de acordo com as equações constitutivas de cada meio. A equação de transporte de fótons é dada pela (Equação 2.20) (SILVARES, 2006).

$$
\begin{aligned}
& \frac{\partial}{\partial t} \int_{\forall} n_{\boldsymbol{\Omega}, v} d V+\int_{A} n_{\boldsymbol{\Omega}, v}(c \boldsymbol{\Omega}) \cdot \boldsymbol{n} d A
\end{aligned}
$$

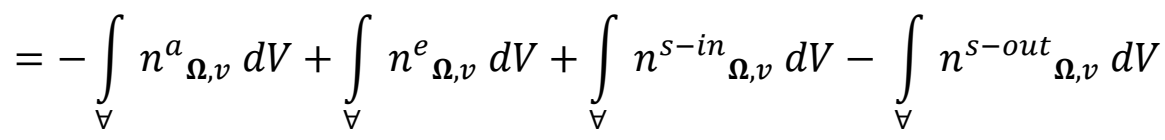

(Equação 2.20)

Sendo:

$n_{\Omega, v}$ : Número de fótons por unidade de ângulo sólido e por unidade de intervalo de frequência;

$\boldsymbol{n}$ : Versor normal a área;

$n_{\Omega, v}^{a}$ : Taxa de absorção de fótons;

$n_{\Omega, v}^{e}$ : Taxa de emissão de fótons;

$n^{s-i n}{ }_{\Omega, v}$ : Taxa de ganho de fótons devido à entrada por espalhamento;

$n^{s-o u t}{ }_{\Omega, v}$ :Taxa de perda de fótons devido à saída por espalhamento. 


\section{CAPÍTULO 3. PLANO DE TRABALHO}

O plano de trabalho foi dividido em algumas etapas, conforme esquematizado na Figura 3.1.

\section{Revisão Bibliográfica}

- Legislação aplicada ao VOC

- Fotoquímica

- Fotocatálise

- CFD aplicada a Fotocatálise

- Modelos de Radiação

\section{Estudo do sistema experimental a ser modelado}

- Projeto PIPE Fase 1

- Dimensionamento

- Aquisição de equipamentos

- Montagem do sistema

\section{Modelagem do Reator}

- Geometria

- Condições de Contorno

- Cinética do Poluente Modelo

\section{Experimental}

- Experimentos com BTEX

- Experimentos com poluente modelo

\section{Modelagem CFD}

- Hidrodinâmica do reator

- Reação fotocatalítica no CFD

\section{Validação}

Figura 3.1 - Plano de Trabalho. (Fonte: O autor, 2017) 


\section{CAPÍTULO 4. METODOLOGIA}

Os itens 4.1,4.2, 4.3, 4.4, 4.5 e 4.6 apresentam o reator escolhido para ser construído, os métodos analíticos usados, a unidade laboratorial construída, as variáveis de processo analisadas e a instrumentação utilizada, respectivamente.

Os itens 4.7 e 4.8 apresentam a metodologia para o composto orgânico volátil a ser degradado (BTX) e a metodologia para o poluente modelo, respectivamente. Dentro de cada item, explica-se o critério para a seleção do composto, catalisador utilizado e a configuração dos ensaios.

Por fim, o item 4.9 apresenta a metodologia utilizada para a modelagem em CFD.

\subsection{REATOR EM LEITO CIRCULANTE EXPERIMENTAL}

A partir do conhecimento sobre os fatores relatados na literatura que afetam o desempenho de reatores fotocatalíticos, este trabalho construiu um reator de leito fluidizado circulante, como forma de possibilitar o controle da concentração de partículas sólidas do catalisador no sistema. Na literatura, esta configuração de reator é conhecida como STTR (straight-throught transport reactor) (FOGLER, 2006). A Figura 4.1 compara as configurações de reator de leito fixo, fluidizado e a proposta. Entende-se que esta configuração potencializa o contato gás-radiação UV-catalisador.

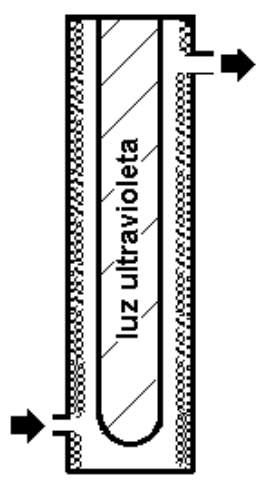

(a)

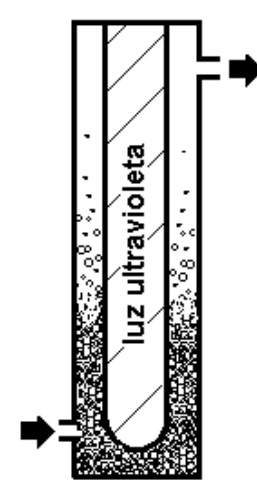

(b)

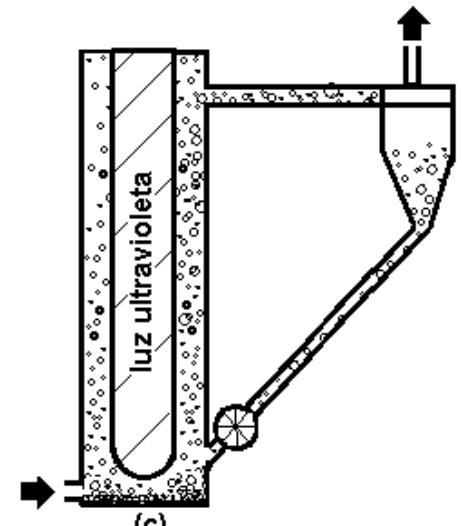

(c)

Figura 4.1 - Reatores fotocatalíticos: (a) imobilizado na parede, (b) em leito fluidizado, (c) em leito circulante. (Fonte: (FOGLER, 2006))

\subsection{MÉTODOS ANALÍTICOS} análises.

A Tabela 4.1 apresenta sucintamente os métodos analíticos utilizados e objetivos destas 
Tabela 4.1 - Resumo das metodologias de análise.

(Fonte: Relatório FAPESP, 2017)

\begin{tabular}{|l|l|l|}
\hline Métodos Analíticos & Objetivo & Local \\
\hline $\begin{array}{l}\text { Difratometria de Raios-X } \\
\text { (DRX) }\end{array}$ & $\begin{array}{l}\text { Caracterizar a estrutura do catalisador de } \\
\text { forma qualitativa }\end{array}$ & $\begin{array}{l}\text { Central Analítica } \\
\text { IQUSP }\end{array}$ \\
\hline $\begin{array}{l}\text { Inductively Coupled } \\
\text { Plasma (ICP) }\end{array}$ & $\begin{array}{l}\text { Caracterizar a estrutura do catalisador de } \\
\text { forma quantitativa }\end{array}$ & $\begin{array}{l}\text { Central Analítica } \\
\text { IQUSP }\end{array}$ \\
\hline $\begin{array}{l}\text { Brunauer-Emmett-Teller } \\
\text { (BET) Particle Analysis }\end{array}$ & $\begin{array}{l}\text { Caracterizar áreas superficiais específicas } \\
\text { do catalisador }\end{array}$ & IQUSP \\
\hline $\begin{array}{l}\text { Cromatografia Gasosa } \\
\text { (CG) }\end{array}$ & $\begin{array}{l}\text { Determinar concentrações de COV de } \\
\text { entrada e de saída do reator }\end{array}$ & Adox POLI-USP \\
\hline $\begin{array}{l}\text { Espalhamento de Luz } \\
\text { Dinamico (DLS) }\end{array}$ & $\begin{array}{l}\text { Determinar a distribuição de diâmetro de } \\
\text { partículas dos catalisadores }\end{array}$ & Adox POLI-USP \\
\hline Microscopia ótica & $\begin{array}{l}\text { Medir o tamanho das partículas e tirar } \\
\text { imagens do catalisador }\end{array}$ & POLI-USP \\
\hline
\end{tabular}

A difratometria de Raios- $\mathrm{X}$ foi realizada em um difratômetro de raios $\mathrm{X}$, Rigaku, modelo Miniflex ${ }^{\circledR} 2 \theta$ de $0^{\circ}$ a $80^{\circ}$, fonte: tubo de cobra estacionário $(\mathrm{K} \alpha 1,2 ; \lambda=1,5418 \AA$; aprox 8,0 $\mathrm{keV})$.

O ICP-OES foi feito em um espectrômetro Óptico de Emissão Atômica com Plasma indutivamente acoplado - Spectro, modelo Arcos com visão radial (SOP).

As áreas superficiais das partículas do catalisador foram caracterizadas em um BET da Quantachrome 100E model para análise de adsorção com $\mathrm{N}_{2}$.

O cromatógrafo gasoso GC-PID/TID (Meta), equipado com um detector de fotoionização e acoplado com um amostrador automático MSU-8V4S-RS48 (Meta), foi usado para quantificar a concentração de entrada e saída do poluente. As condições de operação do cromatógrafo foram as seguintes:

- Temperatura 1 do Forno sem rampa: $70^{\circ} \mathrm{C}$

- Injetor - Volume de loop: $98 \mu \mathrm{L}$

- Injetor - Pressão: $4 \mathrm{Kgf} \mathrm{pol}^{-2}$

- Injetor - Gás de Arraste: Nitrogênio

- Detector - Tipo: Fotoionização

- Detector - Temperatura: $200^{\circ} \mathrm{C}$

- Coluna: RTX-Volatiles column (30 m, $0.32 \mathrm{~mm}$ i.d., $2.0 \mu \mathrm{m}$ film thickness, Restek). 
Uma caixa de calibração de volume de $27 \mathrm{~L}$, selada hermeticamente, foi usada para o preparo de padrões gasosos de concentrações conhecidas. O ar interno foi contaminado através da injeção do poluente através de um septo por uma seringa microliter (Hamilton). Um ventilador interno auxilia a mistura interna após a injeção, e o ar contaminado na caixa circula pelo loop do CG com o auxílio de uma bomba peristáltica. Calibrações foram feitas assegurando a temperatura ambiente na faixa de $23-27^{\circ} \mathrm{C}$. A Tabela 4.2 mostra os coeficientes de ajuste angular e os limites de detecção e quantificação do cromatógrado para os poluentes.

Tabela 4.2 - Coeficiente de ajuste linear e limites de detecção e quantificação por CG.

\begin{tabular}{|c|c|c|c|c|}
\hline Poluente & Inclinação & $\boldsymbol{R}^{\mathbf{2}}$ & $\begin{array}{c}\text { Limite de } \\
\text { detecção }\left(\mathbf{m g ~ m}^{\mathbf{3}} \mathbf{)}\right)\end{array}$ & $\begin{array}{c}\text { Limite de } \\
\text { quantificação } \\
\left(\mathbf{m g ~ m}^{\mathbf{3}} \mathbf{)}\right.\end{array}$ \\
\hline Benzeno & 0,0000353 & 0,99 & 0,6 & 2,4 \\
\hline Tolueno & 0,0000493 & 0,98 & 0,7 & 2,8 \\
\hline Xileno & 0,0000823 & 0,96 & 0,4 & 1,6 \\
\hline$n$-hexano & 8559 & 0,988 & 1,6 & 6,4 \\
\hline
\end{tabular}

Para a determinação da distribuição de diâmetro de partículas dos catalisadores, foi utilizado a técnica de espalhamento de luz, através de um Malvern Mastersizer MSX17 (1-600 $\mu \mathrm{m})$.

Por fim, algumas imagens e medidas foram tiradas a partir de um microscópio ótico, modelo Olympus®BX60F-3.

\subsection{EQUIPAMENTOS E FLUXOGRAMA DE PROCESSO}

A Figura 4.2 apresenta um fluxograma simplificado da unidade que foi construída para realização dos experimentos. A Tabela 4.3 mostra os principais equipamentos empregados. 


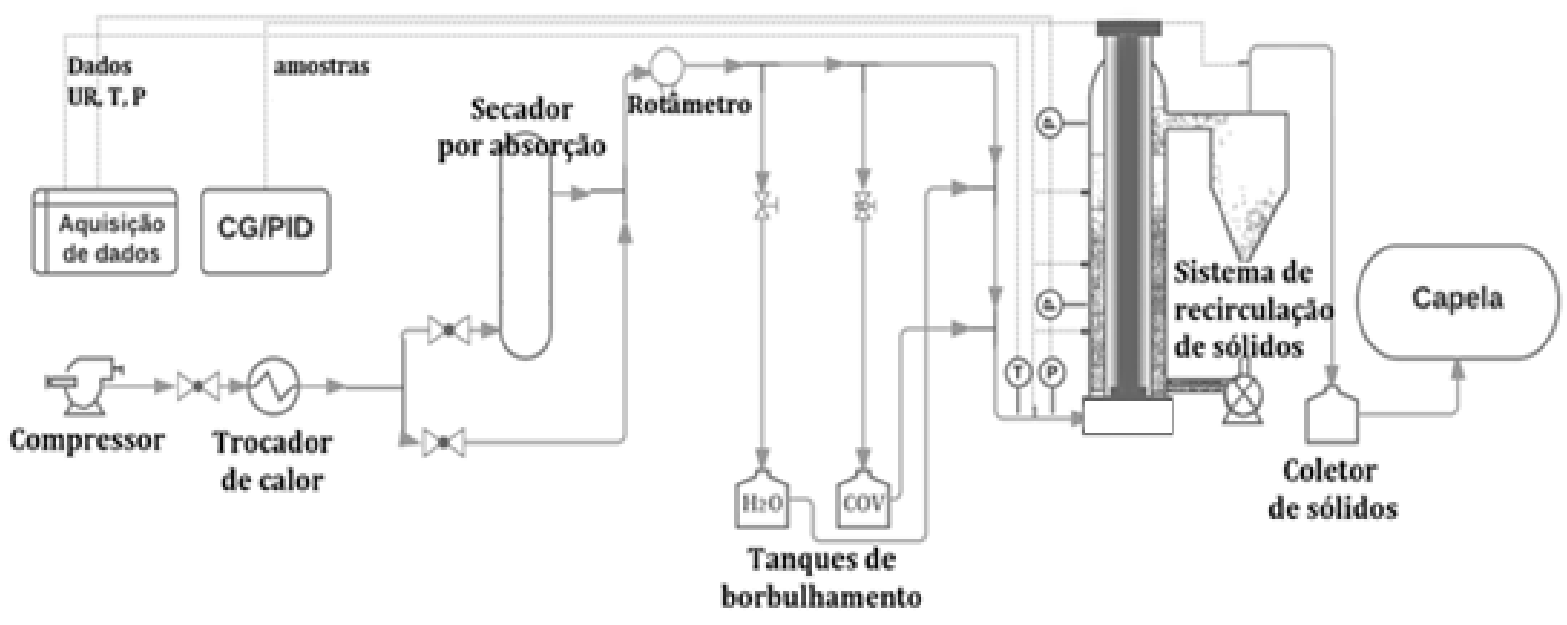

Figura 4.2 - Fluxograma simplificado do processo.

(Fonte: Relatório FAPESP, 2017)

Tabela 4.3 - Equipamentos adquiridos na construção unidade experimental.

(Fonte: Relatório FAPESP, 2017)

\begin{tabular}{|l|l|}
\hline \multicolumn{1}{|c|}{ Equipamento } & \multicolumn{1}{c|}{ Objetivo } \\
\hline Compressor Radial CR-02 1/6CV T & Captação de ar \\
\hline $\begin{array}{l}\text { Secador Metalplan TOTALPOINT 06 } \\
\text { PCM }\end{array}$ & Controle da umidade do ar \\
\hline Banho Termostatizado TE-184 & Controle da temperatura do saturador de COV \\
\hline $\begin{array}{l}\text { Computador Novo Inspiron DT Série } \\
3000\end{array}$ & $\begin{array}{l}\text { Computador para aquisição e armazenamento } \\
\text { de dados da unidade de laboratório }\end{array}$ \\
\hline
\end{tabular}

A Figura 4.3 apresenta o fluxograma do processo mais detalhado com as dimensões principais (em $\mathrm{mm})$. 


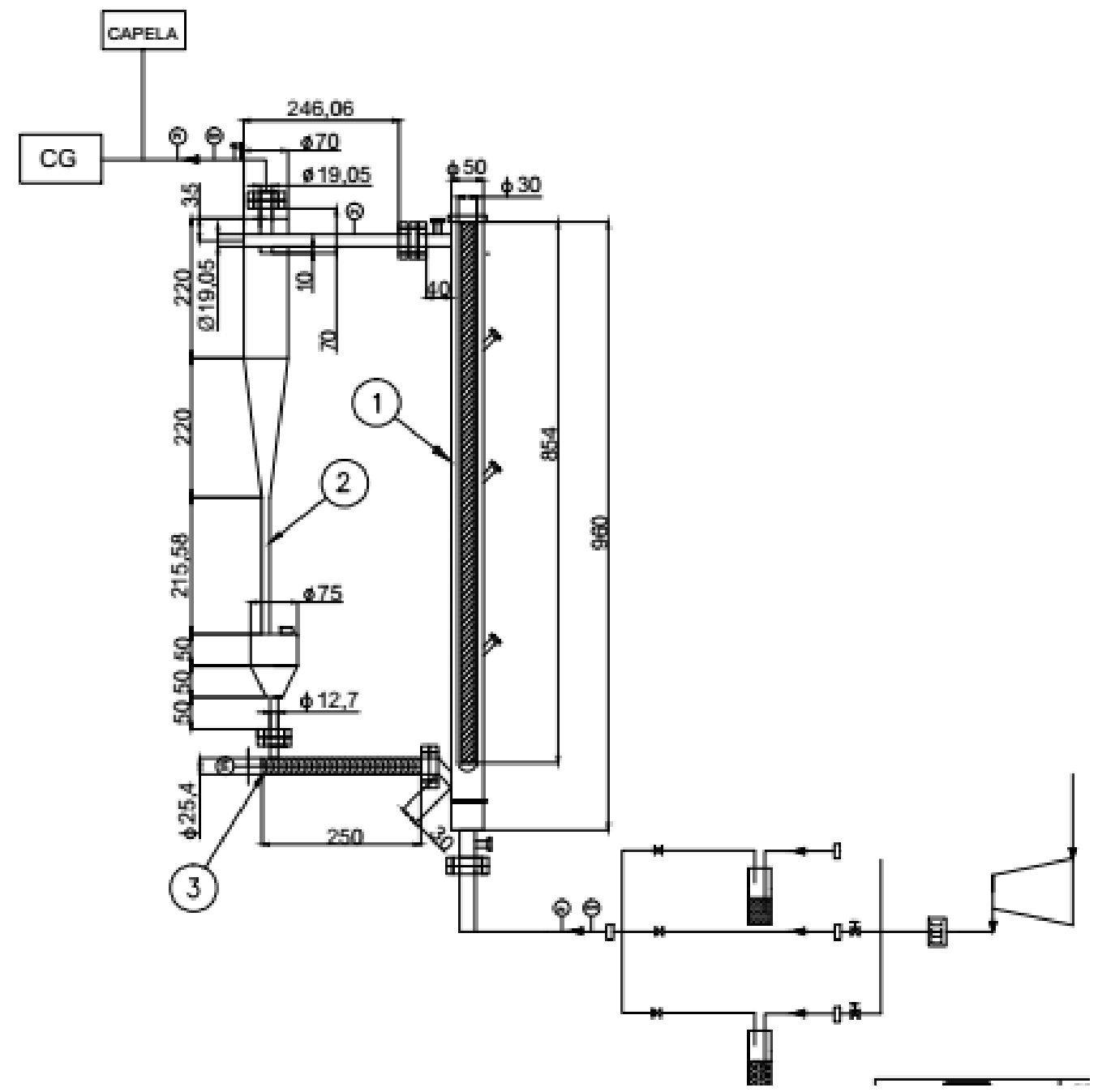

Figura 4.3 - Fluxograma do Processo. (1) Reator fotocatalítico com lâmpada anular (2) Ciclone (3) Rosca Transportadora

(Fonte: Relatório FAPESP, 2017)

A Figura 4.4 apresenta a unidade experimental construída em 3D. 


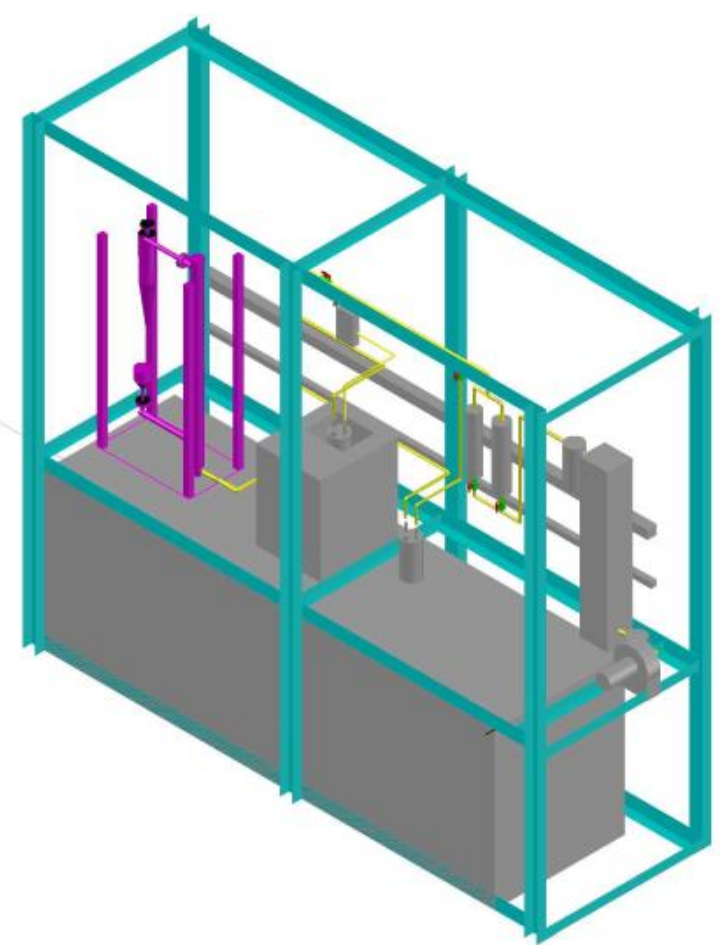

Figura 4.4 - Unidade Experimental em 3D.

(Fonte: Relatório FAPESP, 2017)

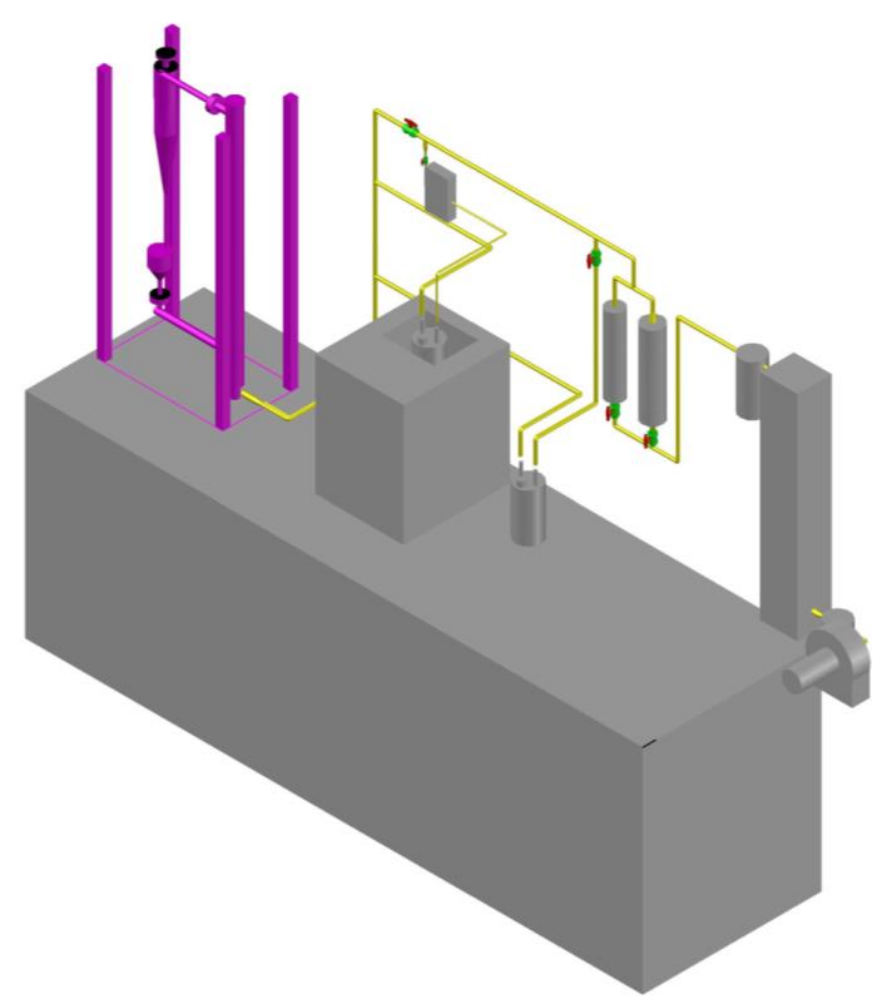

Figura 4.5 - Unidade Experimental em 3D sem estrutura.

(Fonte: Relatório FAPESP, 2017)

$\mathrm{Na}$ unidade construída, o ar foi inicialmente captado pelo compressor (CRMP75230660, Ideal). A umidade do ar capturado é controlada pelo secador (D4, Metalplan) e um 
sistema de saturação de uma parcela desta corrente de ar. Uma parte da corrente é contaminada com uma concentração conhecida de BTX (benzeno, tolueno e xileno) ou de n-hexano. Após essa etapa, as três correntes são misturas na própria tubulação e enviadas para o reator fotocatalítico.

O reator fotocatalítico foi construído em vidro e consiste de um canal anular de fluxo ascendente, com um prato para distribuição de fluxo em sua entrada. Na porção interior deste ânulo está instalada uma lâmpada de radiação luminosa ultravioleta, protegida por um invólucro de quartzo. Acoplado a este ânulo, tem-se um ciclone e um elemento mecânico de retorno do catalisador. No ciclone, construído em vidro, o catalisador é separado e conduzido para o retorno. O gás tratado será exaurido e analisado. O elemento de retorno consiste em um acessório de transporte mecânico que possibilita o catalisador retornar para o ânulo irradiado, sem permitir a passagem de ar pelo duto de retorno. A quantificação dos sólidos não retidos pelo ciclone no decorrer dos ensaios foi feita pesando-se a massa de sólidos restante ao final dos experimentos. A Figura 4.6 e a Figura 4.7 ilustram a instalação construída.

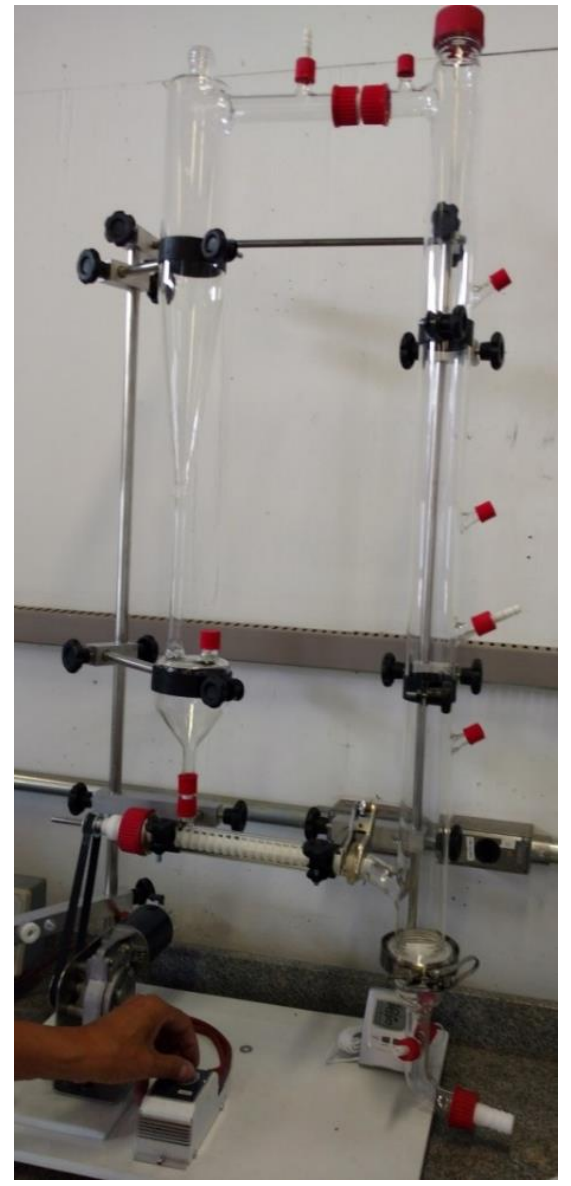

Figura 4.6 - Foto do Reator Fotocatalítico de Arraste.

(Fonte: Relatório FAPESP, 2017) 


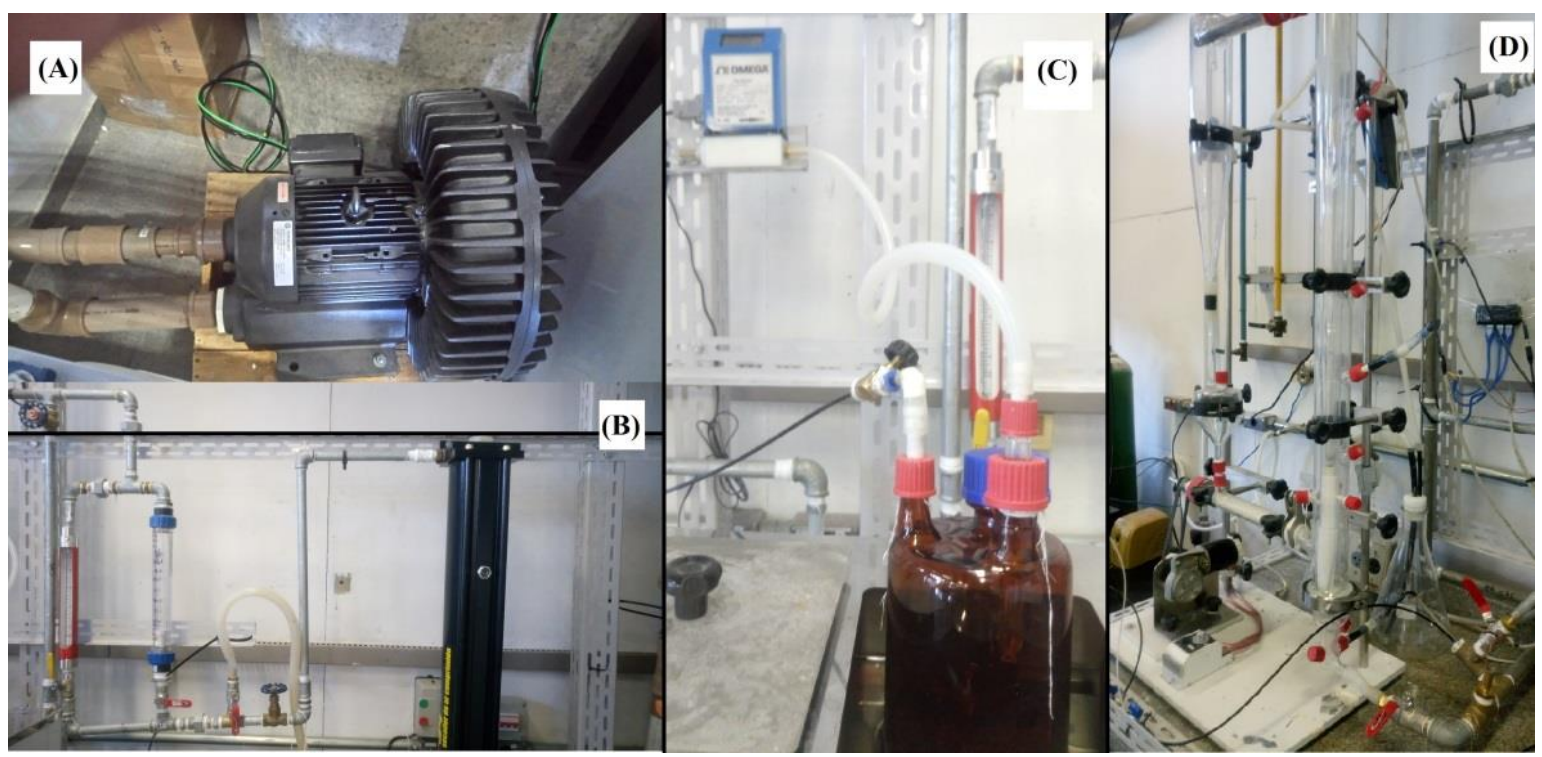

Figura 4.7 - Unidade laboratorial construída. (A) compressor para alimentação de ar; (B) coluna de secagem e medidores de vazão; (C) reservatório de poluente (contaminação do ar limpo por arraste); e (D) reator.

(Fonte: Relatório FAPESP, 2017)

\subsection{O REATOR FOTOCATALÍTICO}

Detalhadamente, o reator fotocatalítico utilizado nos experimentos é composto externamente por um tubo de vidro borossilicato com $860 \mathrm{~mm}$ de comprimento (L) e diâmetro interno $\left(\phi_{i}\right)$ de $50 \mathrm{~mm}$. Internamente, contém um invólucro interno construído em quartzo de alta pureza com diâmetro externo $\left(\phi_{e}\right)$ de $30 \mathrm{~mm}$, onde a lâmpada UV-C monocromática com comprimento de onda de $254 \mathrm{~nm}$ (TUV36 4P T5 HO, Phillips), comprimento de $775 \mathrm{~mm}$, foi posicionada no centro. O gás contendo o contaminante será alimentado pela parte inferior, onde está instalado um distribuidor de gás, constituído por uma placa porosa de vidro sinterizado. A parte superior está conectada a tubos que direcionam o fluxo gasoso ao ciclone e ao retorno de sólidos.

A Figura 4.8 ilustra o reator modelado em 3D. 


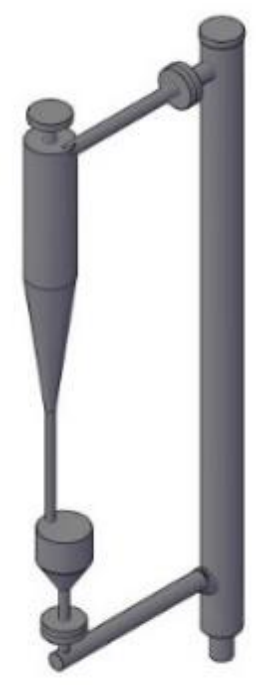

Figura 4.8 - Detalhe do Reator Fotocatalítico de Arraste modelado em 3D. (Fonte: Relatório FAPESP, 2017)

O cromatógrafo gasoso GC-PID/TID (Meta), equipado com um detector de fotoionização e acoplado com um amostrador automático MSU-8V4S-RS48 (Meta), foi usado para quantificar a concentração de entrada e saída do poluente. Foram conectadas mangueiras de Teflon ${ }^{\circledR}$ na entrada e na saída do reator fotocatalítico a uma bomba peristáltica (AWM5900-AX-D, Provitec), que constantemente direcionava $100 \mathrm{~mL} \mathrm{~min}^{-1}$ ao loop do cromatógrafo.

A condição de regime permanente era definda a partir das análises de amostras consecutivas da saída do reator, três medidas na entrada e três medidas na saída eram obtidas de forma a obter uma conversão média em um estado estacionário e assegurando uma reprodutibilidade do experimento.

\subsection{PARÂMETROS E VARIÁVEIS DE PROCESSO}

As principais variáveis de processo consideradas foram as seguintes:

- Massa de catalisador: o reator operou com diferentes quantidades de partículas (100g e 200g), para avaliar os efeitos da superfície específica e do espalhamento de radiação UV sobre a eficiência de tratamento.

- Temperatura: os experimentos foram realizados à temperatura ambiente $\left(25-30^{\circ} \mathrm{C}\right)$ sem alterações significativas nas taxas de degradação (ZHANG, 2013).

- Fluxo de fótons : um maior número de fótons eleva a taxa de degradação, dentro de certos limites (ZHANG, 2013). A lâmpada foi operada em potência nominal neste limite, garantindo fluxo de fótons constante e uniforme na superfície emissora. 
- Concentração de entrada de poluente: em princípio, a taxa de degradação eleva-se com o aumento da concentração inicial de poluente até o ponto em que se torna limitada por adsorção (KIM; HONG, 2002). Nos experimentos, alimentou-se ar com diferentes níveis de poluente a uma temperatura controlada, com medição da vazão. O valor real de concentração de entrada será medido por amostragem e análises , descritas no item 4.2 .

- Umidade: o grau de degradação está fortemente relacionado à umidade do ar (ZHANG, 2013). Portanto, seu controle é imprescindível para garantir a fidelidade dos resultados obtidos. Para controlá-la, todo o ar coletado passou por um secador comercial e uma parcela dele foi saturada com água. A umidade foi constantemente medida por uma sonda.

- Vazão total no reator: a operação requer uma vazão de gás suficientemente alta para arraste das partículas. Acima dela, pode haver ganho na degradação por transferência de massa mais intensa ou perda por tempo de residência menor (YAO; KUO, 2015a). Para controle da vazão, ajustaram-se as válvulas agulha e medição por rotâmetro.

\subsection{INSTRUMENTAÇÃO}

A Tabela 4.4 lista os instrumentos de medida que foram utilizados na operação da unidade.

Tabela 4.4 - Medidas necessárias na unidade em escala laboratorial.

(Fonte: Relatório FAPESP, 2017)

\begin{tabular}{|c|c|c|}
\hline Medida & Objetivo & $\begin{array}{l}\text { Instrumento de } \\
\text { medição }\end{array}$ \\
\hline $\begin{array}{l}\text { Vazão de ar no saturador } \\
\text { de Poluente }\end{array}$ & $\begin{array}{l}\text { Controle da concentração de entrada } \\
\text { do reator }\end{array}$ & $\begin{array}{l}\text { Mass flowmeter FMA- } \\
\text { A2305 (Omega). }\end{array}$ \\
\hline $\begin{array}{l}\text { Temperatura do saturador } \\
\text { de Poluente }\end{array}$ & $\begin{array}{l}\text { Controle da concentração de entrada } \\
\text { no reator }\end{array}$ & Sensor de temperatura \\
\hline $\begin{array}{l}\text { Vazão de ar no saturador } \\
\text { de água }\end{array}$ & Controle da umidade do processo & Rotâmetro \\
\hline Vazão de ar puro e seco & $\begin{array}{l}\text { Controle da umidade e da } \\
\text { concentração de entrada do reator }\end{array}$ & Rotâmetro \\
\hline $\begin{array}{l}\text { Umidade relativa na } \\
\text { entrada do reator }\end{array}$ & Registro da umidade do processo & $\begin{array}{l}\text { Sensor de umidade e } \\
\text { temperatura }\end{array}$ \\
\hline $\begin{array}{l}\text { Concentração de entrada } \\
\text { do reator }\end{array}$ & Cálculo da eficiência de remoção & $\begin{array}{l}\text { Análise em } \\
\text { cromatografia gasosa }\end{array}$ \\
\hline
\end{tabular}




\begin{tabular}{lll}
\hline Medida & Objetivo & $\begin{array}{l}\text { Instrumento de } \\
\text { medição }\end{array}$ \\
\hline $\begin{array}{l}\text { Pressão na entrada do } \\
\text { reator }\end{array}$ & Cálculo da perda de carga & Barômetro BMP180 \\
\hline $\begin{array}{l}\text { Concentração de saída do } \\
\text { reator }\end{array}$ & Cálculo da eficiência de remoção & $\begin{array}{l}\text { Análise em } \\
\text { cromatografia gasosa }\end{array}$ \\
\hline $\begin{array}{l}\text { Pressão na saída do reator } \\
\text { Pressão na saída do ânulo álo da perda de carga }\end{array}$ & $\begin{array}{l}\text { Cálculo da perda sem o ciclone de } \\
\text { recuperação }\end{array}$ & Barômetro BMP180 \\
\hline \begin{tabular}{l} 
irradiado \\
\hline
\end{tabular} & & \\
\hline
\end{tabular}

\subsection{COMPOSTO ORGÂNICO VOLÁTIL BTX}

\subsubsection{Seleção Do Composto Orgânico Volátil}

A escolha do contaminante utilizado nos experimentos toma como base dois aspectos: ser um poluente relevante no cenário atual de gestão ambiental e que, quando submetido ao tratamento foto-oxidativo catalítico, seja, em termos relativos, de difícil degradação (isto é, se este COV for abatido, outros COV mais simples também serão).

Com relação à relevância do tema, dados de 2012 da Agência Nacional de Petróleo (ANP) ilustrados na Figura 4.9-a retratam os solventes orgânicos mais produzidos no cenário nacional. O benzeno é o solvente orgânico mais produzido no Brasil, com uma parcela de 43\% do volume total de produção, seguido pelo tolueno com 13\%. Somado a isto, o Relatório de Áreas Contaminadas de 2014 da CETESB (Figura 4.9-b) mostra que 75\% dos relatos estão associados a postos de combustíveis e, portanto, a COV derivados do petróleo. Na literatura, a mistura BTX (benzeno, tolueno e xilenos) é conhecida como representante dos COV derivados do petróleo (TANG, 2000). Todos estes dados estão ilustrados na Figura 4.9. 


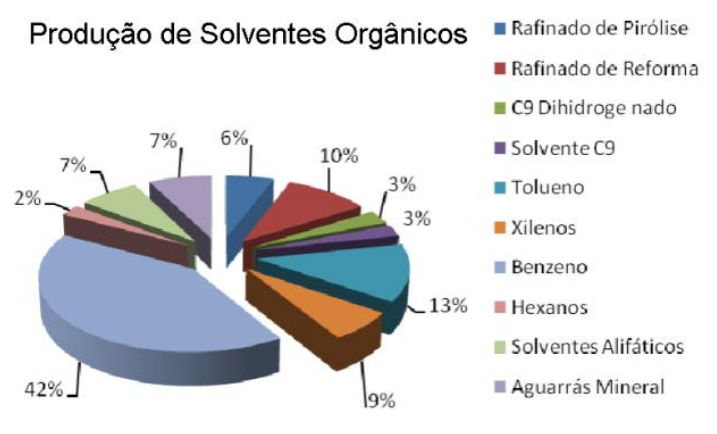

(a)

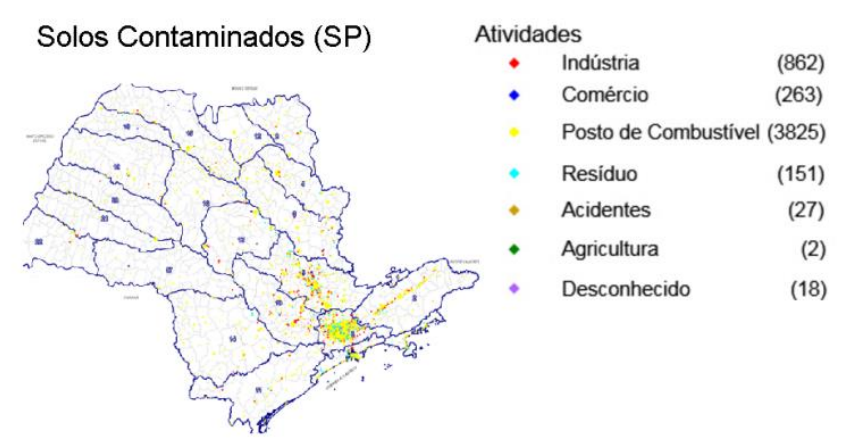

(b)

Figura 4.9 - (a) Distribuição da parcela percentual de produção de solventes orgânicos no Brasil $^{1}$. (b) Relação de áreas contaminadas do estado de São Paulo ${ }^{2}$. (Fonte: $6^{\circ}$ EBDQUIM da ANP e CETESB)

No que tange à dificuldade de degradação por processo foto-oxidativo catalítico, Alberici (1997) mostrou que a oxidação de compostos aromáticos como tolueno e cumeno é mais lenta que a de alcanos, álcoois, cetonas e éteres simples. A degradação destes aromáticos é mais rápida apenas que a de alguns organoclorados e a de aromáticos mais complexos. Além disto, a oxidação de compostos aromáticos está diretamente ligada à perda de atividade dos fotocatalisadores heterogêneos (ROCHETTO, 2012, p. 59). Todos os compostos BTX são aromáticos. Por estes motivos, os compostos BTX foram os inicialmente considerados na avaliação da viabilidade técnica do reator.

\subsubsection{Catalisador Para BTX}

\subsubsection{Preparo}

Esse material foi preparado por método sol-gel em meio ácido com a utilização de um precursor de titânio. Exemplos de precursores utilizados são o isopropóxido de titânio (PARK et al., 2011; YAO; KUO, 2015a), e o epóxido de titânio (KIM; HONG, 2002). O procedimento de preparo do catalisador está ilustrado na Figura 4.10.

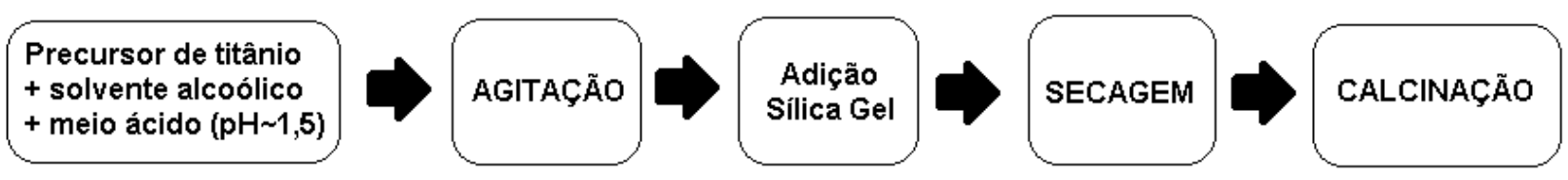

Figura 4.10 - Fluxograma simplificado do procedimento de preparo do catalisador.

(Fonte: Relatório FAPESP, 2017)

\footnotetext{
${ }^{1} 6^{\circ}$ EBDQUIM da ANP, disponível em https://www.associquim.org.br/ebdquim2012/palestras/Ebdquim2012_RubensFreitas.pdf

${ }^{2}$ Disponível em http://areascontaminadas.cetesb.sp.gov.br/relacao-de-areas-contaminadas/
} 


\subsubsection{Caracterização}

Os métodos utilizados para caracterização do catalisador serão BET para determinação da superfície específica e Difratometria de Raios-X (DRX) para confirmar a estrutura do catalisador preparado.

\subsubsection{Configuração dos ensaios com BTX}

Para os ensaios de degradação de BTX, o catalisador utilizado no leito do reator foi o $\mathrm{TiO}_{2}$ impregnado em sílica-gel por método sol-gel. Antes destes ensaios, foram realizados alguns testes sem o poluente para obtenção das velocidades mínimas de fluidização $\left(U_{m f}\right)$ para este catalisador. Estas velocidades foram obtidas a partir da curva de perda de carga do leito $\left(\Delta P_{\text {leito }}\right)$ por massa de catalisador $(\mathrm{m})$ em função da velocidade superficial do gás $\left(\mathrm{U}_{\mathrm{g}}\right)$. Experimentos de fotólise, ou seja, na ausência de catalisador foram também realizados.

Para cada experimento de degradação, a massa de catalisador era colocada na região anular do reator e as vazões eram reguladas através dos rotâmetros e do massflow. Então, após o equilíbrio de adsorção ser atingido, a lâmpada UV-C era ligada. Após isso, a condição de estado estacionário era atingida e o procedimento descrito anteriormente no cromatógrafo era realizado.

\subsection{POLUENTE MODELO (N-HEXANO)}

\subsubsection{Seleção Do Poluente Modelo}

O BTX apresentou baixas taxas de degradação e intensa desativação do catalisador, apresentado uma inviabilidade técnica do reator. Então, para a modelagem do reator em CFD, foi escolhido um poluente modelo. Conforme levantamento da literatura (BOULAMANTI; PHILIPPOPOULOS, 2009), um dos principais compostos padrão para poluente é o n-hexano, que, portanto, foi utilizado no presente estudo (grau analítico, pureza > 99\%, Dinâmica).

\subsubsection{Catalisador Para Poluente Modelo}

Nos experimentos envolvendo o n-hexano, dióxido de titânio comercial em pó, Anatase (pureza > 99\%, Sigma-Aldrich), tamanho de partícula -325 mesh, foi usado como fotocatalisador.

\subsubsection{Caracterização}

Os métodos utilizados para caracterização do catalisador comercial serão Difratometria

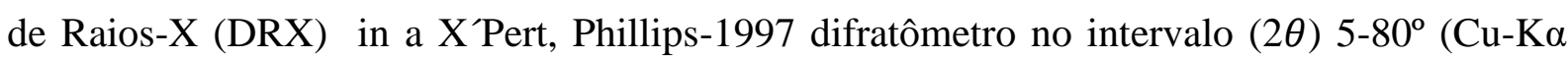


radiação $\lambda=1.542 \AA, 2.2 \mathrm{~kW}$ ) foi usado para determinar a estrutura cristalina do dióxido de titânio comercial. A distribuição de tamanho de partículas foi medida por espalhamento de luz dinâmica (DLS) em um Malvern $2000(0.02$ - $2000 \mu \mathrm{m})$ e imagens do catalisador foram tiradas por um microscópio Olympus BX60.

\subsubsection{Configuração dos ensaios com Poluente modelo}

Para os ensaios com o poluente modelo, n-hexano, o catalisador utilizado no leito do reator foi o $\mathrm{TiO}_{2}$ comercial Anatáse da Sigma Aldrich. Os mesmos procedimentos de obtenção da velocidade mínima de fluidização e de fotólise foram realizados conforme o item 4.7.3.

Neste caso, todos experimentos foram realizados mantendo a corrente de entrada de ar a temperatura (T) e umidade constante (UR) em $25 \pm 3{ }^{\circ} \mathrm{C}$ e $55 \pm 5 \%$, respectivamente.

Para a obtenção da cinética da reação para posterior modelagem, dois tipos diferentes de configurações do reator fotocatalítico foram usados. No Setup 1, a parte superior da lâmpada UVC $(720 \mathrm{~mm})$ foi coberta com papel alumínio, deixando apenas $140 \mathrm{~mm}$ de altura irradiada, como detalhado na Figura 4.11. Então, $100 \mathrm{~g}$ de $\mathrm{TiO}_{2}$ anátase foram colocadas no interior da região anular do reator, ocupando o volume irradiado, o que permite que somente a cinética da região densa seja avaliada no leito fluidizado.
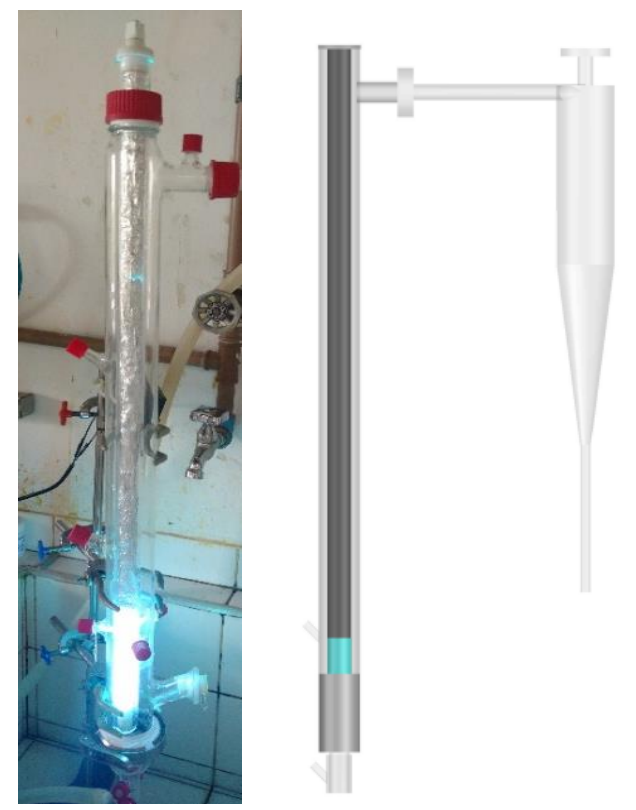

Figura 4.11 - Reator Fotocatalítico - Setup 1.

(Fonte: O Autor, 2018)

Alternativamente, no Setup 2, o reator foi operado com a lâmpada UVC totalmente descoberta, como mostrado na Figura 4.12. Utilizou-se a mesma massa de catalisador do Setup 
1 (o mesmo volume de região densa) de forma a avaliar a cinética somente da região diluída. Adicionalmente, os experimentos foram usados para validação do modelo do reator fotocatalítico completo.

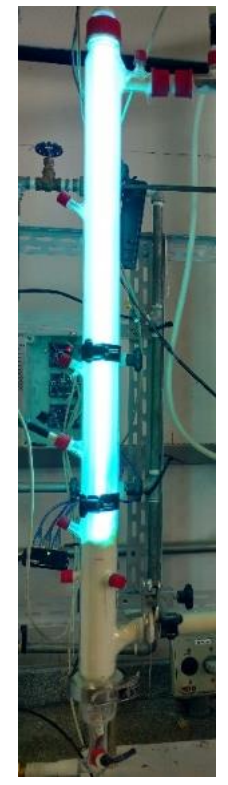

Figura 4.12 - Reator Fotocatalítico - Setup 2.

(Fonte: O Autor, 2018)

\subsection{CÓDIGO DE CFD UTILIZADO}

Neste trabalho utilizou-se o método dos volumes finitos (MVF) para a discretização das equações de conservação e empregado no código Fluent, na sua versão acadêmica 19.1 e comercializado pela empresa Ansys, sendo utilizados os módulos de geometria Design Modeler, o módulo de malhas da Ansys, o solver Fluent e o módulo Results para o pósprocessamento.

\subsubsection{Computadores utilizados}

Para a execução das simulações deste projeto foram utilizados os computadores descritos na Tabela 4.5 .

Tabela 4.5 - Computadores utilizados nas simulações. (Fonte: O autor, 2018)

\begin{tabular}{llc}
\hline Máquina - Sistema & Processador & RAM \\
\hline Windows 7 & Intel $®$ Xeon $®$ CPU ES-2620 & $12 G B$ \\
\hline
\end{tabular}




\begin{tabular}{lll}
\hline Máquina - Sistema & Processador & RAM \\
\hline Windows 7 & Intel ® Core (TM) i7-3770 CPU 3.4 GHz & $8 \mathrm{~GB}$ \\
\hline Windows 8.1 & Intel ® Core (TM) i7-6500 CPU 2.5 GHz & $8 \mathrm{~GB}$ \\
\hline
\end{tabular}

\subsection{2}

\section{Geometria}

\subsubsection{Geometria Tridimensional}

O domínio considerado para simulação do reator pode ser visualizado na Figura 4.13, sendo $\phi_{e}=0,05 \mathrm{~m}, \phi_{i}=0,03 \mathrm{~m} \mathrm{e} \mathrm{L}=0,775 \mathrm{~m}$, correspondente ao comprimento da lâmpada, sendo que o volume reator de $0,974 \times 10^{-3} \mathrm{~m}^{3}$. A entrada dos gases se localiza na parte inferior do reator e a saída é lateral com $\phi=0,0254 \mathrm{~m}$.

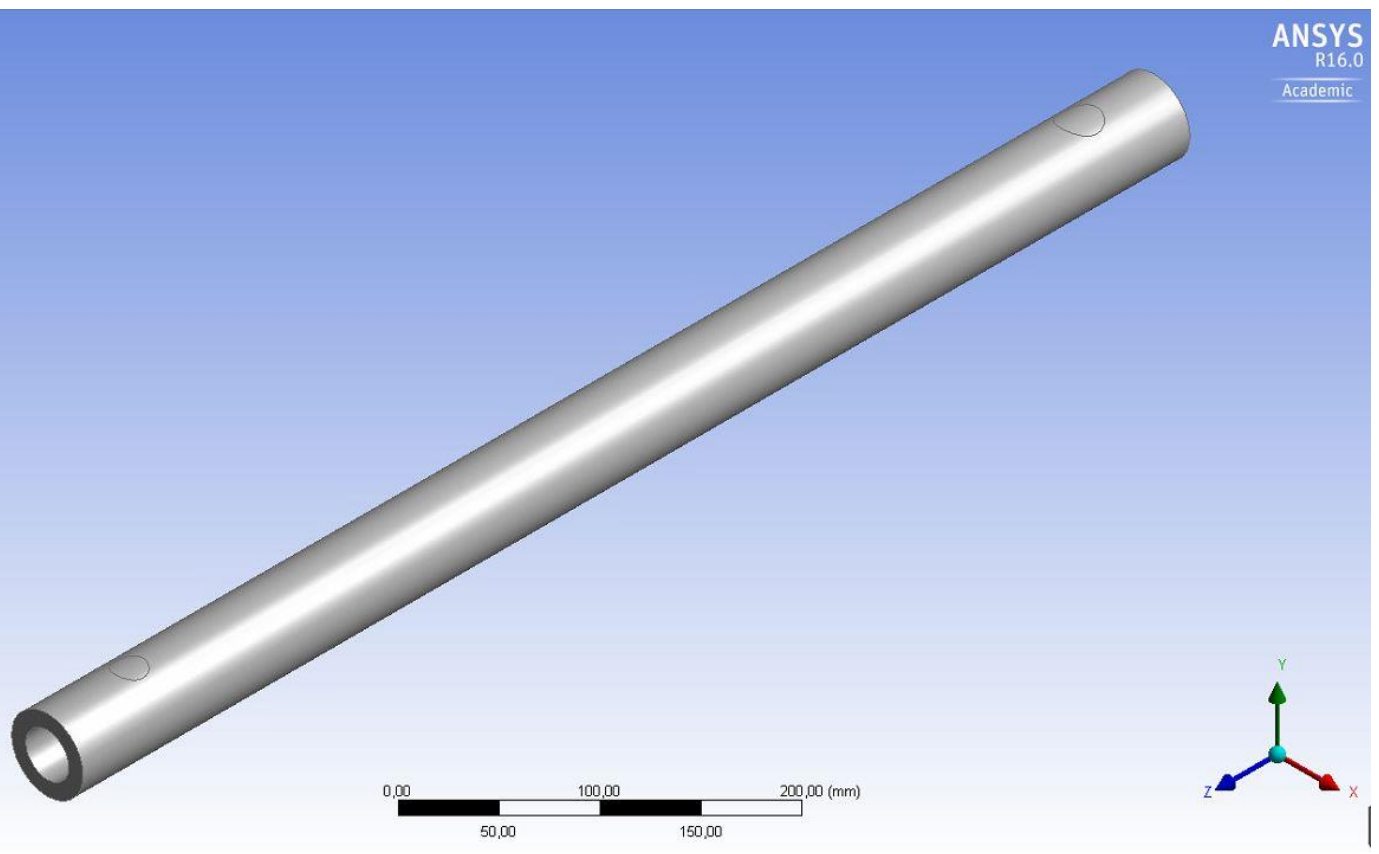

Figura 4.13 - Geometria 3D do reator modelado no Ansys.

(Fonte: O autor, 2018)

A Figura 4.14 apresenta os cortes no plano YZ e no plano XZ, respectivamente. 

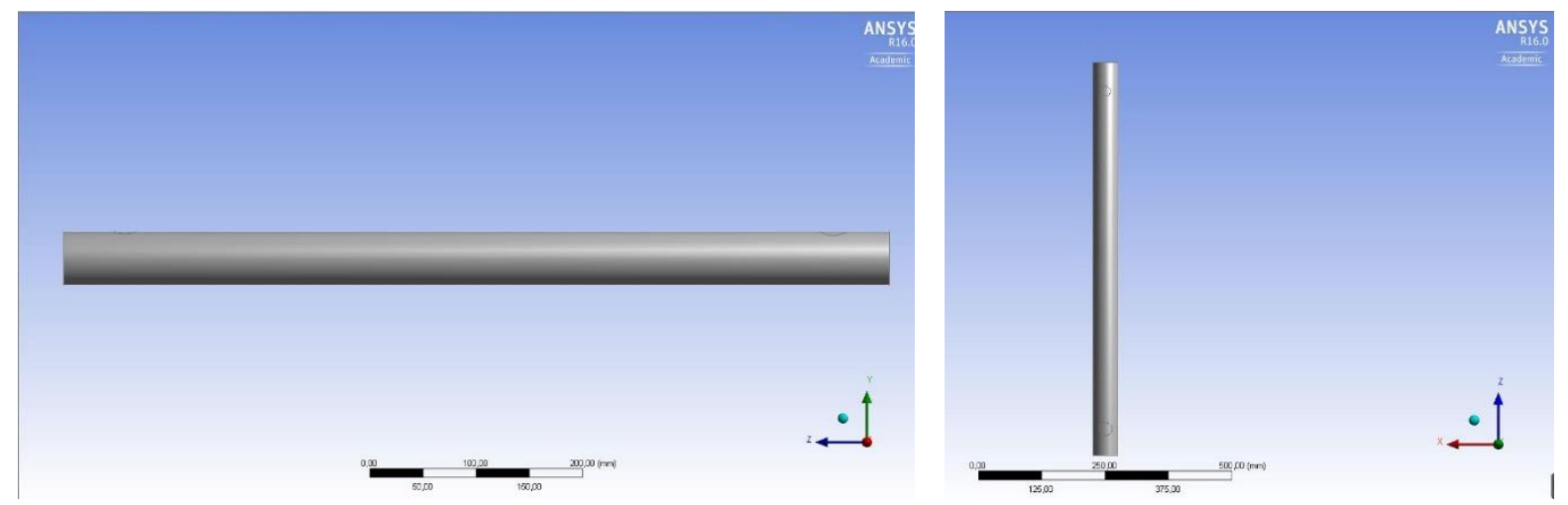

Figura 4.14 - Cortes no plano YZ e no plano XZ reator modelado no Ansys.

(Fonte: O autor, 2018)

\subsubsection{Geometria Bidimensional}

Visando obter maior rapidez nas simulações, foi adotada uma geometria bidimensional, onde somente a área anular do reator fotocatalítico seria simulada. Neste caso foi adotada a hipótese de simetria radial da geometria, onde foram consideradas duas alternativas para a saída lateral:

- Manutenção de uma saída lateral, como se fosse uma faixa fina que ocuparia o cilindro todo, de forma que a área do mesmo fosse equivalente à da saída original.

- Uma saída superior, pois existe uma grande distância entre o leito e a saída, não havendo uma influência muito grande na hidrodinâmica do reator.

O domínio considerado pode ser visualizado na Figura 4.16, sendo $\phi_{e}=0,05 \mathrm{~m}, \phi_{i}=$ $0,03 \mathrm{~m}$ e $\mathrm{L}=0,775 \mathrm{~m}$. A entrada dos gases se localiza na parte inferior do reator e a saída é lateral com $\mathrm{h}=0,0032 \mathrm{~m}$, demarcada em verde na Figura 4.16.

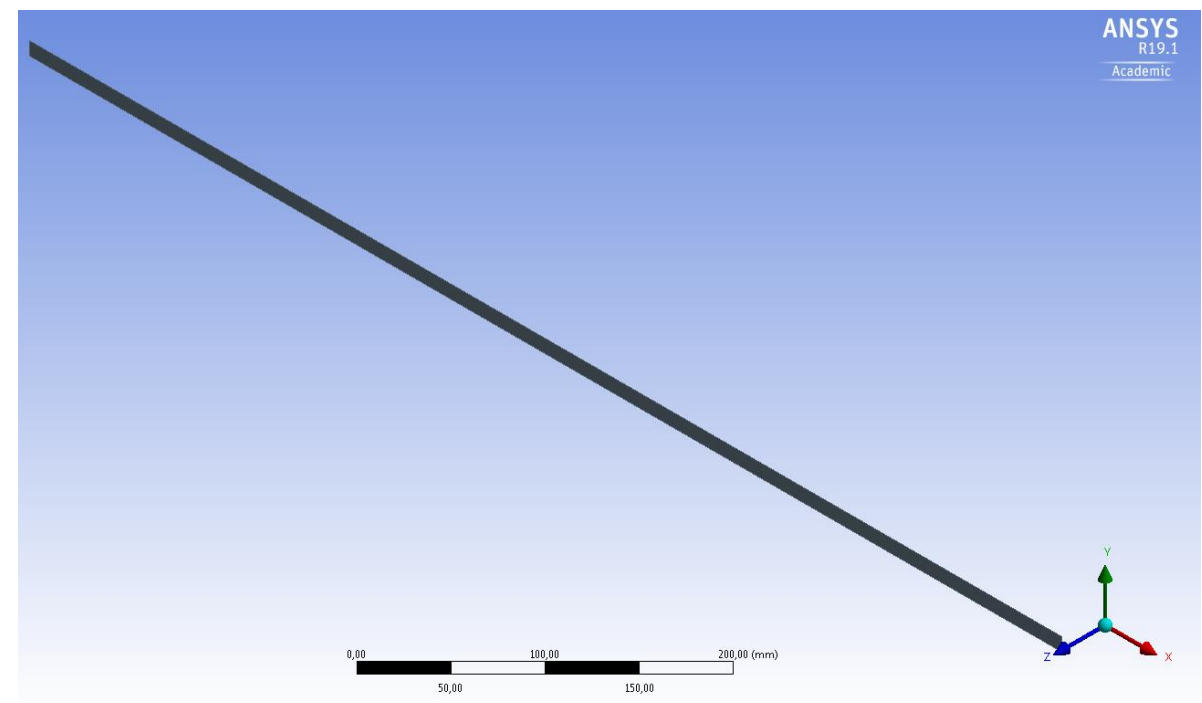

Figura 4.15 - Geometria 2D do reator modelado no Ansys - Saída Lateral.

(Fonte: O autor, 2018) 


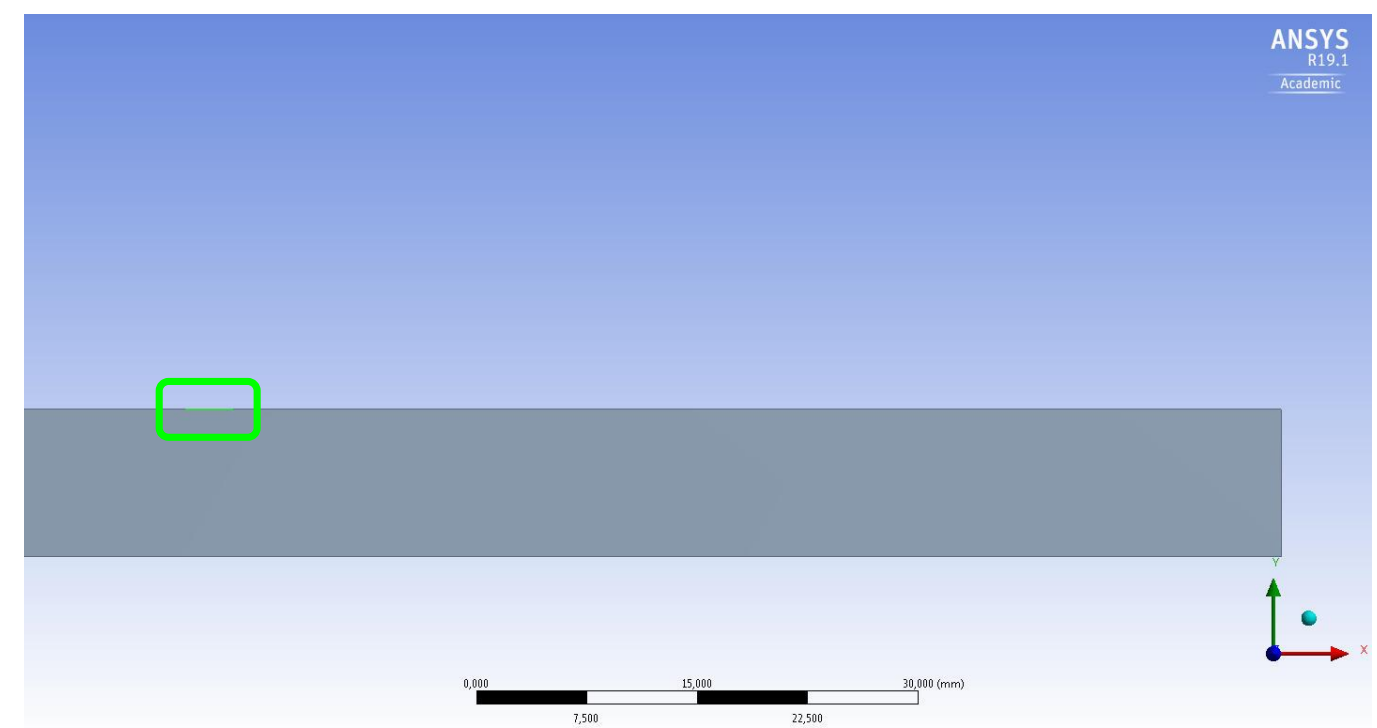

Figura 4.16 - Geometria 2D do reator modelado no Ansys - Saída Lateral em verde.

(Fonte: O autor, 2018)

A Figura 4.17 apresenta a geometria com a saída superior localizada em verde.
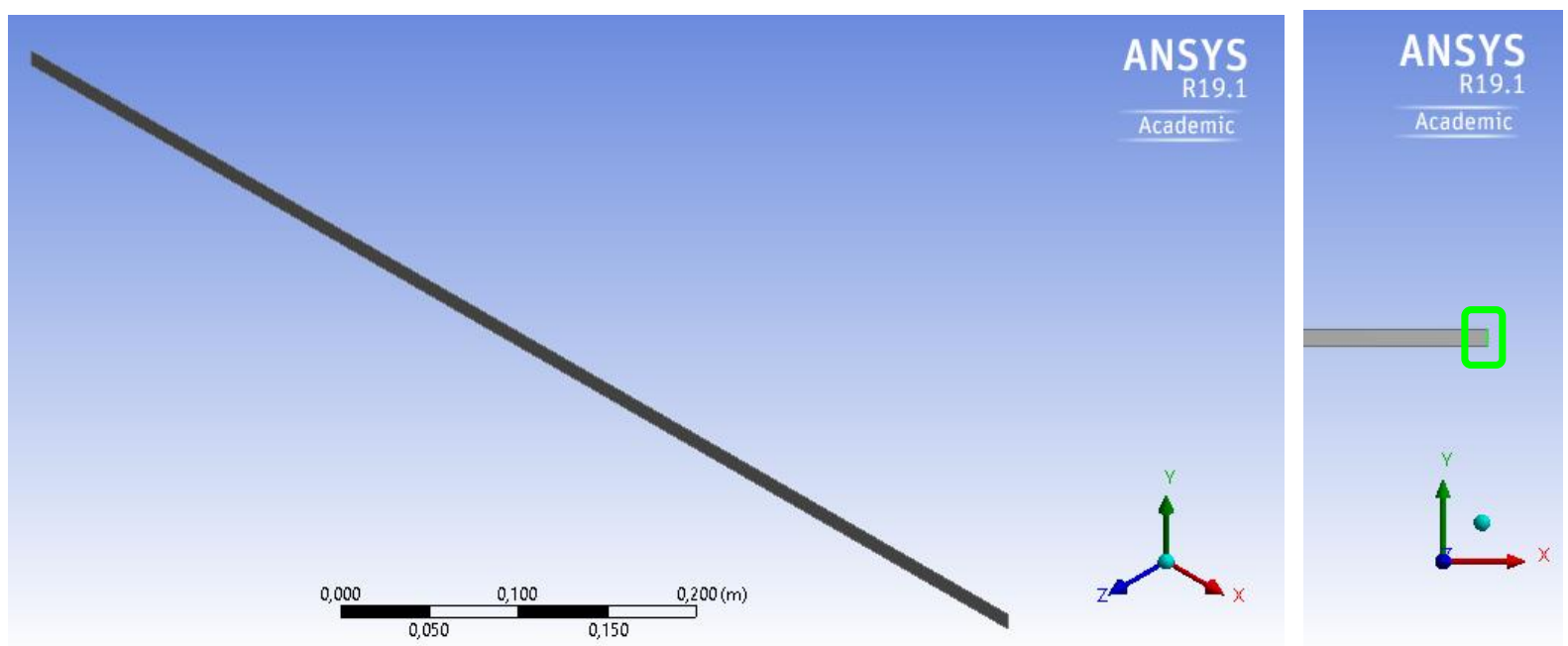

Figura 4.17 - Geometria 2D do reator modelado no Ansys - Saída Superior em verde.

(Fonte: O autor, 2018)

\subsubsection{Seleção de Malha}

\subsubsection{Geometria Tridimensional}

A seleção da malha para a análise do escoamento no reator fotocatalítico, no modelo tridimensional, foi feita partindo-se da simulação de uma malha com poucos elementos e refinando-se a malha sucessivamente, a até que os campos de velocidade, pressão e a altura do não se modificassem de forma significativa com a malha e que o tempo de processamento não fosse alto. Utilizando-se esses dois critérios, foram simuladas as duas malhas descritas na Tabela 4.6. A malha 1 escolhida está ilustrada na Figura 4.18 e na Figura 4.19. 
Tabela 4.6 - Malhas testadas no software ANSYS para seleção de malha para geometria tridimensional.

(Fonte: O autor, 2018)

\begin{tabular}{ccc}
\hline Parâmetros & Malha 1 & Malha 2 \\
\hline Número de Nós & 499138 & 1220158 \\
Número de Elementos & 334712 & 842095 \\
\hline
\end{tabular}

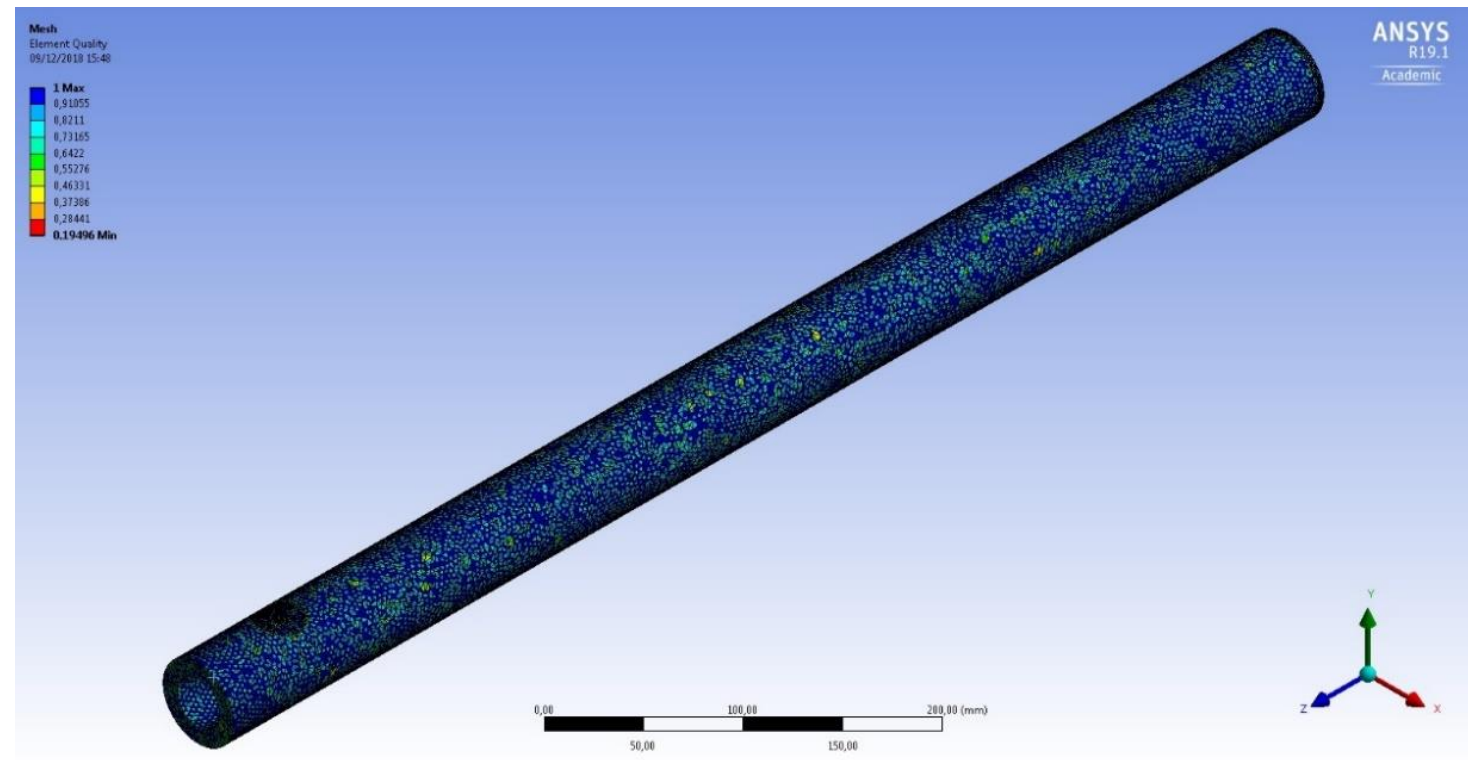

Figura 4.18 - Malha 1, com 334712 elementos, selecionada para simulações tridimensionais. (Fonte: O autor, 2018)

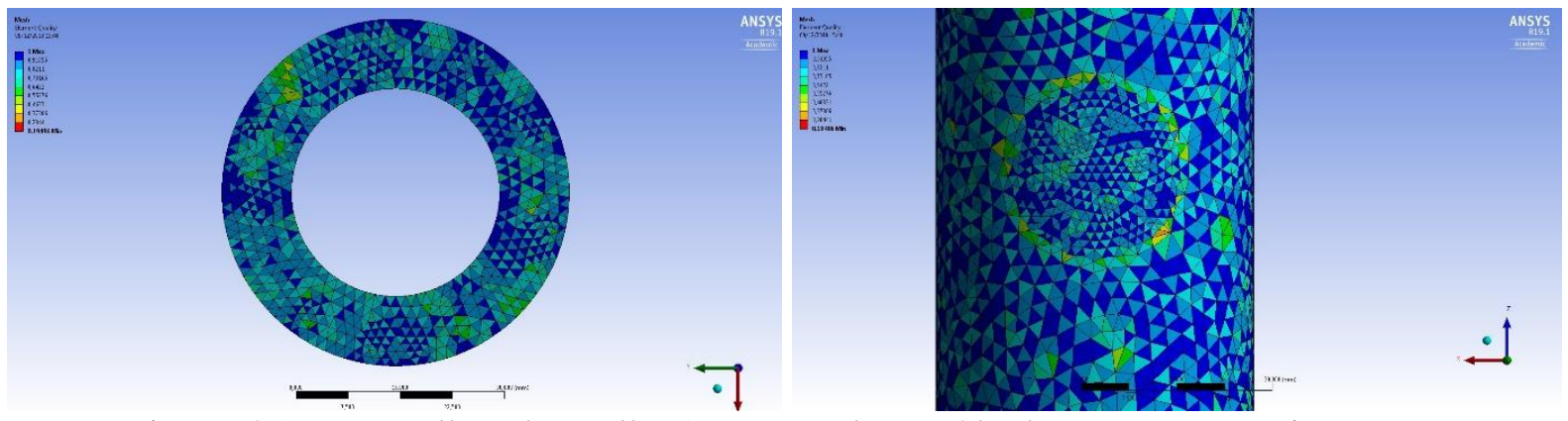

Figura 4.19 - Detalhes da Malha 1 na entrada e saída de gases, respectivamente.

(Fonte: O autor, 2018)

Os resultados para a malha escolhida estão detalhados no item 6.2.1.

\subsubsection{Geometria Bidimensional}

Para a geometria bidimensional foi realizado o mesmo procedimento descrito no item 4.9.3.1. Utilizando-se os dois critérios mencionados, foram simuladas as três malhas descritas na Tabela 4.6. A malha 2 escolhida está ilustrada naFigura 4.20. 
Tabela 4.7 - Malhas testadas no software ANSYS para seleção de malha da geometria bidimensional. (Fonte: O autor, 2018)

\begin{tabular}{cccc}
\hline Parâmetros & Malha 1 & Malha 2 & Malha 3 \\
\hline Número de Nós & 8000 & 17500 & 25000 \\
Número de Elementos & 8421 & 18226 & 26026 \\
\hline
\end{tabular}

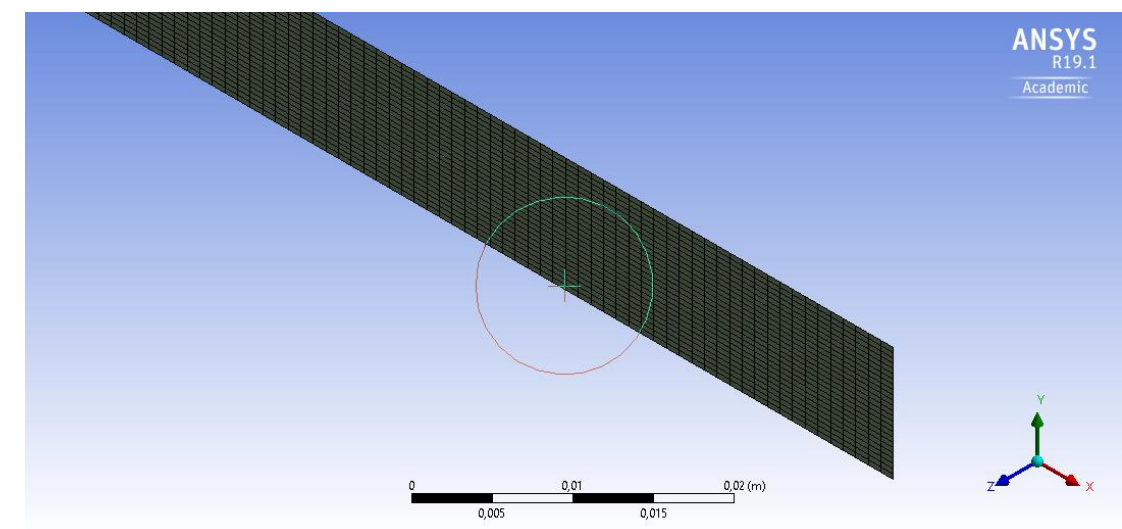

Figura 4.20 - Malha 2, com 17.500 elementos, selecionada para simulações bidimensionais. (Fonte: O autor, 2018)

Realizaram-se as simulações da hidrodinâmica nas condições expressas na Tabela 4.10 $\left(\mathrm{Q}=10 \mathrm{~L} \cdot \mathrm{min}^{-1} \mathrm{e} \mathrm{m}=0,1 \mathrm{~kg}\right)$. Os campos de pressão e velocidade para as três malhas estudadas após 10s de simulação podem ser vistos na Figura 4.21 e na Figura 4.22.

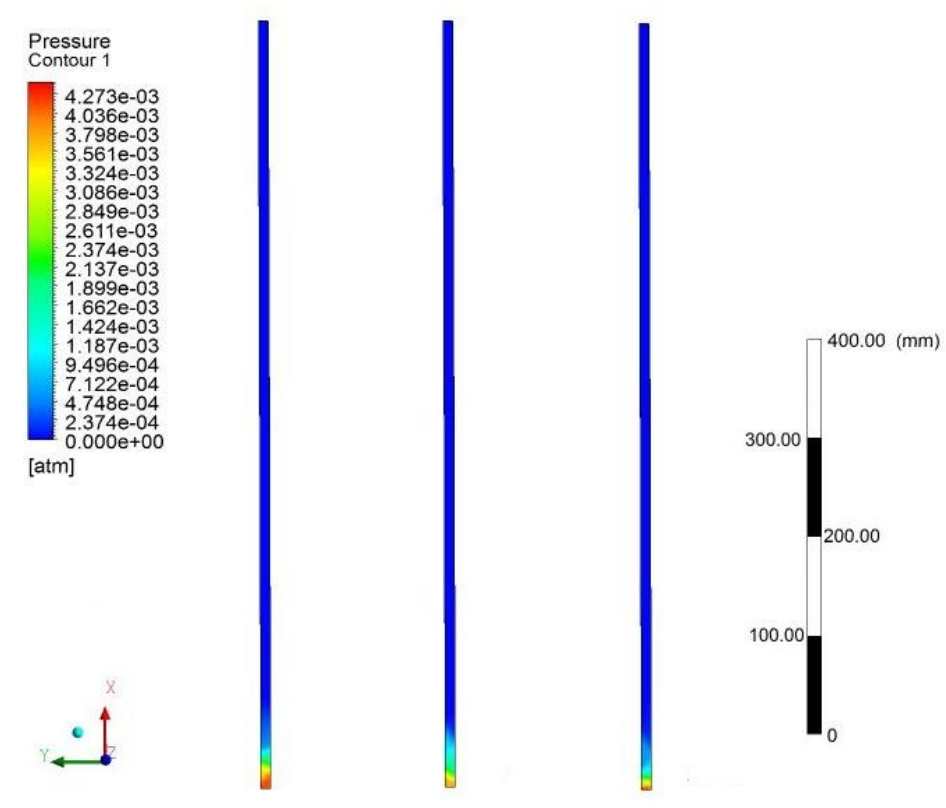

Malha 1 Malha 2 Malha 3

Figura 4.21 - Campo de pressão para Malha 1, Malha 2 e Malha 3 em t =10s.

Condições simuladas: $\mathrm{Q}=10 \mathrm{~L} \cdot \mathrm{min}^{-1} \mathrm{e} \mathrm{m}=0,1 \mathrm{~kg}$. (Fonte: $\mathrm{O}$ autor, 2018) 


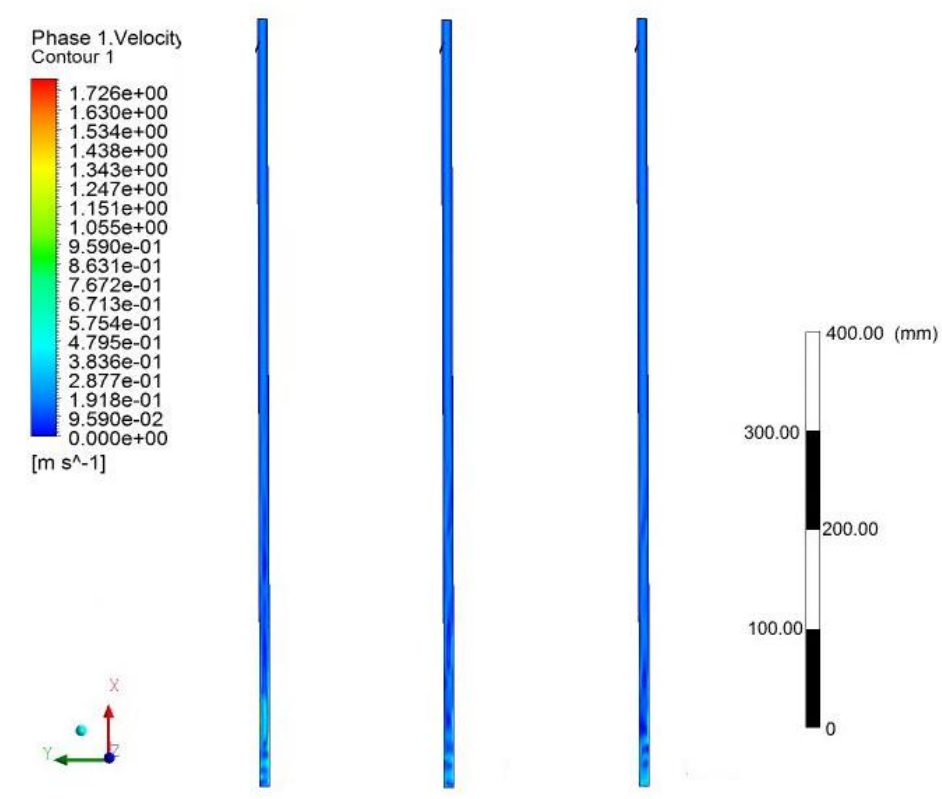

Malha 1 Malha 2 Malha 3

Figura 4.22 - Campo de velocidade para Malha 1, Malha 2 e Malha 3, em t =10s.

Condições simuladas: $\mathrm{Q}=10 \mathrm{~L} \cdot \mathrm{min}^{-1} \mathrm{e} \mathrm{m}=0,1 \mathrm{~kg}$. (Fonte: $\mathrm{O}$ autor, 2018)

Para uma melhor análise, foram traçados alguns gráficos de pressão em função da altura do reator $(\mathrm{x})$ e um perfil da velocidade do gás em função do raio $(\mathrm{y})$ em uma altura $\mathrm{x}=500 \mathrm{~mm}$, como pode ser visualizado na Figura 4.23 e na Figura 4.24, respectivamente.

A terceira análise feita foi através da altura do leito, ou seja, pela análise da fração volumétrica de sólidos. A altura do leito fluidizado varia muito ao longo do tempo, conforme pode ser observado na Figura 4.25. Então, para uma análise quantitativa mais precisa, foram traçados gráficos da fração volumétrica de sólido, média na secção, em função da altura do leito (x) para 10 diferentes instantes de tempo, conforme a Figura 4.26. As alturas médias e perda de carga no leito obtidas podem ser visualizadas na Tabela 4.8 .

Tabela 4.8 - Alturas médias e perda de carga para cada malha estudada.

(Fonte: O autor, 2018)

\begin{tabular}{cccc}
\hline Variável & Malha 1 & Malha 2 & Malha 3 \\
\hline Altura $(\mathrm{mm})$ & 9,0 & 11,0 & 11,0 \\
Perda de carga $(\mathrm{Pa})$ & 424 & 379 & 443 \\
\hline
\end{tabular}

Conclui-se, a partir destes resultados, que não há mudanças significativas dos resultados da malha 2 para a malha 3, com exceção de uma diferença na perda de carga. Optou-se, portanto, pela simulação empregando-se a malha 2. 


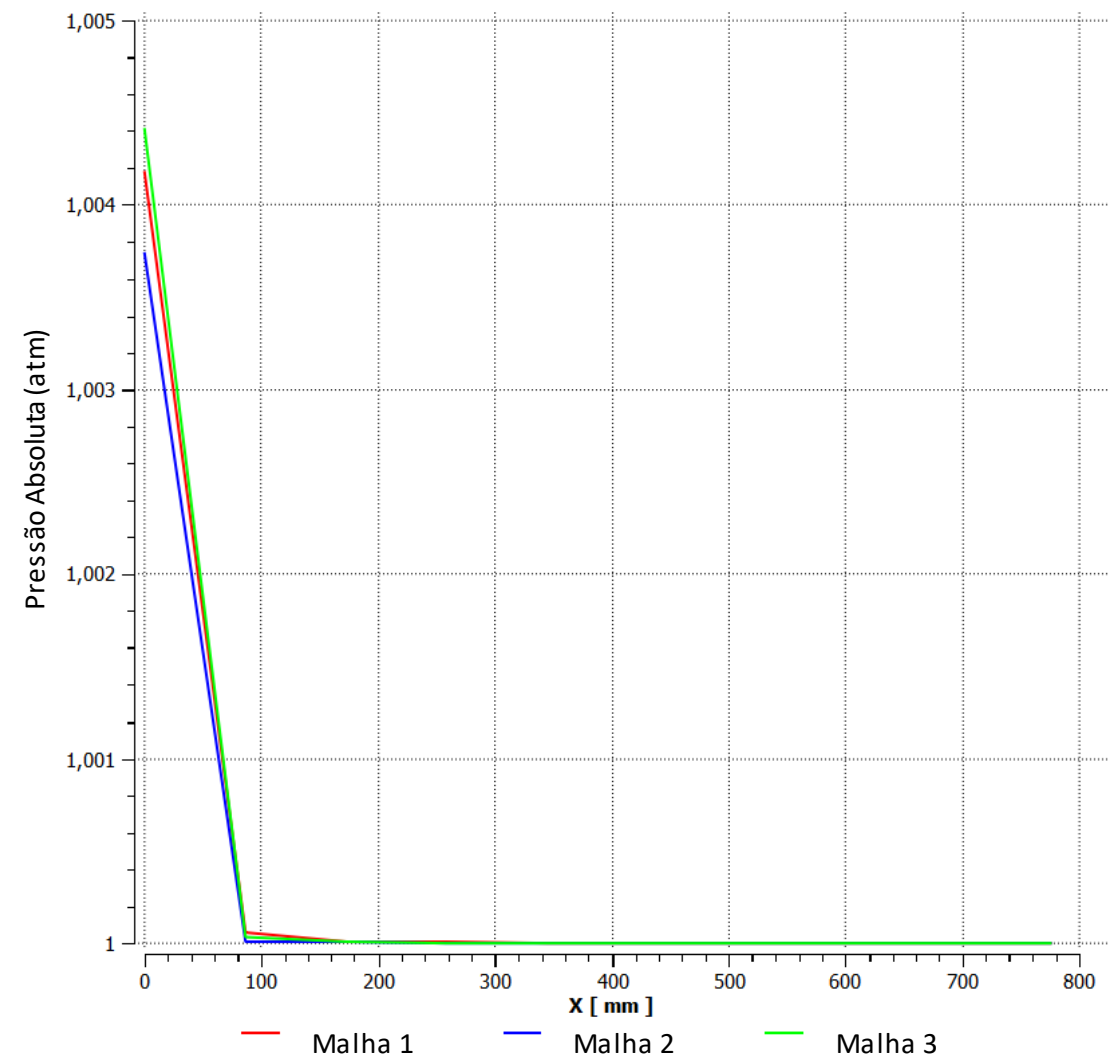

Figura 4.23 - Perfil de pressão em função de x para cada malha em $t=10$ s. Condições simuladas: $\mathrm{Q}=10 \mathrm{~L} \cdot \mathrm{min}^{-1}$ e $\mathrm{m}=0,1 \mathrm{~kg}$. (Fonte: $\mathrm{O}$ autor, 2018)

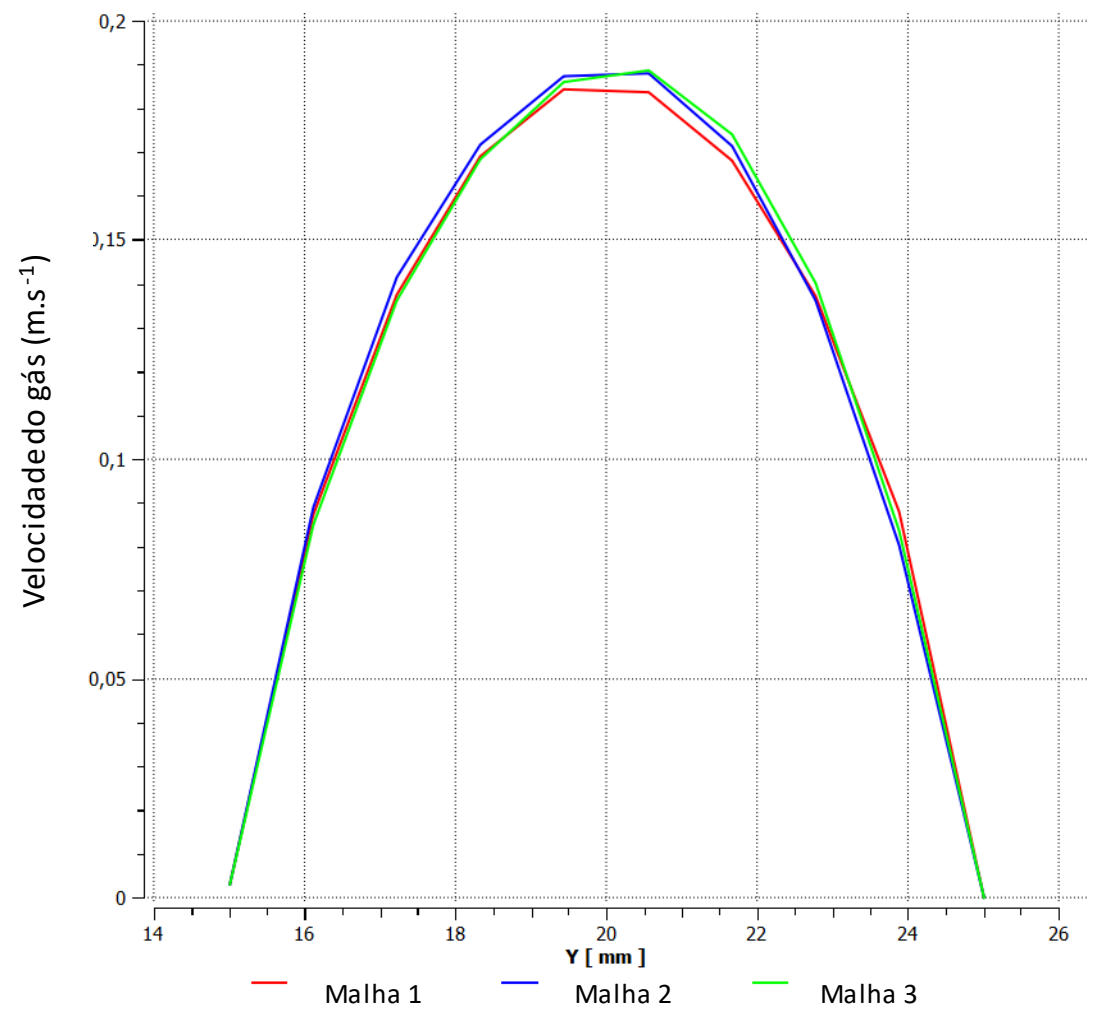

Figura 4.24 - Perfil de velocidade por y para cada malha analisada em $\mathrm{t}=10 \mathrm{~s}$.

Condições simuladas: $\mathrm{Q}=10 \mathrm{~L} \cdot \mathrm{min}^{-1}$ e $\mathrm{m}=0,1 \mathrm{~kg}$. 
(Fonte: O autor, 2018)

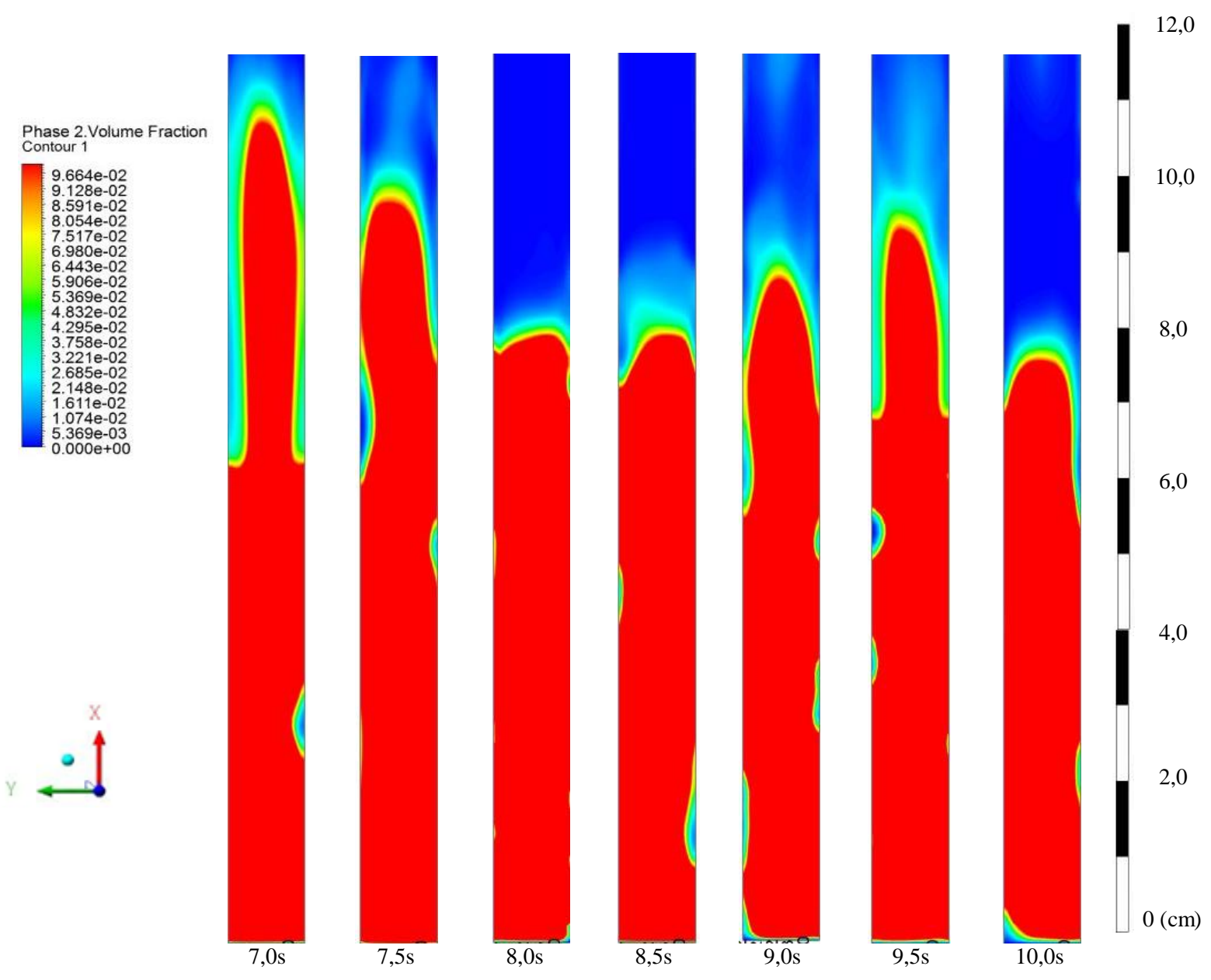

Figura 4.25 - Fração volumétrica de sólidos para $\mathrm{t}=7 \mathrm{~s}$ a $10 \mathrm{~s}$, Malha 2 e na condição de regime permanente $\left(\mathrm{Q}=10 \mathrm{~L} \cdot \mathrm{min}^{-1} \mathrm{e} \mathrm{m}=0,1 \mathrm{~kg}\right)$. (Fonte: $\mathrm{O}$ autor, 2018)

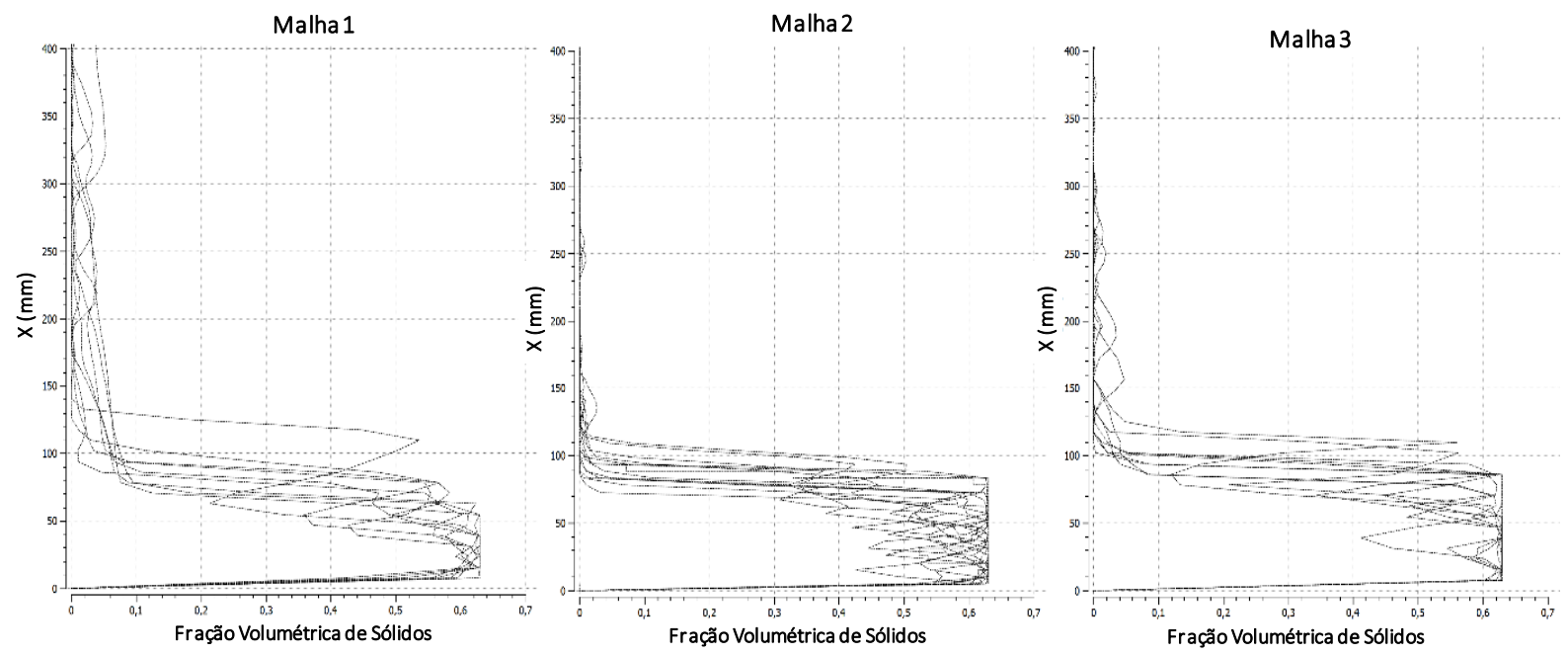

Figura 4.26 - Fração volumétrica de sólido, média na secção, em função da altura do leito (x) do reator para 13 instantes de tempo: malhas 1,2 e 3 .

(Fonte: O autor, 2018)

Os resultados detalhados para a malha escolhida estão detalhados no item 6.2.2.3. 


\subsubsection{Passo de tempo}

Uma abordagem semelhante à utilizada para a malha foi feita para a seleção do passo de tempo para as simulações. Foram simulados três passos de tempo para a malha bidimensional 3, selecionada no item 4.9.3.2: $\Delta t=0,01 \mathrm{~s}, \Delta t=0,005 \mathrm{~s}$ e $\Delta t=0,001 \mathrm{~s}$. Os critérios escolhidos para análise foram os perfis e campos de velocidade e pressão, perda de carga no leito e a altura da fração de vazios. Para estas simulações a vazão considerada foi de $Q=10 \mathrm{~L}_{\mathrm{min}} \mathrm{min}^{-1} \mathrm{e}$ a massa de catalisador de $m=100 \mathrm{~g}$.

Os perfis de pressão e velocidade para os três passos de tempo após 10s de simulação podem ser vistos na Figura 4.27.

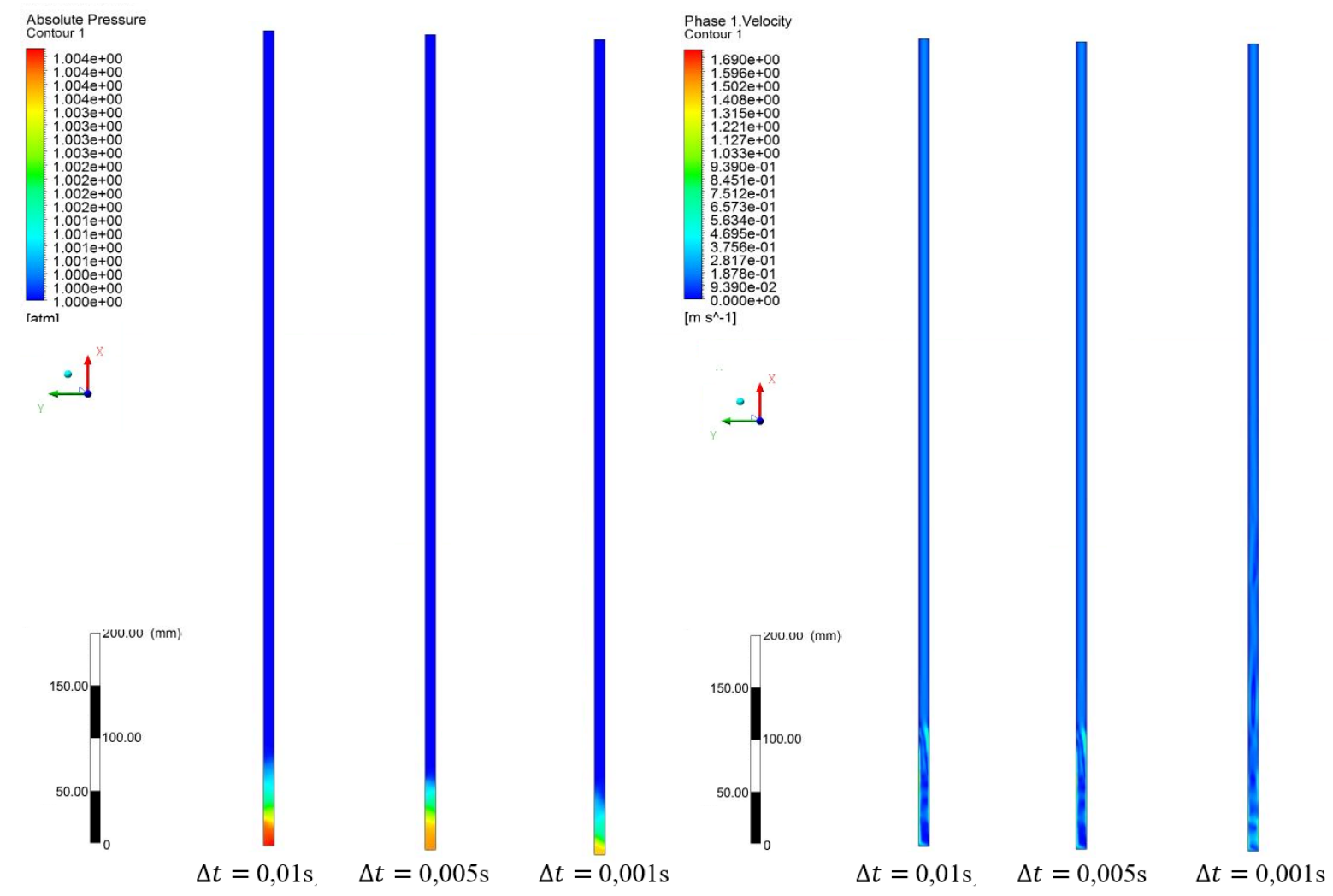

Figura 4.27 - Campo de pressão e velocidade para $\Delta t=0,01 \mathrm{~s}, \Delta t=0,005 \mathrm{~s}$ e $\Delta t=$ 0,001s em t $=10$ s. Condições simuladas: $\mathrm{Q}=10 \mathrm{~L} \cdot \mathrm{min}^{-1} \mathrm{e} \mathrm{m}=0,1 \mathrm{~kg}$. (Fonte: $\mathrm{O}$ autor, 2018)

Para uma melhor análise, foram traçados alguns gráficos de pressão em função de $\mathrm{x}$ e um perfil da velocidade em função do raio (y) em uma altura $x=500 \mathrm{~mm}$, como pode ser visualizado na Figura 4.28 e Figura 4.29, respectivamente. A terceira análise feita foi a altura do leito, sendo traçados gráficos da fração volumétrica de sólido, média na secção, em função da altura do leito (x). Consideraram-se 10 instantes de tempo para cada passo de tempo analisado, conforme a Figura 4.31. As alturas médias e a perda de carga obtidas podem ser visualizadas na Tabela 4.9 . 
Tabela 4.9 - Alturas médias e perda de carga para cada passo de tempo estudado.

(Fonte: O autor, 2018)

\begin{tabular}{cccc}
\hline Variável & $\Delta \boldsymbol{t}=\mathbf{0 , 0 1 s}$ & $\Delta \boldsymbol{t}=\mathbf{0 , 0 0 5 s}$ & $\Delta \boldsymbol{t}=\mathbf{0 , 0 0 1 s}$ \\
\hline Altura $(\mathrm{mm})$ & 12,5 & 11,0 & 11,0
\end{tabular}

Perda de carga $(\mathrm{Pa}) \quad 460 \quad 409 \quad 379$

Por estes dados, pode-se concluir que não há mudanças significativas na malha de $0,005 \mathrm{~s}$ para $0,001 \mathrm{~s}$. No entanto, as simulações para a malha de $0,001 \mathrm{~s}$ demoraram em torno de 4 dias. Então, o passo de tempo escolhido foi de $0,005 \mathrm{~s}$.

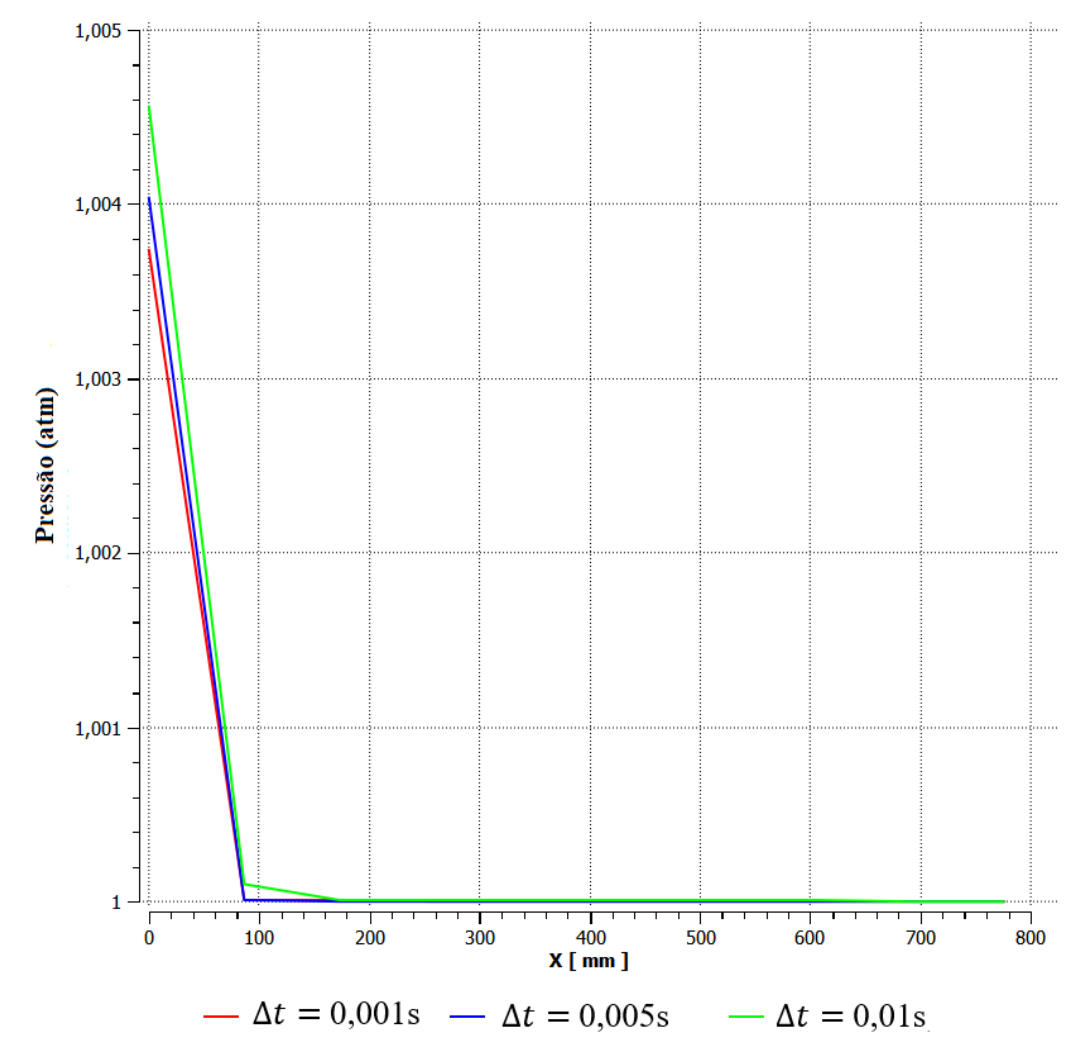

Figura 4.28 - Perfil de pressão em função de x, para $\Delta t=0,01 \mathrm{~s}, \Delta t=0,005 \mathrm{~s}$ e $\Delta t=$ 0,001s em $\mathrm{t}=10 \mathrm{~s}$. Condições simuladas: $\mathrm{Q}=10 \mathrm{~L} \cdot \mathrm{min}^{-1} \mathrm{e} \mathrm{m}=0,1 \mathrm{~kg}$. (Fonte: $\mathrm{O}$ autor, 2018) 


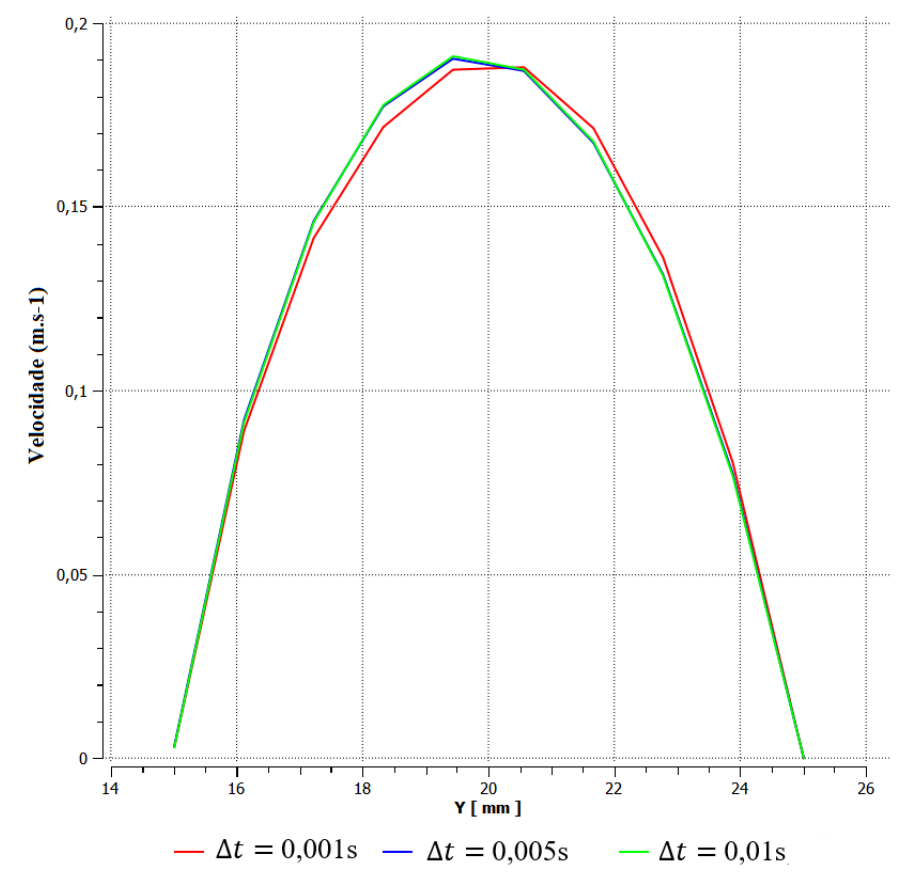

Figura 4.29 - Perfil de velocidade em função da posição radial (y), para $\Delta t=0,01 \mathrm{~s}$, $\Delta t=0,005 \mathrm{~s}$ e $\Delta t=0,001 \mathrm{~s} \mathrm{em} \mathrm{t}=10 \mathrm{~s}$ na altura $\mathrm{h}=500 \mathrm{~mm}$. Condições simuladas: $\mathrm{Q}=10$ L. $\min ^{-1}$ e $\mathrm{m}=0,1 \mathrm{~kg}$. (Fonte: $\mathrm{O}$ autor, 2018)
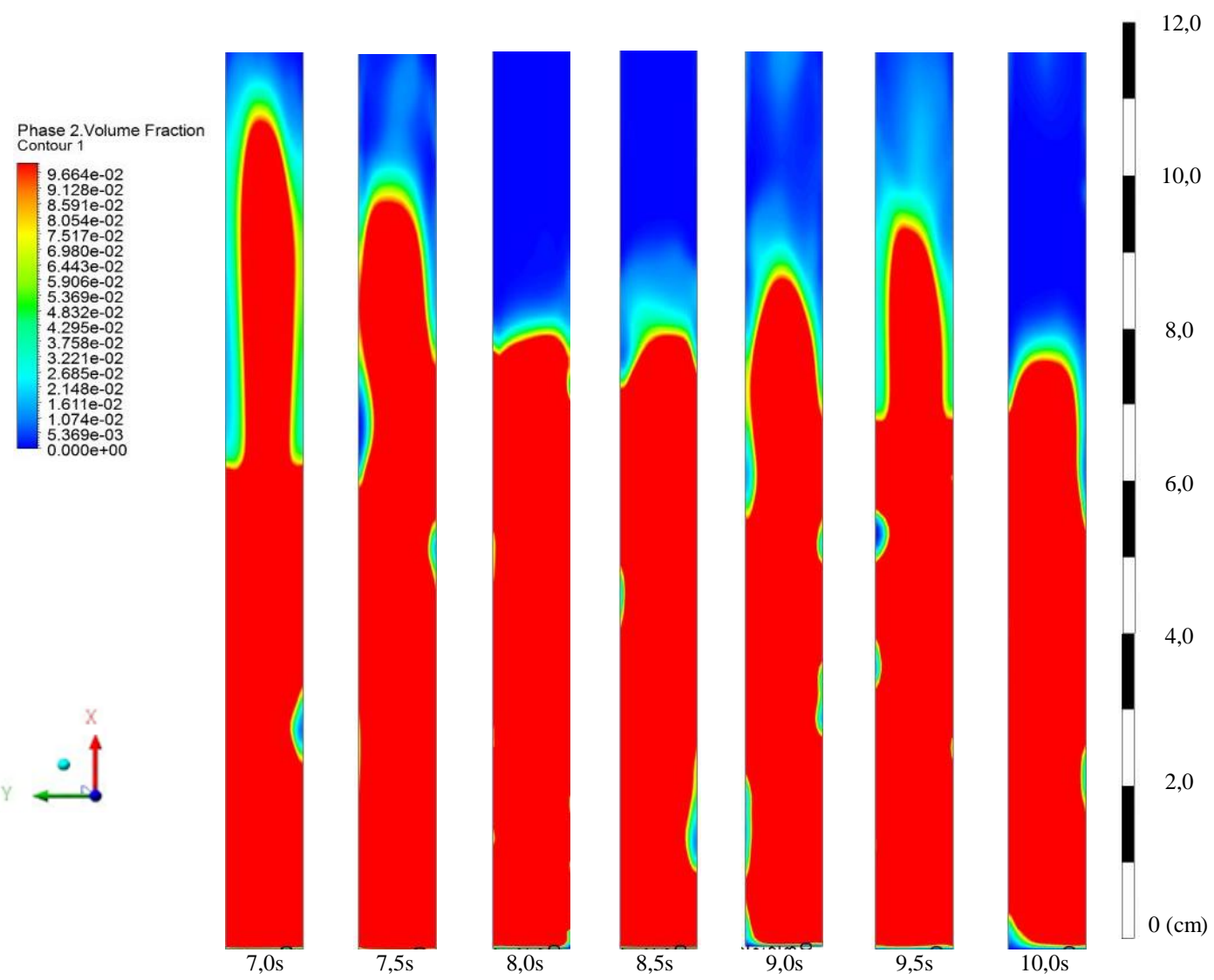

Figura 4.30 - Fração volumétrica de sólidos para $\mathrm{t}=7 \mathrm{~s} 10 \mathrm{~s}$ para $\Delta t=0,001 \mathrm{~s}$, na condição de regime permanente: $\mathrm{Q}=10 \mathrm{~L} \cdot \mathrm{min}^{-1}$ e $\mathrm{m}=0,1 \mathrm{~kg}$.. (Fonte: $\mathrm{O}$ autor, 2018) 

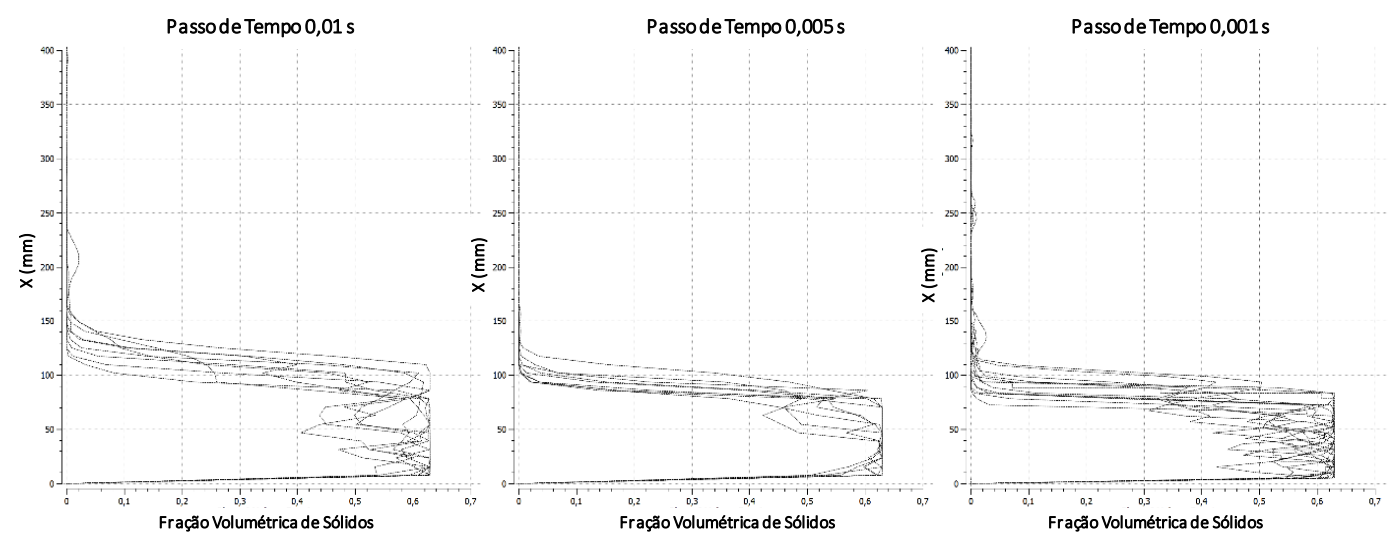

Figura 4.31 - Fração volumétrica de sólido, média na secção, em função da altura do leito (x) do reator para 10 instantes de tempo e para cada passo de tempo analisado.

\subsubsection{Modelagem Multifásica}

(Fonte: O autor, 2018)

\subsubsection{Modelos Escolhidos}

Para a região anular do reator fotocatalítico, para a vazão de 10 L.min ${ }^{-1}$, o número de Reynolds calculado foi de 156 para a fase gasosa, considerando-se apenas a presença do gás. No entanto, com a presença de sólido e na condição de fluidização criam-se zonas de turbulência, sendo o modelo de turbulência $k-\varepsilon$ escolhido para as simulações, em conformidade com o observado na literatura.

O reator fotocatalítico apresenta duas fases distintas: gás e sólido. Para o sistema multifásico estudado, a abordagem escolhida foi a Euler-Euler implícita. A abordagem EulerLagrange mostra como seriam as trajetórias de cada partícula do sólido, sendo utilizada para casos onde deseja-se conhecer o movimento das partículas e suas colisões, como por exemplo casos de erosão. A abordagem Euler-Euler considera a fase sólida como uma fase contínua, como se fosse um fluido, sendo os resultados baseados em médias e mostrando a interação das fases. A escolha da abordagem Euler-Lagrange, exige muito mais computacionalmente, o que levaria a tempos de simulação muito maiores. (PAREEK, V. K. ADESINA, 2003)

No software Fluent, existem alguns modelos para a fase sólida. A partir da análise dos trabalhos de CFD aplicados à simulação de leitos fluidizados (item 2.7) . Decidiu-se para as simulações multifásicas a abordagem Euler-Euler, sendo a fase sólida esta fase foi considerada como sendo granular, conforme o modelo proposto por Gidaspow. E o cálculo da viscosidade granular cinética é dado pela seguinte expressão (GIDASPOW, D., BEZBURUAH R., DING, 1992):

$$
\mu_{s, \text { kin }}=\frac{10 \rho_{s} d_{s} \sqrt{\Theta_{s} \pi}}{96 \alpha_{s}\left(1+e_{s s}\right) g_{0, s s}}\left[1+\frac{4}{5} g_{0, s s} \alpha_{s}\left(1+e_{s s}\right)\right]^{2} \alpha_{s}
$$


A viscosidade média do sólido considera a resistência das partículas granulares à compressão e a expansão, para estas simulações foi considerado o modelo Lun et al, descrito em (LICHTAROWICZ, A. K. ; DUGGINS, R. K. ; MARKLAND, 1965).

Para a viscosidade friccional, o software Fluent considera o modelo de Schaeffer's. (RANZ, 1952). Por fim, entre as fases foi considerado o modelo de arraste proposto por Gidaspow.

Outros parâmetros e propriedades importantes considerados no modelo multifásico podem ser vistos na Tabela 4.10. Todas simulações foram realizadas considerando-se partículas monodispersas e esféricas.

Tabela 4.10 - Parâmetros e propriedades para o modelo multifásico. (Fonte: O autor, 2018)

\begin{tabular}{lcc}
\hline Parâmetro & Valor & Unidade \\
\hline Densidade do $\mathrm{TiO}_{2}, \boldsymbol{\rho}$ & 3000 & $\mathrm{~kg} \cdot \mathrm{m}^{-3}$ \\
Viscosidade, $\boldsymbol{\mu}$ & 0,001044 & $\mathrm{~kg} \cdot \mathrm{m}^{-1} \cdot \mathrm{s}^{-1}$ \\
Diâmetro da partícula, $\boldsymbol{\phi}_{\boldsymbol{p}}$ & 400 & $\mu \mathrm{m}$ \\
\hline
\end{tabular}

\subsubsection{Condições Iniciais e de Contorno}

Para cada simulação realizada, algumas condições de contorno e iniciais foram definidas. Para as simulações de comparação tridimensional e bidimensional, as condições de contorno podem ser visualizadas na Tabela 4.11.

Tabela 4.11 - Condições iniciais e de contorno - Tridimensional x Bidimensional.

(Fonte: O autor, 2018)

\begin{tabular}{lcc}
\hline Condição Experimental & Valor & Unidade \\
\hline Massa de catalisador, $m$ & 0,1 & $\mathrm{~kg}$ \\
Vazão volumétrica, $Q$ & 10 & $\mathrm{~L} \cdot \mathrm{min}^{-1}$ \\
Velocidade dos gás, $\mathrm{v}$ & 0,1326 & $\mathrm{~m} \cdot \mathrm{s}^{-1}$ \\
Altura do leito inicial & 9,6 & $\mathrm{~cm}$ \\
Fração volumétrica de sólido em $\mathrm{t}=0 \mathrm{~s}$ & 0,62 & - \\
\hline
\end{tabular}

Para as simulações de comparação entre as saídas lateral e superior, as condições de contorno podem ser visualizadas na Tabela 4.12.

Tabela 4.12 - Condições de contorno - Saídas Lateral e Superior.

(Fonte: O autor, 2018)

\begin{tabular}{lcc}
\hline Condição Experimental & Valor & Unidade \\
\hline Massa de catalisador, $m$ & 0,1 & $\mathrm{~kg}$ \\
Vazão volumétrica, $Q$ & 10 & $\mathrm{~L} \cdot \mathrm{min}^{-1}$ \\
Velocidade dos gás, $\mathrm{v}$ & 0,1326 & $\mathrm{~m} \cdot \mathrm{s}^{-1}$ \\
Altura do leito inicial & 9,6 & $\mathrm{~cm}$ \\
Fração volumétrica de sólido em & 0,62 & - \\
$\mathrm{t}=0 \mathrm{~s}$ & & \\
\hline
\end{tabular}


Para as simulações realizadas para seleção da malha e seleção do passo do tempo, foi realizada uma modificação na fração volumétrica de sólidos em $\mathrm{t}=0$ s para a fração de vazios do $\mathrm{TiO}_{2}$. Estas condições de contorno podem ser visualizadas na Tabela 4.13.

Tabela 4.13 - Condições de contorno - Seleção de malhas e passo de tempo .

(Fonte: O autor, 2018)

\begin{tabular}{lcc}
\hline Condição Experimental & Valor & Unidade \\
\hline Massa de catalisador, $m$ & 0,1 & $\mathrm{~kg}$ \\
Vazão volumétrica, $Q$ & 10 & $\mathrm{~L} \cdot \mathrm{min}^{-1}$ \\
Velocidade dos gás, $\mathrm{v}$ & 0,1326 & $\mathrm{~m} \cdot \mathrm{s}^{-1}$ \\
Altura do leito inicial & 9,6 & $\mathrm{~cm}$ \\
Fração volumétrica de sólido em & 0,62 & - \\
$\mathrm{t}=0 \mathrm{~s}$ & & \\
\hline
\end{tabular}

Para as simulações de análise da hidrodinâmica do reator fotocatalítico do item 6.2.3, as condições iniciais e de contorno podem ser visualizadas na Tabela 4.14.

Tabela 4.14 - Condições iniciais e de contorno - Analise da Hidrodinâmica .

(Fonte: O autor, 2018)

\begin{tabular}{lcc}
\hline Condição Experimental & Valor & Unidade \\
\hline Massa de catalisador, $m$ & 0,1 & $\mathrm{~kg}$ \\
Vazão volumétrica, $Q$ & $5,7,5,10$ e 15 & L.min \\
Altura do leito inicial & 9,6 & $\mathrm{~cm}$ \\
Fração volumétrica de sólido em & 0,62 & - \\
$\mathrm{t}=0 \mathrm{~s}$ & & - \\
\hline
\end{tabular}

\subsubsection{Modelagem da Reação Fotoquímica}

\subsubsection{Modelos Escolhidos}

Para a modelagem da reação fotoquímica, foi utilizado o módulo do Fluent chamado de Species Transport and Finite-Rate Chemistry. A reação de degradação do poluente modelo pode ser considerada uma reação volumétrica, conforme descrito no item 6.1. Para este tipo de reação, a fração mássica local de cada espécie i é obtida da resolução da equação de convecçãodifusão para cada espécie i. A equação de conservação para a espécie i é apresentada na seguinte forma:

$$
\frac{\partial}{\partial t}\left(\rho Y_{i}\right)+\nabla \cdot\left(\rho \vec{v} Y_{i}\right)=-\nabla \cdot \vec{J}_{l}+R_{i}+S_{i}
$$

(Equação 4.2)

Sendo,

$R_{i}$ : Taxa de produção de espécies i pela reação química

$S_{i}$ : Taxa de criação pela adição de uma fase dispersa em uma fonte definida pelo usuário. 
A implementação da cinética química foi feita a partir da reação global expressa pela Equação 4.3. e considerando-se a o termo de produção apenas na fase gasosa.

$$
\mathrm{C}_{6} \mathrm{H}_{14}+9.5 \mathrm{O}_{2} \rightarrow \text { Produtos Intermediários } \rightarrow 6 \mathrm{CO}_{2}+7 \mathrm{H}_{2} \mathrm{O}
$$

( Equação 4.3)

A partir disso, criou-se uma função chamada User Defined Funciton to Volumetric Rate. Esta função é escrita em C e colocada como um hook-up para o cálculo das taxas de produção da reação química.

Como discutido no item 6.1.1, o domínio físico do reator foi subdividido em duas regiões: densa e diluída. As cinéticas obtidas no item 6.1.1 foram implementadas em cada uma destas regiões.

4.9.5.2 Condições de Contorno e iniciais

Para as simulações da cinética da reação, foram consideradas as condições iniciais e de contorno apresentadas na Tabela 4.15.

Tabela 4.15 - Condições de contorno e iniciais - Modelagem Cinética .

(Fonte: O autor, 2018)

\begin{tabular}{lcc}
\hline Condição Experimental & Valor & Unidade \\
\hline Massa de catalisador, $m$ & 0,1 & $\mathrm{~kg}$ \\
Vazão volumétrica, $Q$ & 10 & $\mathrm{~L} \cdot \mathrm{min}^{-1}$ \\
Velocidade dos gás, $v$ & 0,1326 & $\mathrm{~m}^{-1}$ \\
Altura do leito inicial & 9,6 & $\mathrm{~cm}$ \\
Fração volumétrica de sólido em & 0,62 & - \\
$\mathrm{t}=0 \mathrm{~s}$ & 250 & \\
{$[\mathrm{C}]_{0}$ n-hexano } & 500 & \\
& 1000 & \\
& 2000 & \\
\hline
\end{tabular}




\section{CAPÍTULO 5. RESULTADOS PARA COMPOSTOS ORGÂNICOS VOLÁTEIS}

\subsection{PESQUISA DE MERCADO}

O mercado consumidor de equipamentos para controle de poluição atmosférica é vasto e encontra-se em rápida expansão. Foi feito um levantamento de todas as autuações aplicadas pela CETESB, órgão responsável pela fiscalização ambiental no estado de São Paulo, no ano de 2015 referentes à poluição atmosférica. Os principais resultados podem ser vistos nas Figura 5.1 e 5.2 :

Autuações CETESB - 2015 - Poluição Atmosférica

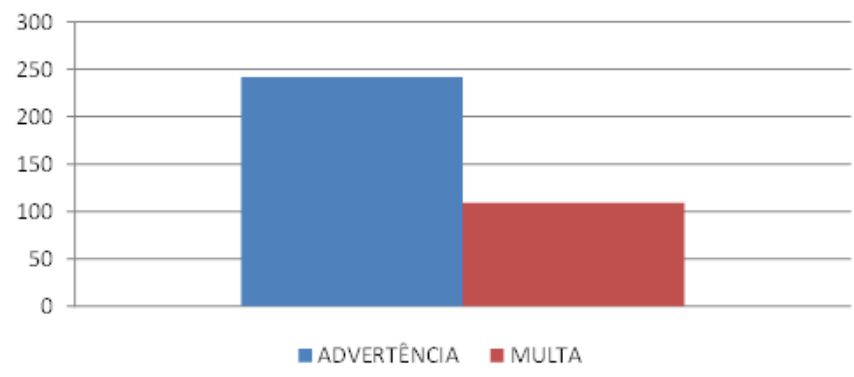

Figura 5.1 - Multas e advertências aplicadas pela CETESB em 2015, referentes à poluição atmosférica. ${ }^{3}$ (Fonte: CETESB)

ADVERTÊNCIA - SP - 2015

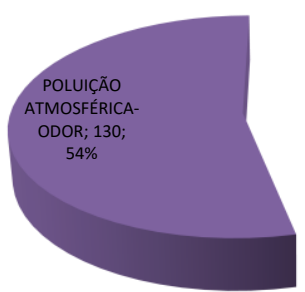

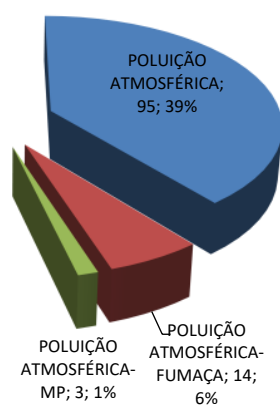

MULTAS - SP - 2015

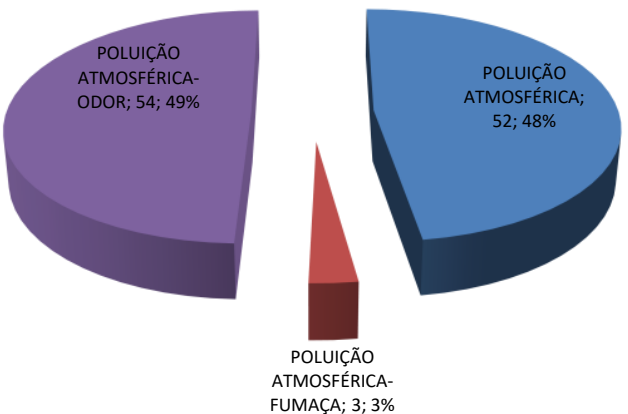

Figura 5.2 - Classificação das multas advertências aplicadas pela CETESB em 2015, referentes à poluição atmosférica. ${ }^{3}$ (Fonte: CETESB)

Essas figuras mostram que 242 empresas foram advertidas e 109 empresas foram multadas, em 2015, por desrespeitarem a legislação ambiental que envolve poluição atmosférica. Das empresas multadas, 54\% tiveram problemas com emissão de odor, o que sugere a contaminação com ácido sulfídrico, amônia ou COV sulfonados. Além destes

\footnotetext{
${ }^{3}$ Disponível em http://www.cetesb.sp.gov.br/servicos/documentos-emitidos/autuacoes/
} 
problemas com odor, os COV ainda estão associados a toxicidade e persistência. Portanto, um dos potencias mercados consumidores do reator fotoquímico são estas empresas. Além do tratamento de gases provenientes de recuperação de solos e da própria indústria química de produção de solventes, outro exemplo de ramo industrial que apresenta um altíssimo potencial consumidor é a indústria de tintas, que em 2014 apresentou faturamento de 4 bilhões de dólares, segmentado conforme a Figura 5.3 seguinte

\section{SEE⿱OR DE TINTAS NO BRASIL}

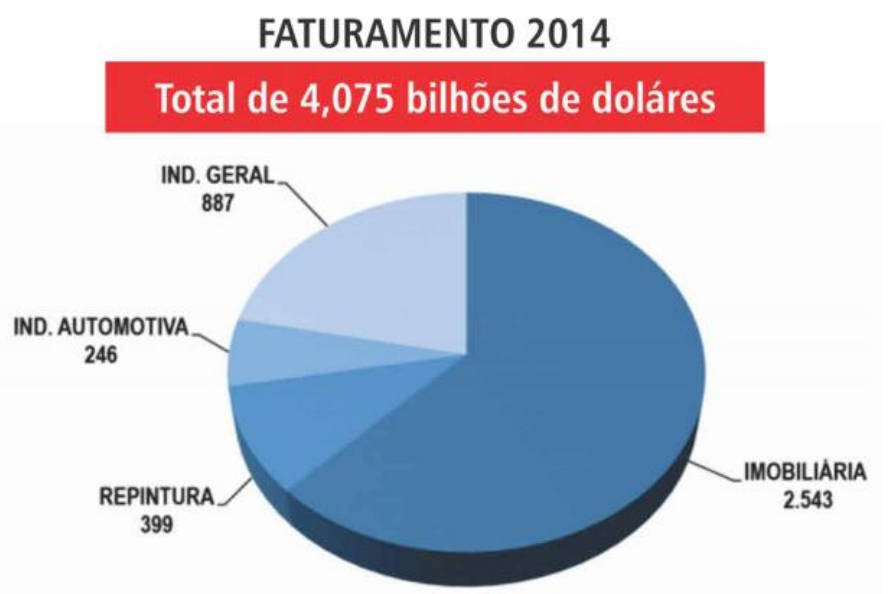

Figura 5.3 - Setor de tintas no Brasil no ano de 2014. ${ }^{4}$ (Fonte: ABRAFATI)

Os solventes orgânicos predominam no mercado brasileiro e têm relevante participação na indústria de tintas e thinner. Tintas, thinner e adesivos são representativos no consumo de solventes, pois estão associados a setores de grande performance (automotivo e construção civil). Compostos como aguarrás, tolueno e xilenos dominam o mercado de solventes hidrocarbônicos por apresentarem relação custo-benefício atraente em vários segmentos, conforme as Figura 5.4 e Figura 5.5.

\footnotetext{
${ }^{4}$ Disponível em: http://www.abrafati.com.br/wp-content/uploads/2015/08/apresentacao-jaime-abrafati.pdf
} 

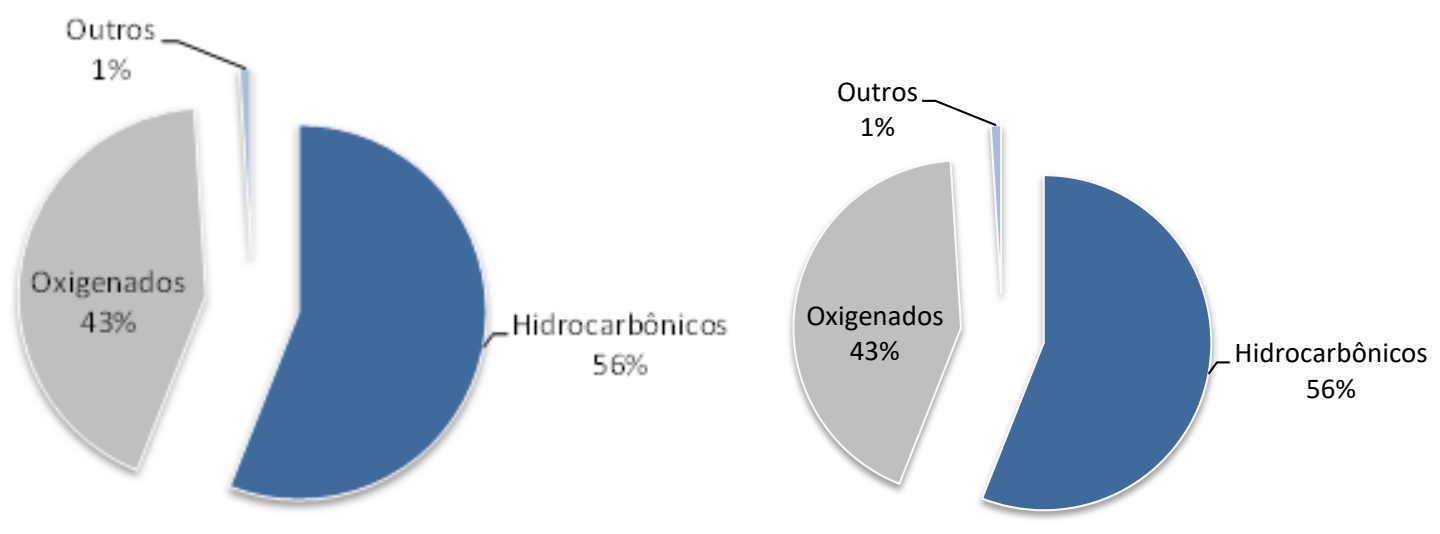

Figura 5.4 - Mercado Brasileiro de Solventes ${ }^{5}$ (Fonte: ABRAFATI)
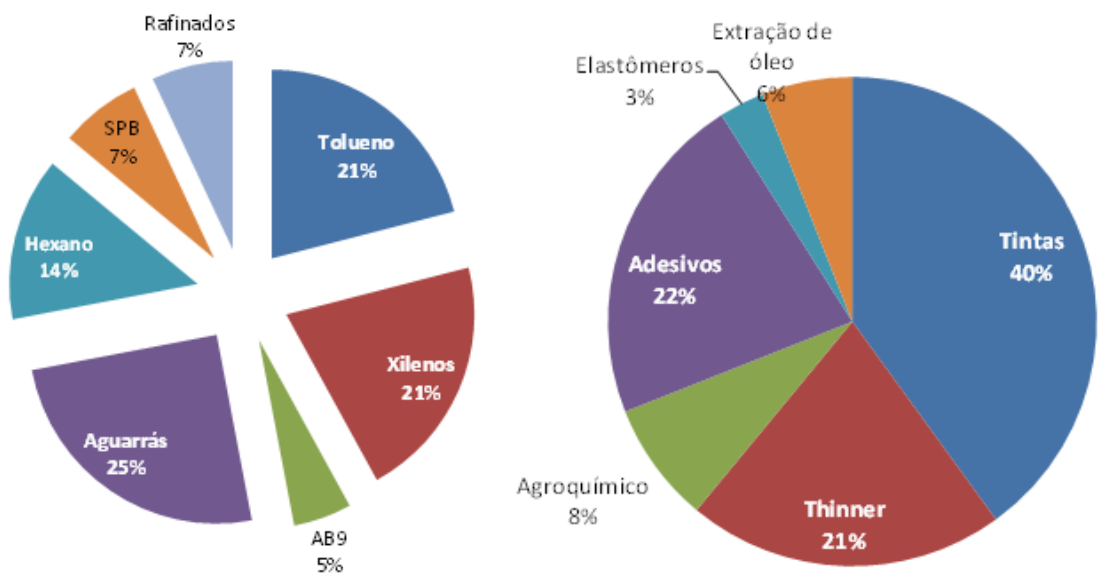

Figura 5.5 - Principais Solventes Hidrocarbônicos por aplicação. ${ }^{5}$ (Fonte: ABRAFATI)

O tolueno é amplamente utilizado devido a sua grande pureza, poder de solvência e principalmente rápida evaporação, favorecendo aplicação na formulação de tintas base solvente (esmaltes e primers), e como diluente em thinner. Já os xilenos são demandados na produção de tintas e thinner por apresentar elevado poder de solvência, mesmo com sua taxa de evaporação, considerada média e também possui alta capacidade de diluir princípios ativos agroquímicos.

Durante estes processos de diluição, formulação e produção muitas emissões gasosas contendo estes poluentes são geradas e precisam de tratamento adequado garantido um limite inferior ao permitido pela legislação ambiental. Atualmente, existem diversas opções de tratamento como: adsorção em carvão ativado, biofiltros e oxidação térmica. No entanto, em visitas a diversos clientes em potencial, constatou-se a ineficiência deste tipo de equipamento,

\footnotetext{
${ }^{5}$ Disponível em: http://www.abrafati.com.br/wp-content/uploads/2013/08/a-industria-quimica-e-de-materiasprimas-essenciais-para-a-industria-de-tintas.pdf
} 
problemas com operação e custos elevados, mostrando a possibilidade de mercado para o desenvolvimento de uma tecnologia mais limpa, eficiente, com minimização de resíduos e custo acessível.

\subsection{CARACTERIZAÇÃO DE CATALISADORES}

Na Figura 5.6 são apresentados os difratogramas de Raios X dos diferentes materiais utilizados como catalisadores, a saber: sílica-gel comercial, $\mathrm{TiO}_{2}$ na forma de Anátase e compósito $\mathrm{TiO}_{2} / \mathrm{SiO}_{2}$. Nota-se que o difratograma das partículas de $\mathrm{SiO}_{2}$ possui um halo entre 15 e 35 graus característico de materiais amorfos. Já para as partículas de $\mathrm{TiO}_{2}$ puro nota-se picos de difração característica do polimorfo anatase, como por exemplo $2 \Theta=25,3^{\circ}$, o que corresponde a difração no plano (101) da estrutura cristalina da anatase. Após a incorporação do $\mathrm{TiO}_{2}$ as partículas de $\mathrm{SiO}_{2}$, nota-se que claramente o surgimento dos picos referentes a estrutura cristalina da anatase no fotocatalisador $\mathrm{TiO}_{2} / \mathrm{SiO}_{2}$. As imagens de microscopia eletrônica da varredura dos diferentes materiais são apresentadas na Figura 5.7. Nota-se que as partículas de $\mathrm{SiO}_{2}$ puro, Figura 5.7 A, não possuem morfologia definida e a sua superfície é pouco rugosa. $\mathrm{O}$ diâmetro das partículas de $\mathrm{SiO}_{2}$ não é uniforme, com valores de diâmetro compreendidos entre 50 e $300 \mu \mathrm{m}$. Na Figura 5.7 B e C, observa-se que após a impregnação com $\mathrm{TiO}_{2}$ a ocorre uma mudança significativa na rugosidade da superfície das partículas de $\mathrm{SiO}_{2}$. Este aumento na rugosidade sugere que as nano partículas de $\mathrm{TiO}_{2}$ foram depositadas sobre a superfície da micropartícula de $\mathrm{SiO}_{2}$. Entretanto, nota-se que além do recobrimento da superfície do $\mathrm{SiO}_{2}$, as nano partículas de $\mathrm{TiO}_{2}$ aglomeram-se formando cluster individuais segredados das micropartículas de sílica.

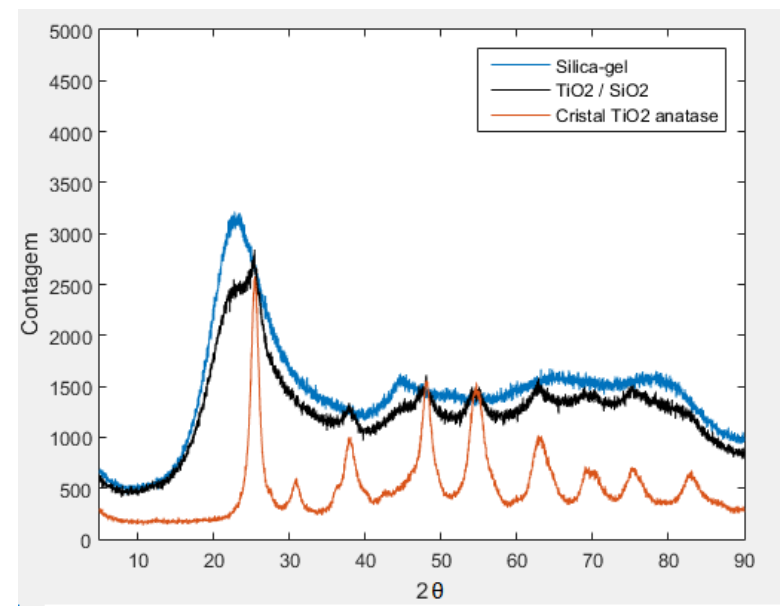

Figura 5.6 - Difração de Raios-X da sílica-gel comercial (azul), cristal $\mathrm{TiO}_{2}$ anatase (laranja) e dos compósitos $\mathrm{TiO}_{2} / \mathrm{SiO}_{2}$ (preta). Os picos indicam a formação da fase anatase no $\mathrm{TiO}_{2} / \mathrm{SiO}_{2}$. (Fonte: Central Analítica IQ-USP) 


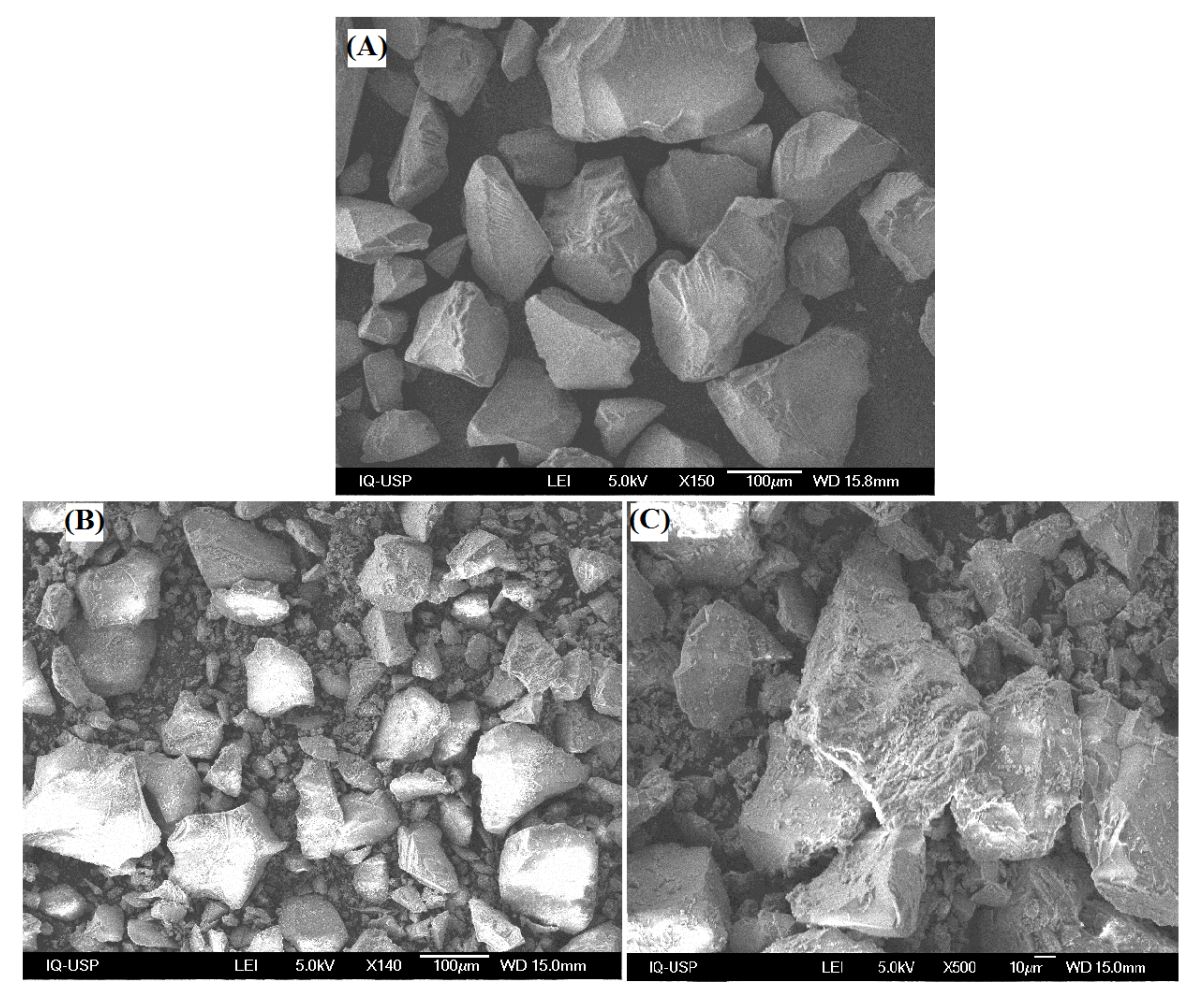

Figura 5.7 - (A) Partículas de sílica-gel $\left(\mathrm{SiO}_{2}\right)$ pura; (B) Compósitos $\mathrm{TiO}_{2} / \mathrm{SiO}_{2}$ com $20 \%$ de $\mathrm{TiO}_{2}$. Nota-se a geração de partículas menores; (C) Compósitos $\mathrm{TiO}_{2} / \mathrm{SiO}_{2} \operatorname{com} 20 \%$ de $\mathrm{TiO}_{2}$. Nota-se a não homogeneidade do recobrimento. (Fonte: Central Analítica IQ-USP)

A geração de finos na síntese foi quantificada pela análise da distribuição de tamanhos de partículas por espalhamento de luz, como mostrado na Figura 5.8, que revelou uma redução do diâmetro de Sauter $(\mathrm{D}[3,2])$ de $74,1 \mu \mathrm{m}$ da $\mathrm{SiO}_{2}$ para 28,4 $\mu$ m dos compósitos $\mathrm{TiO}_{2} / \mathrm{SiO}_{2}$.
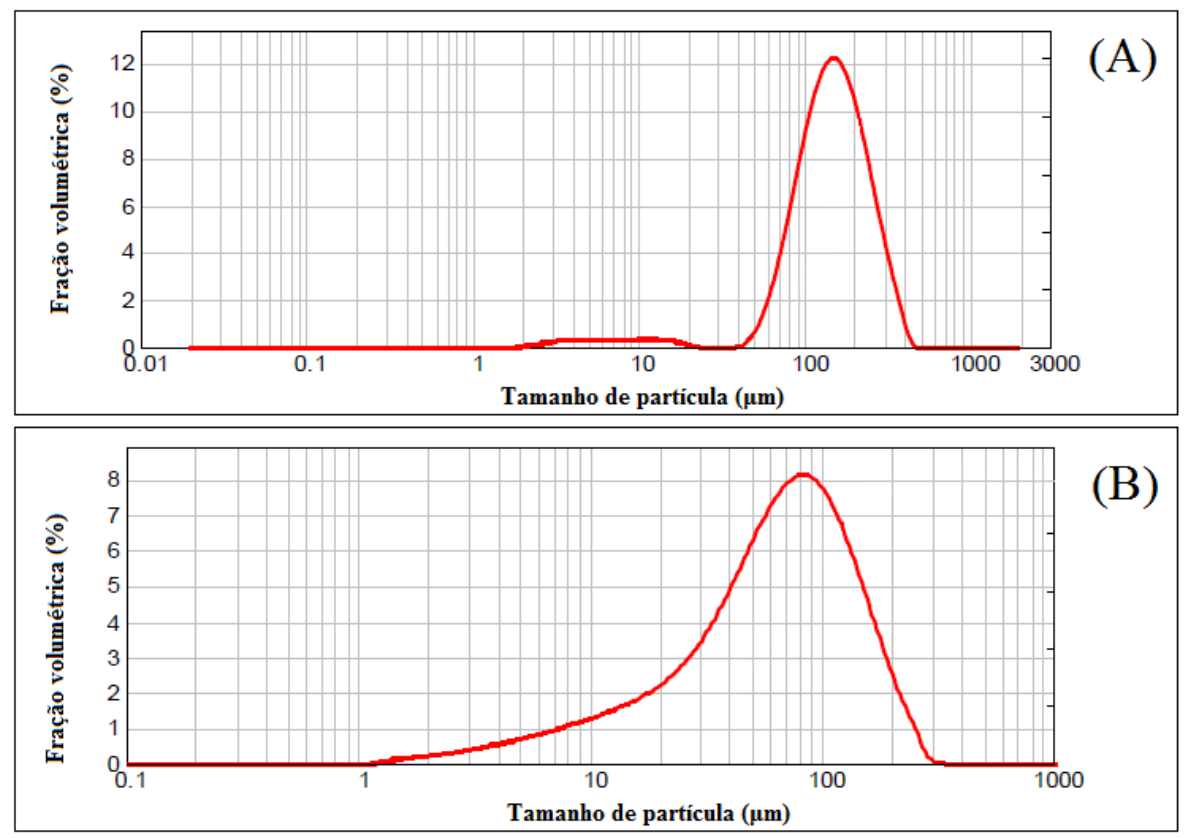

Figura 5.8 - Distribuição de tamanho de partículas para (A) Partículas de sílica-gel comerciais $\left(\mathrm{SiO}_{2} 63-200 \mu \mathrm{m}\right)$ pura; (B) Compósitos $\mathrm{TiO}_{2} / \mathrm{SiO}_{2}$ com $20 \%$ de $\mathrm{TiO}_{2}$. (Fonte: LCT) 
Os sólidos sintetizados foram peneirados de modo a descartar aqueles cujo diâmetro de peneira $\left(d_{p}\right)$ fosse inferior a $38 \mu \mathrm{m}$. No entanto, como havia a suspeita de que as partículas menores surgissem da aglomeração do $\mathrm{TiO}_{2}$ durante a síntese, três análises de ICP foram realizadas separadamente: uma de uma amostra representativa de todos os sólidos sintetizados (amostra global), uma da fração de sólidos com $\mathrm{d}_{\mathrm{p}}<38 \mu \mathrm{m}$ e uma da fração de sólidos com $\mathrm{d}_{\mathrm{A}}$ $>38 \mu \mathrm{m}$. Este resultado é mostrado na Tabela 5.1. Nota-se que, embora a composição global dos sólidos sintetizados resultasse no valor esperado (20\%), há uma perda considerável de $\mathrm{TiO}_{2}$ nos sólidos que são de fato aproveitáveis no reator, estimando-se que a fração mássica de $\mathrm{TiO}_{2}$ nos sólidos utilizados nos experimentos de degradação seja de 13,19\%.

Tabela 5.1 - Resultado da análise quantitativa de elementos da fração de sólidos aproveitável $\left(\mathrm{d}_{\mathrm{p}}>38 \mu \mathrm{m}\right)$ e não aproveitável $\left(\mathrm{d}_{\mathrm{p}}<38 \mu \mathrm{m}\right)$. (Fonte: Relatório FAPESP, 2017)

\begin{tabular}{lcc}
\hline $\begin{array}{c}\text { Análise quantitativa de } \\
\text { elementos }(\% \text { mássica) }\end{array}$ & \% Ti & \% $^{\mathbf{T i O}_{2}{ }^{*}}$ \\
\hline Amostra global & $12,26 \pm 0,05$ & 20,47 \\
\hline Amostra $\mathrm{d}_{\mathrm{P}}<38 \mu \mathrm{m}$ & $22,62 \pm 0,13$ & 37,76 \\
\hline Amostra $\mathrm{d}_{\mathrm{P}}>38 \mu \mathrm{m}$ & $7,90 \pm 0,01$ & 13,19 \\
\hline
\end{tabular}

Para o catalisador comercial, $\mathrm{TiO}_{2}$ anatase, foi obtido por análise DLS, a distribuição de tamanho de partículas em termos de fração volumétrica, conforme pode ser visto na Figura 5.9, revelando que as maioria das partículas apresentam um tamanho menor que $3 \mu \mathrm{m}$. Este tamanho pequeno faz com que este catalisador seja classificado como sólido do tipo Geldart C (KUNII, D.; LEVENSPIEL, 1991), sendo inadequado para a fluidização. No entanto, quando colocado no interior do reator e submetido a um força de arraste suficiente, após algum tempo de estabilização de pressão, os sólidos se reorganizam em aglomerados esféricos de $\mathrm{TiO}_{2}$ com tamanho milimétrico de aproximadamente $0,4 \mathrm{~mm}$, como mostrado nas Figura 5.10 e Figura 5.11, comparando os sólidos antes e após a operação com uma vazão de 10 L.min ${ }^{-1}$.

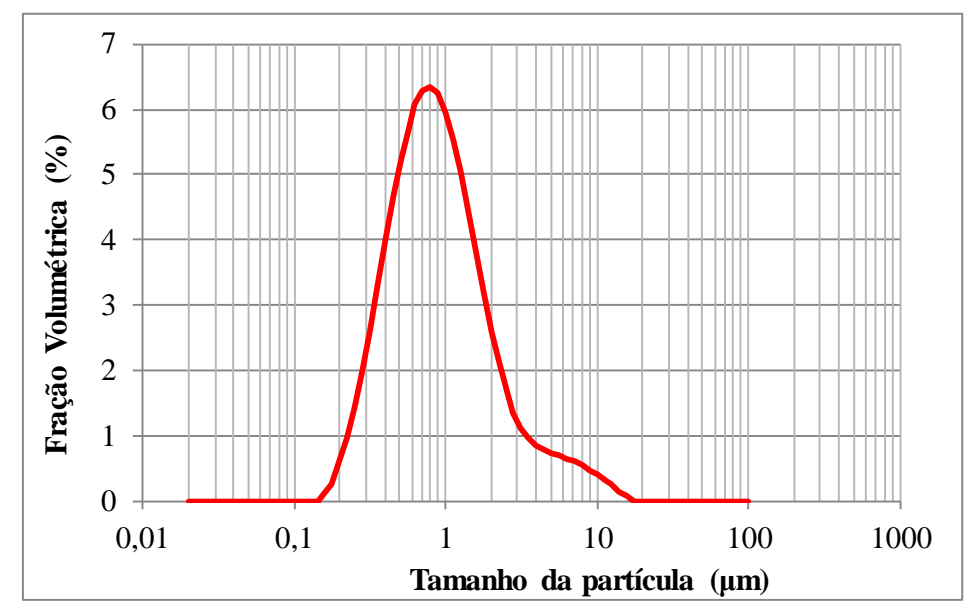

Figura 5.9 - Análise DLS do $\mathrm{TiO}_{2}$ Anatase . (Fonte: LCT) 


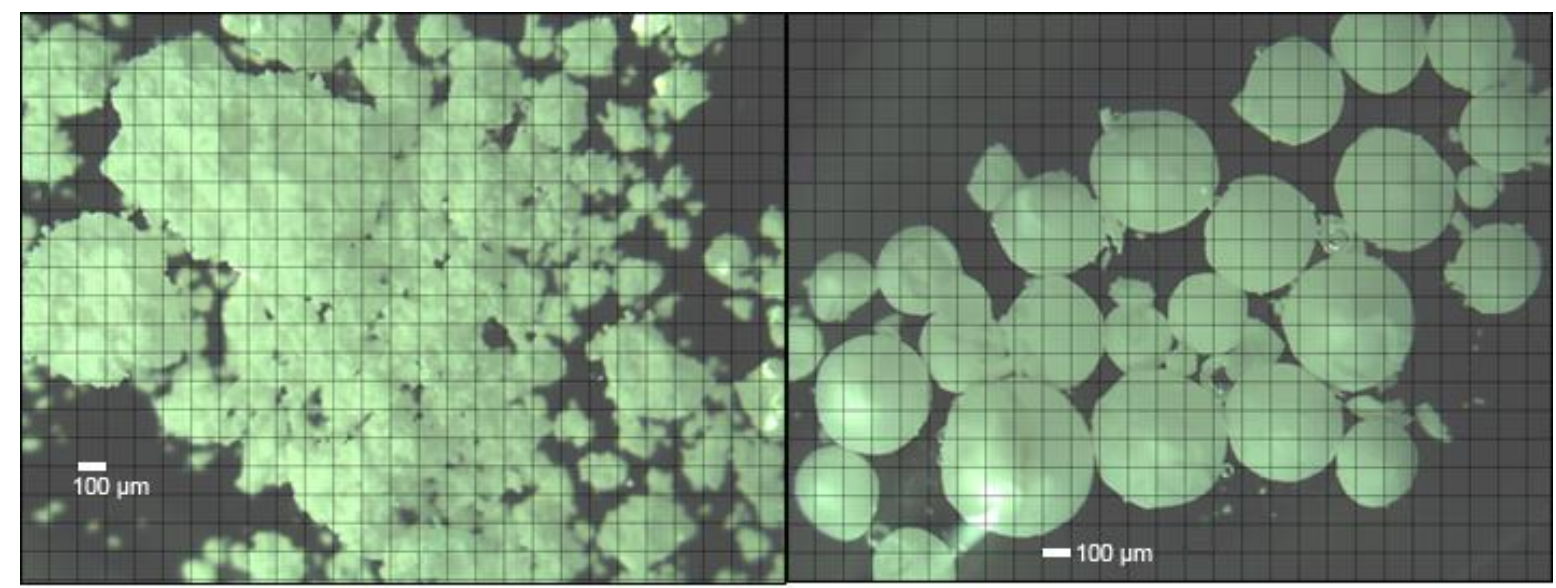

A

B

Figura 5.10 - Fotografias de partículas de $\mathrm{TiO}_{2}$, (A) antes da fluidização; (B) após a fluidização . (Fonte: DEQ-Poli USP)

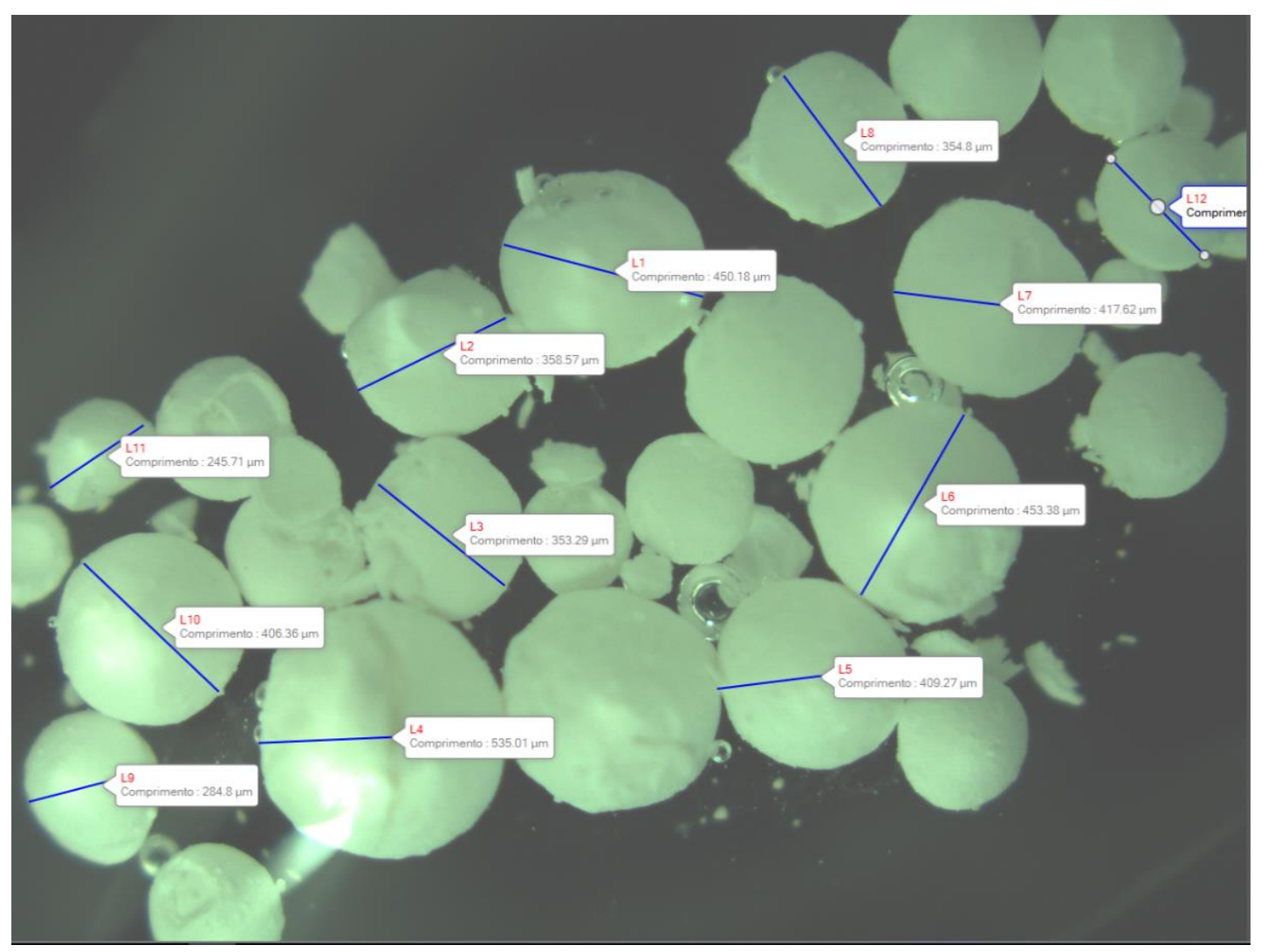

Figura 5.11 - Fotografias de partículas de $\mathrm{TiO}_{2}$ após a fluidização. (Fonte: DEQ-Poli USP)

\subsection{ENSAIOS EXPERIMENTAIS DE DEGRADAÇÃO DE BTX}

Operando o reator conforme descrito no item 4.7.3, foram retiradas as amostras da entrada e da saída do reator e estas foram analisadas por cromatografia gasosa. A porcentagem de degradação do poluente foi calculada por:

$$
X(\%)=\frac{C_{B T E X e n t r a d a}-C_{B T E X s a i ́ d a}}{C_{B T E X e n t r a d a}} \times 100 \%
$$


Mensurando-se a degradação em estado estacionário relacionada à massa de catalisador utilizado, a capacidade de tratamento da unidade foi avaliada para diferentes concentrações de BTX na entrada do reator, de acordo com valores típicos de emissão (50 a 200 ppmv).

\subsubsection{Planejamento Experimental}

Os experimentos foram realizados em três etapas: ensaios preliminares, experimentos de degradação fotocatalítica dos poluentes alvo e ensaio de regeneração do catalisador, descritos a seguir.

- Ensaios preliminares: determinação da velocidade mínima de fluidização dos compósitos $\mathrm{TiO}_{2} / \mathrm{SiO}_{2}$, para determinar a vazão mínima de operação do reator; e fotólise dos poluentes por radiação UVC, com o intuito de isolar este efeito da taxa de degradação fotocatalítica;

- Ensaios de degradação fotocatalítica: as variáveis estudadas foram: concentração de inicial do COV no reator ( $C_{0}$, níveis 50, 100 e 200 ppmv), vazão de gás ( $Q$, níveis 5 , 10,15 e $20 \mathrm{~L} \mathrm{~min}^{-1}$ ) e massa de catalisador ( $m$, níveis 100 e $200 \mathrm{~g}$ ), para três poluentes alvo: benzeno, tolueno e xilenos. Os ensaios de degradação do benzeno, com $C_{0}=$ 50 ppmv, foram realizados com todas as combinações de $Q$ e $m$, para avaliação das diferentes condições fluidodinâmicas do reator. Para os demais poluentes, operou-se apenas com uma vazão $Q$ e massa $=100 \mathrm{~g}$ de catalisador. Além disto, cada poluente teve uma de suas condições testada nos outros níveis de $C_{0}$, com o intuito de verificar o comportamento da taxa de degradação com esta variável. Por fim, um ensaio de degradação simultânea dos três poluentes foi realizado. Esta parte do planejamento está mostrada na Tabela 5.2. Todos estes ensaios foram realizados mantendo-se a umidade relativa do ar (UR) próxima de 50\%.

- Ensaio de regeneração do catalisador: um método de regeneração do catalisador com ar umedecido (UR > 80\%) foi avaliado quantitativamente em termos de remoção de carbono depositado na estrutura do $\mathrm{TiO}_{2} / \mathrm{SiO}_{2}$.

Tabela 5.2 - Planejamento dos ensaios de degradação fotocatalítica de benzeno, tolueno e xilenos. (Fonte: Relatório FAPESP, 2017)

\begin{tabular}{|c|c|c|c|c|c|c|c|c|c|c|c|c|c|c|c|c|c|}
\hline \multicolumn{18}{|c|}{ BENZENO } \\
\hline \multicolumn{6}{|c|}{$\mathrm{C}_{0}=50 \mathrm{ppmv}$} & \multicolumn{6}{|c|}{$\mathrm{C}_{0}=100 \mathrm{ppmv}$} & \multicolumn{6}{|c|}{$\mathrm{C}_{0}=200 \mathrm{ppmv}$} \\
\hline & & \multicolumn{4}{|c|}{$\mathrm{Q}$} & & & \multicolumn{4}{|c|}{$\mathrm{Q}$} & & & \multicolumn{4}{|c|}{$\mathrm{Q}$} \\
\hline & & 5 & 10 & 15 & 20 & & & 5 & 10 & 15 & 20 & & & 5 & 10 & 15 & 20 \\
\hline \multirow{2}{*}{$\mathrm{m}$} & 100 & $X$ & X & $X$ & $X$ & \multirow[b]{2}{*}{$\mathrm{m}$} & 100 & & & & & \multirow[b]{2}{*}{$\mathrm{m}$} & 100 & & & & \\
\hline & 200 & $\mathrm{X}$ & $\mathrm{X}$ & $\mathrm{X}$ & $\mathrm{X}$ & & 200 & & & $\mathrm{X}$ & & & 200 & & & $\mathrm{X}$ & \\
\hline
\end{tabular}




\begin{tabular}{|c|c|c|c|c|c|c|c|c|c|c|c|c|c|c|c|c|c|}
\hline \multicolumn{18}{|c|}{ TOLUENO } \\
\hline \multicolumn{6}{|c|}{$\mathrm{C}_{0}=50 \mathrm{ppmv}$} & \multicolumn{6}{|c|}{$\mathrm{C}_{0}=100 \mathrm{ppmv}$} & \multicolumn{6}{|c|}{$\mathrm{C}_{0}=200 \mathrm{ppmv}$} \\
\hline & & \multicolumn{4}{|c|}{ Q } & & & \multicolumn{4}{|c|}{ Q } & & & \multicolumn{4}{|c|}{ Q } \\
\hline & & 5 & 10 & 15 & 20 & & & 5 & 10 & 15 & 20 & & & 5 & 10 & 15 & 20 \\
\hline \multirow{2}{*}{$\mathrm{m}$} & 100 & & & $\mathrm{X}$ & & \multirow[b]{2}{*}{$\mathrm{m}$} & 100 & & & $\mathrm{X}$ & & \multirow{2}{*}{$\mathrm{m}$} & 100 & & & $\mathrm{X}$ & \\
\hline & 200 & & & & & & 200 & & & & & & 200 & & & & \\
\hline \multicolumn{18}{|c|}{ XILENOS } \\
\hline \multicolumn{6}{|c|}{$\mathrm{C}_{0}=50 \mathrm{ppmv}$} & \multicolumn{6}{|c|}{$\mathrm{C}_{0}=100 \mathrm{ppmv}$} & \multicolumn{6}{|c|}{$\mathrm{C}_{0}=200 \mathrm{ppmv}$} \\
\hline & & \multicolumn{4}{|c|}{ Q } & & & \multicolumn{4}{|c|}{ Q } & & & \multicolumn{4}{|c|}{$\mathrm{Q}$} \\
\hline & & 5 & 10 & 15 & 20 & & & 5 & 10 & 15 & 20 & & & 5 & 10 & 15 & 20 \\
\hline \multirow{2}{*}{$\mathrm{m}$} & 100 & & & $\mathrm{X}$ & & \multirow{2}{*}{$\mathrm{m}$} & 100 & & & $\mathrm{X}$ & & \multirow{2}{*}{$\mathrm{m}$} & 100 & & & $\mathrm{X}$ & \\
\hline & 200 & & & & & & 200 & & & & & & 200 & & & & \\
\hline \multicolumn{18}{|c|}{ MISTURA BTX } \\
\hline \multicolumn{6}{|c|}{$\mathrm{C}_{0}=50 \mathrm{ppmv}$} & \multicolumn{6}{|c|}{$\mathrm{C}_{0}=100 \mathrm{ppmv}$} & \multicolumn{6}{|c|}{$\mathrm{C}_{0}=200 \mathrm{ppmv}$} \\
\hline & & \multicolumn{4}{|c|}{$\mathrm{Q}$} & & & \multicolumn{4}{|c|}{ Q } & & & \multicolumn{4}{|c|}{ Q } \\
\hline & & 5 & 10 & 15 & 20 & & & 5 & 10 & 15 & 20 & & & 5 & 10 & 15 & 20 \\
\hline \multirow[b]{2}{*}{$\mathrm{m}$} & 100 & & & & & \multirow[b]{2}{*}{$\mathrm{m}$} & 100 & & & $\mathrm{X}$ & & \multirow[b]{2}{*}{$\mathrm{m}$} & 100 & & & & \\
\hline & 200 & & & & & & 200 & & & & & & 200 & & & & \\
\hline
\end{tabular}

\subsubsection{Resultados Experimentais}

\subsubsection{Velocidade mínima de fluidização}

A velocidade mínima de fluidização $\left(\mathrm{V}_{\mathrm{mf}}\right)$ pode ser definida pela relação da queda de pressão do leito $\left(\Delta \mathrm{P}_{\text {Leito }}\right)$ por massa de $\mathrm{TiO}_{2} / \mathrm{SiO}_{2}\left(\mathrm{~m}_{\mathrm{TiO} 2}\right)$ com a velocidade superficial do gás $\left(\mathrm{U}_{\mathrm{g}}\right)$. Para o catalisador sintetizado, foi realizado um ensaio com $150 \mathrm{~g}$ de $\mathrm{TiO}_{2} / \mathrm{SiO}_{2}$ no reator, fluidizado com ar ambiente. A Figura 5.12 apresenta o gráfico da relação $\Delta \mathrm{P}_{\text {Leito }} \times \mathrm{U}_{\mathrm{g}}$. $\mathrm{O}$ valor $\Delta \mathrm{P}_{\text {Leito }}$ foi obtido pela diferença da queda pressão com $150 \mathrm{~g}$ de sólido em relação à queda de pressão com o reator sem sólidos; a velocidade superficial foi calculada pela razão entre a a vazão de gás $(\mathrm{Q})$ área anular do leito $\left(\mathrm{A}_{\mathrm{s}}\right)$. A figura indica uma $\mathrm{V}_{\mathrm{mf}}$ de aproximadamente 4,3 $\mathrm{cm} / \mathrm{s}$, equivalente a uma vazão operacional de $3,3 \mathrm{~L} \mathrm{~min}^{-1}$. A partir de uma vazão de $10 \mathrm{~L} \mathrm{~min}$ ${ }^{1}\left(3,0 \mathrm{~V}_{\mathrm{mf}}\right)$ foi possível observar o efeito de circulação dos sólidos por todo o reator, com captura no ciclone e retorno pela rosca transportadora. 


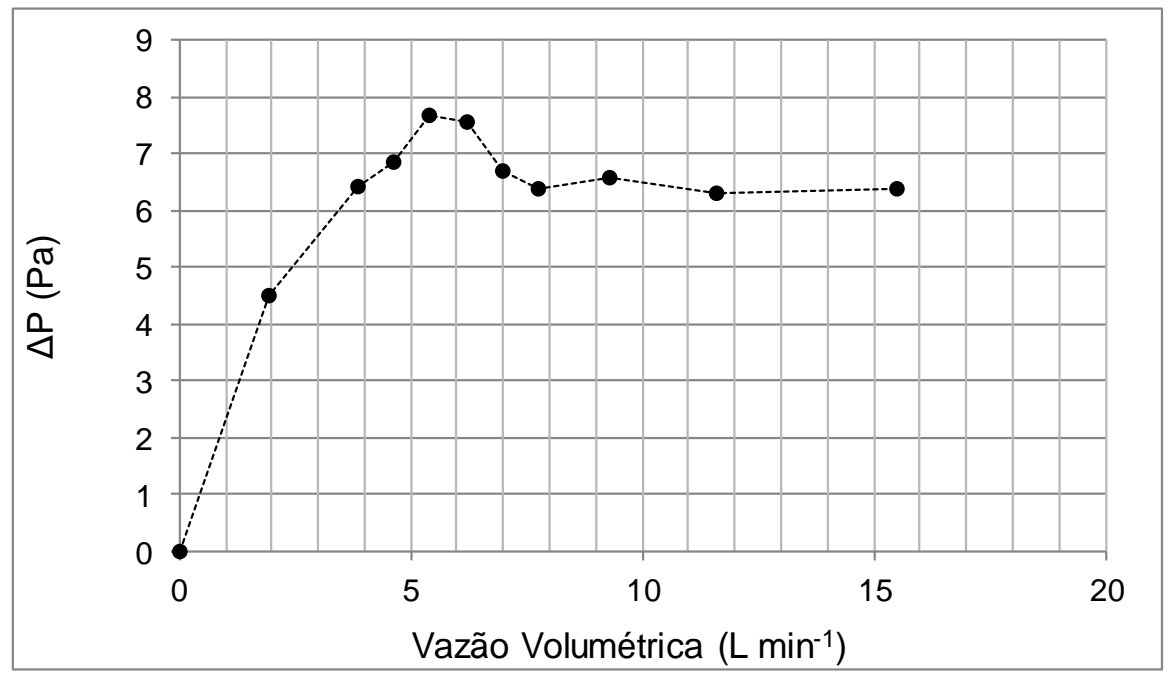

Figura 5.12 - Queda de pressão no leito em função da vazão volumétrica de gás.

(Fonte: Relatório Fapesp, 2017)

\subsubsection{Fotólise dos poluentes}

A degradação dos poluentes benzeno, tolueno e xileno pela ação da radiação ultravioleta $(\lambda=254 \mathrm{~nm})$ foi avaliada no reator sem sólidos, ou seja, a fotólise dos poluentes, para o intervalo de vazões de $2,5 \mathrm{~L} \mathrm{~min}^{-1}$ a $15 \mathrm{~L} \mathrm{~min}^{-1}$, que representaram tempos de residência no volume irradiado de $25,7 \mathrm{~s}$ a 4,3 s. Os resultados para uma corrente de ar contaminado com concentração de entrada $\left(\mathrm{C}_{0}\right)$ de 100 ppmv de cada um dos poluentes é mostrado na Figura 5.13. O tolueno e xileno degradaram quando expostos à radiação UVC, ao contrário do benzeno. No entanto, foi necessário, no melhor dos casos, um tempo de residência de 25,7 segundos $(\mathrm{Q}=$ 2,5 $\mathrm{L} \mathrm{min}^{-1}$ ) para a degradação de $9 \%$ de xilenos.

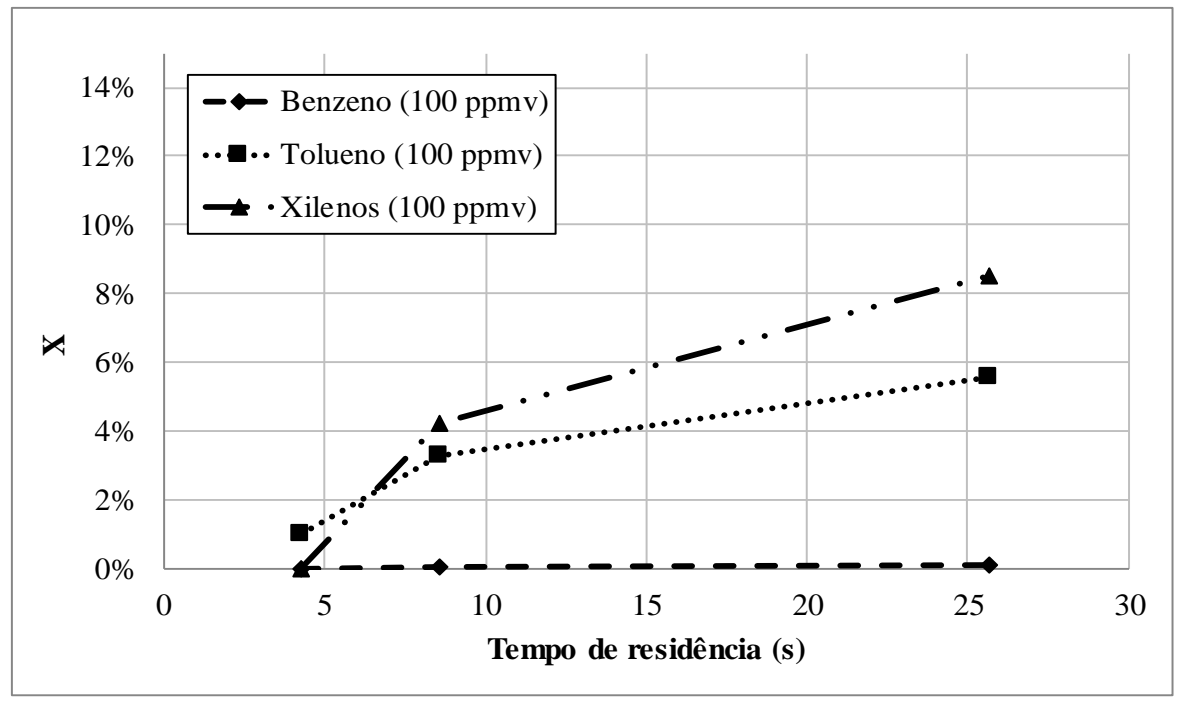

Figura 5.13 - Degradação no reator devido à fotólise por radiação luminosa $(\lambda=254 \mathrm{~nm})$ para benzeno $\left(C_{0}=100 \pm 0,7 \mathrm{ppmv}\right)$, tolueno $\left(C_{0}=100 \pm 1,1 \mathrm{ppmv}\right)$ e xilenos $\left(C_{0}=100 \pm 2,0\right.$ ppmv). (Fonte: Relatório Fapesp, 2017) 


\subsubsection{Degradação fotocatalítica do benzeno}

Durante o estudo da degradação fotocatalítica do benzeno, os regimes operacionais do reator foram avaliados de maneira exploratória, conforme descrito no item 5.3.1. O reator foi alimentado com massas (m) de catalisador de 100 e $200 \mathrm{~g}$, e as vazões (Q) de 5, 10, 15 e $20 \mathrm{~L}$ $\mathrm{min}^{-1}$, representando respectivamente valores de velocidade de $1,5 \mathrm{v}_{\mathrm{mf}}, 3,0 \mathrm{v}_{\mathrm{mf}}, 4,5 \mathrm{v}_{\mathrm{mf}}, 6,0 \mathrm{v}_{\mathrm{mf}}$.

O efeito das diferentes vazões de operação na degradação fotocatalítica de uma corrente contaminada com 50 ppmv de benzeno no reator alimentado com $100 \mathrm{~g}$ de catalisador está mostrado na Figura 5.14. A maior porcentagem de degradação de benzeno foi de $13,1 \%$, correspondendo à vazão de $15 \mathrm{~L} \mathrm{~min}^{-1}(4,5 \mathrm{vmf})$, empregando-se catalisador novo. Ressalta-se que apenas o primeiro teste pode ser realizado com o catalisador novo. Para evitar que o efeito da adsorção irreversível de poluentes na superfície não interferisse na compreensão de qual a melhor vazão de trabalho, o teste com a vazão $15 \mathrm{~L} \mathrm{~min}^{-1}$ foi refeito após o uso do catalisador nas outras três vazões avaliadas, e manteve-se como a de melhor desempenho no reator alimentado com $100 \mathrm{~g}$ de catalisador, degradando 7,8\% do benzeno com o catalisador já em uso. Por este motivo, esta vazão foi escolhida para os demais testes.

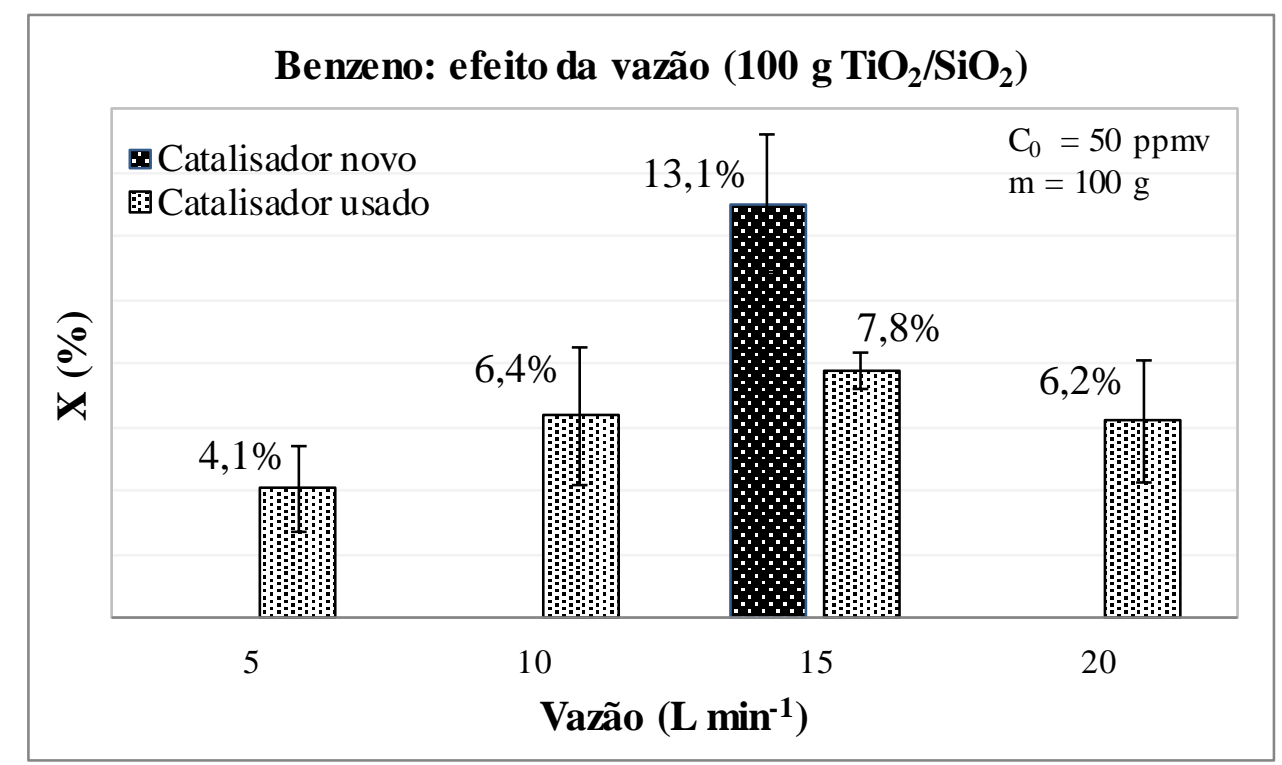

Figura 5.14 - Degradação fotocatalítica do benzeno: avaliação de diferentes vazões com 100 $\mathrm{g}\left(20 \% \mathrm{TiO}_{2} / 80 \% \mathrm{SiO}_{2}\right)$ e UR $=50 \%$. (Fonte: Relatório Fapesp, 2017)

Avaliou-se, também, o efeito de um aumento na massa de catalisador de $100 \mathrm{~g}$ para 200 $\mathrm{g}$ no interior do reator. $\mathrm{O}$ aumento da massa leva a dois efeitos operacionais positivos: i) maior concentração de sólidos na porção circulante do reator; ii) maior exposição da porção não circulante do leito à radiação, devido à elevação na altura do leito expandido. Para uma quantidade de $200 \mathrm{~g}$ de catalisador, o desempenho do reator foi reavaliado para as diferentes vazões. Neste caso, a vazão de $20 \mathrm{~L} \mathrm{~min}^{-1}$ apresentou-se inoperável, levando a uma perda 
intensa de sólidos no ciclone e constante entupimento das linhas a jusante do reator. O resultado da degradação do benzeno em função da vazão de gás está mostrado na Figura 5.15.

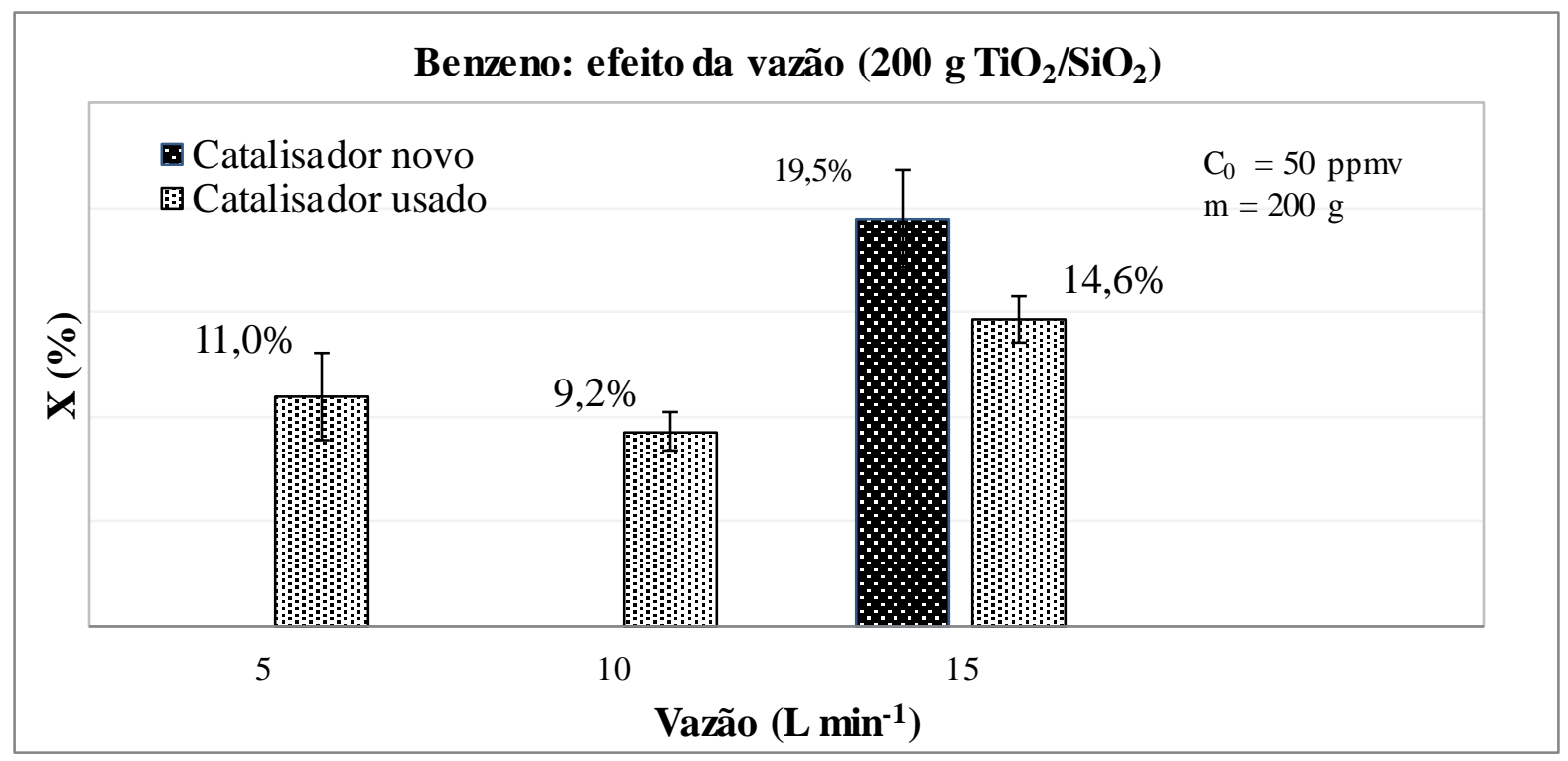

Figura 5.15 - Degradação fotocatalítica do benzeno: avaliação de diferentes vazões com 200 $\mathrm{g}\left(20 \% \mathrm{TiO}_{2} / 80 \% \mathrm{SiO}_{2}\right)$ e UR=50\%. (Fonte: Relatório Fapesp, 2017)

O aumento da massa de catalisador leva a uma melhoria mais acentuada na vazão de 5 $\mathrm{L} \min ^{-1}$ do que na vazão de $10 \mathrm{~L} \mathrm{~min}^{-1}$, associado ao efeito combinado da elevação da altura do leito expandido com o maior tempo de residência para a menor vazão. No entanto, novamente, o melhor resultado foi observado para vazão de $15 \mathrm{~L} \mathrm{~min}^{-1}(4,5 \mathrm{v} \mathrm{mf})$, mostrando o efeito do aumento da concentração de sólidos na região circulante e desta vez degradando $19,5 \%$ do benzeno com catalisador novo.

Por fim, avaliou-se o efeito da concentração de entrada no desempenho do reator como mostrado na Figura 5.16 (A) na condição de $15 \mathrm{~L} \mathrm{~min}^{-1}$ e $200 \mathrm{~g}$ de $\mathrm{TiO}_{2} / \mathrm{SiO}_{2}$, com o catalisador usado. Os valores de taxa de degradação $\mathrm{R}\left(\mathrm{ppmv} \mathrm{g}^{-1} \mathrm{~s}^{-1}\right)$ para o benzeno foram calculados de acordo com a (Equação 5.2) e estão mostrados na Figura 5.16 (B).

$$
R=\frac{C_{0}-C}{\tau \times m}
$$

(Equação 5.2)

Com o aumento da concentração de entrada, observa-se um pequeno decréscimo na conversão e um aumento linear de R. Este comportamento já foi discutido na literatura, caracterizando a reação e a adsorção em baixas concentrações de poluente, com comportamento próximo ao de primeira ordem (Prieto, Fermoso e Irusta, 2007). Ao fim da realização dos ensaios, houve uma notável mudança de cor do $\mathrm{TiO}_{2} / \mathrm{SiO}_{2}$ de branco para amarelo. O processo 
de extração com metanol e análise em CG/MS revelou que o benzofurano foi o principal responsável pela desativação.

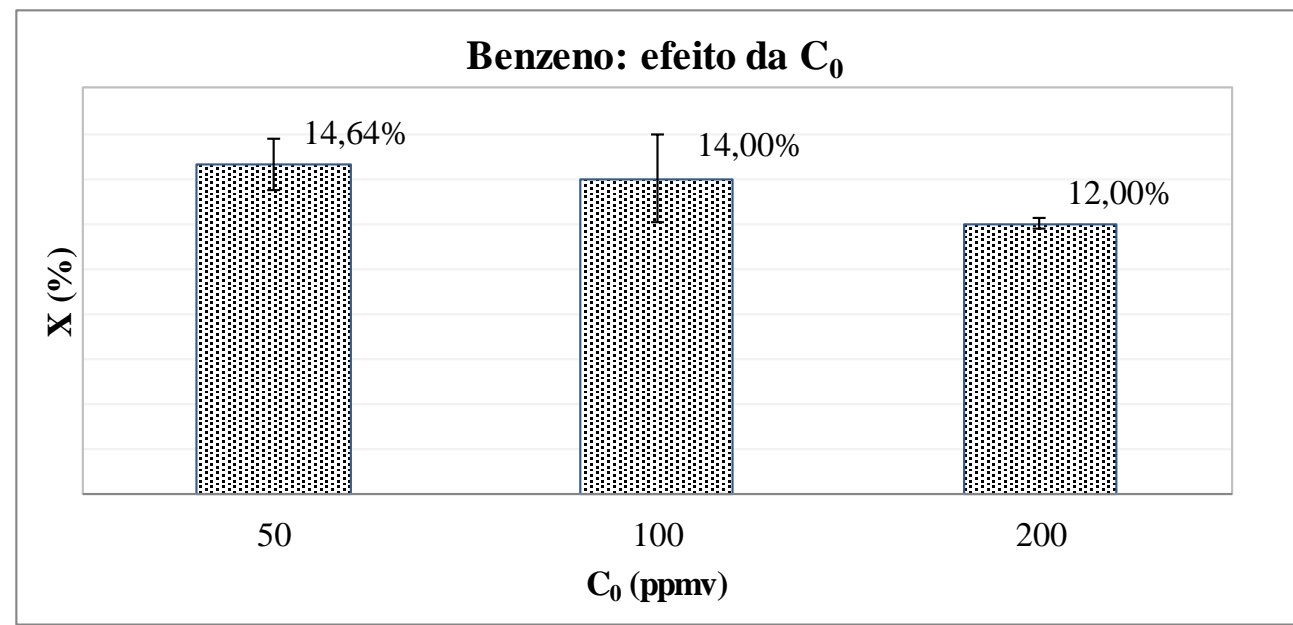

(A)

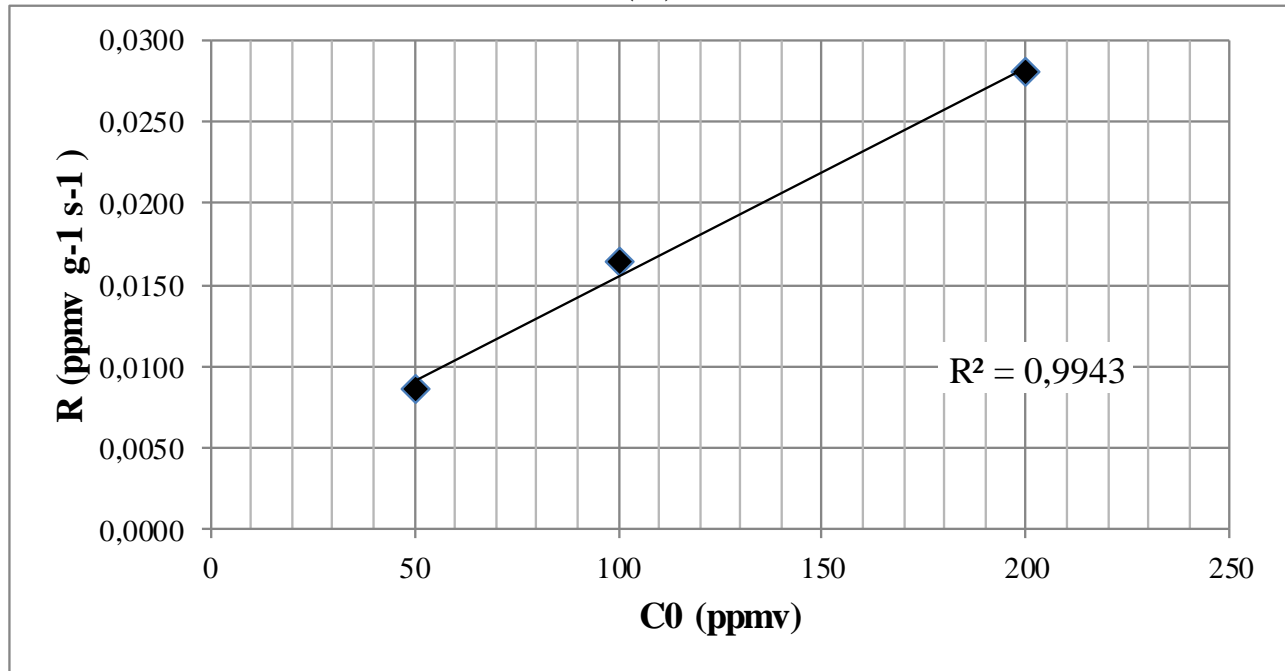

(B)

Figura 5.16 - Degradação fotocatalítica do benzeno: avaliação de diferentes concentrações de entrada. Condições de ensaio: $\mathrm{m}=200 \mathrm{~g}, \mathrm{Q}=15 \mathrm{~L} \mathrm{~min}^{-1}$, $\mathrm{UR}=50 \%$.

(Fonte: Relatório Fapesp, 2017)

\subsubsection{Degradação fotocatalítica do tolueno}

Para avaliar o desempenho do processo na degradação do tolueno, $100 \mathrm{~g}$ de catalisador novo foram utilizados, com vazão de $15 \mathrm{~L} \mathrm{~min}^{-1}$ e para concentrações de entrada de 50,100 e 200 ppmv de tolueno. Os resultados da degradação estão mostrados na Figura 5.17. O comportamento da velocidade de R (Figura 5.17(B)) se assemelha ao observado para o benzeno, apresentando, no entanto, valores inferiores, que indicam uma maior dificuldade de degradação fotocatalítica no caso do tolueno. Um comportamento inverso na comparação entre benzeno e tolueno foi publicado por Park et al. (2011). Ao fim da realização dos ensaios, houve uma notável mudança de cor do $\mathrm{TiO}_{2} / \mathrm{SiO}_{2}$ de branco para amarelo. O processo de extração com 
metanol e análise em CG/MS revelou que provavelmente o benzaldeído foi o responsável pela desativação.

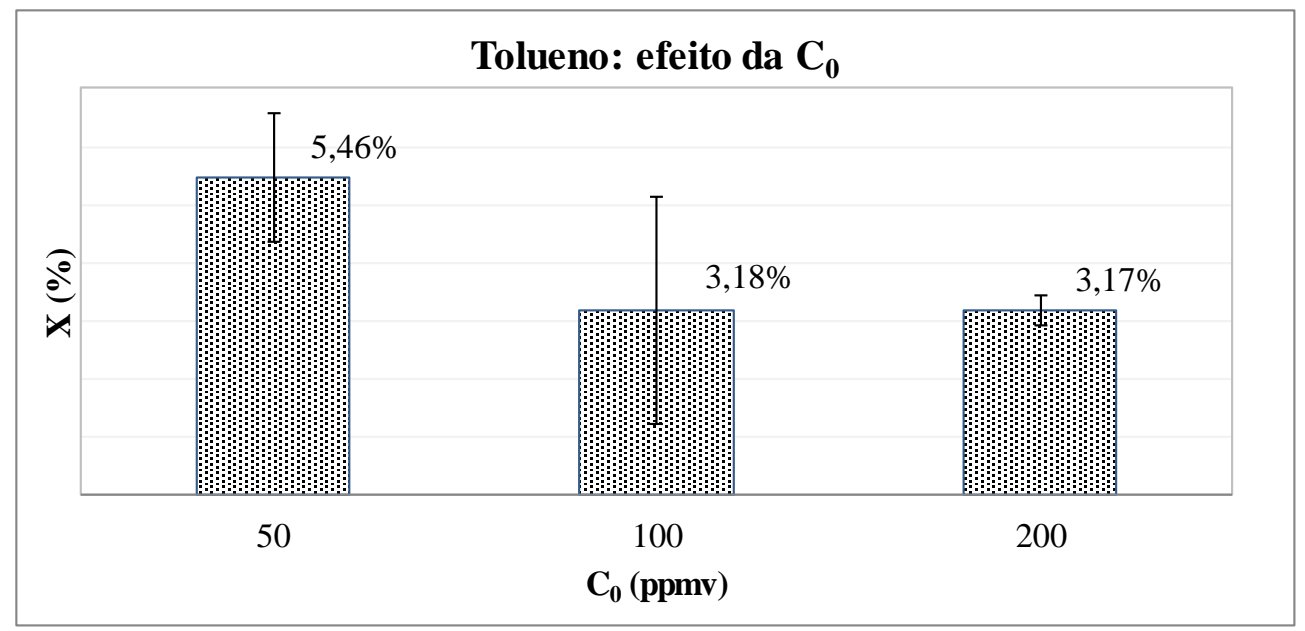

(A)

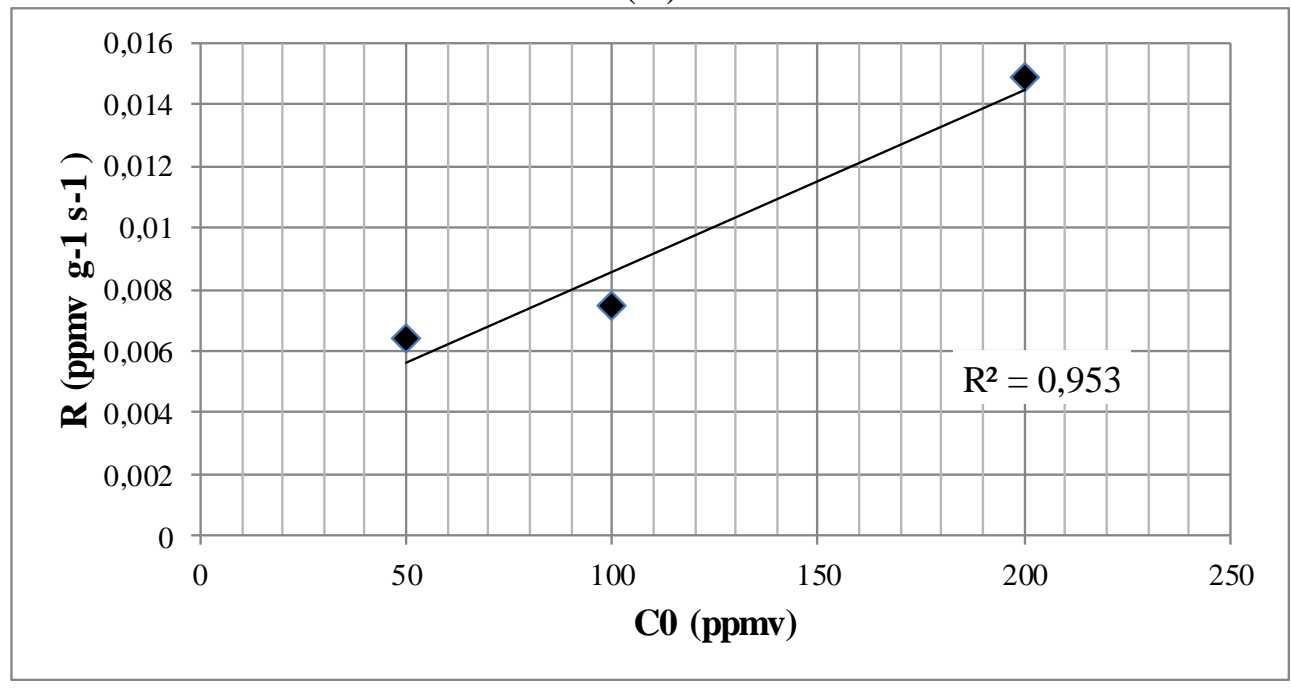

(B)

Figura 5.17 - Degradação fotocatalítica do tolueno: avaliação de diferentes concentrações de entrada. Condições de ensaio: $\mathrm{m}=100 \mathrm{~g}, \mathrm{Q}=15 \mathrm{~L} \mathrm{~min}^{-1}$, $\mathrm{UR}=50 \%$.

(Fonte: Relatório Fapesp, 2017)

\subsubsection{Degradação fotocatalítica de xilenos}

Para avaliar o desempenho do processo na degradação de xilenos, $100 \mathrm{~g}$ de catalisador novo foram utilizados na vazão de $15 \mathrm{~L} \mathrm{~min}^{-1}$ para concentrações de entrada de 50, 100 e 200 ppmv de uma mistura de isômeros deste composto, contendo o-, m-, p-xilenos e etil-benzeno. Os resultados estão mostrados na Figura 5.18 (A). O comportamento da velocidade R (Figura 5.18 (B)) se assemelha ao observado para os outros dois poluentes, apresentando, no entanto, valores bastante superiores, que indicam uma maior facilidade no tratamento dos xilenos. Este resultado concorda com o publicado por Park et al. (2011). Ao fim da realização dos ensaios, houve uma notável mudança de cor do $\mathrm{TiO}_{2} / \mathrm{SiO}_{2}$ de branco para amarelo. O processo de 
extração com metanol e análise em CG/MS revelou que o metil-benzaldeído foi o responsável pela desativação.

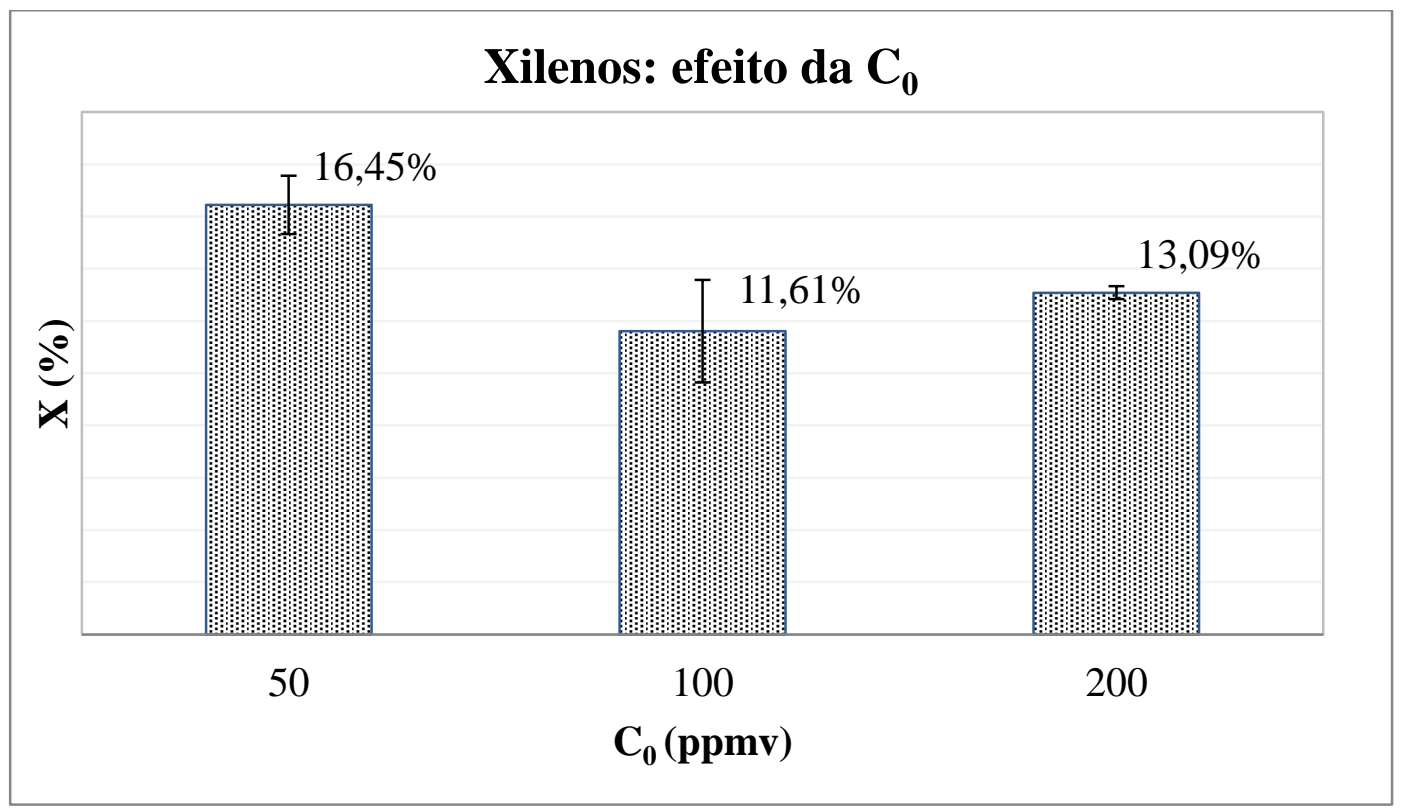

(A)

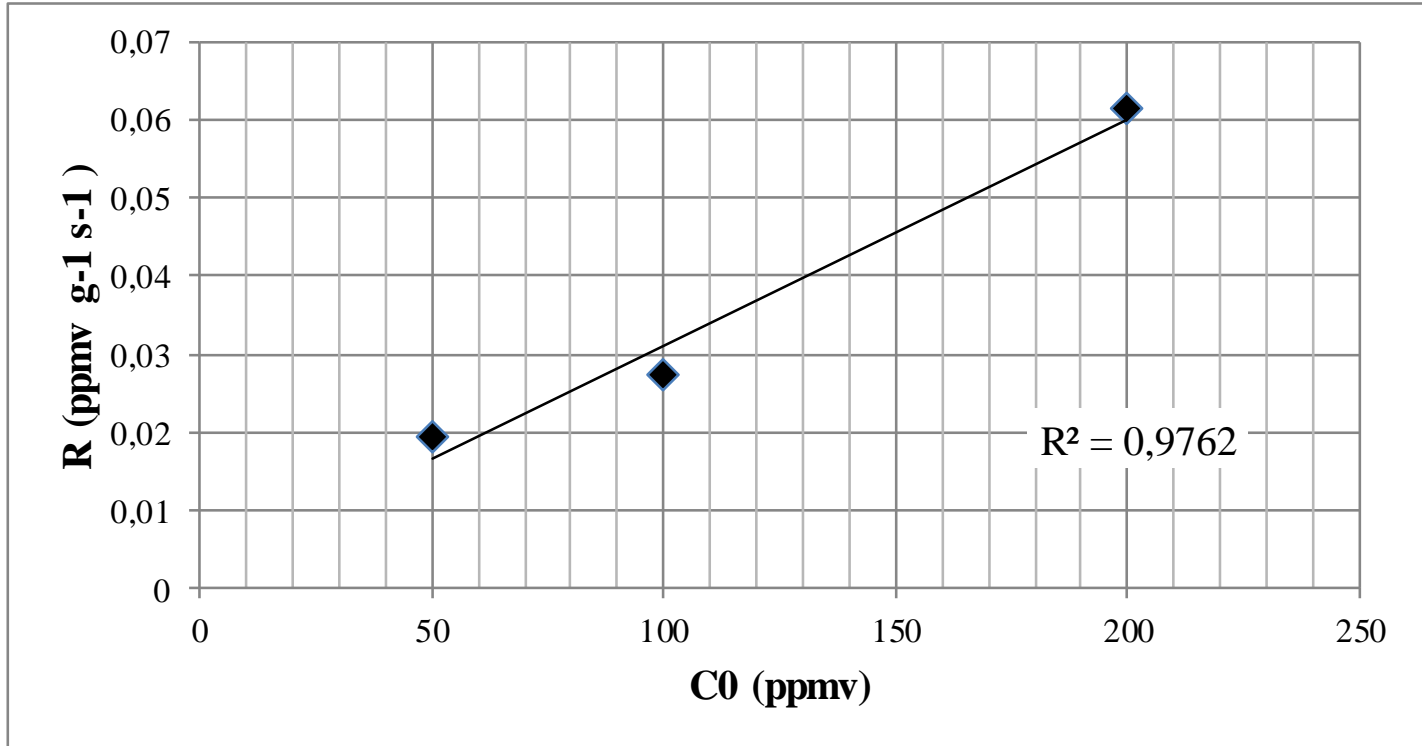

(B)

Figura 5.18 - Degradação fotocatalítica dos xilenos: avaliação de diferentes concentrações de entrada. Condições de ensaio: $\mathrm{m}=100 \mathrm{~g}, \mathrm{Q}=15 \mathrm{~L} \mathrm{~min}^{-1}, \mathrm{UR}=50 \%$.

(Fonte: Relatório Fapesp, 2017)

5.3.2.6 Degradação fotocatalítica de uma mistura BTX: teste para avaliação da desativação do catalisador

Um ensaio adicional de degradação de uma mistura de BTX foi realizado, tendo como objetivo verificar a seletividade do processo fotocatalítico quando utilizado na degradação destes compostos e o comportamento do processo ao longo do tempo, com especial interesse na desativação do $\mathrm{TiO}_{2} / \mathrm{SiO}_{2}$. As condições de teste foram de $100 \mathrm{~g}$ de $\mathrm{TiO}_{2} / \mathrm{SiO}_{2}$, com vazão 
de operação de $15 \mathrm{~L} \mathrm{~min}^{-1}$, com concentrações de entrada de 50, 25 e 20 ppmv de benzeno, tolueno e xilenos, respectivamente. A Figura 5.19 apresenta a razão entre a concentração de saída e a de entrada $\left(\mathrm{C} / \mathrm{C}_{0}\right)$ de cada um dos poluentes separadamente ao longo do ensaio. Durante as 4 horas iniciais de ensaio, o sistema entrou em equilíbrio de adsorção. O benzeno foi o primeiro a atingir o equilíbrio entre entrada e saída, seguido pelo tolueno e só então pelos xilenos, mostrando a maior afinidade pela adsorção dos xilenos na estrutura $\mathrm{TiO}_{2} / \mathrm{SiO}_{2}$. Assim que a lâmpada foi acionada, o sistema operou por duas horas e meia com degradação média $11,0 \%$ e $36,4 \%$ de tolueno e xilenos, respectivamente, praticamente não degradando benzeno. A partir da terceira hora de operação, o desempenho do processo começou a diminuir, provavelmente associado ao efeito de adsorção irreversível de intermediários na superfície $\mathrm{TiO}_{2} / \mathrm{SiO}_{2}$. Com 6 horas de operação, o catalisador foi praticamente todo desativado.

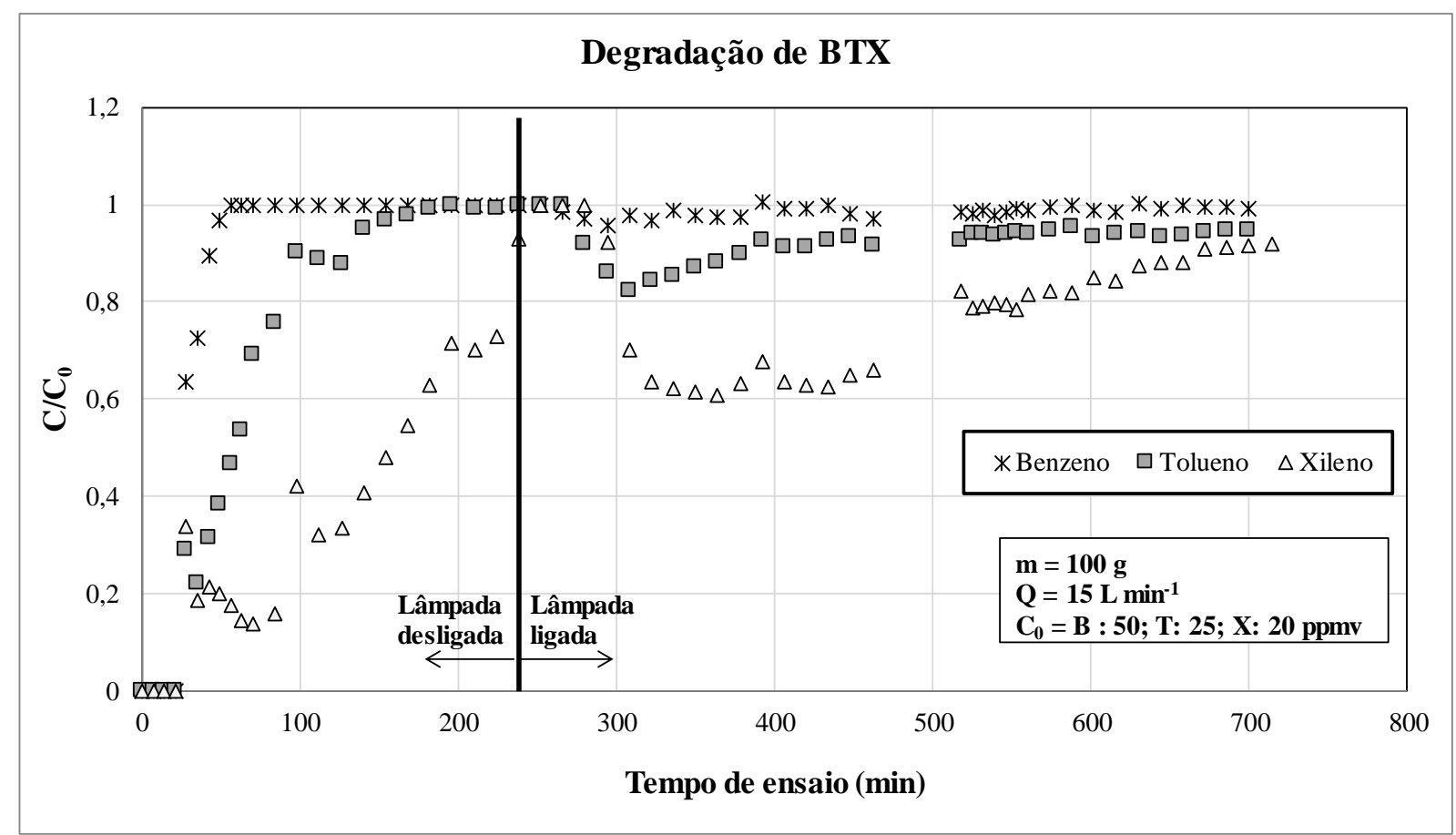

Figura 5.19 - Degradação fotocatalítica de uma mistura BTX: avaliação do tempo de operação antes da ocorrência de desativação do fotocatalisador pela deposição de espécies intermediárias. Teste realizado com $\mathrm{m}=100 \mathrm{~g}, \mathrm{Q}=15 \mathrm{~L} \mathrm{~min}^{-1}, \mathrm{C}_{0}=50 \mathrm{ppmv}$ de benzeno, 25 ppmv de tolueno e $20 \mathrm{ppmv}$ de xilenos, $\mathrm{UR}=50 \%$.

Nota-se que o catalisador apresenta um comportamento de adsorção preferencial pelo benzeno, conforme relatado pela literatura (KOROLOGOS et al., 2012).Este tipo de experimento não foi feito para o poluente modelo, n-hexano, pois não observamos o comportamento de desativação do catalisador para este poluente. 


\subsection{REGENERAÇÃO DO CATALISADOR}

Considerando-se a dinâmica de inativação do catalisador para estes poluentes, concluiuse que a recuperação do catalisador, por um procedimento sem necessidade de sua retirada do reator, é essencial para a aplicabilidade deste processo. Então, os sólidos desativados no ensaio descrito na Item 5.3.2.6 (Degradação fotocatalítica de uma mistura BTX: teste para avaliação da desativação do catalisador) foram submetidos a um processo de regeneração com ar úmido limpo (isento de poluentes) e radiação da lâmpada UV-C. O reator operou com vazão de $15 \mathrm{~L}$ $\min ^{-1}$ durante 12 horas. As amostras do sólido foram analisadas por TGA antes e depois do processo de regeneração, com o intuito de quantificar o carbono orgânico superficial. $\mathrm{O}$ resultado está mostrado na Tabela 5.3, indicando que o fotocatalisador teve uma regeneração parcial de 55\%. Isso mostra que a técnica de regeneração é viável.

Tabela 5.3 - Análise TGA do fotocatalisador novo, degradado e após do processo de regeneração. (Fonte: Relatório FAPESP, 2017)

\begin{tabular}{cc}
\hline Fotocatalisador & $\begin{array}{c}\text { Variação de massa da amostra com exposição a ar } \\
\text { sintético a } 950^{\circ} \mathbf{C}(\boldsymbol{\%})\end{array}$ \\
\hline $\mathrm{TiO}_{2} / \mathrm{SiO}_{2}$ novo & 7,9 \\
$\mathrm{TiO}_{2} / \mathrm{SiO}_{2}$ desativado & 11,1 \\
$\mathrm{TiO}_{2} / \mathrm{SiO}_{2}$ regenerado & 9,5 \\
\hline
\end{tabular}

\subsection{ASPECTOS OPERACIONAIS DO REATOR}

Ao se operar o reator por longos tempos há uma considerável perda de sólidos na exaustão do ciclone. Essa perda ocorre devido à abrasão e quebra de partículas, característica de leitos fluidizados, junto à incapacidade do ciclone de coletar as partículas mais finas.

A perda de sólidos foi quantificada durante o ensaio de degradação da mistura BTX. Como mostrado na Figura 4.2, um coletor de sólidos (recipiente de choque e redução de velocidade) após o ciclone foi utilizado para coletar parte das partículas perdidas na saída do reator. Além disto, a massa de catalisador restante no leito ao final do ensaio foi pesada, de modo a quantificar a perda total de sólidos. Ao final de 12 horas do ensaio iniciado com $100 \mathrm{~g}$ de sólidos no leito, operando-se com uma vazão constante de $15 \mathrm{~L} \mathrm{~min}^{-1}$, restaram 75,5 g de sólidos no leito, que resulta em uma taxa de perda de sólidos de 2,04 $\mathrm{g} \mathrm{h}^{-1}$. Deste total, 13,7 $\mathrm{g}$ foram recuperados no coletor, sugerindo que poderiam ser recuperados durante a operação pela melhoria ou instalação de outro ciclone. Os outros 10,8 g perdidos estão associados a um processo de abrasão e geração de finos, cuja taxa de perda estimada foi de $0,9 \mathrm{~g} \mathrm{~h}^{-1}$. 
Estes resultados sugerem a necessidade de melhoria na resistência dos catalisadores sintetizados ao processo de abrasão e a necessidade de aperfeiçoamento do sistema de coleta de sólidos, possibilitando que se trabalhe com maiores quantidades de massa no leito e de vazão de gás sem que haja um aumento considerável na taxa de perda de sólidos do leito.

\subsection{ENSAIOS EXPERIMENTAIS DE DEGRADAÇÃO DE POLUENTE MODELO}

Os ensaios experimentais para o $\mathrm{n}$-hexano foram executados conforme descrito no item 4.8.3. Para o Setup 1, pode-se ver uma foto durante a operação na Figura 5.20.

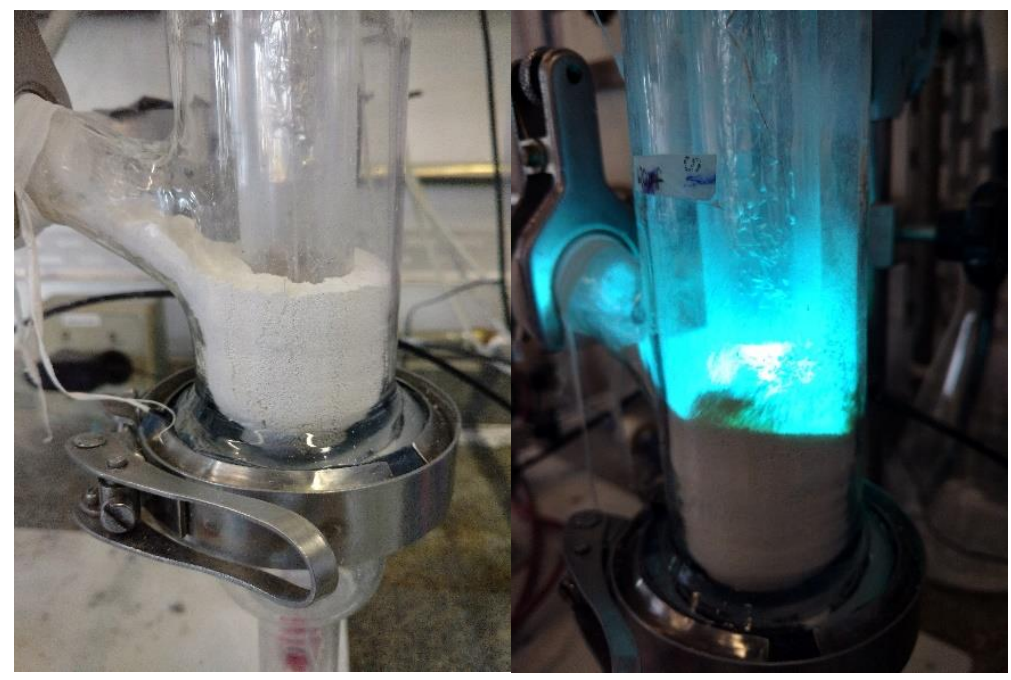

Figura 5.20 - Reator para os experimentos do poluente modelo n-hexano - Setup 1.

(Fonte: O autor, 2018)

A partir das amostras da entrada e da saída do reator, a porcentagem de degradação do poluente foi calculada pela equação 5.3:

$$
X(\%)=\frac{C_{B T E X e n t r a d a}-C_{B T E X s a i ́ d a}}{C_{B T E X e n t r a d a}} \times 100 \%
$$

(Equação 5.3)

\subsubsection{Planejamento Experimental}

Os experimentos foram realizados em dois Setup e três etapas:

- Setup 1: as variáveis estudadas foram: concentração de entrada do reator $\left(C_{0}, 12\right.$ concentrações diferentes), vazão de gás $\left(Q, 10 \mathrm{~L} \mathrm{~min}^{-1}\right)$ e massa de catalisador $(m$, $100 \mathrm{~g}$ ), para um poluente: n-hexano.

- Setup 2: as variáveis estudadas foram: concentração de entrada do reator $\left(C_{0}, 10\right.$ concentrações diferentes), vazão de gás $\left(Q, 10 \mathrm{~L} \mathrm{~min}^{-1}\right)$ e massa de catalisador $(m$, $100 \mathrm{~g}$ ), para um poluente: n-hexano. 
- Setup 2 e ensaios de degradação fotocatalítica: estes ensaios foram executados com o intuito de validação do modelo cinético construído a partir dos experimentos anteriores. As variáveis estudadas foram: concentração de entrada do reator $\left(C_{0}, 6\right.$ concentrações diferentes), vazão de gás $\left(Q, 5,7,5,10\right.$ e $\left.15 \mathrm{~L} \mathrm{~min}^{-1}\right)$ e massa de catalisador ( $m, 100$ e $200 \mathrm{~g}$ ), para um poluente: n-hexano.

\subsubsection{Resultados Experimentais}

\subsubsection{Velocidade mínima de fluidização}

Após a estabilização da pressão no leito e a formação dos aglomerados esféricos, a velocidade mínima de fluidização pode ser determinada para o fotocatalisador comercial pela curva de perda de carga em função da vazão volumétrica, como mostrado na Figura 5.21. A queda de pressão no leito atinge seu valor máximo para a vazão volumétrica de 5,0 L.min ${ }^{-1}$, o que resulta em uma velocidade mínima de fluidização de $6,6 \mathrm{~cm} \cdot \mathrm{s}^{-1}$.

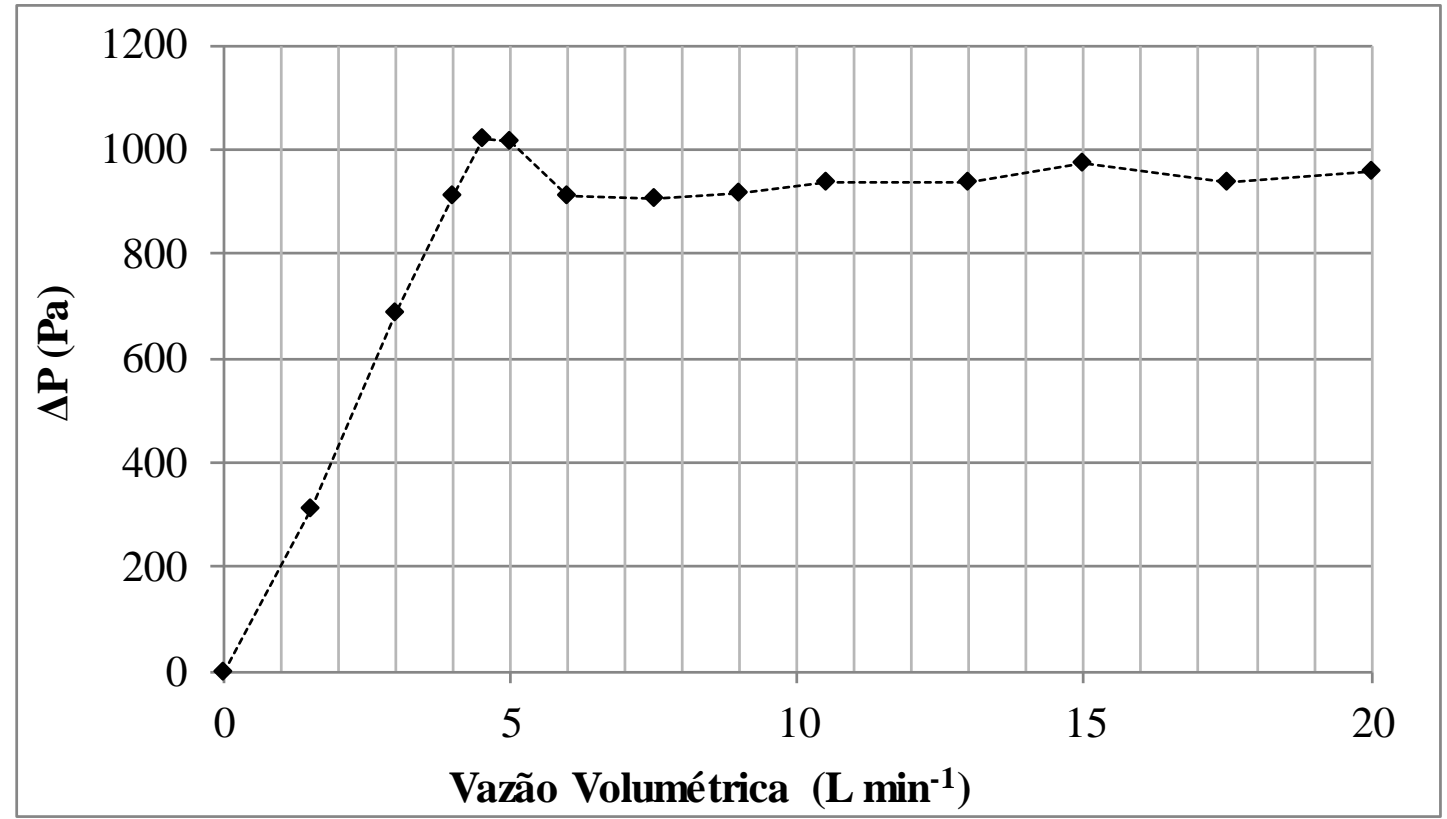

Figura 5.21 - Queda de pressão no leito em função da vazão volumétrica de gás para o catalisador $\mathrm{TiO}_{2}$ comercial.

(Fonte: O autor, 2018)

\subsubsection{Fotólise do n-hexano}

A degradação n-hexano pela ação da radiação luminosa ultravioleta $(\lambda=254 \mathrm{~nm})$ foi avaliada no reator sem sólidos para o intervalo de vazões de $2,5 \mathrm{~L} \mathrm{~min}^{-1}$ a $10 \mathrm{~L} \mathrm{~min}^{-1}$, que representaram tempos de residência no volume irradiado respectivamente de $25,8 \mathrm{~s}$ e $6,5 \mathrm{~s}$. Os 
resultados para uma corrente de ar contaminado com concentração de entrada $\left(\mathrm{C}_{0}\right)$ de 171 ppmv é mostrado na Figura 5.22. Nota-se que, dentro do erro experimental, observou-se degradação por fotólise apenas para o maior tempo de residência de 25,8s. Para os tempos de residência menores, a fotólise pode ser desconsiderada.

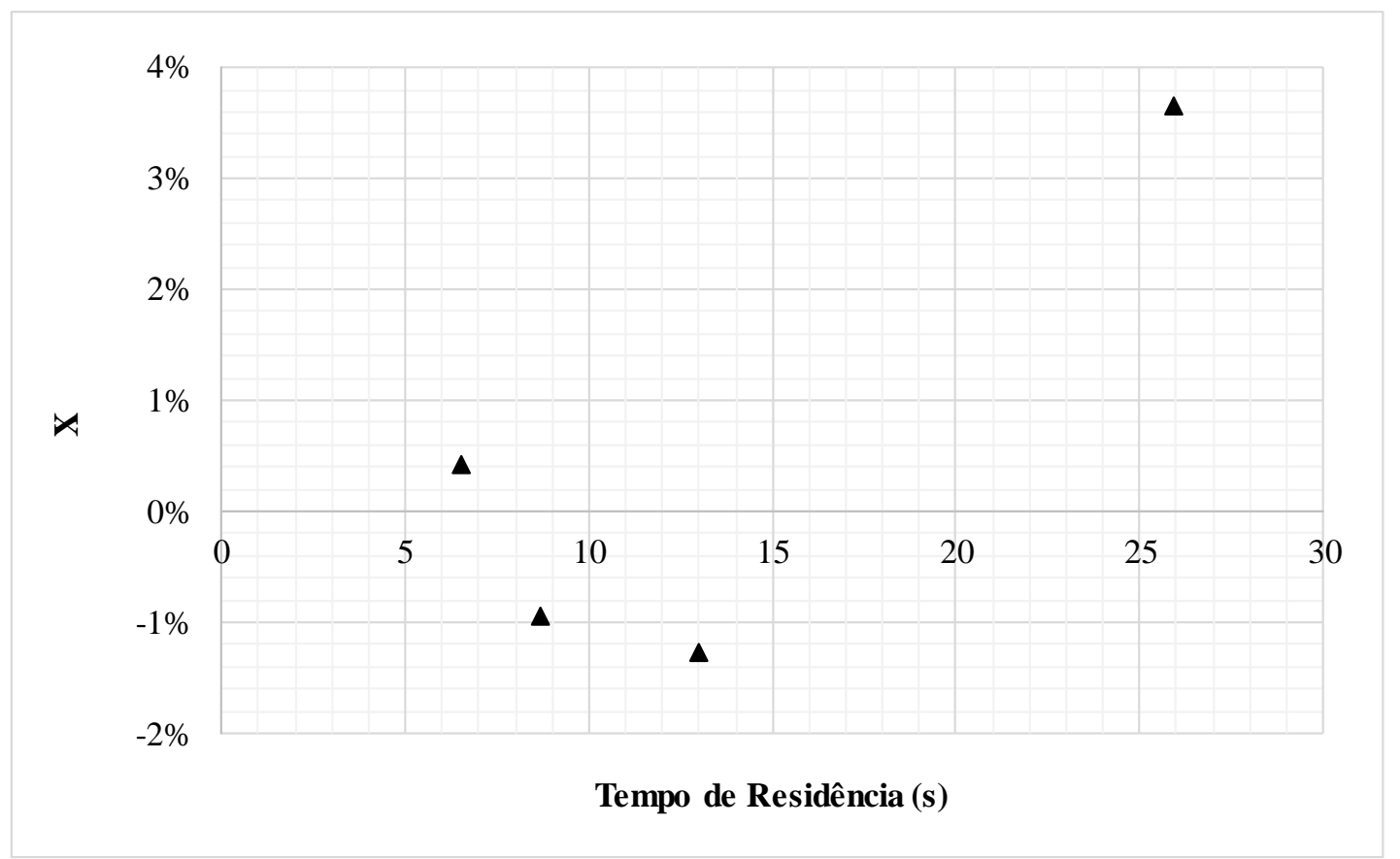

Figura 5.22 - Degradação do n-hexano no reator devido à fotólise por radiação luminosa $(\lambda=$ $254 \mathrm{~nm}$ e $\left.[\mathrm{C}]_{0}=171 \pm 14 \mathrm{ppmv}\right)$.

(Fonte: $\mathrm{O}$ autor, 2018)

5.6.2.3 Degradação fotocatalítica do n-hexano

Durante o estudo da degradação fotocatalítica do n-hexano, o regime operacional do reator foi do tipo leito fluidizado diferencial, considerando-se que as conversões foram menores que $15 \%$, para obtenção da cinética de reação do poluente modelo. O reator foi alimentado com massa (m) de catalisador de $100 \mathrm{~g}$ e a vazão (Q) de $10 \mathrm{~L} \mathrm{~min}^{-1}$.

A porcentagem de conversão do n-hexano foi definida conforme a ( Equação 5.4), na qual $[C]_{0}$ e $[C]$ representam, respectivamente, as concentrações de entrada e saída do reator na condição de estado estacionário.

$$
X=\frac{[C]_{0}-[C]}{[C]_{0}} \quad x 100 \%
$$

( Equação 5.4) 
Foram analisados dois cenários: Setup 1, onde a lâmpada foi parcialmente coberta, sendo a irradiação apenas na região densa, e o Setup 2, com a lâmpada totalmente descoberta e irradiando para todo o reator, incluindo a região densa e a região diluída.

A influência da concentração de n-hexano, na entrada do reator, na degradação fotocatalítica operando-se com a lâmpada parcialmente coberta, conforme o Setup 1, está mostrado na Figura 5.23.

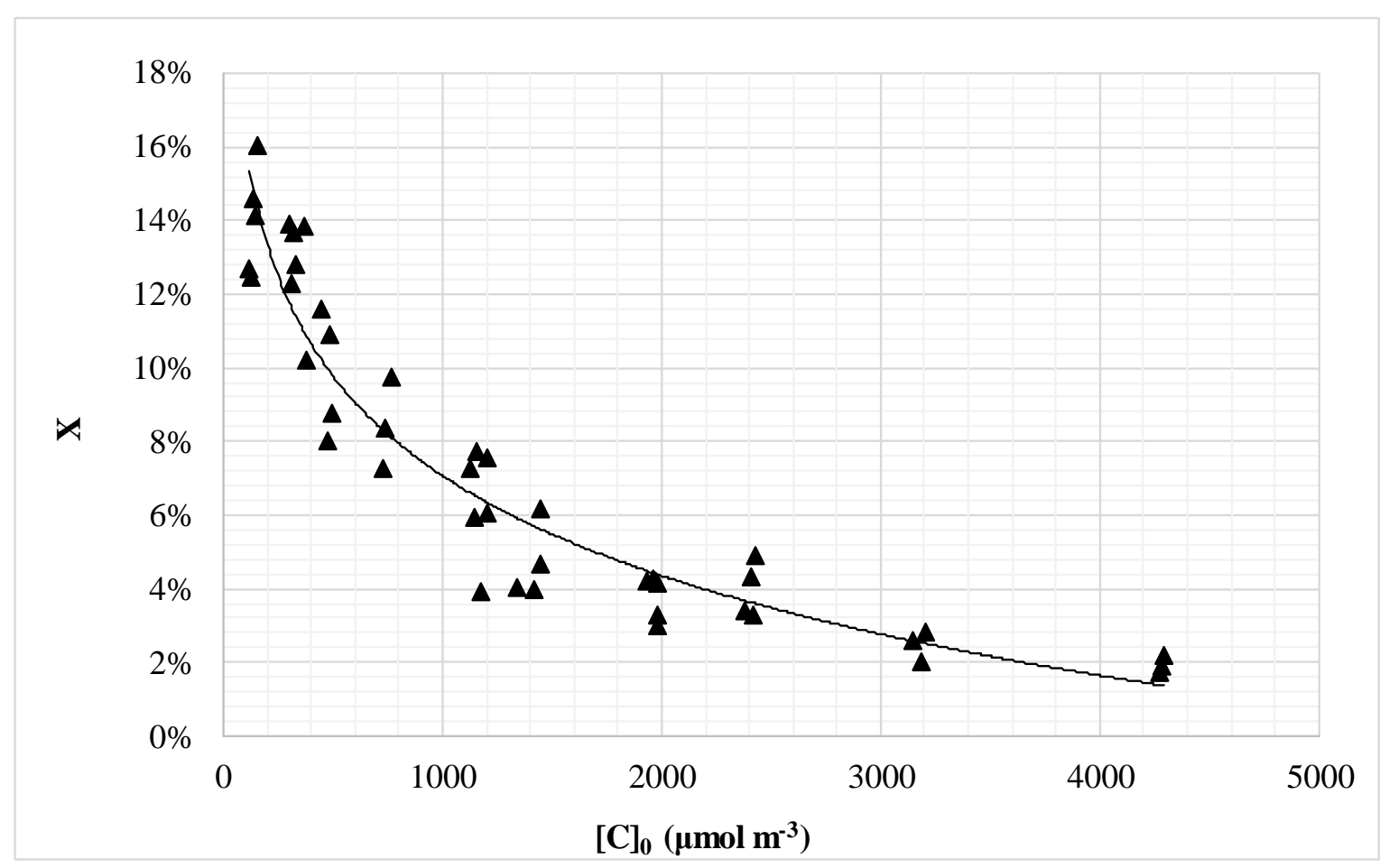

Figura 5.23 - Degradação fotocatalítica do n-hexano em função da concentração de entrada nas seguintes condições: lâmpada parcialmente coberta, $100 \mathrm{~g}\left(\mathrm{TiO}_{2}\right.$ comercial) e UR $=50 \%$ (Fonte: $\mathrm{O}$ autor, 2018)

O cenário Setup 2 de experimentos foi executado operando-se com o reator alimentado com massa (m) de catalisador de $100 \mathrm{~g}$, vazão (Q) de $10 \mathrm{~L} \mathrm{~min}^{-1}$ e a lâmpada totalmente descoberta. Os resultados da porcentagem de degradação somente na região diluída em função da concentração de entrada nesta região pode ser visto na Figura 5.24 


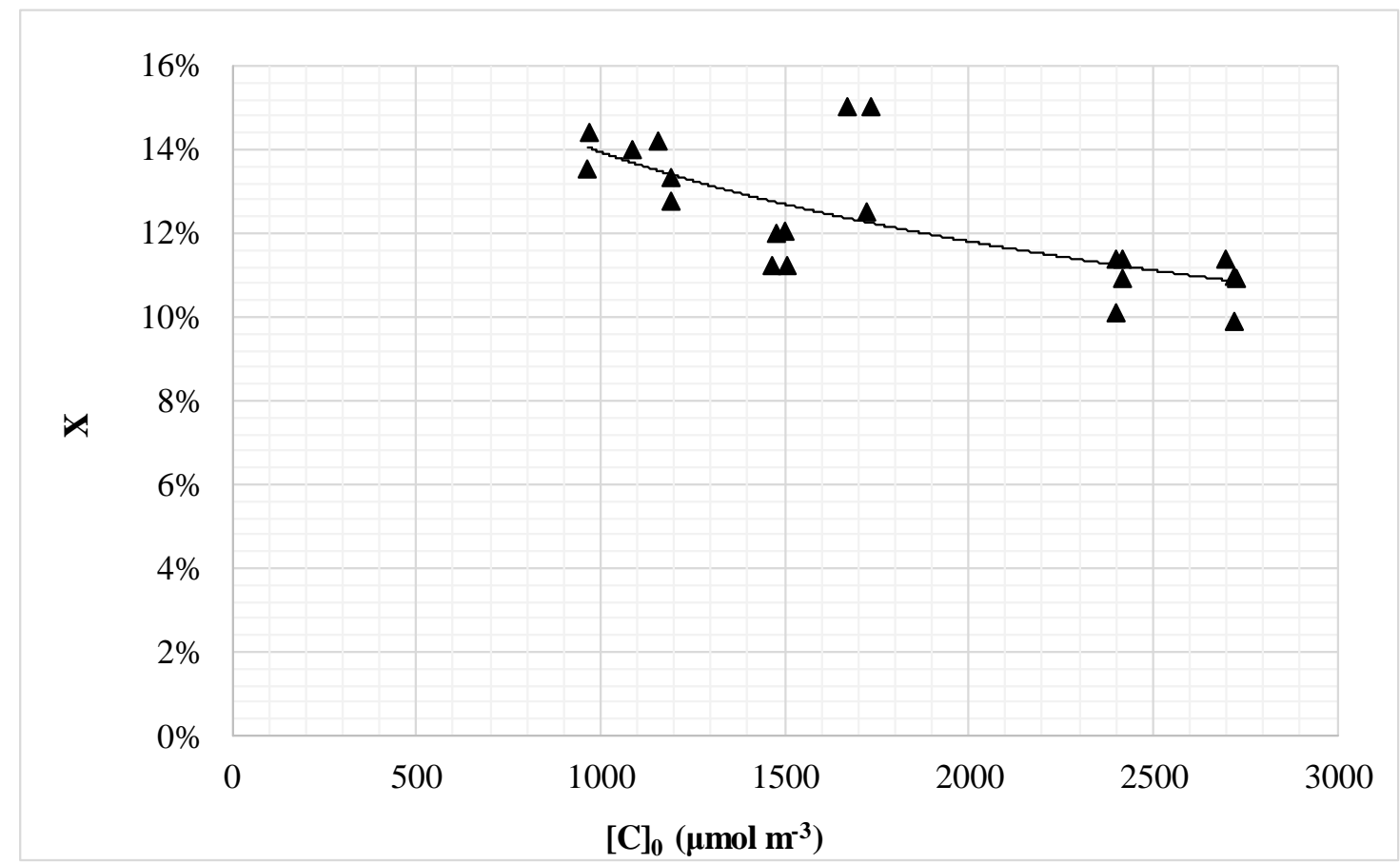

Figura 5.24 - Degradação fotocatalítica do n-hexano em função da concentração de entrada na região diluída, nas seguintes condições: lâmpada descoberta, $100 \mathrm{~g}\left(\mathrm{TiO}_{2}\right.$ comercial) e UR $=50 \%$.

(Fonte: $\mathrm{O}$ autor, 2018)

Com o aumento da concentração de entrada, observa-se um decréscimo na conversão. Este comportamento já foi discutido na literatura, caracterizando a reação e a adsorção em baixas concentrações de poluente, com comportamento próximo ao de primeira ordem (Prieto, Fermoso e Irusta, 2007).

Avaliou-se o efeito da cobertura da lâmpada no desempenho do reator diferencial na condição de $10 \mathrm{~L} \mathrm{~min}^{-1}$ e $100 \mathrm{~g}_{\text {de }} \mathrm{TiO}_{2}$ comercial, de modo a obter os valores de taxa de degradação $\mathrm{R}\left(\mu \mathrm{mol} \mathrm{m} \mathrm{m}^{-3} \mathrm{~s}^{-1}\right.$ ) para o n-hexano de acordo com a equação 5.5. O resultado é mostrado na Figura 5.25.

$$
\mathrm{R}=\frac{Q}{V}\left([C]_{0}-[C]\right)
$$




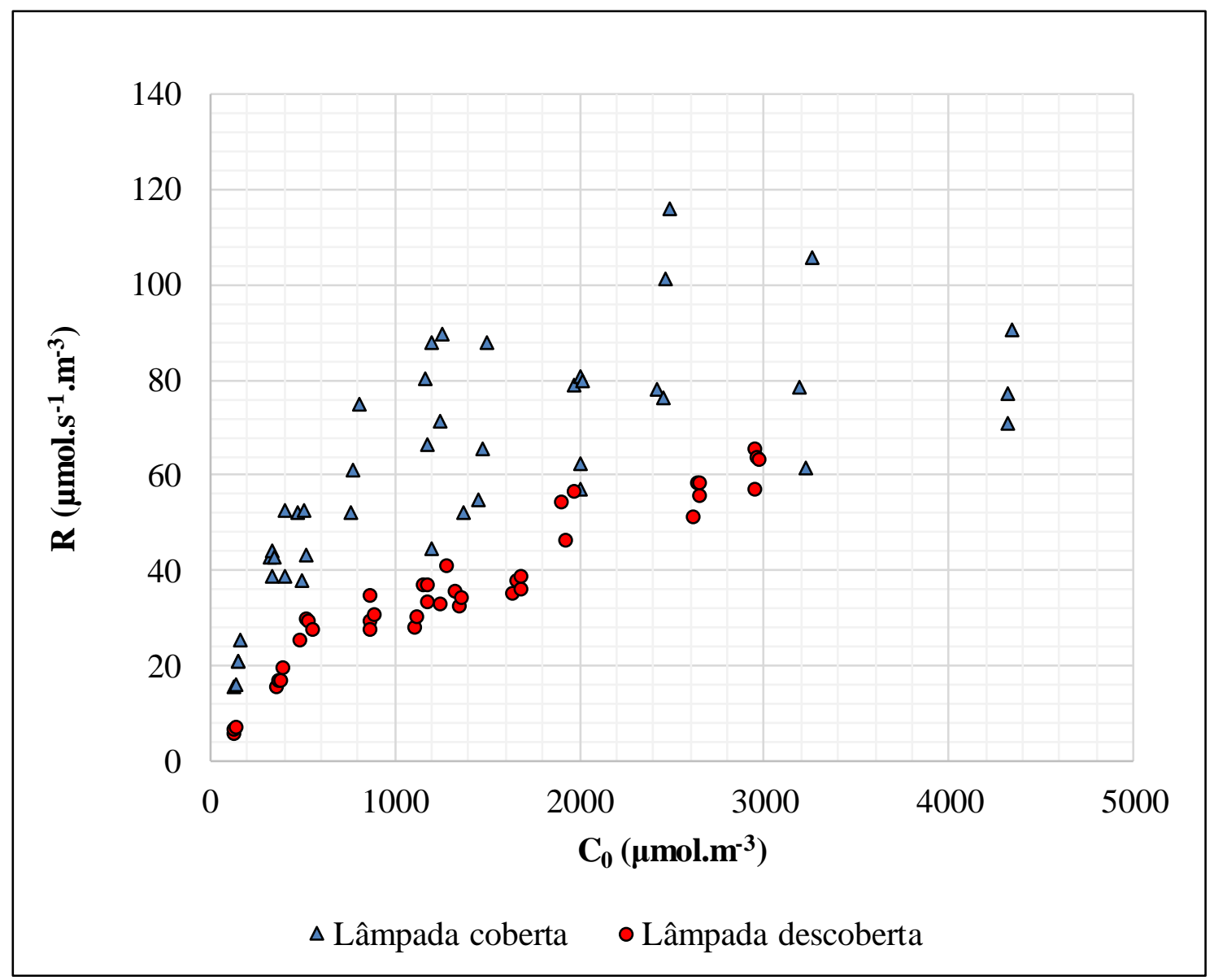

Figura 5.25 - Degradação fotocatalítica do n-hexano: Efeito da cobertura da lâmpada com $100 \mathrm{~g}\left(\mathrm{TiO}_{2}\right.$ comercial $)$ e UR $=50 \%$.

(Fonte: O autor, 2018)

Com o aumento da área irradiada, observa-se um aumento na conversão para a mesma concentração inicial, porém um decréscimo da taxa de reação R. Este comportamento mostra que a maior parte da reação ocorre no leito fluidizado do que na parte diluída do reator, apresentando dois comportamentos distintos descritos no item 2.6. A região diluída do reator pode ser visualizada na Figura 5.26.

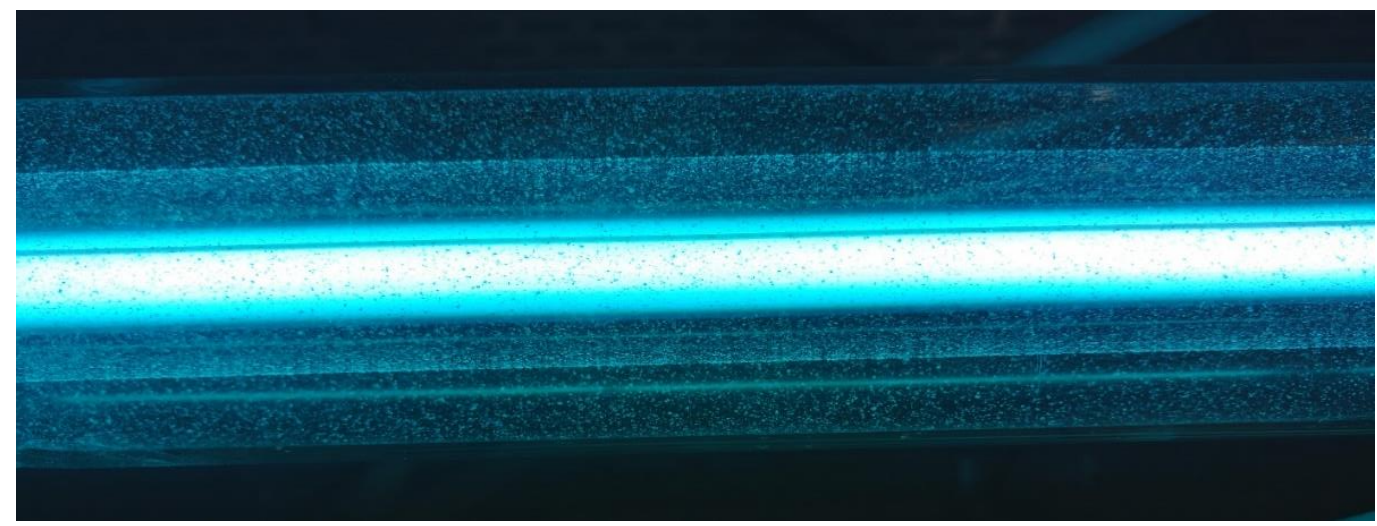

Figura 5.26 - Quantidade de partículas de TiO2 na região diluída do reator. (Fonte: O autor, 2018) 


\section{CAPÍTULO 6. RESULTADOS DA MODELAGEM MATEMÁTICA E SIMULAÇÃO COMPUTACIONAL DO REATOR FOTOQUÍMICO}

\subsection{MODELAGEM DA CINÉTICA DA REAÇÃO DO POLUENTE MODELO - ABORDAGEM LANGMUIR-HINSHELWOOD}

A partir da análise da literatura do item 2.6, considerou-se para a modelagem do poluente modelo, n-hexano, que a reação química a ser estudada será a mineralização do nhexano para a formação de produtos intermediários e depois de dióxido de carbono e água, sem a geração de qualquer orgânico intermediário, ou seja:

$$
\mathrm{C}_{6} \mathrm{H}_{14}+9.5 \mathrm{O}_{2} \rightarrow \text { produtos intermediários } \rightarrow 6 \mathrm{CO}_{2}+7 \mathrm{H}_{2} \mathrm{O}
$$

( Equação 6.1)

Para a parametrização dos modelos cinéticos, a vazão volumétrica $(Q)$, concentração de entrada $\left([C]_{0}\right)$ e massa de catalisador $(m)$ foram ajustadas e selecionadas de forma que as conversões fossem baixas o suficiente $(<15 \%)$ e, assim, a hipótese de reator diferencial pudesse ser considerada ( Equação 6.2). Como [C]o e $[C]$ não diferem muito, o comportamento cinético do tipo Langmuir-Hinshelwood pode ser ajustado pela concentração média do poluente $[\bar{C}]($ Equação 6.3) (DASHLIBORUN et al., 2013).

$$
\begin{gathered}
R_{\text {região }}=\frac{Q \cdot\left([C]_{0}-[C]\right)}{V_{\text {região }}} \\
R_{\text {região }}=\frac{k_{1, \text { região }[\bar{C}]}}{1+k_{2, \text { região } o}[\bar{C}]}
\end{gathered}
$$

( Equação 6.3)

Os experimentos do Setup 1 foram utilizados para obtenção dos parâmetros k1,densa e $\mathrm{k} 2$,densa associados a região densa do leito, considerando Vregião $=$ Vdensa, ou seja, somente o volume irradiado da região densa, e [C] como a concentração medida na saída do reator, conforme a Figura 6.1. Adicionalmente, dados experimentais obtidos pela configuração Setup 2 foram usados para estimar a cinética da região diluída através do seguinte procedimento: [C]0 foi usada na ( Equação 6.2) e na ( Equação 6.3) juntamente com os valores paramétricos da região densa k1,densa e k2,densa para obtenção de uma estimativa de uma concentração intermediária no limiar das duas regiões, $[\mathrm{C}]=[\mathrm{C}]$ limiar, conforme a Figura 6.2. 


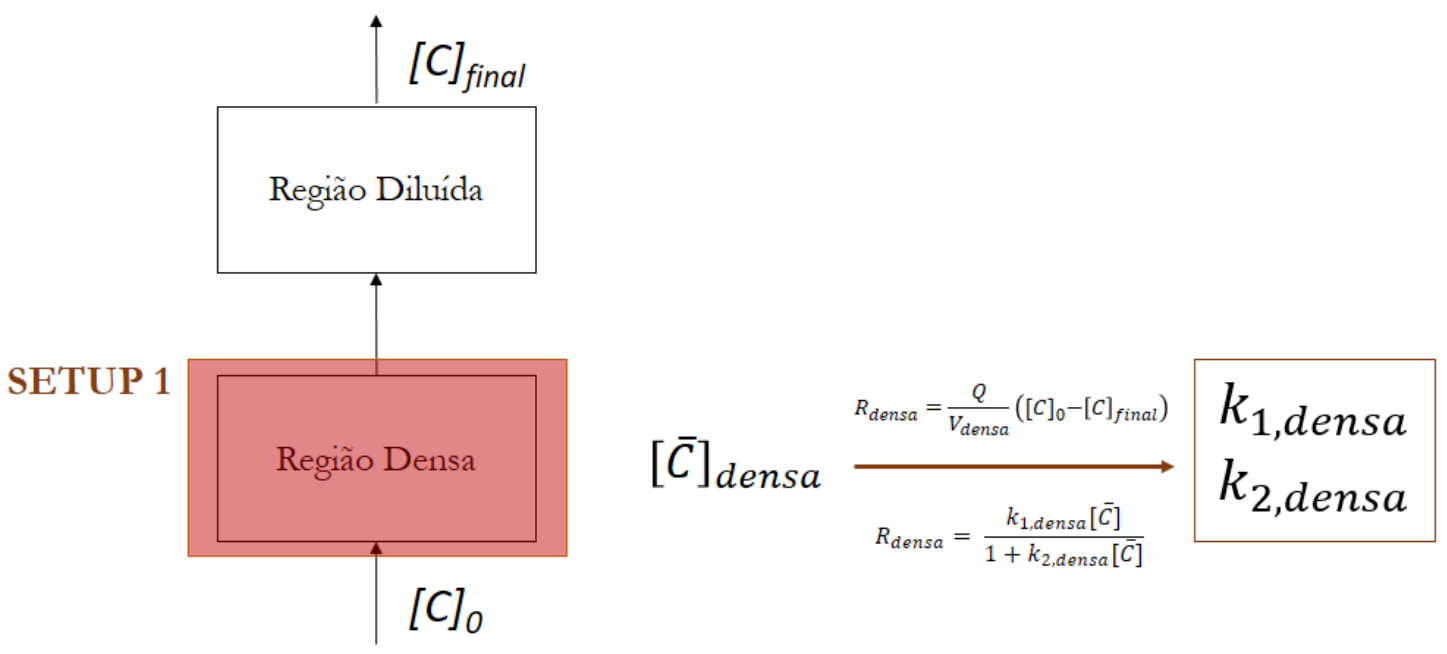

Figura 6.1 - Esquema da Modelagem Cinética - Setup 1.

(Fonte: O autor, 2019)

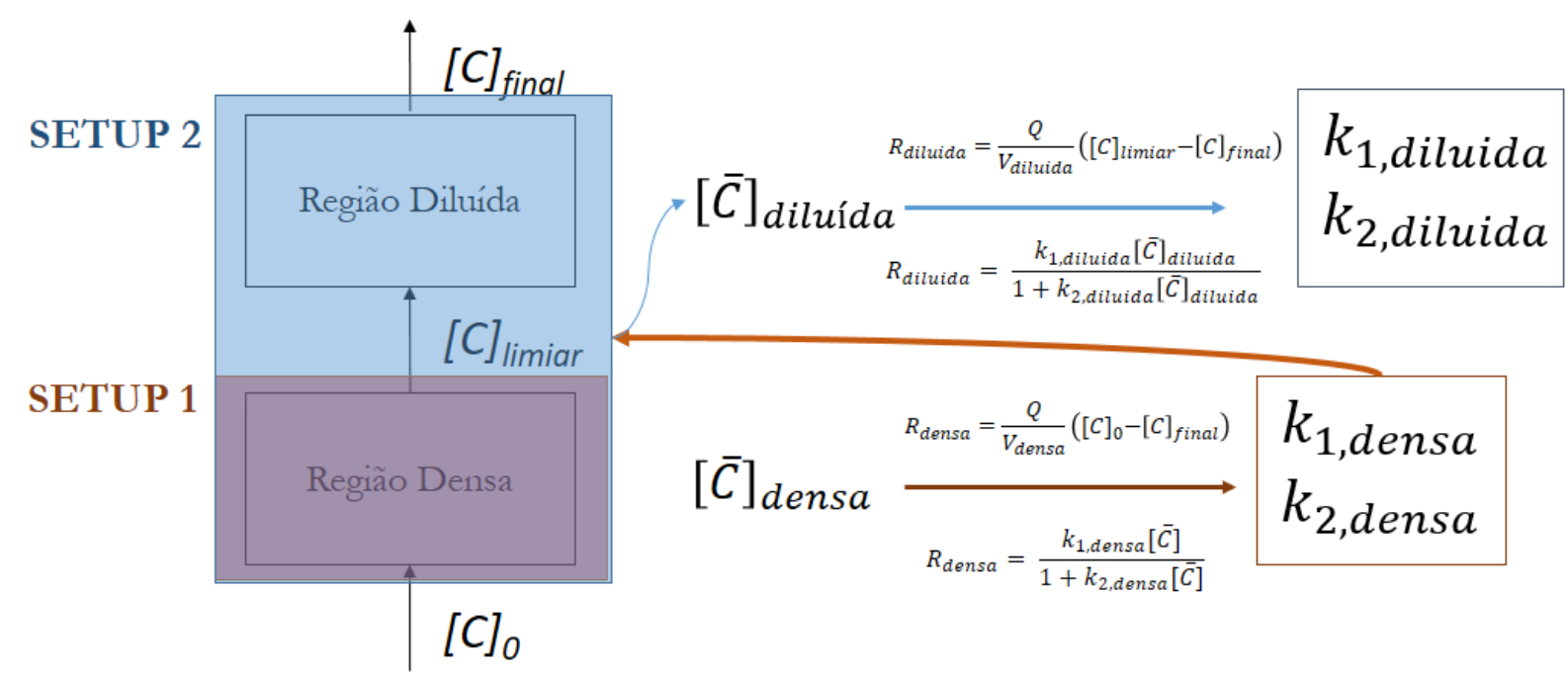

Figura 6.2 - Esquema da Modelagem Cinética - Setup 2.

(Fonte: O autor, 2019)

Após esse procedimento, a ( Equação 6.2) e a ( Equação 6.3) foram aplicadas, porém para $V_{\text {região }}=V_{\text {diluida }}$, considerando somente o volume da região diluída, $[C]_{0}=[C]_{\text {limiar }}$ e $[C]$ como a concentração medida na saída do reator. Então, esse dados também foram linearizados para calcular o $k_{1, \text { diluida }}$ e $k_{2 \text {, diluída. }}$

Após a definição dos parâmetros cinéticos, novos experimentos foram realizados utilizando o Setup 2 de forma a validar o modelo acoplando as duas regiões. O modelo proposto assumiu as diferentes regiões como dois reatores em série, considerando que a hidrodinâmica da região densa pudesse ser tratada como um reator de mistura perfeita (CSTR) e a região diluída como um reator plug-flow (PFR), ambos acoplados com a cinética LH obtida 
anteriormente. As simulações destes modelos foram resolvidas pela aplicação da rotina não linear de gradiente reduzido generalizada (GRG) em Microsoft Excel.

\subsubsection{Determinação dos parâmetros cinéticos}

As condições experimentais utilizadas para a determinação dos parâmetros cinéticos descritos anteriormente podem ser visualizadas na Tabela 6.1. Estas condições foram utilizadas para o Setup 1 e Setup 2.

Tabela 6.1 - Condições experimentais. (Fonte: O autor, 2018)

\begin{tabular}{lcc}
\hline Condição Experimental & Valor & Unidade \\
\hline Massa de catalisador, $m$ & 0,1 & $\mathrm{~kg}$ \\
Vazão volumétrica, $Q$ & $1,67.10^{-4}$ & $\mathrm{~m}^{3} \cdot \mathrm{s}^{-1}$ \\
{$[C]_{0}$ n-hexano } & $100-4200$ & $\mu \mathrm{mol} \mathrm{m}^{-3}$ \\
Fluxo de fótons & $1,05 \times 10^{-4}$ & Einstein s \\
Volume da região densa, $V_{\text {densa }}$ & $1,76.10^{-4}$ & $\mathrm{~m}^{3}$ \\
Volume da região diluída, $V_{\text {diluída }}$ & $8,29.10^{-4}$ & $\mathrm{~m}^{3}$ \\
\hline
\end{tabular}

Como descrito anteriormente, o Setup 1 foi utilizado para obtenção dos parâmetros para o leito fluidizado da região densa. De acordo com a ( Equação 6.2) e a ( Equação 6.3) , a regressão linear $\mathrm{R}^{-1} \times\left[\mathrm{C}_{0}{ }^{-1}\right.$ foi usada para obter $k_{1, \text { densa }}$ e $k_{2, \text { densa }}$ como mostrado na Figura 6.3. Os parâmetros obtidos podem ser visualizados na Tabela 6.2.

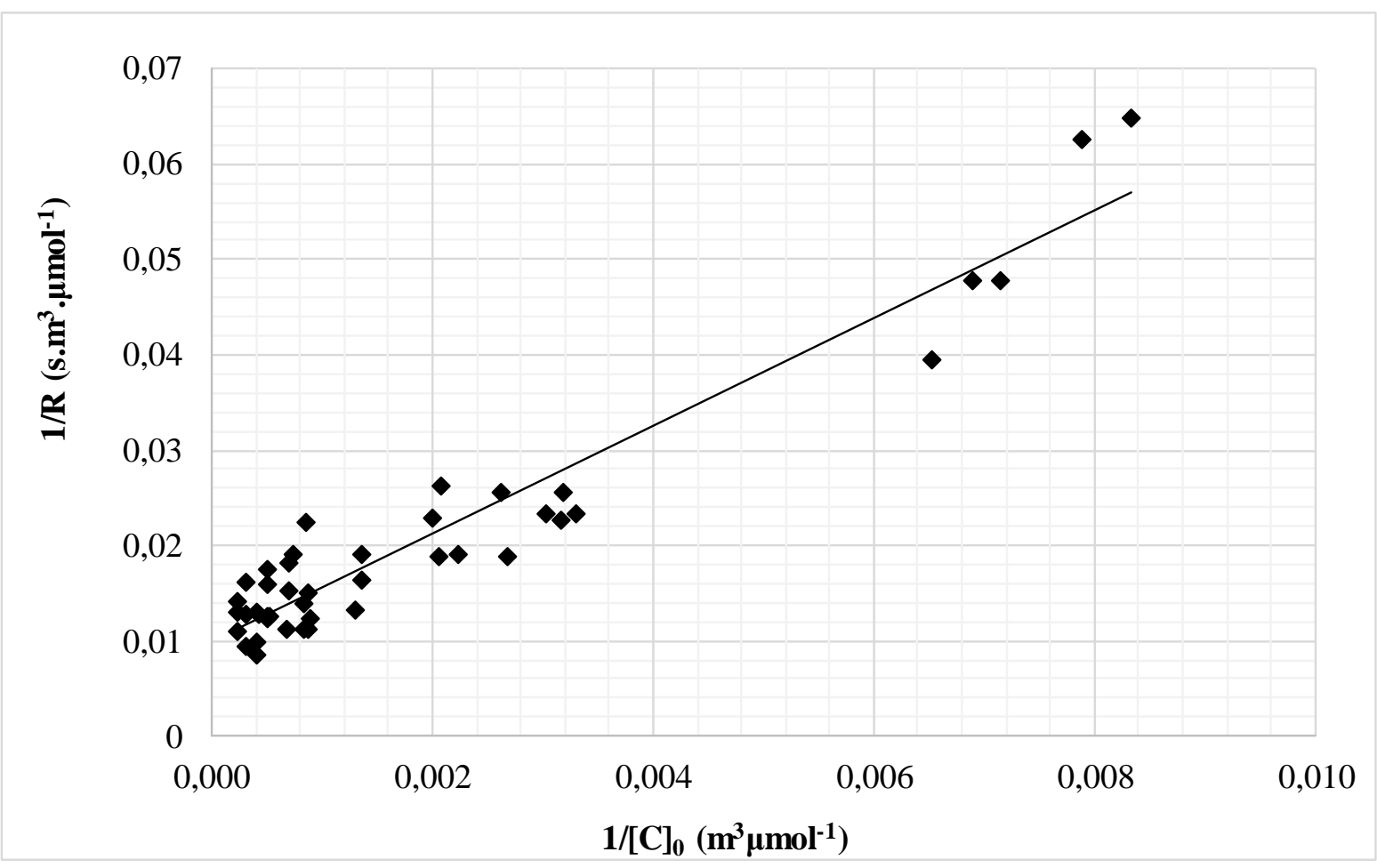

Figura 6.3 - Linearização da velocidade de reação para a região densa do reator.

(Fonte: O autor, 2018) 
Após essa etapa, experimentos com a o Setup 2 foram analisados para determinar os parâmetros para a região diluída do leito fluidizado. A concentração de entrada foi variada. No entanto, como descrito anteriormente, a concentração inicial da região diluída $\left([C]_{\text {limiar }}\right)$ foi estimada pelo modelo obtido para a região densa. Estes dados estão mostrados na Figura 6.4 e o mesmo procedimento foi realizado para obter $k_{1, \text { diluída }}$ e $k_{2, \text { diluída, }}$ também mostrados na Tabela 6.2 .

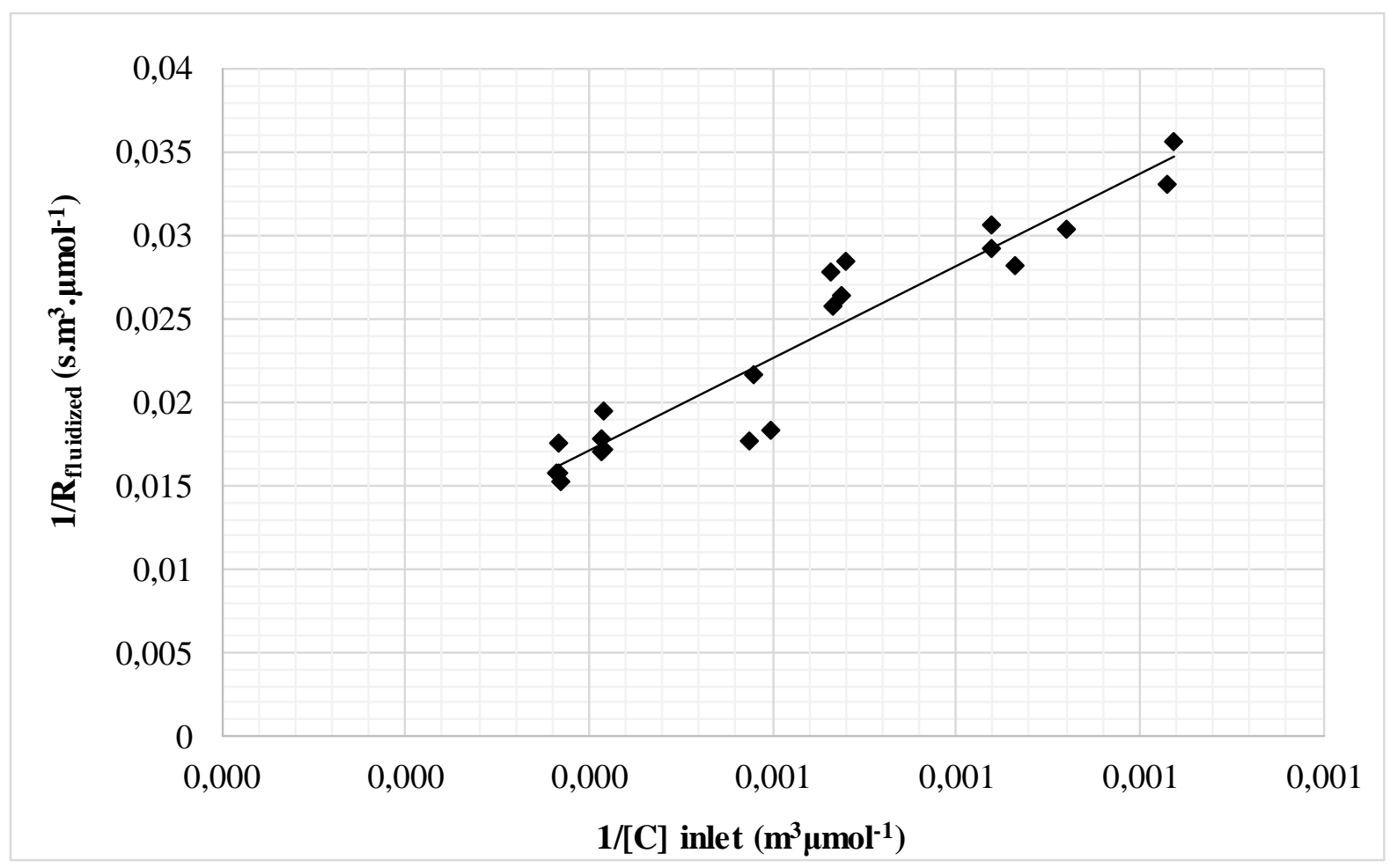

Figura 6.4 - Linearização da velocidade de reação para a região diluída do reator. (Fonte: O autor, 2018)

Tabela 6.2 - Parâmetros cinéticos obtidos pela linearização de dados experimentais do Setup 1 (região densa) e do Setup 2 (região diluída) (Fonte: O autor, 2018)

\begin{tabular}{cccc}
\hline Parâmetro & Unidade & Valor & $\mathbf{R}^{2}$ \\
\hline $\mathrm{k}_{1, \text { densa }}$ & $\mathrm{s}^{-1}$ & 0,177 & \multirow{2}{*}{0,9176} \\
$\mathrm{k}_{2 \text {,densa }}$ & $\mathrm{m}^{3} \mu \mathrm{mol}^{-1}$ & 0,00174 & \multirow{2}{*}{0,9044} \\
\hline $\mathrm{k}_{1 \text {,dilú́da }}$ & $\mathrm{s}^{-1}$ & 0,0362 & 0,000221 \\
$\mathrm{k}_{2 \text {,diluída }}$ & $\mathrm{m}^{3} \mu \mathrm{mol}^{-1}$ & 0 & \\
\hline
\end{tabular}

Os valores de $k_{l}$ mostrados na Tabela 6.2 revelam que a cinética da região densa supera a cinética da região diluída em mais que duas vezes, pois este parâmetro é aquele associado com a velocidade especifica da reação quando os sítios não estão saturados. Os valores de $k_{2}$ estão associados com a capacidade de adsorção de cada região. 


\subsubsection{Verificação do modelo}

O modelo proposto para o reator fotocatalítico para região densa consiste de um reator de mistura perfeita (CSTR), uma vez que a porção com o catalisador é pequena e a formação de bolha promove uma mistura intensa no leito, e um reator do tipo PFR para região diluída, dado que esta parte do reator se comporta como um reator tubular, assim como o modelado por (ROCHETTO, 2012). As duas regiões foram consideradas como dois reatores em séries, ambos acoplados com a cinética LH parametrizada com os valores da Tabela 6.2. Com o objetivo de avaliar o modelo proposta, mais conversões em estado estacionário foram obtidas com o Setup 2, primeiramente nas mesmas condições mostradas na Tabela 6.1. As concentrações de saída experimentais e previstas pelo modelo são comparadas na Figura 6.5. O leve desvio para cima na $[C]_{\text {previsto }}$ quando comparado com a diagonal revela que o modelo calcula degradações levemente maiores do que as concentrações experimentais. O erro médio do modelo em relação ao domínio todo foi de $13,3 \%$.

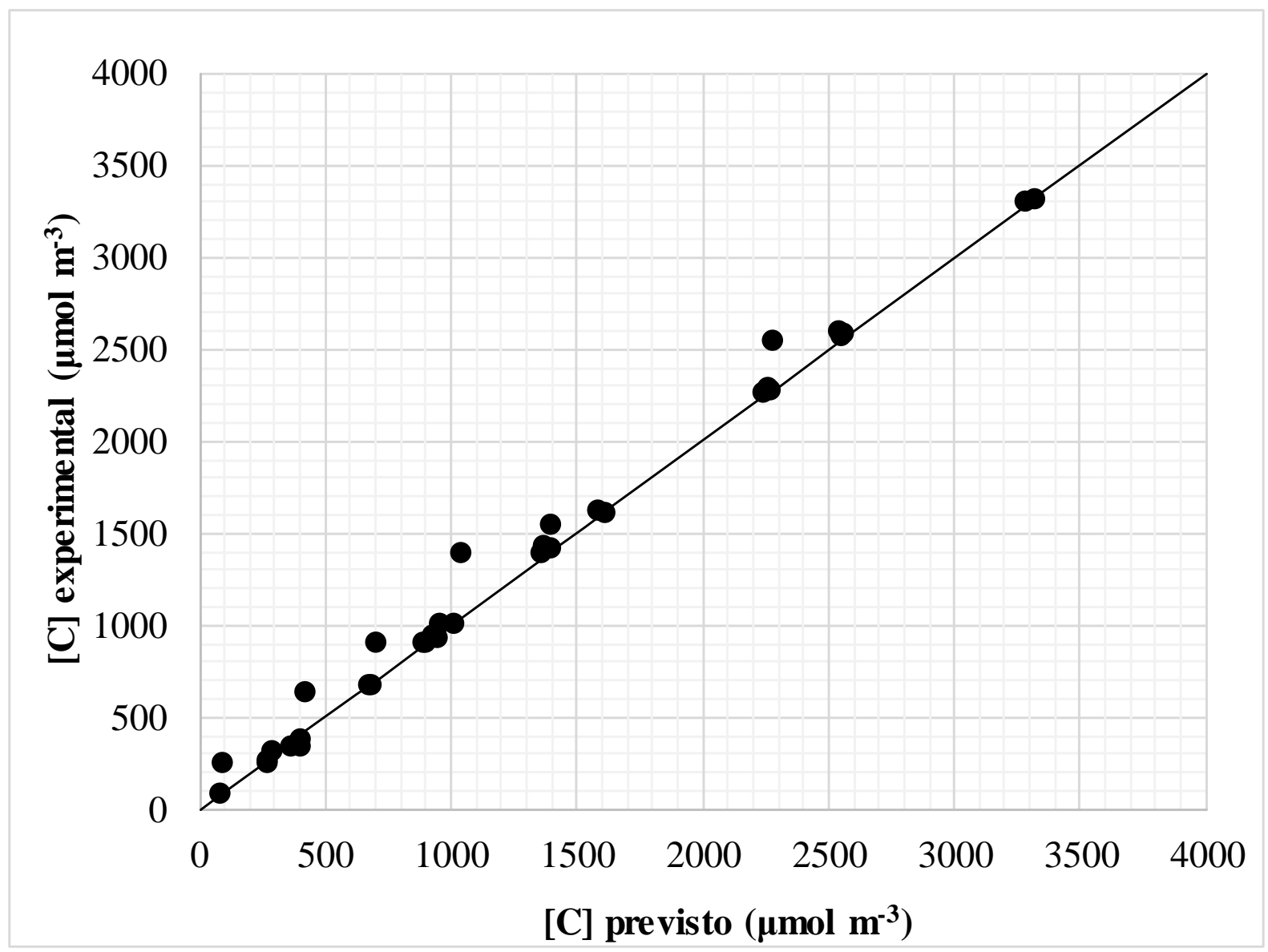

Figura 6.5 - Validação do modelo cinético do reator fotocatalítico (Região densa = CSTR, Região diluída = PFR). $Q=10$ L.min ${ }^{-1}, m=0,1 \mathrm{~kg}$ (Fonte: $\mathrm{O}$ autor, 2018) 
De forma a verificar a validade do modelo feito em outras condições operacionais, a vazão volumétrica foi variada para $5 \mathrm{~L} \mathrm{~min}^{-1}, 7,5 \mathrm{~L} \mathrm{~min}^{-1}$ e $15 \mathrm{~L} \mathrm{~min}^{-1}$ (correspondendo respectivamente a $1,1,5$ e 3 vezes a $u_{m f}$ ), e $[C]_{0}$ foi fixada em $1.200 \mu \mathrm{mol} \mathrm{m}{ }^{-3}$ e a massa de catalisador $m=100 \mathrm{~g}$. Os resultados destes experimentos estão mostrados na Figura 6.6. Para estas vazões, também foi medida a altura do leito durante a fluidização, conforme a Tabela 6.3.

Tabela 6.3 - Resultados de queda de pressão no leito e altura do leito.

(Fonte: O autor, 2018)

\begin{tabular}{ccc}
\hline $\begin{array}{c}\text { Vazão } \\
\text { (L.min-1) }\end{array}$ & $\begin{array}{c}\text { Massa } \\
(\mathbf{k g})\end{array}$ & $\begin{array}{c}\text { Altura do leito } \\
(\mathbf{c m})\end{array}$ \\
\hline 5 & 0,1 & $10,1 \pm 0,2$ \\
7,5 & 0,1 & $10,8 \pm 0,6$ \\
10 & 0,1 & $12,2 \pm 0,6$ \\
15 & 0,1 & $14,5 \pm 0,7$ \\
10 & 0,2 & $20,4 \pm 0,8$ \\
\hline
\end{tabular}

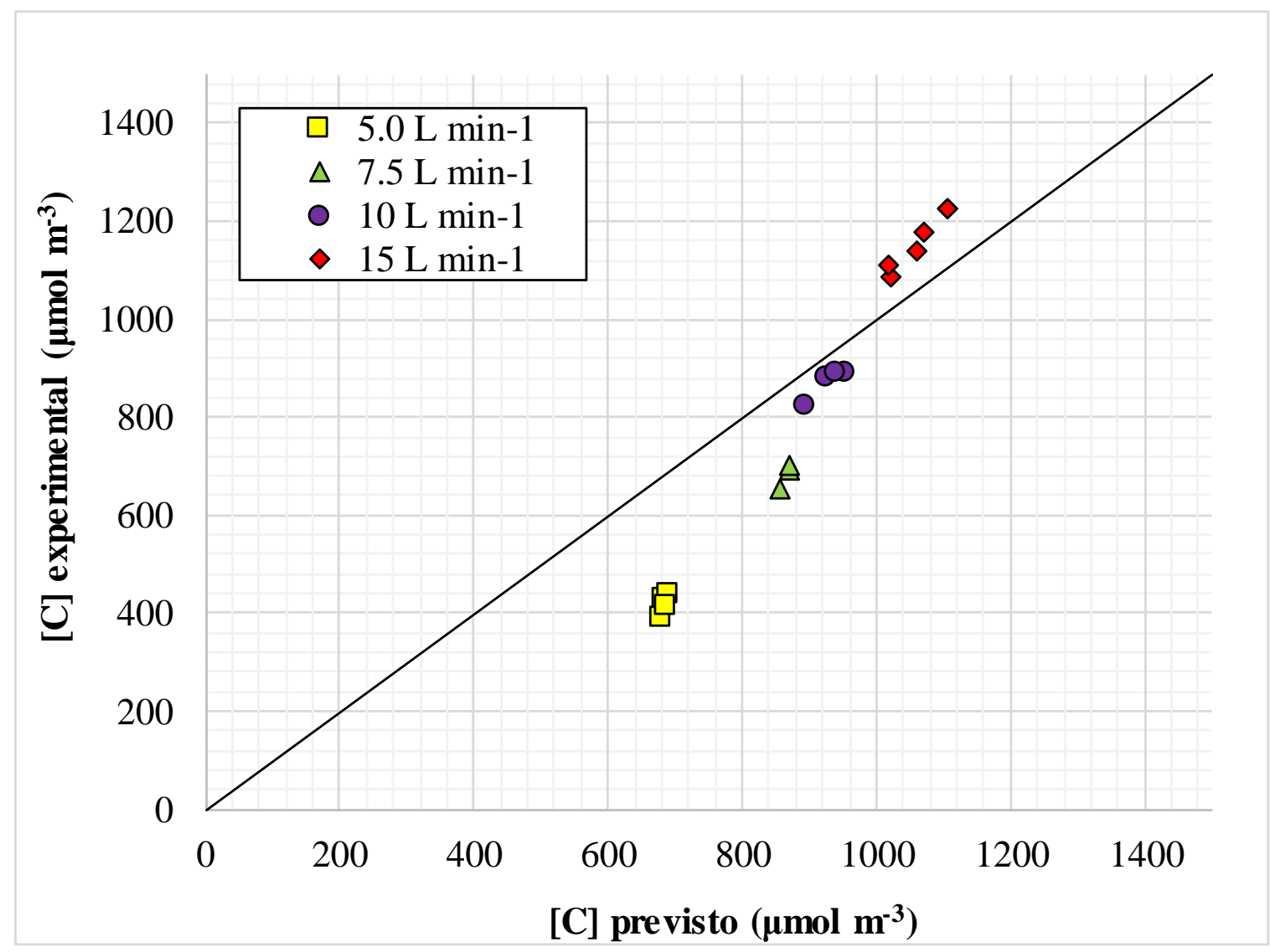

Figura 6.6 - Validação do modelo cinético do reator fotocatalítico (Região densa = CSTR, Região diluída = PFR). $Q=5,7,5,10,15 \mathrm{~L} \cdot \mathrm{min}^{-1}, m=0,1 \mathrm{~kg}$ (Fonte: O autor, 2018) 
Como pode ser visto, o modelo proposto aproximadamente subestima os resultados quando operando na vazão de $5 \mathrm{~L} \cdot \mathrm{min}^{-1}$. Entretanto, para a vazão de 7,5 L.min ${ }^{-1}$ o modelo revela uma predição razoável. Quando a vazão foi configurada para 15 L.min ${ }^{-1}$, o modelo predisse razoavelmente as conversões experimentais. A discrepância entre o modelo e os resultados experimentais em vazões mais baixas pode ser associada às altas conversões obtidas nesta condição. Mesmo a parametrização tendo sido feita para o reator operando com baixas conversões $(<15 \%)$, a inexistência de perfis de concentrações não pode ser completamente assegurada, causando esse desvio. Então, os valores de k obtidos se tornam subestimados para experimentos com altas conversões. O mesmo efeito pode ser notado quando $[\mathrm{C}]_{0}$ diminui, obtendo-se maiores conversões, como pode ser observado na Figura 6.7.

Finalmente, a validade do modelo foi testada com uma quantidade mássica de catalisador maior dentro do reator fotocatalítico. Neste caso, $0,2 \mathrm{~kg}$ de $\mathrm{TiO}_{2}$ foi usada e, como consequência, os valores de $V_{\text {densa }}$ e $V_{\text {diluida }}$ foram modificados. A vazão volumétrica foi mantida em 10 L.min ${ }^{-1}$. Os cálculos para o modelo seguiram as condições apresentadas na Tabela 6.4.

Tabela 6.4 - Condições experimentais para a predição do modelo com carga maior de catalisador. (Fonte: O autor, 2018)

\begin{tabular}{lcc}
\hline Condição Experimental & Valor & Unidade \\
\hline Massa de catalisador, $m$ & 0,2 & $\mathrm{~kg}$ \\
Vazão volumétrica, $Q$ & $1,67.10^{-4}$ & $\mathrm{~m}^{3} \cdot \mathrm{s}^{-1}$ \\
{$[C]_{0}$ n-hexano } & $100-4200$ & $\mu \mathrm{mol} \mathrm{m}^{-3}$ \\
Fluxo de fótons & $0,83 \times 10^{-4}$ & Einstein s \\
Volume da região densa, $V_{\text {densa }}$ & $3,01.10^{-4}$ & $\mathrm{~m}^{3}$ \\
Volume da região diluída, $V_{\text {diluída }}$ & $7,04.10^{-4}$ & $\mathrm{~m}^{3}$ \\
\hline
\end{tabular}

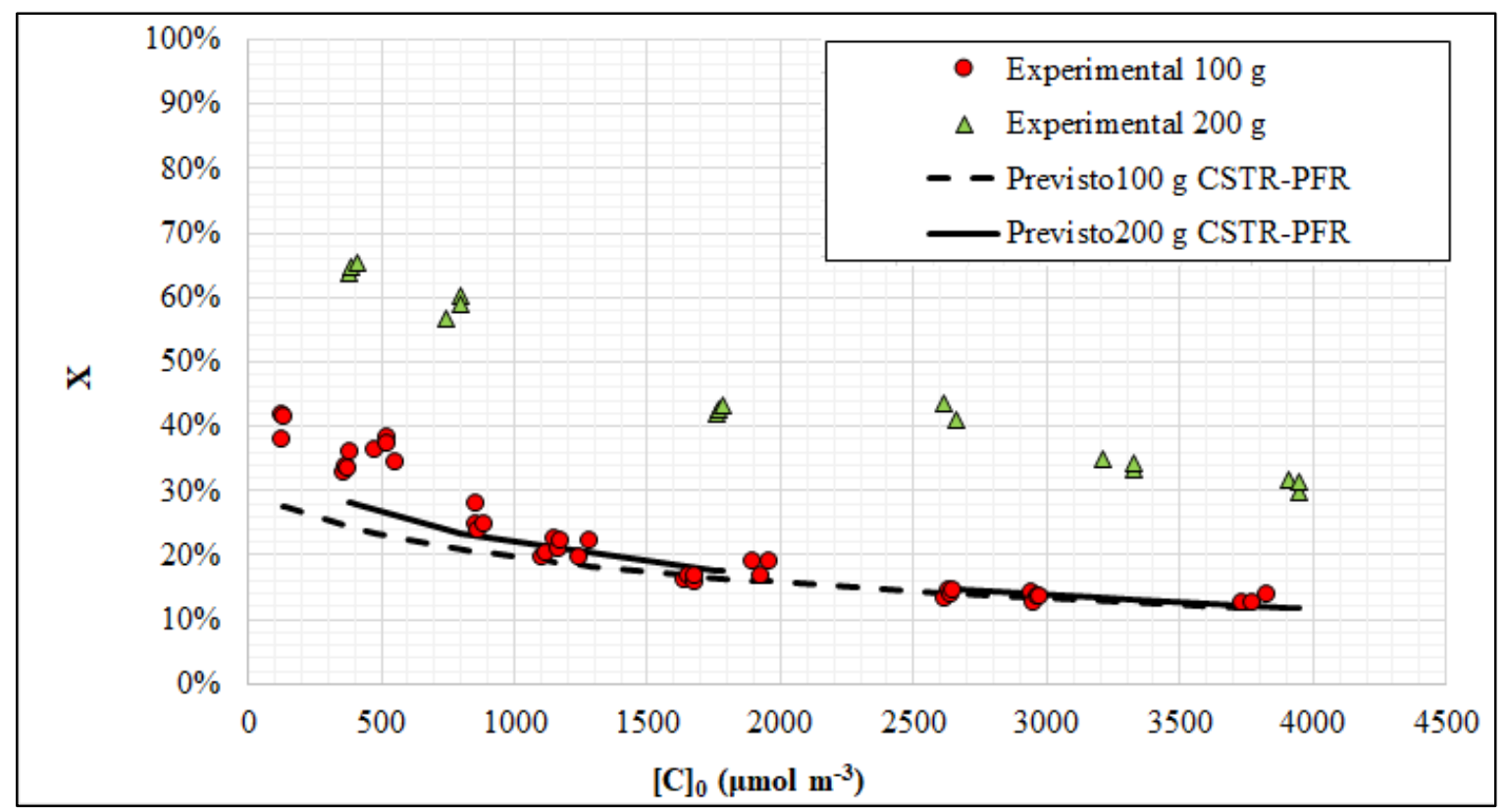

Figura 6.7 - Conversões experimentais e predições do modelo para $Q=10 \mathrm{~L} \cdot \mathrm{min}^{-1}, m=0,1$ $\mathrm{kg}$ e $m=0,2 \mathrm{~kg}$. (Fonte: $\mathrm{O}$ autor, 2018) 
A Figura 6.7 mostra um considerável aumento na conversão experimental do reator fotoquímico para uma vazão volumétrica de $10 \mathrm{~L} \cdot \mathrm{min}^{-1}$ quando a massa de catalisador varia de $0,1 \mathrm{~kg}$ para $0,2 \mathrm{~kg}$. Os resultados da predição do modelo para $0,2 \mathrm{~kg}$ de catalisador estão mostrados na Figura 6.8. Pode ser visto claramente que neste caso, o modelo subestima grosseiramente as degradações experimentais, com um erro médio de $57 \%$ por todo domínio. Este fato acontece devido ao fato de que as estimativas de conversão são fortemente relacionadas aos parâmetros $V_{\text {densa }} \mathrm{e} V_{\text {diluída }} \mathrm{e}$, portanto, não pode predizer variações grandes no volume do leito. Além disso, os sólidos arrastados para região diluída aumentam quanto maior for a massa de catalisador alimentada dentro do reator fotoquímico.

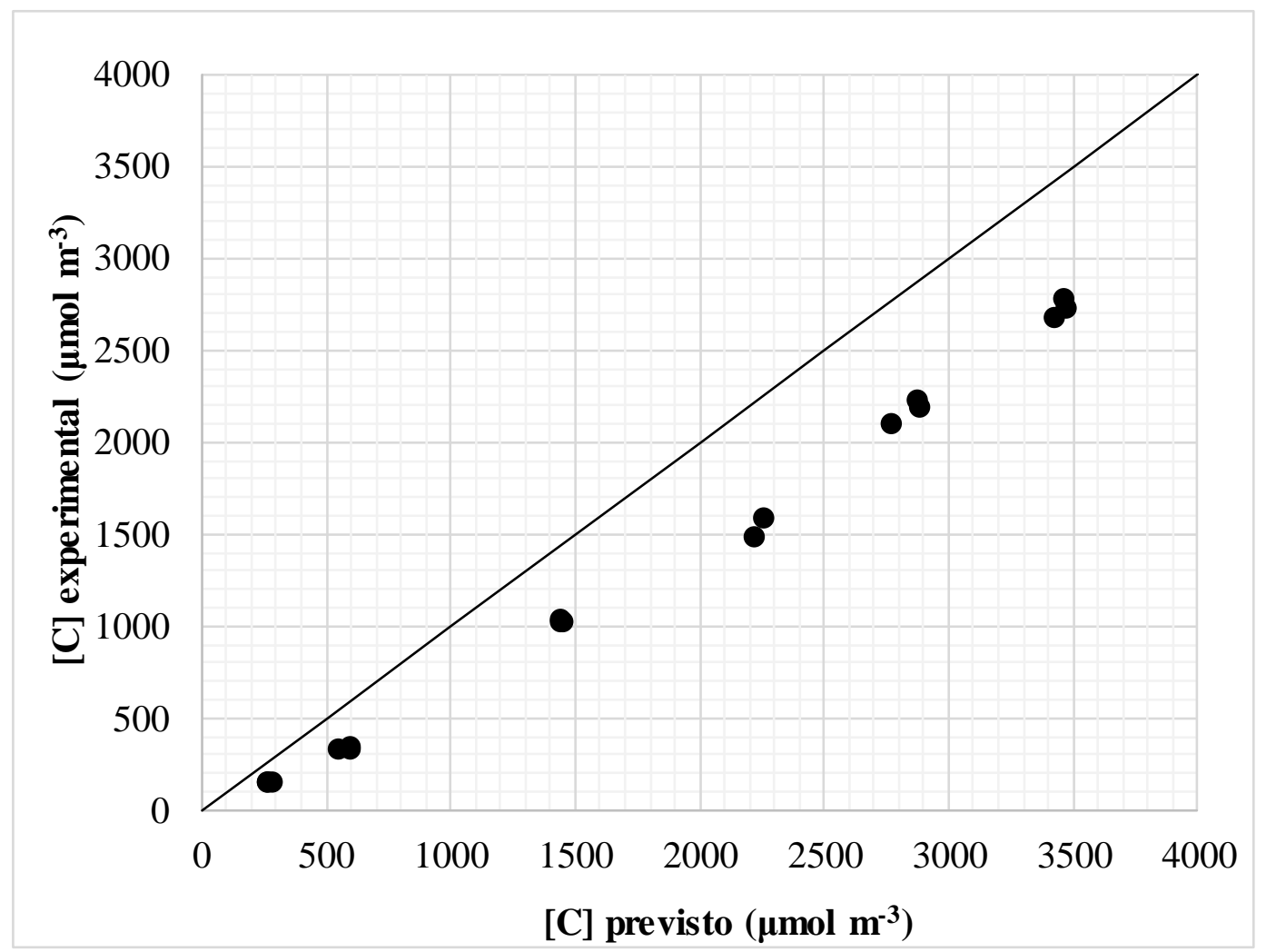

Figura 6.8 - Validação do modelo cinético do reator fotocatalítico (região densa = CSTR, região diluída $=\mathrm{PFR}) \cdot \mathrm{Q}=10 \mathrm{~L} \cdot \mathrm{min}^{-1}, m=0,2 \mathrm{~kg}$.

(Fonte: $\mathrm{O}$ autor, 2018) 


\subsection{FLUIDODINAMICA COMPUTACIONAL}

Para possibilitar o desenvolvimento do modelo no software Fluent, descrito no item 4.9, realizou-se apenas a modelagem das regiões reativas e, assim, considerou-se o reator anular em trecho reto, não sendo modelada a parte do ciclone e mantendo somente o trecho de leito fluidizado.

\subsubsection{Geometria Tridimensional}

Para a malha escolhida tridimensional escolhida no item 4.9.3.1 e com as condições de contorno do item 4.9.4.2, pode-se observar os perfis de pressão e velocidade dos gases na Figura 6.9. O campo de velocidades encontrado mostra um escoamento com intensa recirculação e turbulento na parte do leito e um perfil de laminar na fase diluída, conforme esperado.

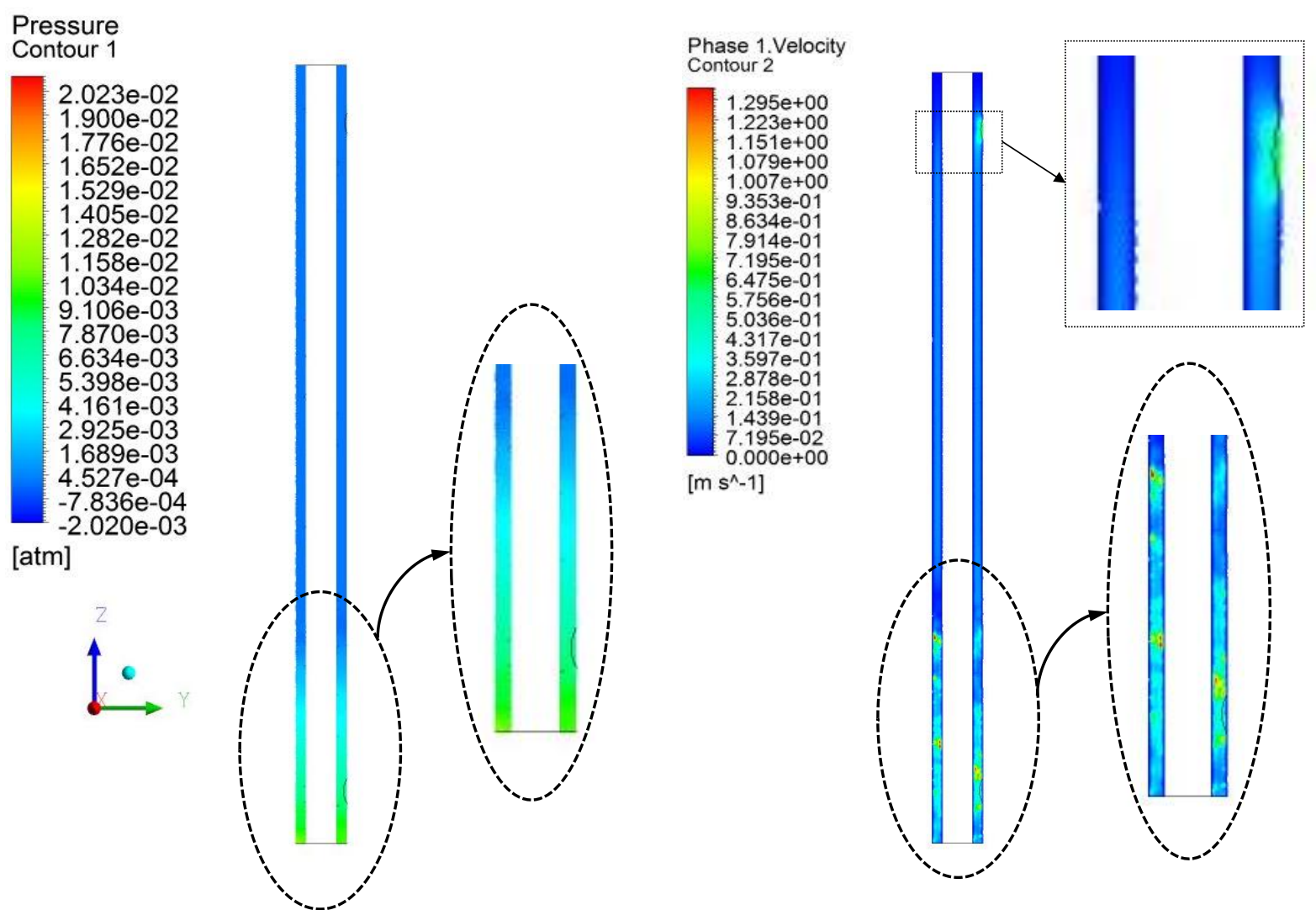

Figura 6.9 - Campos de Pressão e de Velocidade do Gás. Condições simuladas: $\mathrm{Q}=10$ L. $\min ^{-1}$ e $\mathrm{m}=0,17 \mathrm{~kg}$. (Fonte: $\mathrm{O}$ autor, 2018)

Nessa avaliação da hidrodinâmica do reator fotocatalítico, a simulação também fornece uma isosuperfície da fração volumétrica da fase sólida $\left(\mathrm{TiO}_{2}\right)$, de valor 0,1 , que pode ser 
visualizada na Figura 6.10 juntamente com uma foto do experimento em condições de operação próximas das definidas na simulação.

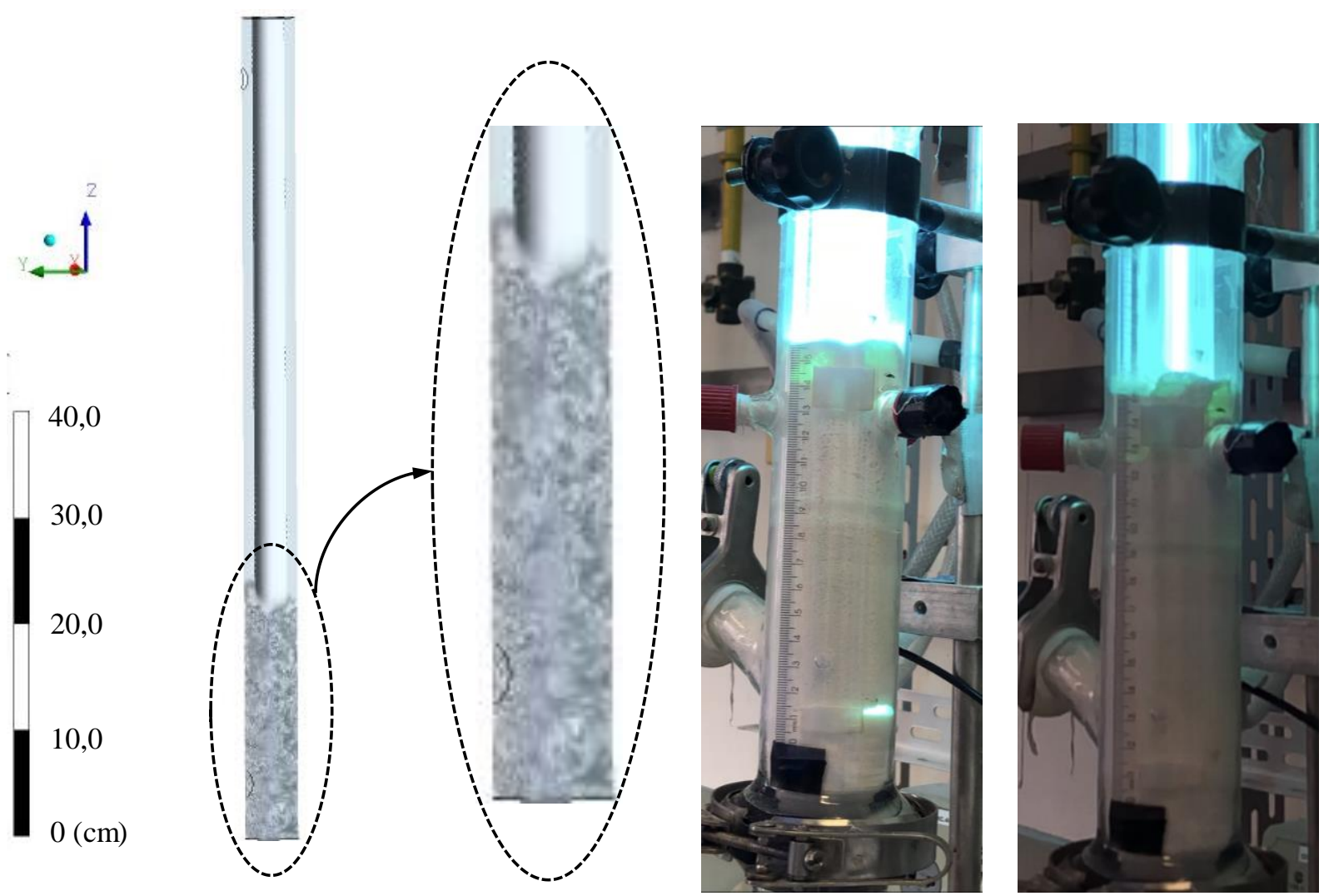

Figura 6.10 - Isossuperfície de fração volumétrica de sólido de 0,1 obtida por simulação e fotos do leito durante o experimento. (Fonte: $\mathrm{O}$ autor, 2018)

A terceira análise foi da altura do leito, por meio da análise da fração volumétrica de sólidos. A altura do leito fluidizado varia muito em função do tempo, como pode ser observado na Figura 6.11 para diferentes instantes e em condição de regime permanente. Para uma análise quantitativa da altura do leito foram traçados gráficos da fração volumétrica de sólido, média na secção, em função da altura do leito (z) para diferentes instantes de tempo, conforme apresentado na Figura 6.15. A validação da simulação com os dados experimentais pode ser feita através da altura do leito que foi de $h_{\text {exp }}=20,4 \mathrm{~cm}$ e de $h_{\text {sim }}=22,5 \mathrm{~cm}$. O desvio de $8 \%$ pode ser atribuído à modelagem, mas também à alta imprecisão medida experimental devido à oscilação do leito durante o experimento. 


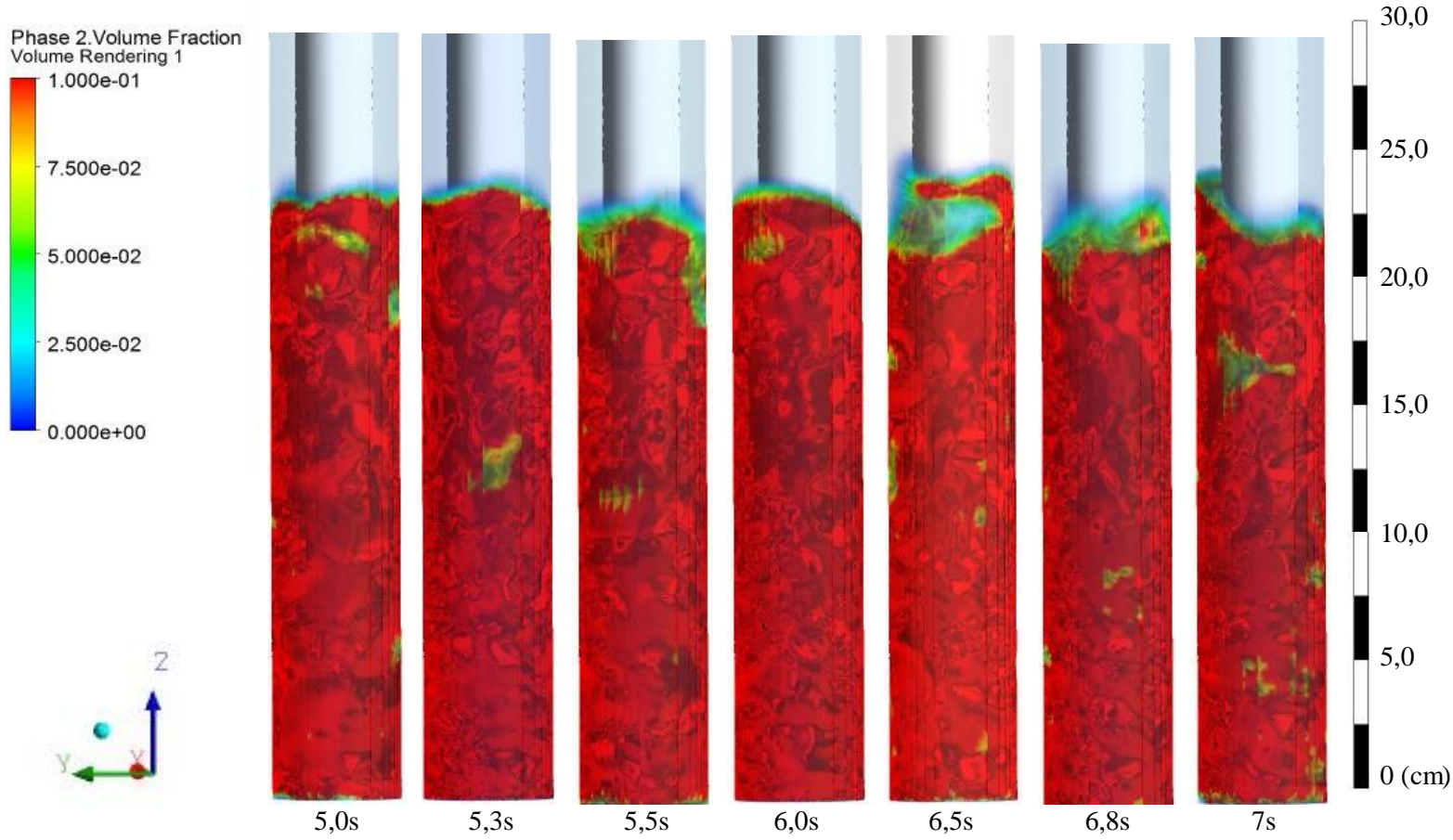

Figura 6.11 - Fração volumétrica de sólidos para $\mathrm{t}=5 \mathrm{~s}$ a $7 \mathrm{~s}$, após o regime permanente ser atingido: $\mathrm{Q}=10 \mathrm{~L} \cdot \mathrm{min}^{-1} \mathrm{e} \mathrm{m}=0,1 \mathrm{~kg}$. (Fonte: $\mathrm{O}$ autor, 2018)

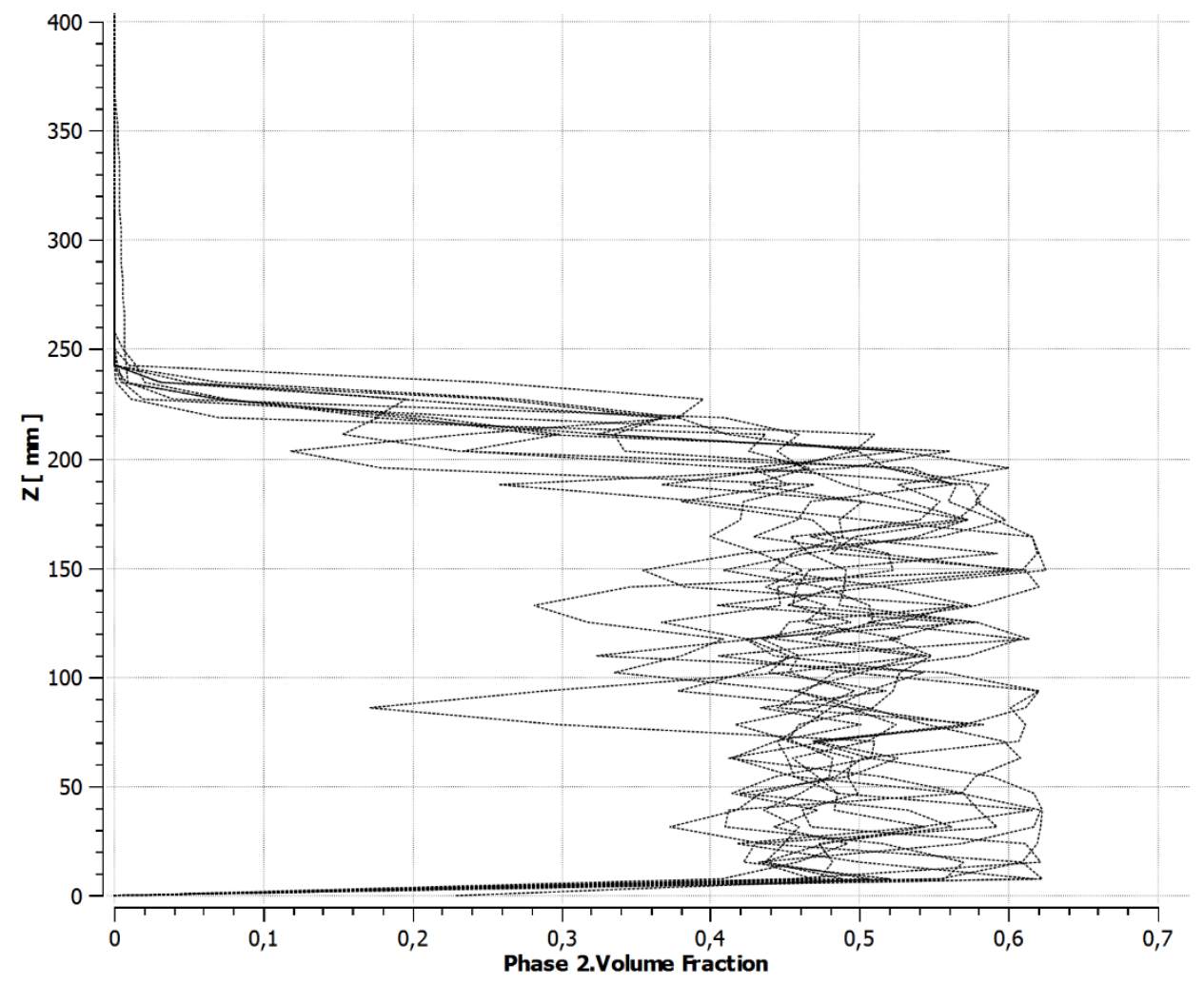

Figura 6.12 - Fração volumétrica média na secção em função da altura do reator, para diferentes instantes de tempo. Condições simuladas: $\mathrm{Q}=10 \mathrm{~L} \cdot \mathrm{min}^{-1} \mathrm{e} \mathrm{m}=0,1 \mathrm{~kg}$.

(Fonte: O autor, 2018) 


\subsubsection{Geometria Bidimensional}

\subsubsection{Comparação entre as Geometrias Tridimensional e Bidimensional}

Visando obter maior rapidez nas simulações, foi adotada uma geometria bidimensional, onde somente a área anular do reator fotocatalítico foi modelada e simulada, conforme descrito no item 4.9.2.2. Neste caso foi adotada a hipótese de simetria radial da geometria. A comparação entre os campos de pressão e velocidade podem ser visualizadas na Figura 6.13 e na Figura 6.14, respectivamente. Nota-se que os campos de velocidades são similares nas duas situações e a perda de carga no leito é de 0,0068 atm para geometria tridimensional e de 0,0052 atm para a geometria bidimensional.

\section{Tridimensional}

\section{Pressure Contour 1}

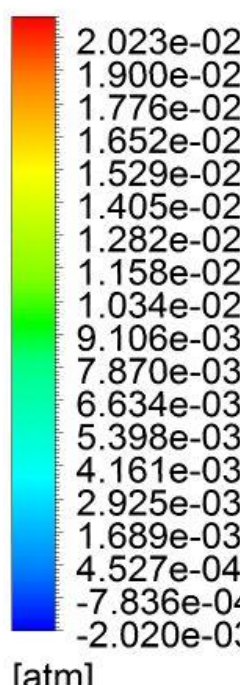

[atm]

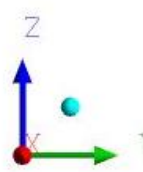

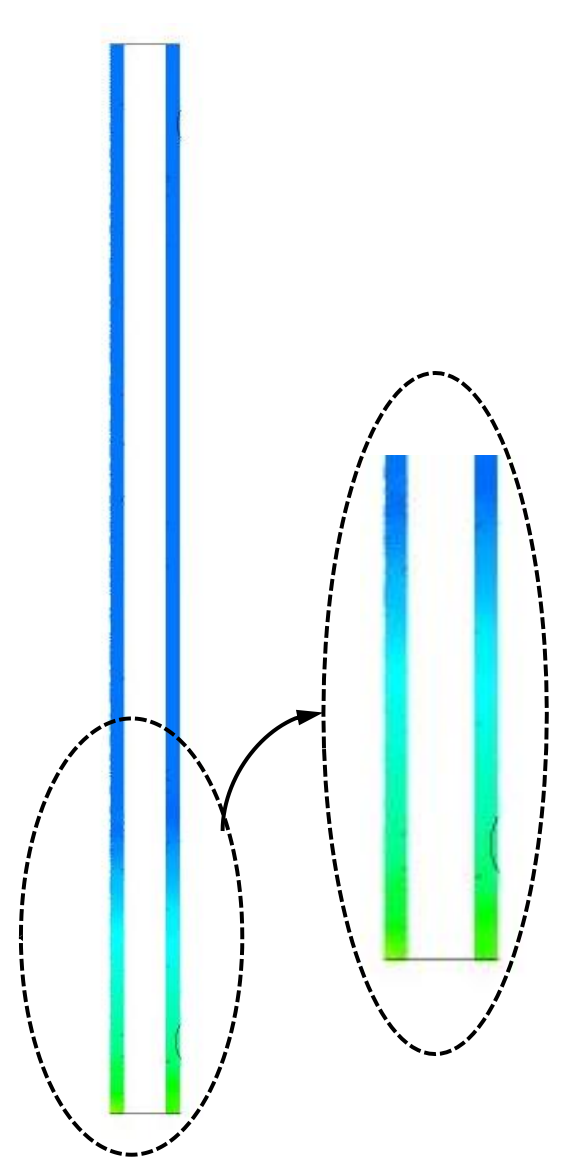

\section{Bidimensional}

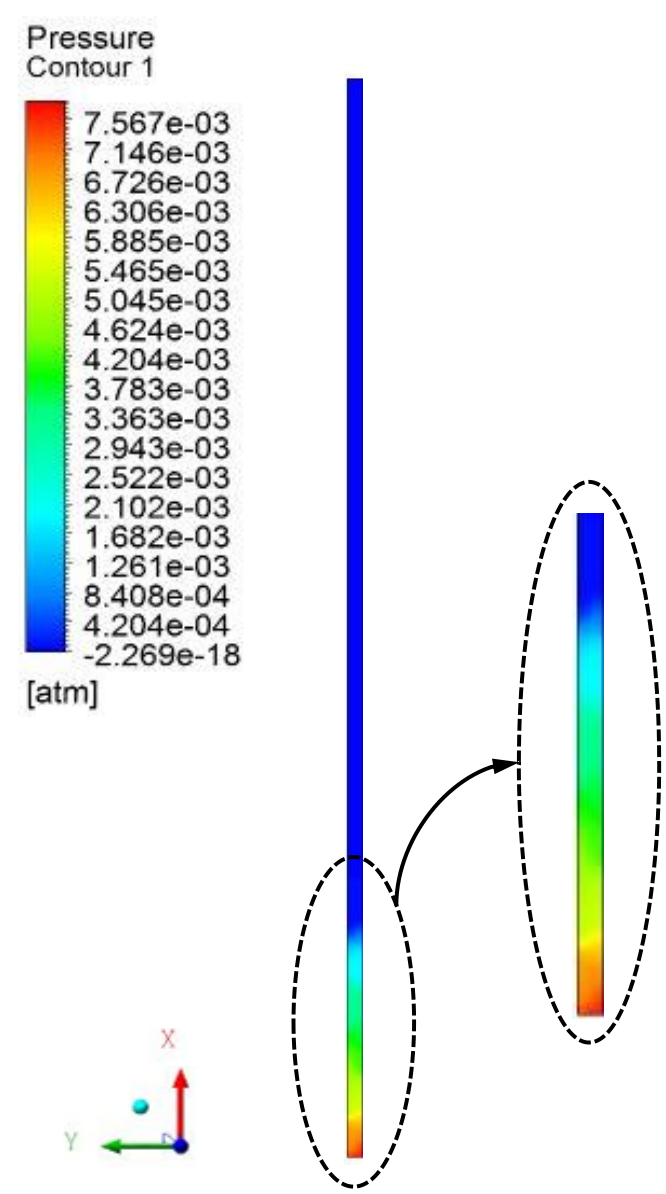

Figura 6.13 - Perfis de Pressão Tridimensional e Bidimensional. Condições simuladas: $\mathrm{Q}=10 \mathrm{~L} \cdot \mathrm{min}^{-1}$ e $\mathrm{m}=0,1 \mathrm{~kg}$

(Fonte: $\mathrm{O}$ autor, 2018) 
Tridimensional

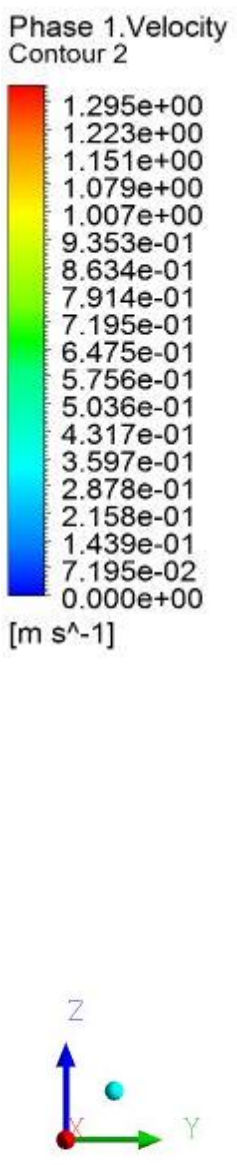

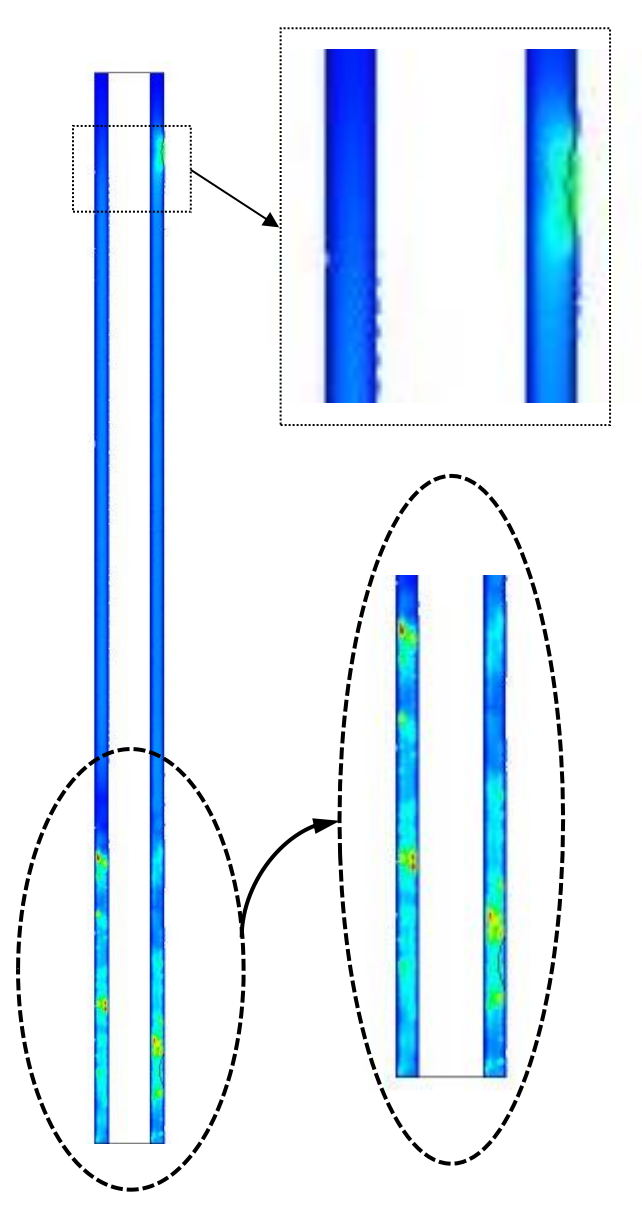

\section{Bidimensional}

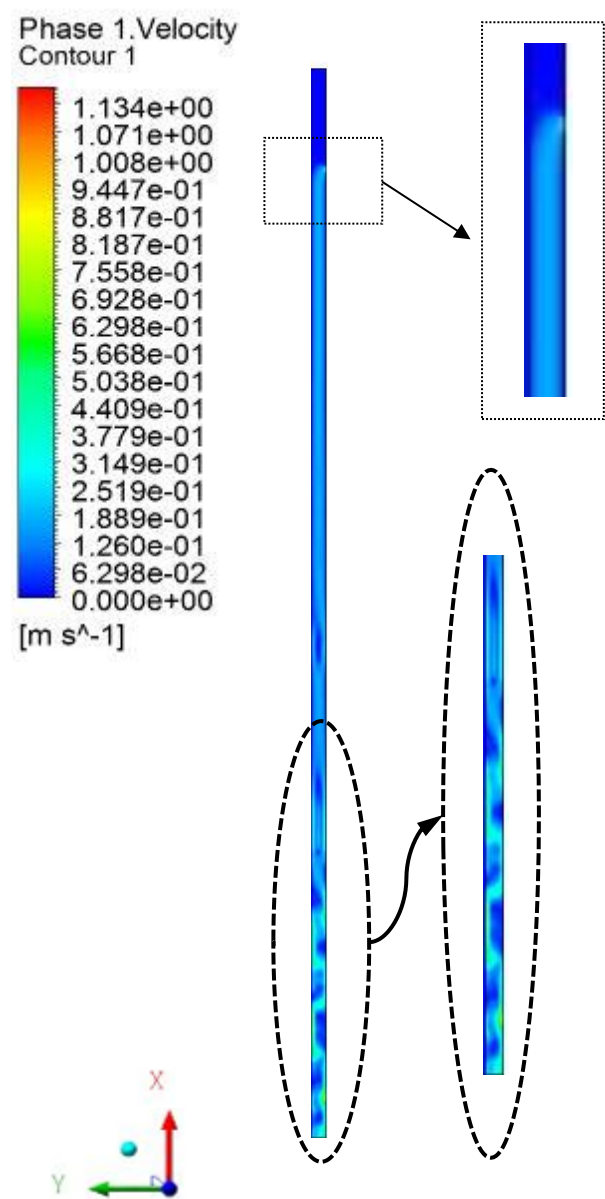

Figura 6.14 - Campos de Velocidade do Gás para geometrias: tridimensional e bidimensional. (Fonte: O autor, 2018)

Analisou-se também a altura do leito por meio da fração volumétrica de sólidos. A altura do leito fluidizado varia muito com os instantes de tempo. Então, para uma análise melhor, foram traçados gráficos da fração volumétrica de sólido, média na secção, em função da altura do leito (z) para diferentes instantes de tempo, conforme a Figura 6.15. 
Tridimensional

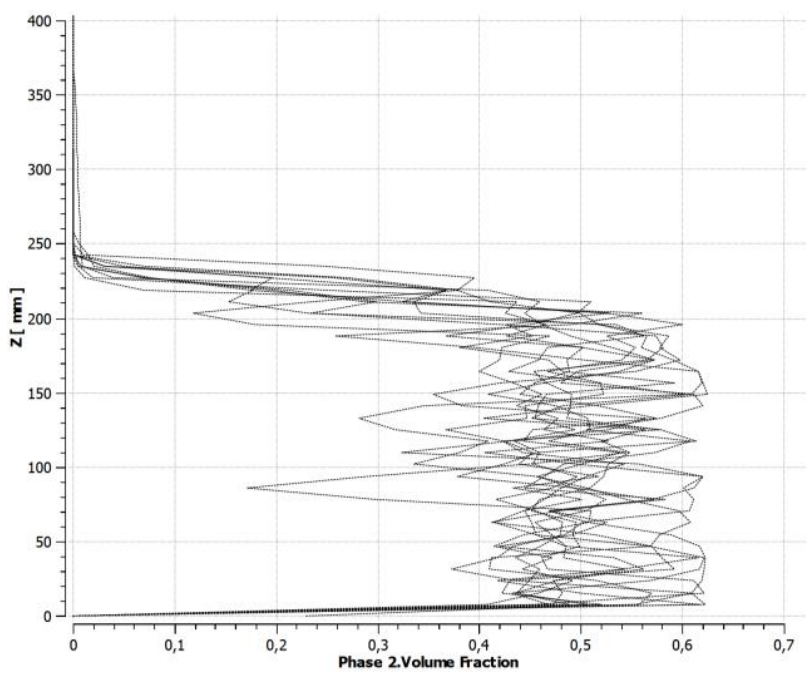

Bidimensional

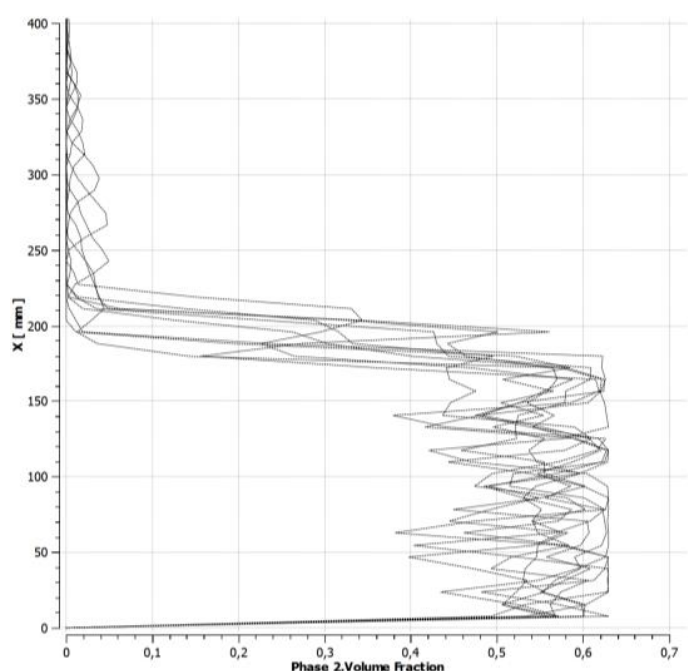

Figura 6.15 - Fração volumétrica média na secção em função da altura do reator, para diferentes instantes de tempo : tridimensional e bidimensional. Condições simuladas: $\mathrm{Q}=10$ L. $\min ^{-1}$ e $\mathrm{m}=0,1 \mathrm{~kg}$ (Fonte: $\mathrm{O}$ autor, 2018)

As alturas médias do leito calculadas a partir do critério de fração volumétrica de sólido média de 0,05 podem ser visualizadas na Tabela 6.5 .

Tabela 6.5 - Alturas médias para geometria 3D e 2D.

(Fonte: O autor, 2018)

\begin{tabular}{ccc}
\hline Variável & 3D & 2D \\
\hline Altura $(\mathrm{mm})$ & 22,5 & 21,5
\end{tabular}

A partir dos perfis e dos resultados expostos, pode-se considerar a hipótese de uma geometria bidimensional para o problema tratado.

\subsubsection{Simplificação da Saída de Gases}

Na geometria bidimensional, foram consideradas duas alternativas para a saída lateral:

- Manutenção de uma saída lateral, como se fosse uma faixa fina que ocuparia o cilindro todo, de forma que a área do mesmo fosse equivalente à da saída original.

- Uma saída superior, pois existe uma grande distância entre o leito e a saída, não havendo uma influência muito grande na hidrodinâmica do reator.

Essa simplificação foi comparada com a Malha 1. Os campos de pressão e velocidade obtidos podem ser vistos na Figura 6.16 e na Figura 6.17. 
Saída Lateral

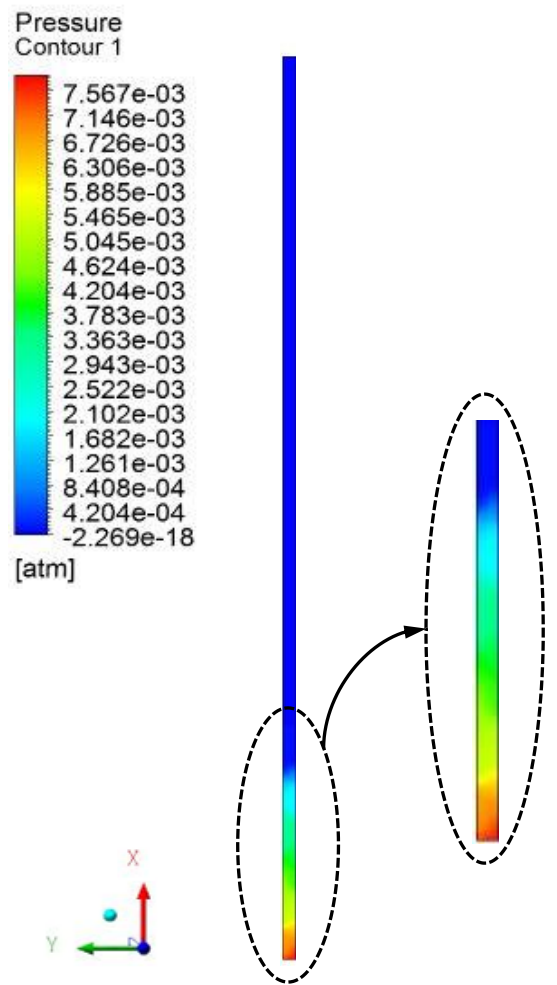

Saída Superior

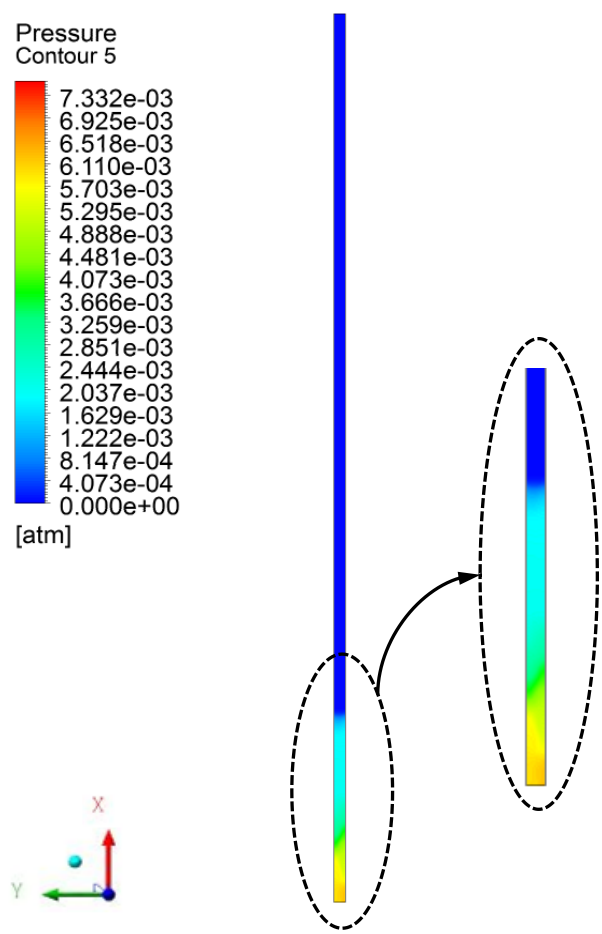

Figura 6.16 - Perfis de Pressão - Saída Lateral e Saída Superior.

(Fonte: O autor, 2018)

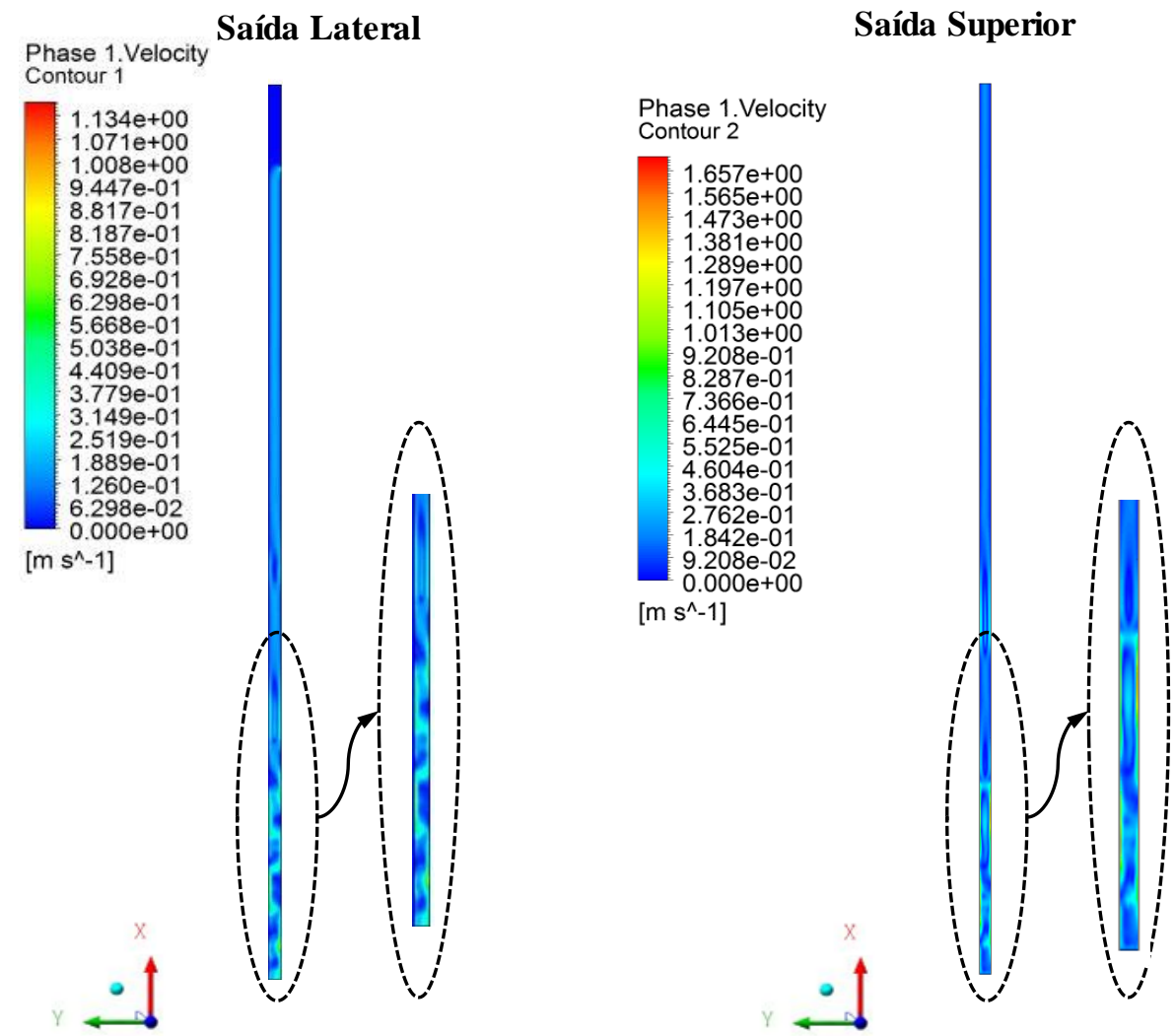

Figura 6.17 - Perfis de Velocidade - Saída Lateral e Saída Superior. Condições simuladas: Q $=10 \mathrm{~L} \cdot \mathrm{min}^{-1} \mathrm{e} \mathrm{m}=0,1 \mathrm{~kg}$

(Fonte: $\mathrm{O}$ autor, 2018) 
Então, foram traçados gráficos da fração volumétrica de sólido, média na secção, em função da altura do leito (z) para diferentes instantes de tempo, conforme a Figura 6.18.
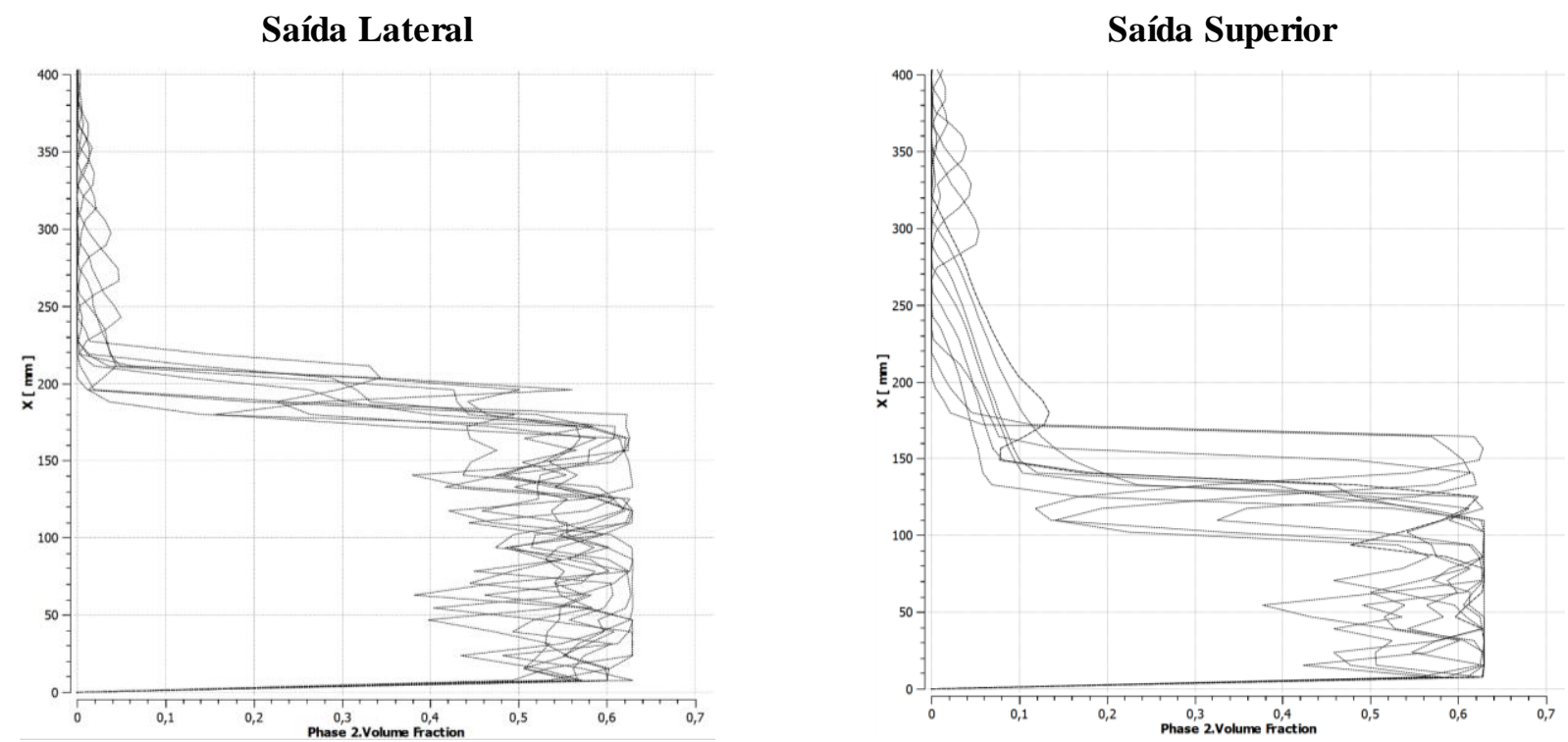

Figura 6.18 - Fração volumétrica média na secção em função da altura do reator para diferentes instantes de tempo e para as duas geometrias bidimensionais. Condições simuladas: $\mathrm{Q}=10 \mathrm{~L} \cdot \mathrm{min}^{-1}$ e $\mathrm{m}=0,1 \mathrm{~kg}$ (Fonte: $\mathrm{O}$ autor, 2018)

As alturas médias e perda de carga no leito obtidas podem ser visualizadas na Tabela 6.6.

Tabela 6.6 - Alturas médias para geometria com saída lateral e com saída superior. (Fonte: O autor, 2018)

\begin{tabular}{ccc}
\hline Variável & $\begin{array}{c}\text { Saída } \\
\text { Lateral }\end{array}$ & $\begin{array}{c}\text { Saída } \\
\text { Superior }\end{array}$ \\
\hline Altura $(\mathrm{mm})$ & 21,5 & 18,0 \\
Perda de Carga $(\mathrm{Pa})$ & 772 & 628 \\
\hline
\end{tabular}

A partir dos perfis e dos resultados expostos, mesmo havendo uma pequena divergência, entre os resultados, o fenômeno do leito fluidizado e o da reação fotocatalítica ocorrem distantes da saída. Portanto, seu efeito pode ser desconsiderado e a geometria simplificada.

\subsubsection{Resultados para a malha escolhida}

Para a malha bidimensional escolhida no item 4.9.3.2, no passo de tempo escolhido em 4.9.3.3, pode-se observar os perfis de pressão e velocidade dos gases na Figura 6.19. O perfil de velocidade encontrado mostra um escoamento com recirculação e turbulento na parte do leito e um perfil de escoamento laminar na fase diluída, conforme esperado. 

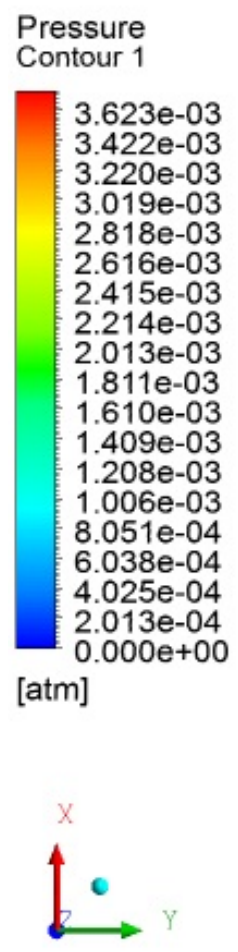
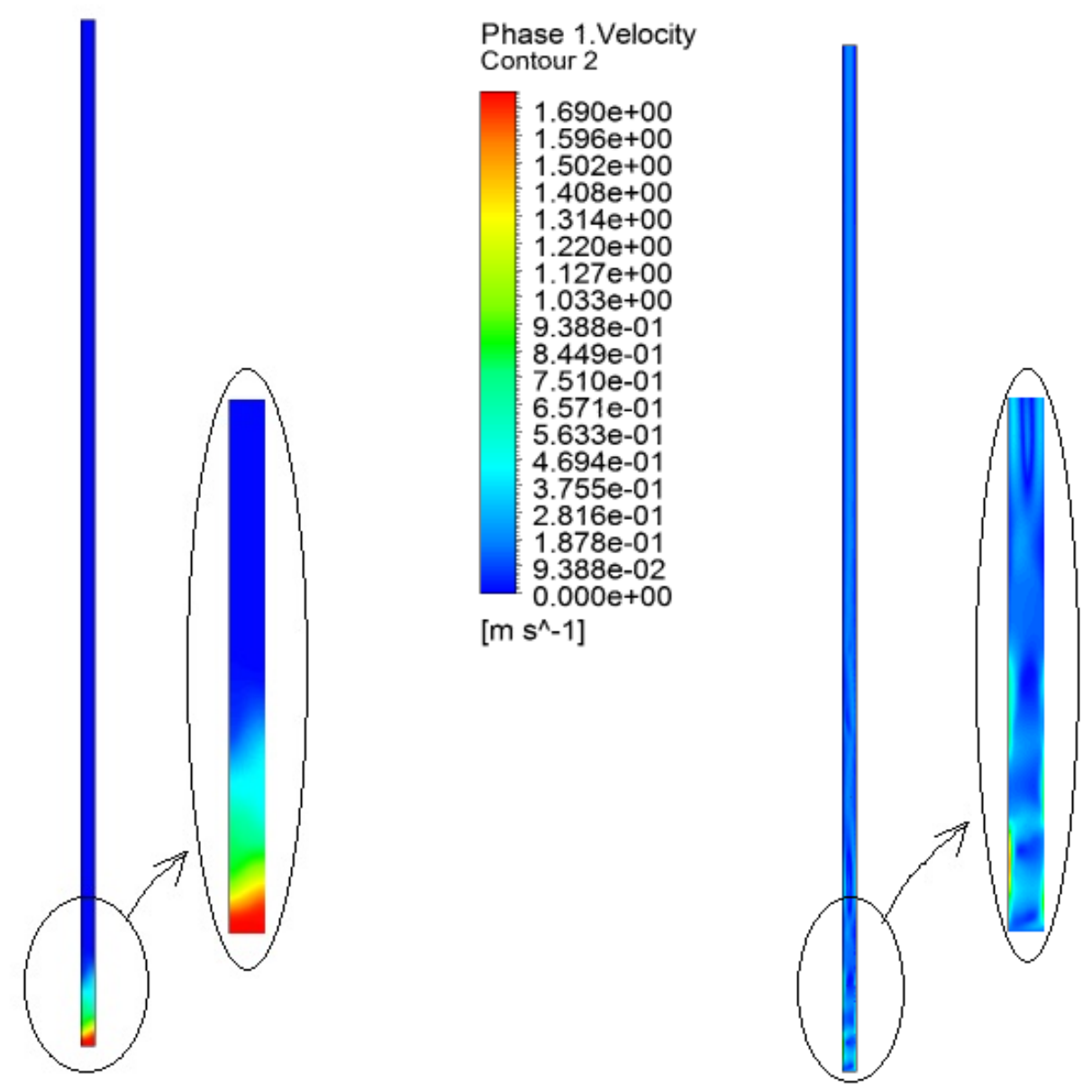

Figura 6.19 - Perfis de Pressão e Velocidade do Gás. Condições simuladas: Q = 10 L.min ${ }^{-1}$ e $\mathrm{m}=0,1 \mathrm{~kg}$ (Fonte: $\mathrm{O}$ autor, 2018)

Nessa avaliação da hidrodinâmica do reator fotocatalítico, a simulação também fornece a fração volumétrica da fase sólida $\left(\mathrm{TiO}_{2}\right)$, que pode ser visualizada na Figura 6.20para diferentes tempos. Novamente, tem-se que a altura do leito fluidizado varia muito com os instantes de tempo. A Figura 6.21 mostra o gráfico da fração volumétrica de sólido, média na secção, em função da altura do leito $(\mathrm{z})$ para 10 instantes de tempo. A validação da simulação com os dados experimentais pode ser feita através da altura do leito que foi de $h_{\text {exp }}=12,2 \mathrm{~cm}$ e de $h_{\text {sim }}=11,0 \mathrm{~cm}$. O desvio de $10 \%$ pode ser explicado devido à alta imprecisão da medida experimental que foi feita com o auxílio de uma régua e a oscilação do leito durante o experimento, conforme ilustrado na Figura 6.22. 


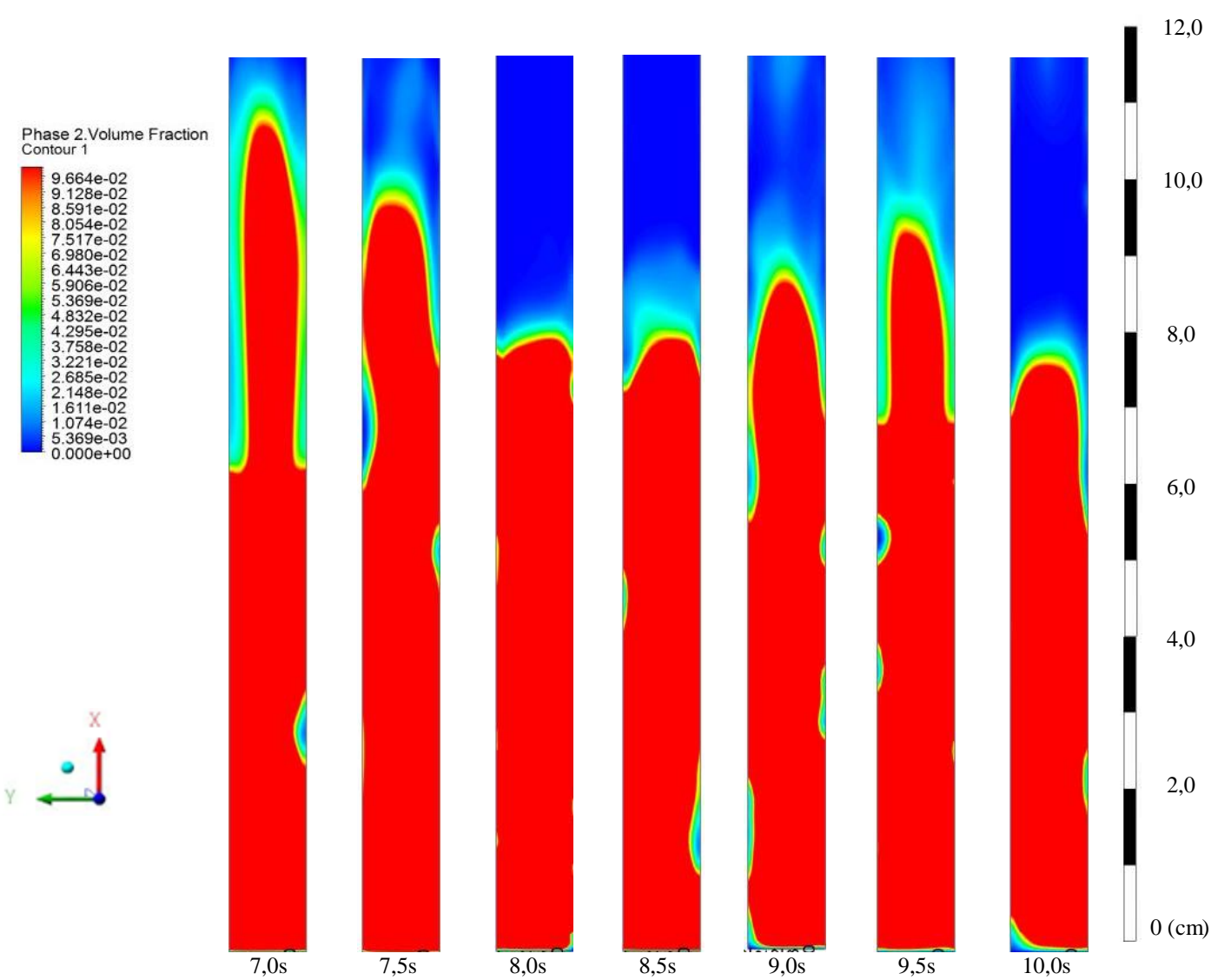

Figura 6.20 - Fração volumétrica de sólidos para $\mathrm{t}=7 \mathrm{~s}$ a $10 \mathrm{~s}$, após o regime permanente ser atingido. Condições simuladas: $\mathrm{Q}=10 \mathrm{~L} \cdot \mathrm{min}^{-1}$ e $\mathrm{m}=0,1 \mathrm{~kg}$ (Fonte: $\mathrm{O}$ autor, 2018)

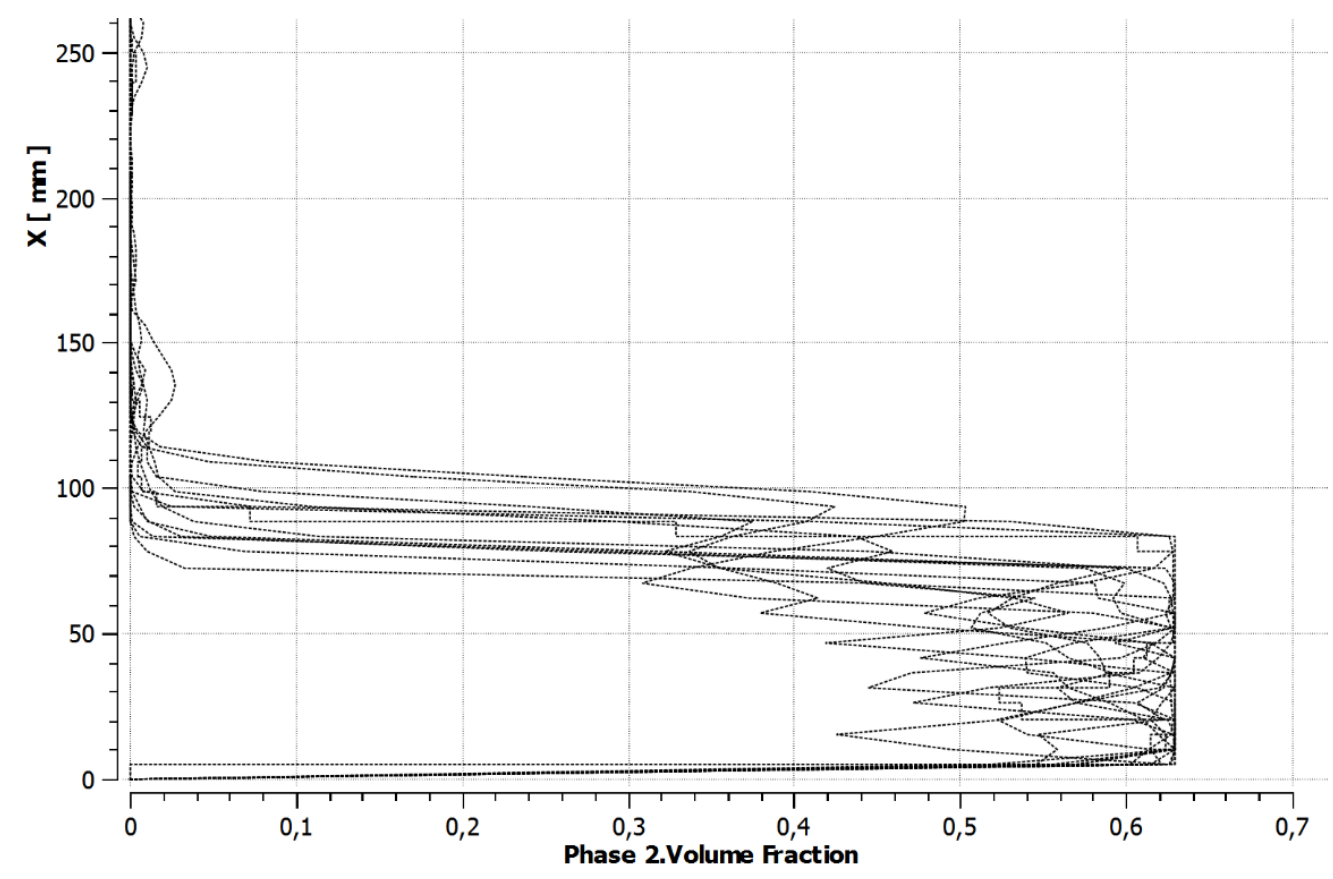

Figura 6.21 - Fração volumétrica média na secção em função da altura do reator para 13 instantes de tempo após o regime permanente ser atingido. Condições simuladas: $Q=10$ L. $\mathrm{min}^{-1}$ e $\mathrm{m}=0,1 \mathrm{~kg}$ (Fonte: $\mathrm{O}$ autor, 2018) 

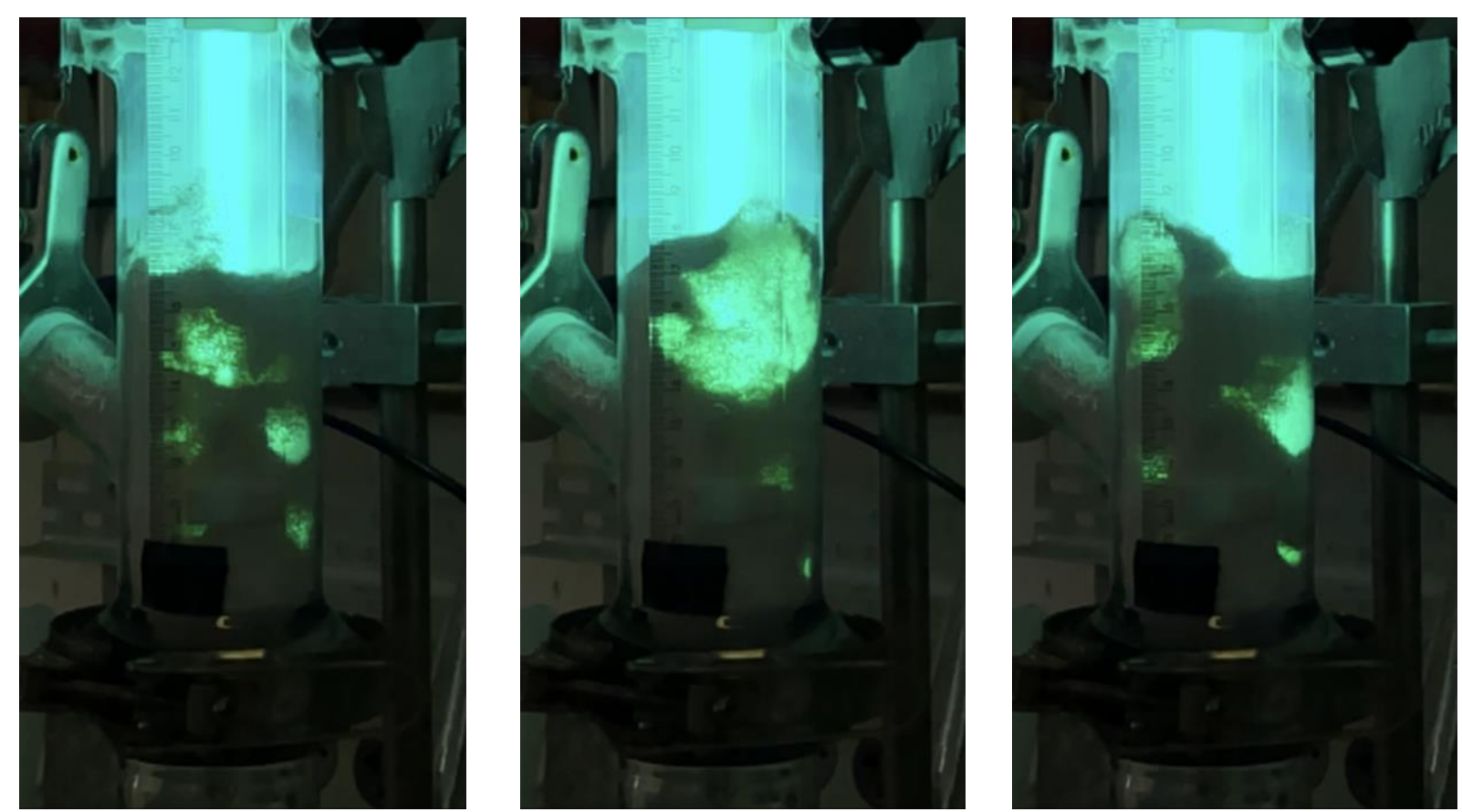

Figura 6.22 - Fotos do experimento mostrando as oscilações na altura do leito. (Fonte: $\mathrm{O}$ autor, 2018)

\subsubsection{Escoamento Multifásico}

Para a malha bidimensional escolhida no item 4.9.3.2, no passo de tempo escolhido em 4.9.3.3, simulações para análise da hidrodinâmica do reator foram executadas, sendo analisadas vazões diferentes de 5 L.min ${ }^{-1}$, 7,5 L.min ${ }^{-1}$ e 15 L.min ${ }^{-1}$.

\subsubsection{Vazão Volumétrica}

Para cada vazão, pode-se observar os campos de pressão e velocidade dos gases na Figura 6.23 e Figura 6.24. O campo de velocidades encontrado mostra um escoamento com recirculação na parte do leito e um perfil de escoamento laminar na fase diluída, conforme esperado. 

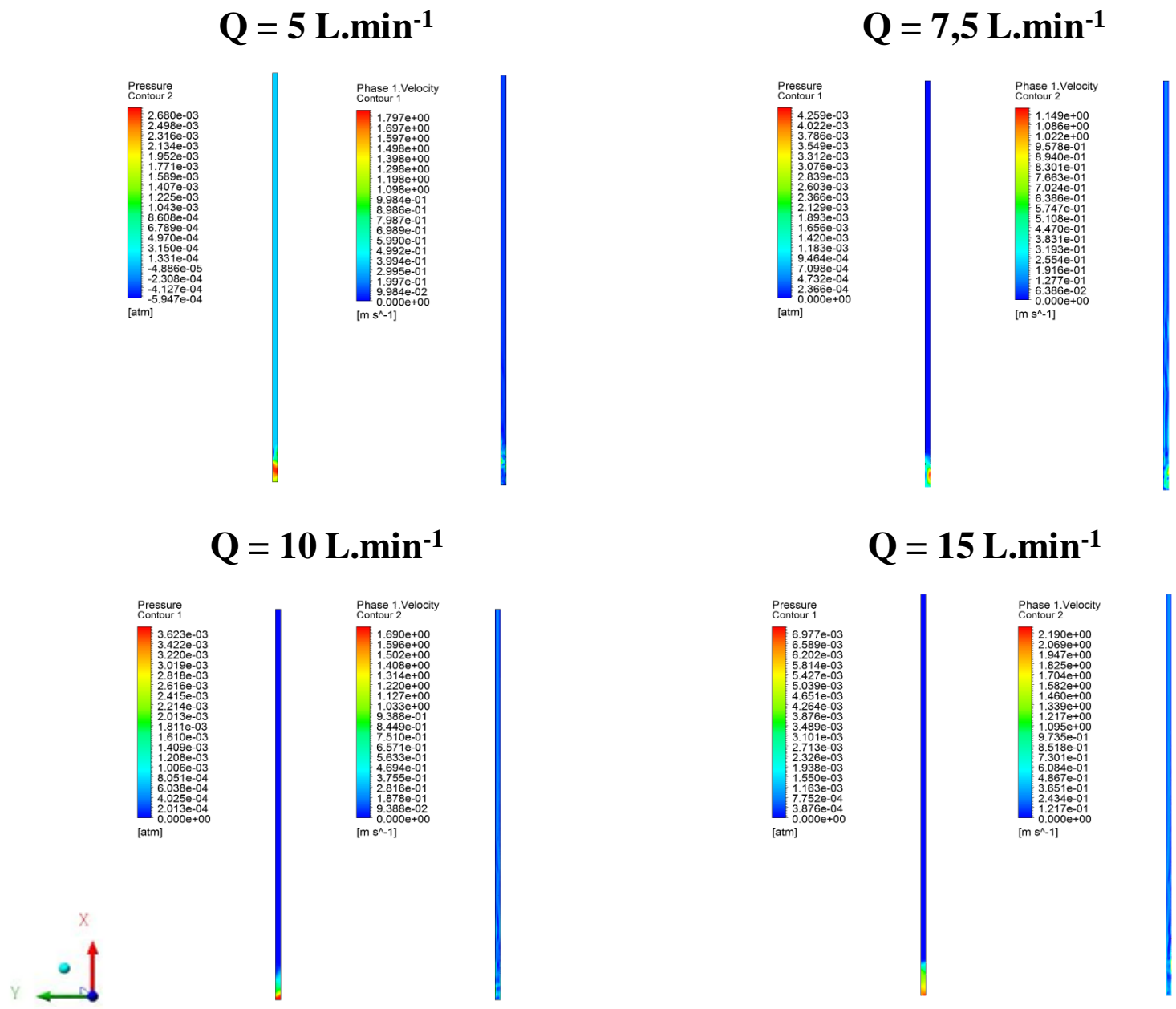

Figura 6.23 - Campos de Pressão e Velocidade do Gás. Condições simuladas: Q = 5, 7,5, 10 e $15 \mathrm{~L} \cdot \mathrm{min}^{-1} \mathrm{e} \mathrm{m}=0,1 \mathrm{~kg}$ (Fonte: O autor, 2018) 

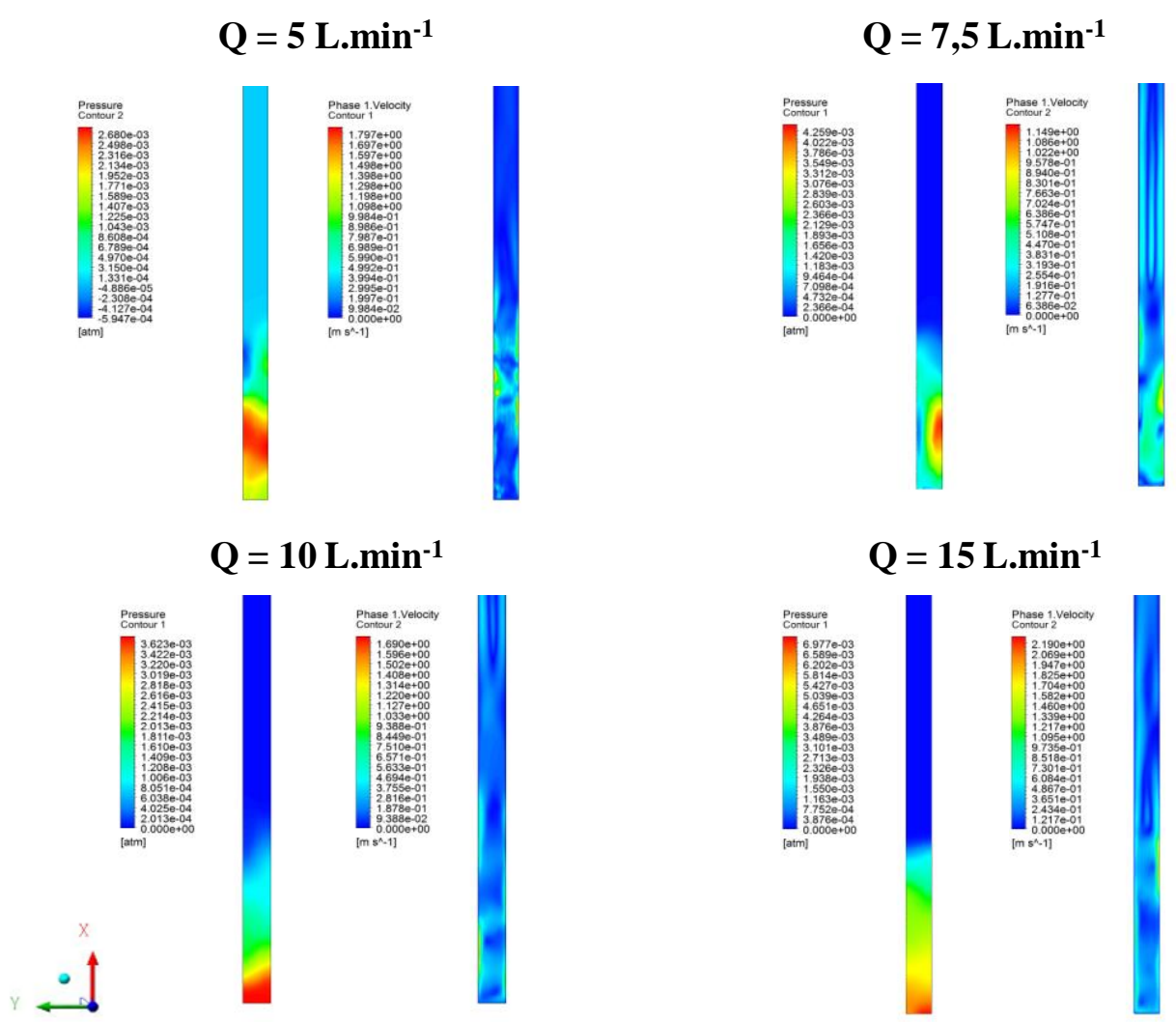

Figura 6.24 - Campos de Pressão e Velocidade do Gás com zoom na parte inferior do reator. Condições simuladas: $\mathrm{Q}=5,7,5,10$ e $15 \mathrm{~L} \cdot \mathrm{min}^{-1}$ e $\mathrm{m}=0,1 \mathrm{~kg}$ (Fonte: $\mathrm{O}$ autor, 2018)

Nessa avaliação da hidrodinâmica do reator fotocatalítico, a simulação também fornece a fração volumétrica da fase sólida $\left(\mathrm{TiO}_{2}\right)$, que pode ser visualizada na Figura 6.25 para diferentes tempos com uma foto do experimento realizado. Novamente, tem-se que a altura do leito fluidizado varia muito com o tempo. A Figura 6.26 mostra o gráfico da fração volumétrica de sólido, média na secção, em função da altura do leito (x) para 10 instantes de tempo. 

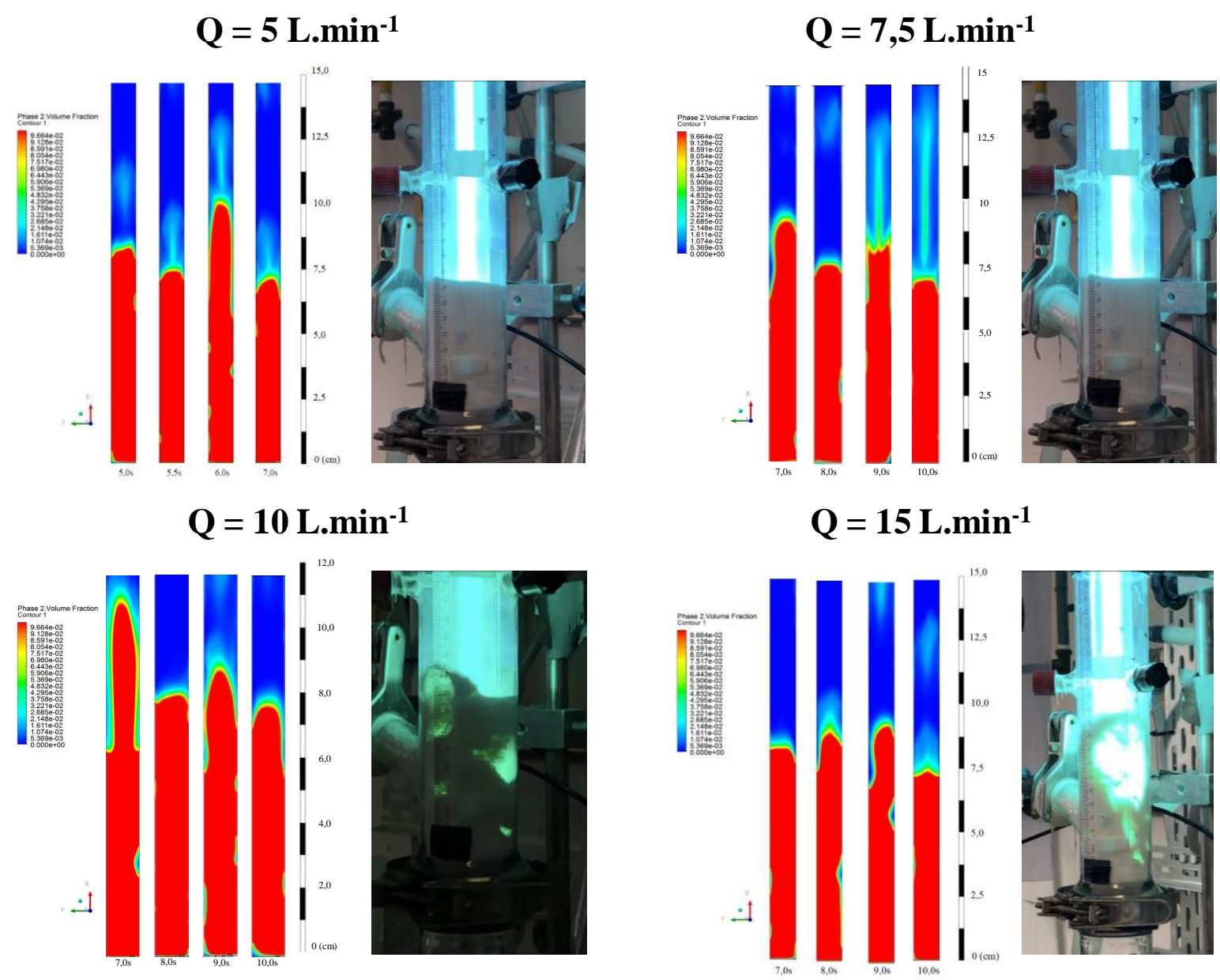

Figura 6.25 - Fração volumétrica de sólidos para $\mathrm{t}=7 \mathrm{~s}$ a $10 \mathrm{~s}$, após o regime permanente ser atingido. Condições simuladas: : $\mathrm{Q}=5,7,5,10$ e $15 \mathrm{~L} \cdot \mathrm{min}^{-1}$ e $\mathrm{m}=0,1 \mathrm{~kg}$ (Fonte: O autor, 2018) 

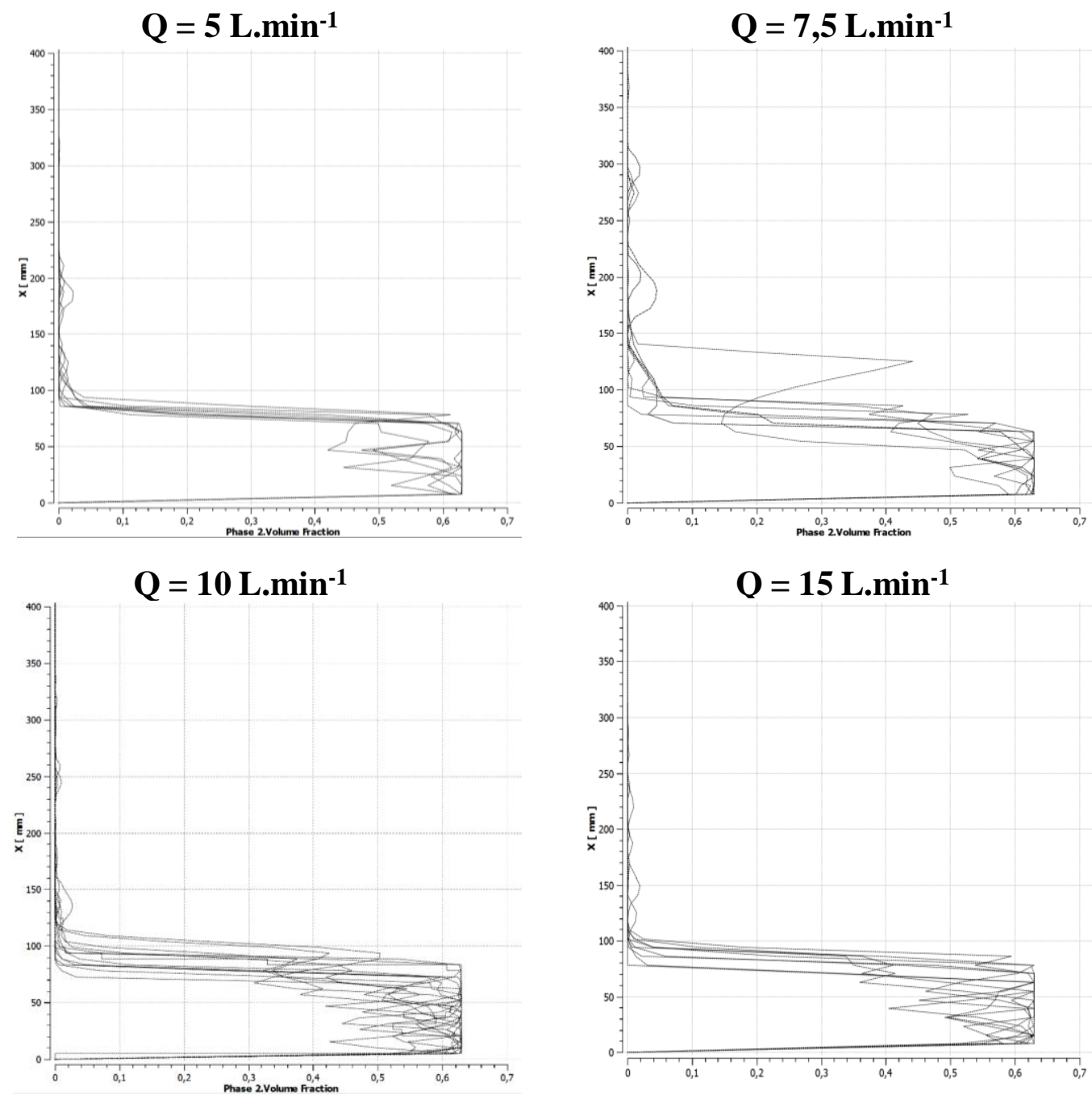

Figura 6.26 - Fração volumétrica média na secção em função da altura do reator para vários instantes de tempo após o regime permanente ser atingido. Condições simuladas: : $Q=5,7,5$, 10 e 15 L.min ${ }^{-1}$ e $\mathrm{m}=0,1 \mathrm{~kg}$ (Fonte: $\mathrm{O}$ autor, 2018)

A validação da simulação com os dados experimentais pode ser feita através das alturas do leito que está apresentada na Tabela 6.7.

Tabela 6.7 - Alturas médias para diferentes vazões testadas e simuladas.

(Fonte: O autor, 2018)

\begin{tabular}{ccc}
\hline Vazão & $\begin{array}{c}\text { Altura Experimental } \\
(\mathbf{m m})\end{array}$ & $\begin{array}{c}\text { Altura Simulada } \\
(\mathbf{m m})\end{array}$ \\
\hline 5 L.min & $\begin{array}{c}-1 \\
\text { 7,5 L.min }\end{array}$ & 9,0 \\
10 L.min & 10,1 & 9,8 \\
15 L.min & 10,8 & 11,0 \\
& 12,2 & 10,0 \\
\hline
\end{tabular}


A partir dos campos e dos resultados expostos, o modelo apresentou uma boa concordância com os dados experimentais para vazões de 5, 7,5 e 10 L.min ${ }^{-1}$. Para a vazão de 15 L.min ${ }^{-1}$, a simulação não conseguiu reproduzir os dados experimentais, o que pode ser explicado pela classificação original das partículas serem do tipo Geldart C, mas com alteração do tamanho das partículas no decorrer dos experimentos, conforme discutido no item5.2, sendo de difícil fluidização e formação de bolhas confinadas na estreita região anular $(1 \mathrm{~cm})$.

\subsubsection{Reator Fotoquímico de Leito Fluidizado}

A modelagem da cinética detalhada no item 6.1 foi implementada no software Fluent, conforme descrito no item 4.9.5. A malha utilizada para todas simulações foi a malha 2 e o passo de tempo utilizado foi de $\Delta t=0,005 \mathrm{~s}$. A vazão simulada foi de $\mathrm{Q}=10 \mathrm{~L} \cdot \mathrm{min}^{-1} \mathrm{e}$ a massa de catalisador utilizada foi de $0,1 \mathrm{~kg}$. Os resultados para os campos de pressão, velocidade e a fração volumétrica foram semelhantes ao do item 6.2.2.3. A concentração de entrada de nhexano foi variada de 250 a $3000 \mu \mathrm{mol} \mathrm{m}{ }^{-3}$.

As simulações da cinética de reação química foram realizadas em um regime transiente até a obtenção de um estado estacionário para as conversões de n-hexano. O estado estacionário para a reação química foi considerado quando não havia mais alteração da conversão ao longo do tempo. Este resultado foi obtido para a região densa, Figura 6.27, e para todo reator, Figura 6.28 .

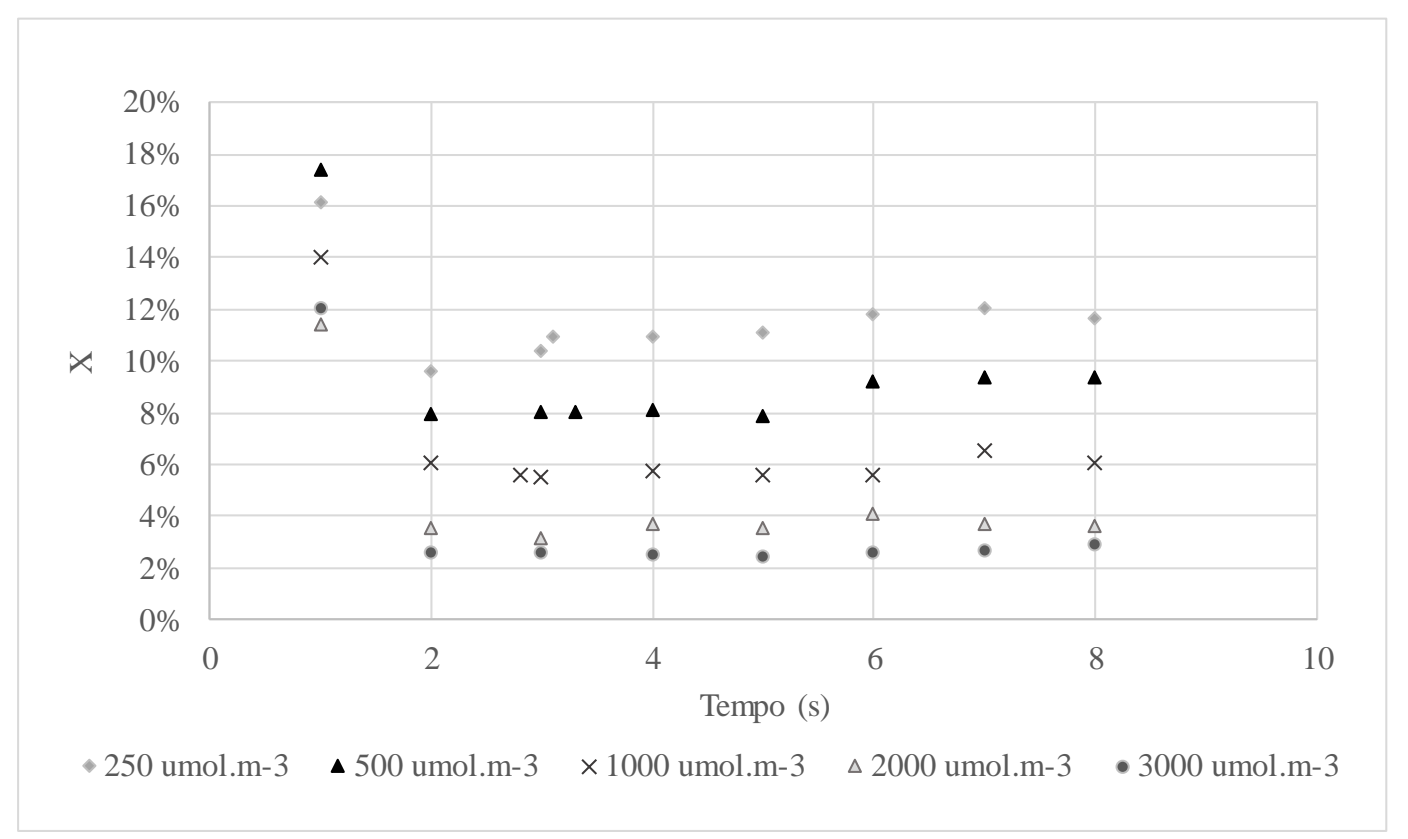

Figura 6.27 - Porcentagem de conversão de n-hexano em função do tempo de simulação na região densa. Condições simuladas: $\mathrm{Q}=10 \mathrm{~L} \cdot \mathrm{min}^{-1} \mathrm{e} \mathrm{m}=0,1 \mathrm{~kg}$ para $\mathrm{C}=250$ a $3000 \mu \mathrm{mol}$ $\mathrm{m}^{-3}$ (Fonte: O autor, 2018) 


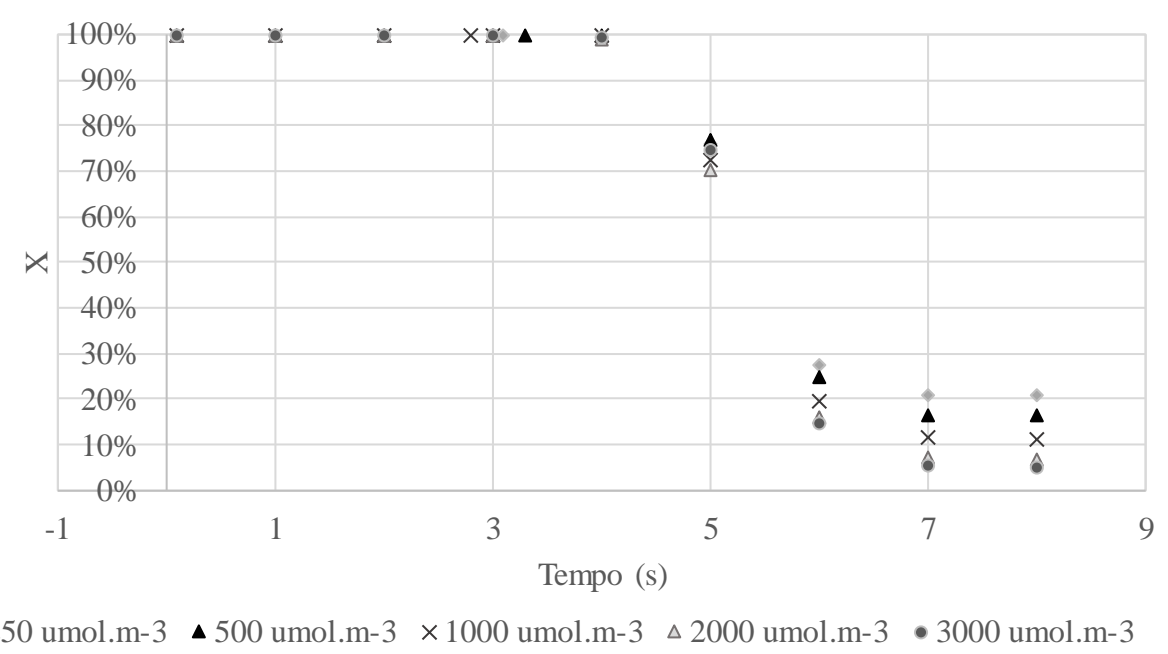

Figura 6.28 - Porcentagem de conversão de n-hexano em função do tempo de simulação em todo reator. Condições simuladas: $\mathrm{Q}=10 \mathrm{~L} \cdot \mathrm{min}^{-1} \mathrm{e} \mathrm{m}=0,1 \mathrm{~kg}$ para $\mathrm{C}=250$ a $3000 \mu \mathrm{mol} \mathrm{m} \mathrm{m}^{-3}$ (Fonte: O autor, 2018)

O campo de concentrações pode ser visualizado na Figura 6.29, através de um perfil da concentração ao longo do comprimento do reator (x). Este campo de concentração, para cada concentração inicial, no estado estacionário (após 8s de simulação), está ilustrado na Figura 6.30 com um fator de aumento de 5 vezes na direção radial. Estes resultados mostram que a velocidade de reação da região densa é maior do que a da região diluída, de acordo com esperado pela cinética obtida. Observa-se, na região densa, como a não uniformidade do campo de velocidades, ao contrário da região diluída, afeta as concentrações do n-hexano.

As conversões provenientes da simulação foram comparadas com as obtidas experimentalmente na região densa e no reator completo, conforme a Figura 6.31 e Figura 6.32, respectivamente, mostrando uma boa concordância entre o modelo CFD e os experimentos para a região densa. A falta de aderência dos resultados simulados aos experimentais para o reator completo, indicam uma discrepância na velocidade de reação calculada na região diluída. 


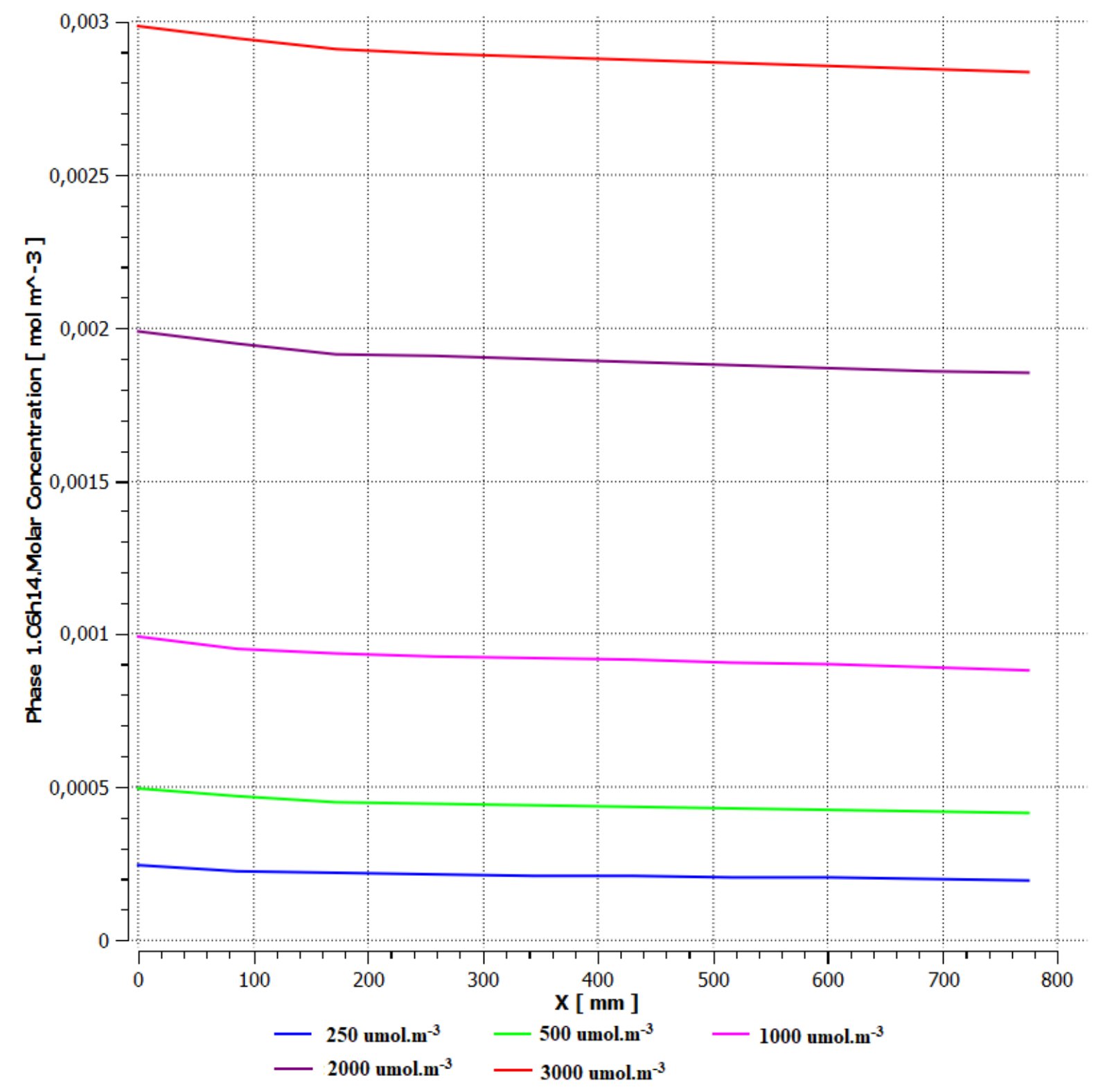

Figura 6.29 - Concentração de n-hexano ao longo do comprimento do reator. Condições simuladas: $\mathrm{Q}=10 \mathrm{~L} \cdot \mathrm{min}^{-1} \mathrm{e} \mathrm{m}=0,1 \mathrm{~kg}$ para $\mathrm{C}=250$ a $3000 \mu \mathrm{mol} \mathrm{m}{ }^{-3}$ (Fonte: $\mathrm{O}$ autor, 2018). 

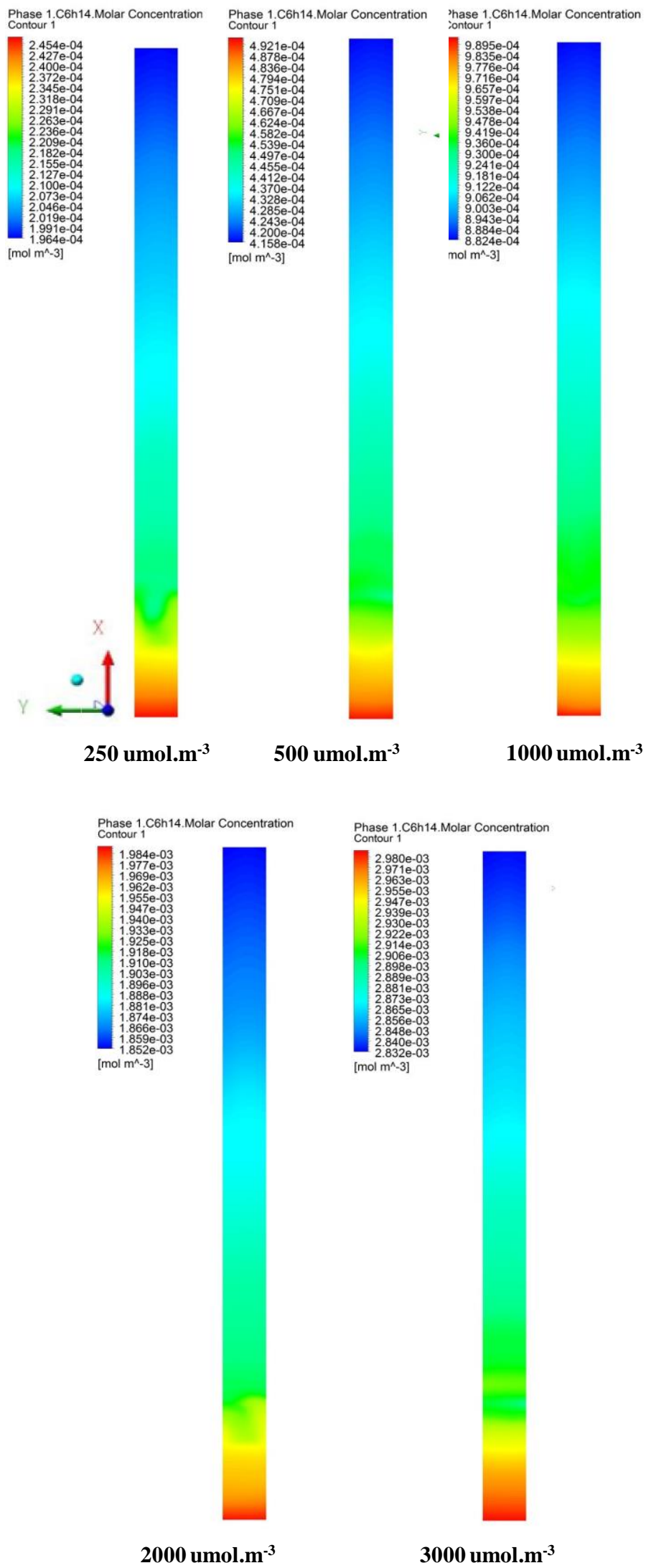

Figura 6.30 - Campos de Concentração de n-Hexano. Condições simuladas: $\mathrm{Q}=10$ L.min ${ }^{-1} \mathrm{e}$ $\mathrm{m}=0,1 \mathrm{~kg}$ para $\mathrm{C}=250$ a $3000 \mu \mathrm{mol} \mathrm{m}{ }^{-3}$ (Fonte: $\mathrm{O}$ autor, 2018) 


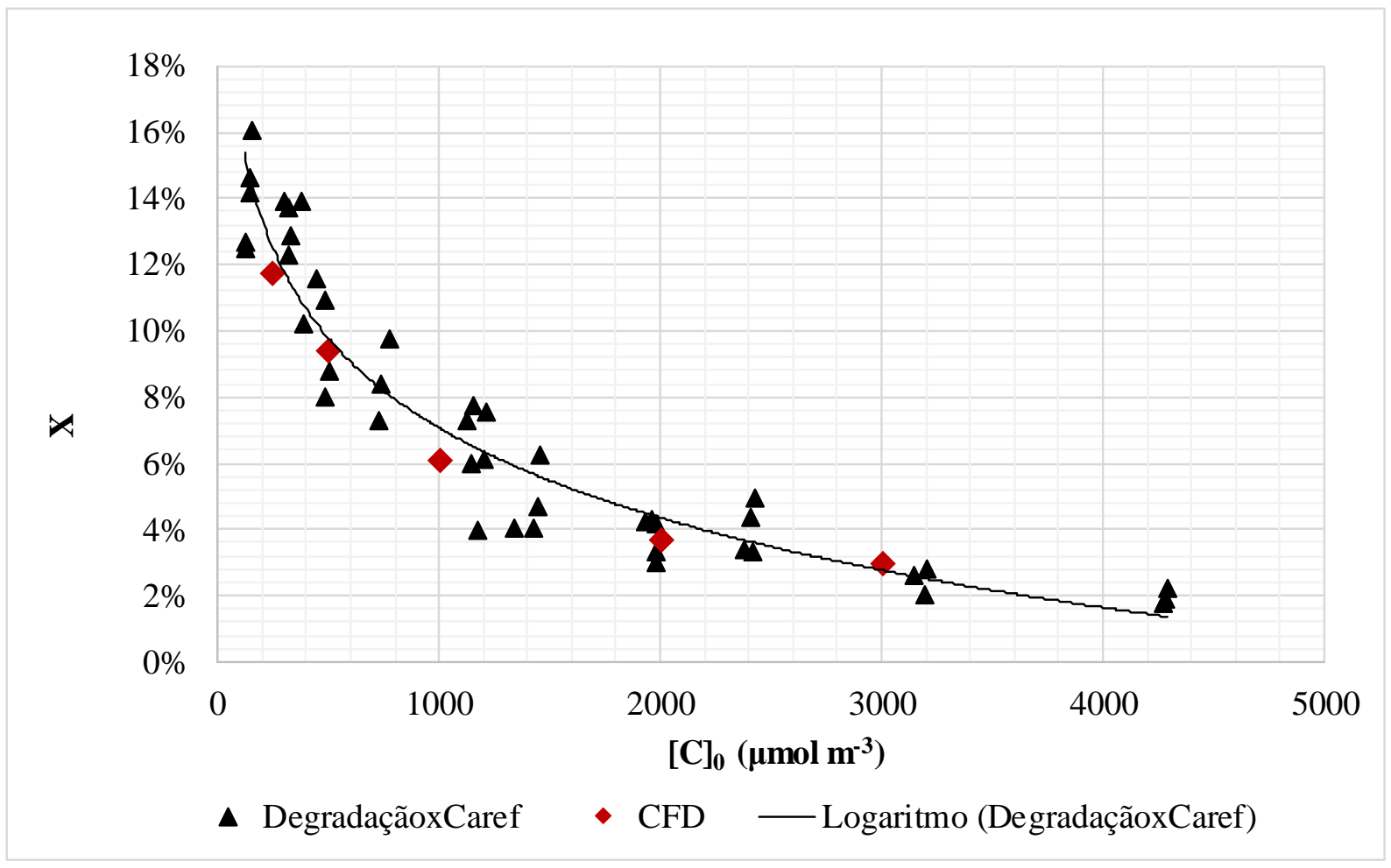

Figura 6.31 - Comparativo dos resultados de simulação com resultados experimentais Região Densa - Conversão em função da concentração de entrada de poluente.

Condições simuladas: $\mathrm{Q}=10 \mathrm{~L} \cdot \mathrm{min}^{-1} \mathrm{e} \mathrm{m}=0,1 \mathrm{~kg}$ para $\mathrm{C}=250 \mathrm{a} 3000 \mu \mathrm{mol} \mathrm{m}{ }^{-3}$ (Fonte: $\mathrm{O}$ autor, 2018)

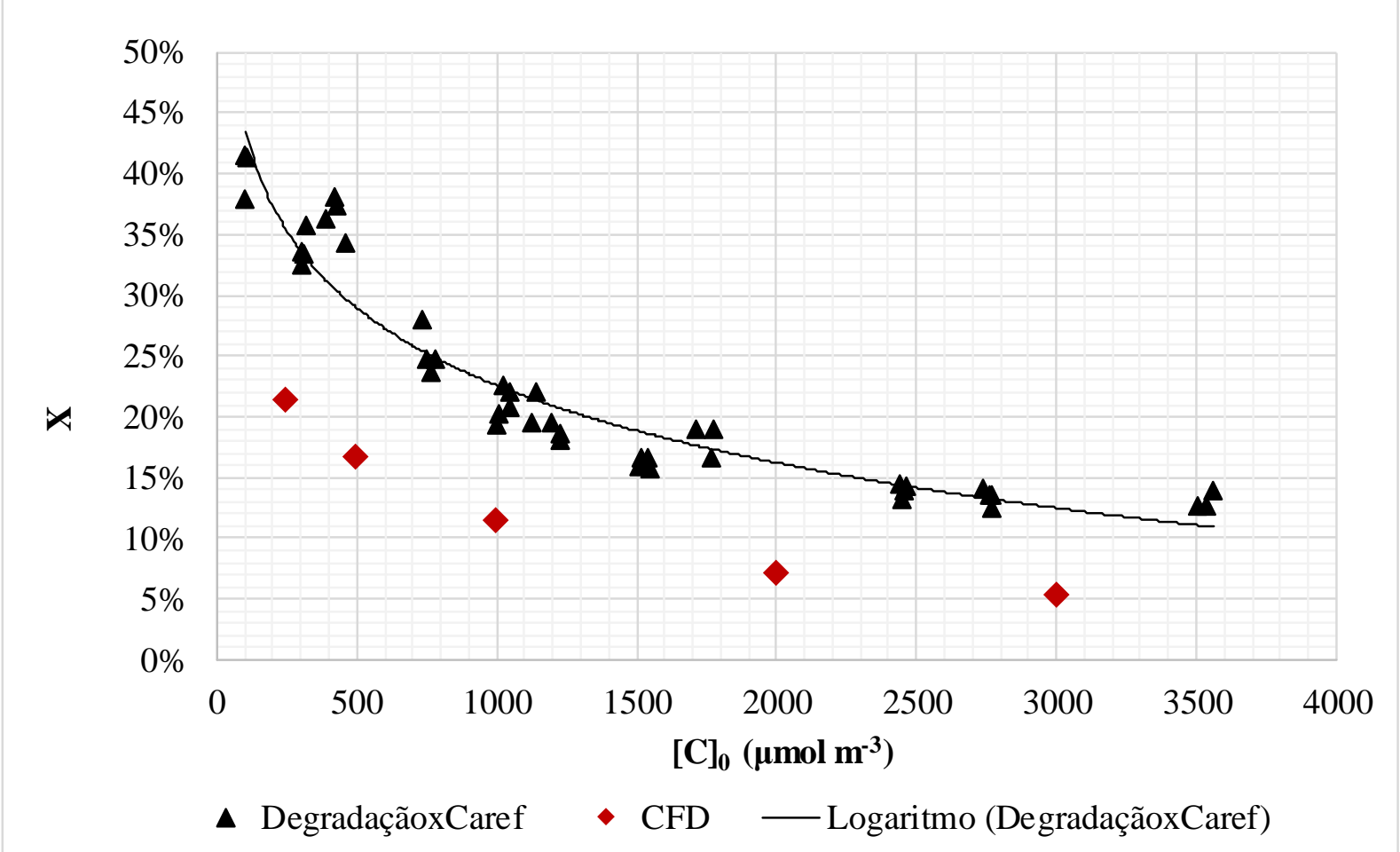

Figura 6.32 - Comparativo dos resultados de simulação com resultados experimentais -

Reator Completo - Conversão em função da concentração de entrada de poluente -

Condições simuladas: $\mathrm{Q}=10 \mathrm{~L} \cdot \mathrm{min}^{-1} \mathrm{e} \mathrm{m}=0,1 \mathrm{~kg}$ para $\mathrm{C}=250$ a $3000 \mu \mathrm{mol} \mathrm{m}{ }^{-3}$ (Fonte: $\mathrm{O}$ autor, 2018) 


\section{CAPÍTULO 7. CONCLUSÕES E CONSIDERAÇÕES FINAIS}

\subsection{ASPECTOS GERAIS}

Dentro do contexto de inovação tecnológica e de aplicação na engenharia nacional, a pertinência do presente estudo em parte pode ser corroborada pela aprovação e execução do mesmo para um Projeto PIPE - FAPESP.

A necessidade de utilização de ferramentas de fluidodinâmica computacional na etapa de modelagem em função da complexidade de um sistema reativo multifásico e submetido a um campo de radiação foi verificada.

\subsection{SÍNTESE}

O método proposto para a produção de fotocatalisadores aplicáveis em leito fluidizado gerou sólidos capazes de degradar fotocataliticamente os poluentes alvos. O método de síntese mostrou-se prático e pode ser reproduzido. No entanto, o recobrimento do $\mathrm{TiO}_{2}$ mostrou-se não homogêneo e resultou em perdas pela aglomeração de partículas de $\mathrm{TiO}_{2}$. Devido a isso, para a modelagem do reator, o catalisador foi substituído pelo catalisador comercial em forma anatase.

\subsection{ASPECTOS OPERACIONAIS DO REATOR}

O reator foi operado de certa forma como um leito fluidizado circulante, atingindo um regime contínuo em estado estacionário para a degradação de compostos orgânicos voláteis. No entanto, ao se operar o reator por longos tempos há uma considerável perda de sólidos na exaustão do ciclone.

Estes resultados sugerem a necessidade de melhoria na resistência dos catalisadores sintetizados ao processo de abrasão e a necessidade de aperfeiçoamento do sistema de coleta de sólidos, possibilitando que se trabalhe com maiores quantidades de massa no leito e de vazão de gás sem que haja um aumento considerável na taxa de perda de sólidos do leito.

\subsection{DEGRADAÇÃO DE BTX}

O reator foi capaz de remover os contaminantes estudados. No entanto, nas condições investigadas, o processo não foi capaz de reduzir significativamente as concentrações de contaminante no ar tratado, mostrando que há a necessidade de uma investigação mais detalhada dos parâmetros operacionais, além da realização de melhorias no processo. Um sumário dos resultados aqui obtidos é apresentado na Tabela 7.1. O desempenho do reator aqui 
apresentado pode ser comparado com Park et al (2011), que utilizaram catalisadores similares para a degradação de BTX, e Yao e Kuo (2015), que os utilizaram na degradação do tolueno. Ambos os trabalhos obtiveram desempenhos superiores aos aqui apresentados. Park et al (2011) atingiram taxas de degradação superiores a $65 \%$ para correntes com concentração de 100 ppmv dos poluentes estudados, enquanto Yao e Kuo (2015) obtiveram degradação de 50\% para o tolueno em corrente contaminada com 300 ppmv de tolueno.

Tabela 7.1 - Sumário de resultados da degradação de BTX no reator de leito fluidizado circulante. Condições do experimento: $\mathrm{m}=100 \mathrm{~g}, \mathrm{Q}=15 \mathrm{~L} \mathrm{~min}^{-1}$ e UR $=50 \%$.

\begin{tabular}{|c|c|c|}
\hline \multirow{2}{*}{ 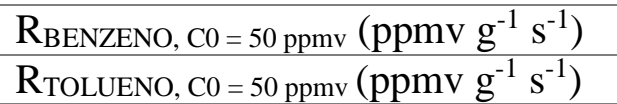 } & \multicolumn{2}{|c|}{0,0086} \\
\hline & \multicolumn{2}{|c|}{0,0064} \\
\hline RXILENOS, C0 = 50 ppmv $\left(\mathrm{ppmv} \mathrm{g}^{-1} \mathrm{~s}^{-1}\right)$ & \multicolumn{2}{|c|}{0,0192} \\
\hline $\begin{array}{l}\text { Tempo de operação até desativação } \\
\text { da mistura BTX com } 100 \text { ppmv } \\
\text { totais }\end{array}$ & \multicolumn{2}{|c|}{8 horas } \\
\hline $\begin{array}{l}\text { Regeneração do catalisador após } 12 \\
\text { horas de tratamento }\end{array}$ & \multicolumn{2}{|c|}{$55,5 \%$} \\
\hline \multirow{4}{*}{$\begin{array}{l}\text { Compostos identificados como } \\
\text { responsáveis pela desativação } \\
\text { durante a fotocatálise }\end{array}$} & Poluente alvo & Intermediário \\
\hline & Benzeno & Benzofurano \\
\hline & Tolueno & Benzaldeído \\
\hline & Xilenos & Metil-bezaldeído \\
\hline
\end{tabular}

A solução técnica, englobando a síntese de catalisador proposta e o reator construído, não é ainda suficientemente eficiente para a degradação dos compostos voláteis estudados (Benzeno, Tolueno e Xilenos).

Este fato se deve principalmente a três pontos:

1. A síntese de fotocatalisadores para o reator deve ser mais estudada de modo a gerar materiais com melhor desempenho e melhor aproveitamento do $\mathrm{TiO}_{2}$ no processo de recobrimento.

2. A necessidade de melhoria na resistência dos catalisadores sintetizados ao processo de abrasão.

3. A necessidade de aperfeiçoamento do sistema de coleta sólida, possibilitando que se trabalhe com maiores quantidades de massa no leito e de vazão de gás sem que haja um aumento considerável na taxa de perda de sólidos do leito.

Uma vantagem a ser notada neste processo é a possibilidade de regeneração do fotocatalisador. 


\subsection{DEGRADAÇÃO DO POLUENTE MODELO}

Um poluente modelo, n-hexano, foi escolhido para a construção de um modelo cinético do reator fotocatalítico. Neste caso, o reator foi operado com um catalisado comercial, $\mathrm{TiO}_{2}$ fase anatáse e de forma diferencial. Os resultados mostraram que a conversão no reator aumenta com o aumento de massa de catalisador e diminuiu com um aumento na vazão volumétrica. Com o aumento da área irradiada, observa-se um aumento na conversão para a mesma concentração inicial, porém um decréscimo da taxa de reação R, evidenciando a existência das duas regiões no leito fluidizado descrito por (KUNII, D.; LEVENSPIEL, 1991).

\subsection{MODELAGEM CINÉTICA DE REATOR FOTOQUÍMICO}

Um modelo cinético baseado na determinação dos parâmetros cinéticos em um reator fotocatalítico usando a abordagem Langmuir-Hinshelwood para a degradação do n-hexano foi desenvolvida. $\mathrm{O}$ modelo proposto dividiu o reator em duas regiões: uma região densa e uma região diluída, e considerou uma modelagem de reatores em série. A parametrização foi realizada com sucesso considerando reatores diferenciais. Para a validação do modelo, uma abordagem CSTR-PFR foi testada. Este modelo teve uma predição global razoável para o reator operando em uma faixa de vazões volumétricas e diferentes concentrações. Entretanto, o modelo não pode predizer a performance do reator quando a massa de catalisador aumentou, devido ao fato da formulação do modelo estar diretamente relacionada com mudanças no volume do leito.

A validação com os dados experimentais confirmar sua aplicabilidade para propostas de engenharia, como design e otimização de um reator fotocatalítico.

\subsection{MODELAGEM FLUIDODINÂMICA DE REATOR FOTOQUÍMICO}

Neste trabalho, utilizou-se a Fluidodinâmica Computacional (CFD) através do software Fluent para as simulações de um reator fotocatalítico de leito fluidizado para o poluente nhexano. Algumas simplificações foram feitas para otimizar os tempos de simulação e os principais resultados do CFD foram os campos de pressão, velocidade, fração volumétrica de sólidos e reação cinética do n-hexano. Houve uma discrepância do modelo com os dados experimentais devido às partículas serem do tipo Geldart C, mas com alteração do tamanho das partículas no decorrer dos experimentos, conforme discutido no item5.2, sendo de difícil fluidização e formação de bolhas confinadas na estreita região anular $(1 \mathrm{~cm})$. 


\section{CAPÍTULO 8. CONTINUIDADE DO TRABALHO}

As principais sugestões de continuidade para este trabalho são:

1. Aperfeiçoamento da operação do reator.

2. Desenvolvimento de novos catalisadores para o mesmo reator.

3. Aperfeiçoamento do ciclone do reator proposto.

4. Integração de um modelo de radiação com a LVREA para modelagem fluidodinâmica do reator.

5. Modelagem em CFD para outro catalisador que não seja do tipo Geldart C.

6. Modelagem em CFD de outros poluentes. 


\section{REFERÊNCIAS BIBLIOGRÁFICAS}

ALBERICI, R. M.; JARDIM, W. F. Photocatalytic destruction of VOCS in the gas-phase using titanium dioxide. Applied Catalysis B: Environmental, v. 14, n. 1-2, p. 55-68, 1997.

ALFANO, M.; CASSANO, E. Radiation field Modelling Homogeneous in Photoreactors-I. Homogeneous Media. Chemical Engineering Science, v. 41, n. 1955, p. $451-444,1986$.

ALMUTTAHAR, A.; TAGHIPOUR, F. Computational fluid dynamics of high density circulating fluidized bed riser : Study of modeling parameters. v. 185, p. 11-23, 2008a.

ALMUTTAHAR, A.; TAGHIPOUR, F. Computational fluid dynamics of a circulating fluidized bed under various fluidization conditions. v. 63, p. 1696-1709, 2008b.

ASKARISHAHI, M. et al. CFD study on solids flow pattern and solids mixing characteristics in bubbling fluidized bed: Effect of fluidization velocity and bed aspect ratio. Powder Technology, v. 274, p. 379-392, 2015.

BENYAHIA, S. et al. Simulation of particles and gas flow behavior in the riser section of a circulating fluidized bed using the kinetic theory approach for the particulate phase. p. 24-33, 2000.

BOULAMANTI, A. K.; PHILIPPOPOULOS, C. J. Photocatalytic degradation of C5C7alkanes in the gas-phase. Atmospheric Environment, v. 43, n. 20, p. 3168-3174, 2009.

CARP, O.; HUISMAN, C. L.; RELLER, A. Photoinduced reactivity of titanium dioxide. Progress in Solid State Chemistry, v. 32, n. 1-2, p. 33-177, 2004.

CASADO, C. et al. Comprehensive multiphysics modeling of photocatalytic processes by computational fluid dynamics based on intrinsic kinetic parameters determined in a differential photoreactor. Chemical Engineering Journal, v. 310, p. 368-380, 2017.

CASSANO, A. E. et al. Photoreactor Analysis and Design: Fundamentals and Applications. Industrial and Engineering Chemistry Research, v. 34, n. 7, p. 2155$2201,1995$.

CASTRILLO, S. R. Performance Evaluation of Photocatalytic Reactors for Air Purification Using Computational Fluid Dynamics ( CFD ). Industrial and Engineering Chemistry Research, v. 46, p. 5867-5880, 2007. 
CHEN, S. et al. CFD simulation of gas-solid two-phase flow and mixing in a FCC riser with feedstock injection. Powder Technology, v. 287, p. 29-42, 2016.

CHOI, W. et al. Investigation on $\mathrm{TiO} 2$-coated optical fibers for gas-phase photocatalytic oxidation of acetone. v. 31, p. 209-220, 2001.

DASHLIBORUN, A. M. et al. Modeling of the photocatalytic degradation of methyl ethyl ketone in a fluidized bed reactor of nano-TiO2/??-A12O3 particles. Chemical Engineering Journal, v. 226, p. 59-67, 2013.

DECRETO. Decreto 8468 de 08 de Setembro de 1976, revisão de 2004. 2004.

DECRETO. Decreto N 59.113 DE 2013. 2013.

DENNY, F. et al. CFD modelling for a TiO2-coated glass-bead photoreactor irradiated by optical fibres: Photocatalytic degradation of oxalic acid. Chemical Engineering Science, v. 64, n. 8, p. 1695-1706, 2009.

DIBBLE, L. A.; RAUPP, G. B. Fluidized-bed photocatalytic oxidation of trichloroethylene in contaminated air streams. Environmental Science \& Technology, v. 26, n. 3, p. 492-495, 1992.

FERMOSO, J. et al. Photocatalytic Degradation of Toluene in Air Using a Fluidized Bed Photoreactor Photocatalytic Degradation of Toluene in Air Using a Fluidized Bed Photoreactor. n. October 2015, 2007.

FOGLER, H. S. Elements of Reaction Engineering. [s.l: s.n.].

GANDHI, V. G.; MISHRA, M. K.; JOSHI, P. A. A study on deactivation and regeneration of titanium dioxide during photocatalytic degradation of phthalic acid. Journal of Industrial and Engineering Chemistry, v. 18, n. 6, p. 1902-1907, 2012. GIDASPOW, D., BEZBURUAH R., DING, J. Hydrodynamics of Circulating Fluidized Beds, Kinetic Theory Approach. J . In Fluidization VII, Proceedings of the 7th Engineering Foundation Conference on Fluidization. Anais...1992

HARTGE, E. et al. Particuology CFD-simulation of a circulating fluidized bed riser. v. 7, p. 283-296, 2009.

HASHIMOTO, K.; IRIE, H.; FUJISHIMA, A. TiO 2 Photocatalysis : A Historical Overview and Future Prospects. Japanese journal of Applied Physics, v. 44, n. 12, p. 8269-8285, 2006.

IMOBERDORF, G. E. et al. Simulation of a multi-annular photocatalytic reactor for degradation of perchloroethylene in air: Parametric analysis of radiative energy efficiencies. Chemical Engineering Science, v. 62, n. 4, p. 1138-1154, 2007.

KIM, S. B.; HONG, S. C. Kinetic study for photocatalytic degradation of volatile organic 
compounds in air using thin film $\mathrm{TiO} 2$ photocatalyst. Applied Catalysis B: Environmental, v. 35, n. 4, p. 305-315, 2002.

KOROLOGOS, C. A. et al. Photocatalytic oxidation of benzene, toluene, ethylbenzene and $\mathrm{m}$-xylene in the gas-phase over TiO 2-based catalysts. Journal of Photochemistry and Photobiology A: Chemistry, v. 244, p. 24-31, 2012.

KUNII, D.; LEVENSPIEL, O. Fluidization engineering. [s.l: s.n.].

KUO, H. P.; WU, C. T.; HSU, R. C. Continuous reduction of toluene vapours from the contaminated gas stream in a fluidised bed photoreactor. Powder Technology, v. 195, n. 1, p. 50-56, 2009.

KUO, H. P.; WU, C. T.; HSU, R. C. Continuous toluene vapour photocatalytic deduction in a multi-stage fluidised bed. Powder Technology, v. 210, n. 3, p. 225-229, 2011.

LI, T. et al. CFD simulations of circulating fl uidized bed risers, part I : Grid study. Powder Technology, v. 254, p. 170-180, 2014.

LI, T.; PANNALA, S.; SHAHNAM, M. CFD simulations of circulating fl uidized bed risers , part II , evaluation of differences between 2D and 3D simulations. Powder Technology, v. 254, p. 115-124, 2014.

LI, Y.; ARMOR, J. N. Catalytic decomposition of nitrous oxide on metal exchanged zeolites. Applied Catalysis B, Environmental, v. 1, n. 3, 1992.

LICHTAROWICZ, A. K. ; DUGGINS, R. K. ; MARKLAND, E. Discharge Coefficients for Incompressible Non-Cavitating Flow Through Long Orifices. Journal of Mechanical Engineering Science, v. 7, n. 2, 1965.

LIM, T. H.; KIM, S. D. Photo-degradation characteristics of TCE (trichloroethylene) in an annulus fluidized bed photoreactor. Korean Journal of Chemical Engineering, v. 21, n. 4, p. 905-909, 2004a.

LIM, T. H.; KIM, S. D. Photo-degradation Characteristics of TCE ( Trichloroethylene ) in an Annulus Fluidized Bed Photoreactor. v. 21, n. 4, p. 905-909, 2004b.

LIM, T. H.; KIM, S. D. Trichloroethylene degradation by photocatalysis in annular flow and annulus fluidized bed photoreactors. Chemosphere, v. 54, n. 3, p. 305-312, 2004c. LIM, T. H.; KIM, S. D. Photocatalytic degradation of trichloroethylene (TCE) over TiO 2/silica gel in a circulating fluidized bed (CFB) photoreactor. Chemical Engineering and Processing: Process Intensification, v. 44, n. 2, p. 327-334, 2005.

LOPES, M. L. A. Avaliação ambiental de compostos orgânicos voláteis (VOC) provenientes da queima da cana-de-açucar. [s.1.] Universidade de São Paulo, 2010. MAHMOUDI, S.; SEVILLE, J. P. K.; BAEYENS, J. The residence time distribution and 
mixing of the gas phase in the riser of a circulating fl uidized bed. Powder Technology, v. 203 , n. 2, p. 322-330, 2010.

MATHIESEN, V.; SOLBERG, T.; HJERTAGER, B. H. An experimental and computational study of multiphase flow behavior in a circulating fluidized bed. v. 26, p. 387-419, 2000.

MATSUDA, S.; HATANO, H. Photocatalytic removal of NOx in a circulating fluidized bed system. Powder Technology, v. 151, n. 1-3, p. 61-67, 2005.

MAUDHUIT, A. et al. Adsorption phenomena in photocatalytic reactions: The case of toluene, acetone and heptane. Chemical Engineering Journal, v. 170, n. 2-3, p. 464470, 2011.

MOHSENI, M.; TAGHIPOUR, F. Experimental and CFD analysis of photocatalytic gas phase vinyl chloride (VC) oxidation. Chemical Engineering Science, v. 59, n. 7, p. 1601-1609, 2004.

MOULIS, F.; KRÝSA, J. Photocatalytic degradation of several VOCs (n-hexane, n-butyl acetate and toluene) on TiO2layer in a closed-loop reactor. Catalysis Today, v. 209, p. 153-158, 2013.

OPPENLÄNDER, T. Photochemical Purification of Water and Air: Advanced Oxidation Processes (AOPs) - Principles, Reaction Mechanisms, Reactor Concepts. Chem Int 368 Enhancing the stepped solar still performance using internal reflectors Desalination 314, v. 25 SRC-, p. 368, 2003.

PAREEK, V. K. ADESINA, A. A. Handbook of Photochemistry and Photobiology. [s.l: s.n.].

PAREEK, V. K. et al. Computational fluid dynamic (CFD) simulation of a pilot-scale annular bubble column photocatalytic reactor. Chemical Engineering Science, v. 58, n. 3-6, p. 859-865, 2003.

PARK, J.-H. et al. Photodegradation of benzene, toluene, ethylbenzene and xylene by fluidized bed gaseous reactor with $\mathrm{TiO} 2 / \mathrm{SiO} 2$ photocatalysts. Korean Journal of Chemical Engineering, v. 28, n. 8, p. 1693-1697, 2011.

PASSALÍA, C. et al. Modeling and Experimental Verification of a Corrugated Plate Photocatalytic Reactor Using Computational Fluid Dynamics. Industrial \& Engineering Chemistry Research, v. 50, n. 15, p. 9077-9086, 2011.

PASSALÍA, C.; ALFANO, O. M.; BRANDI, R. J. Modeling and Experimental Verification of a Corrugated Plate Photocatalytic Reactor Using Computational Fluid Dynamics. Industrial \& Engineering Chemistry Research, v. 50, p. 9077-9086, 2011. 
PETIT, G.; HEMATI, M.; SIMONIN, O. Hydrodynamic and solid residence time distribution in a circulating fluidized bed : Experimental and 3D computational study. $v$. 47, p. 463-473, 2008.

PRIETO, O.; FERMOSO, J.; IRUSTA, R. Photocatalytic Degradation of Toluene in Air Using a Fluidized Bed Photoreactor. International Journal of Photoenergy, v. 2007, n. 32859, p. 1-9, 2007.

QUEFFEULOU, A.; GERON, L.; SCHAER, E. Prediction of photocatalytic air purifier apparatus performances with a CFD approach using experimentally determined kinetic parameters. Chemical Engineering Science, v. 65, n. 18, p. 5067-5074, 2010.

RAJESHWAR, K. Photochemical Strategies for Abating Environmental Pollution. Chem. Ind, v. June, p. 454-458, 1996.

RANZ, W. E. ; AND W. R. M. Evaporation from Drops, Part I and Part II. Chem. Eng. Prog, v. 48, n. 4, p. 173-180, 1952.

RIBEIRO, K. Estudo experimental e modelagem matemática de reator solar híbrido para degradação de fenol em solução aquosa pelo processo foto-Fenton. [s.l.] Escola Politécnica da Universidade de São Paulo, 2009.

ROCHETTO, U. L. Degradação de compostos orgânicos voláteis em fase gasosa por fotocatálise heterogênea com TiO2/UV. [s.1.] Universidade Estadual de Campinas, 2012.

ROEGIERS, J.; VAN WALSEM, J.; DENYS, S. CFD- and radiation field modeling of a gas phase photocatalytic multi-tube reactor. Chemical Engineering Journal, v. 338, n. November 2017, p. 287-299, 2018.

SANCHES, V. L. Remediação de solos da formação são paulo contaminados por vapores de gasolina. 2009.

SHAH, S. et al. CFD modeling of gas-solids flow in a large scale circulating fluidized bed furnace. Powder Technology, v. 274, p. 239-249, $2015 \mathrm{a}$.

SHAH, S. et al. CFD simulations of gas-solid flow in an industrial-scale circulating fluidized bed furnace using subgrid-scale drag models. Particuology, v. 18, p. 66-75, 2015b.

SILVARES, A. F. M. Desenvolvimento experimental e simulação matemática do processo de pré-polimerização fotoiniciada do metacrilato de metila (MMA). [s.1.] Escola Politécnica da Universidade de São Paulo, 2006.

TABATABAIE-RAISSI, I. A. et al. ( 12 ) United States Patent APPARATUS FOR HIGH FLUX PHOTOCATALYTIC POLLUTION CONTROL USING A 
ROTATING FLUIDIZED BED ‘ J, 2003.

TAGHIPOUR, F.; MOHSENI, M. CFD simulation of UV photocatalytic reactors for air treatment. AIChE Journal, v. 51, n. 11, p. 3039-3047, 2005.

TANG, W. Z. Physicochemical Treatment of Hazardous Wastes. Boca Raton, Florida: CRC Press, 2000.

TASBIHI, M. et al. Photocatalytic oxidation of gaseous toluene on titania/mesoporous silica powders in a fluidized-bed reactor. Catalysis Today, v. 161, n. 1, p. 181-188, 2011. UPADHYAY, M.; PARK, J. H. CFD simulation via conventional two-fluid model of a circulating fluidized bed riser: Influence of models and model parameters on hydrodynamic behavior. Powder Technology, v. 272, p. 260-268, 2015.

VERBRUGGEN, S. W. et al. CFD modeling of transient adsorption/desorption behavior in a gas phase photocatalytic fiber reactor. Chemical Engineering Journal, v. 292, p. 42-50, 2016.

VERBRUGGEN, S. W.; LENAERTS, S.; DENYS, S. Analytic versus CFD approach for kinetic modeling of gas phase photocatalysis. Chemical Engineering Journal, v. 262, p. $1-8,2015$.

WANG, Z. et al. CFD modeling of a UV-LED photocatalytic odor abatement process in a continuous reactor. Journal of Hazardous Materials, v. 215-216, p. 25-31, 2012.

YAO, S. W.; KUO, H. P. Photocatalytic Degradation of Toluene on SiO2/TiO2 Photocatalyst in a Fluidized Bed Reactor. Procedia Engineering, v. 102, p. 1254-1260, 2015a.

YAO, S. W.; KUO, H. P. Photocatalytic degradation of toluene on $\mathrm{SiO} 2 / \mathrm{TiO} 2$ photocatalyst in a fluidized bed reactor. v. 102, p. 1254-1260, $2015 \mathrm{~b}$.

YUE, P. L.; KHAN, F.; RIZZUTI, L. Photocatalytic ammonia synthesis in a fluidised bed reactor. Chemical Engineering Science, v. 38, n. 11, p. 1893-1900, 1983.

ZHANG, P.; LIU, J. Photocatalytic degradation of trace hexane in the gas phase with and without ozone addition: Kinetic study. Journal of Photochemistry and Photobiology A: Chemistry, v. 167, n. 2-3, p. 87-94, 2004.

ZHANG, Y. Modeling and Design of Photocatalytic reactors for Air Purification. n. January, 2013.

ZHONG, J. et al. Photocatalytic degradation of gaseous benzene over TiO2/Sr2CeO4: kinetic model and degradation mechanisms. Journal of hazardous materials, v. 139, n. 2, p. 323-31, 2007. 